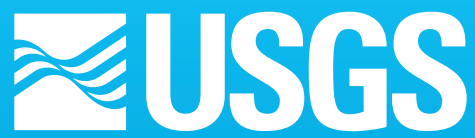

science for a changing world

The Quality of Our Nation's Waters

\title{
Volatile Organic Compounds in the Nation's Ground Water and Drinking-Water Supply Wells
}

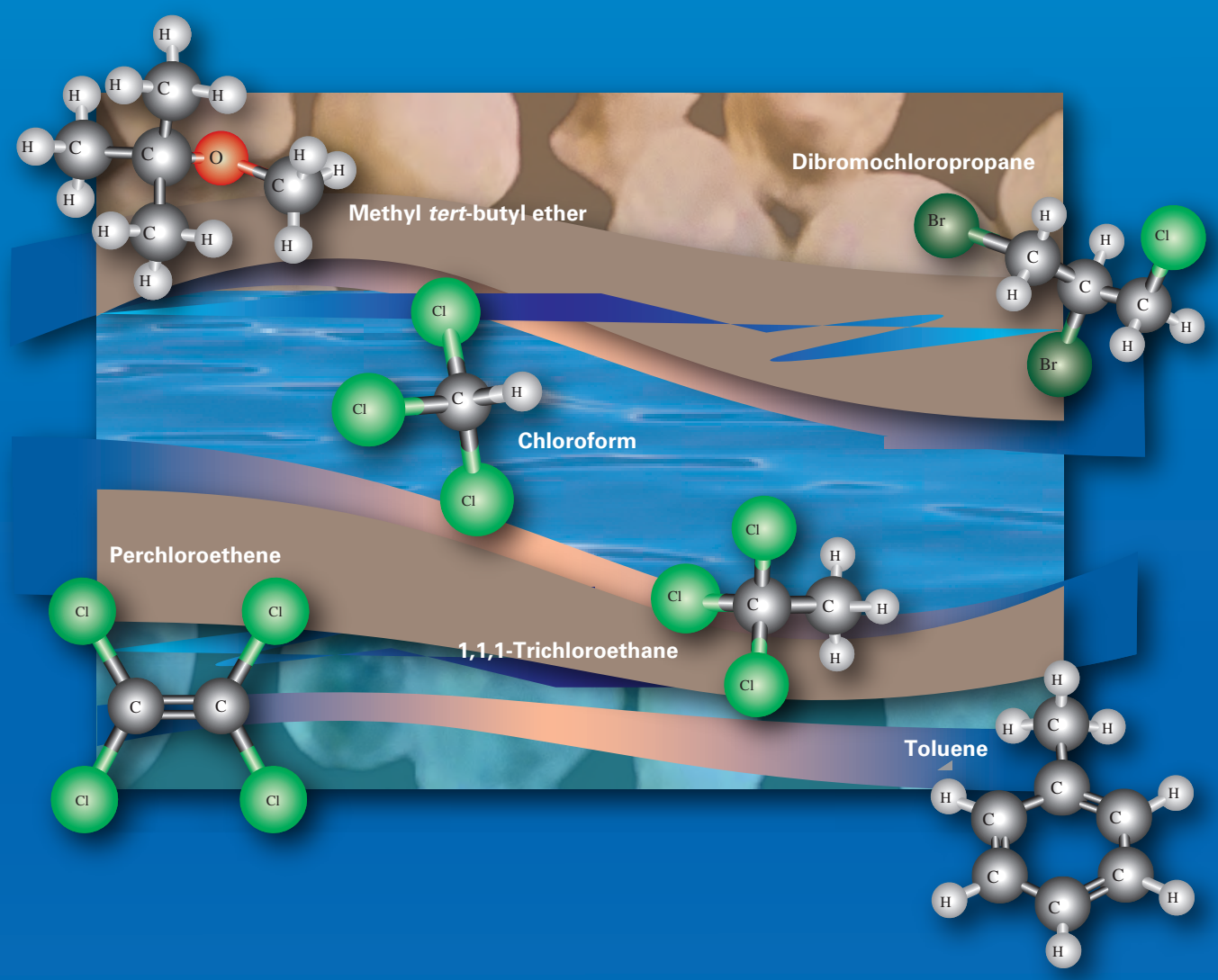

National Water-Quality Assessment Program

Circular 1292

U.S. Department of the Interior U.S. Geological Survey 
"High quality water is more than the dream of the conservationists, more than a political slogan; high quality water, in the right quantity at the right place at the right time, is essential to health, recreation, and economic growth."

Edmund S. Muskie, U.S. Senator

Cover illustration. Three-dimensional molecular configuration and composition of some of the compounds discussed in this report. 


\section{The Quality of Our Nation's Waters}

\section{Volatile Organic Compounds in the Nation's Ground Water and Drinking-Water Supply Wells}

By John S. Zogorski, Janet M. Carter, Tamara Ivahnenko, Wayne W. Lapham, Michael J. Moran, Barbara L. Rowe, Paul J. Squillace, and Patricia L. Toccalino

Circular 1292 


\title{
U.S. Department of the Interior DIRK KEMPTHORNE, Secretary \\ U.S. Geological Survey \\ P. Patrick Leahy, Acting Director
}

\section{U.S. Geological Survey, Reston, Virginia: 2006}

\author{
Available from U.S. Geological Survey, Information Services \\ Box 25286, Denver Federal Center \\ Denver, CO 80225 \\ For more information about the USGS and its products: \\ Telephone: 1-888-ASK-USGS \\ World Wide Web: http://www.usgs.gov/ \\ Additional information about this national assessment is available at http://water.usgs.gov/nawqa/vocs/national \\ assessment
}

Any use of trade, product, or firm names in this publication is for descriptive purposes only and does not imply endorsement by the U.S. Government.

Although this report is in the public domain, permission must be secured from the individual copyright owners to reproduce any copyrighted materials contained within this report.

Suggested citation:

Zogorski, J.S., Carter, J.M., Ivahnenko, Tamara, Lapham, W.W., Moran, M.J., Rowe, B.L., Squillace, P.J., and Toccalino, P.L., 2006, The quality of our Nation's waters - Volatile organic compounds in the Nation's ground water and drinking-water supply wells: U.S. Geological Survey Circular 1292, 101 p.

\section{Library of Congress Cataloging-in-Publication Data}

The Quality of our nation's waters : volatile organic compounds in the nation's ground water and drinking-water supply wells / by John S. Zogorski ... [et al.].

p. cm. -- (Circular 1292)

Includes bibliographical references and index.

1. Organic water pollutants--United States. 2. Organic compounds. 3. Water quality management--United States. 4. Water chemistry--United States. I. Zogorski, John S. II. U.S. Geological Survey circular ; 1292.

TD427.07083 2006

363.738'420973--dc22 


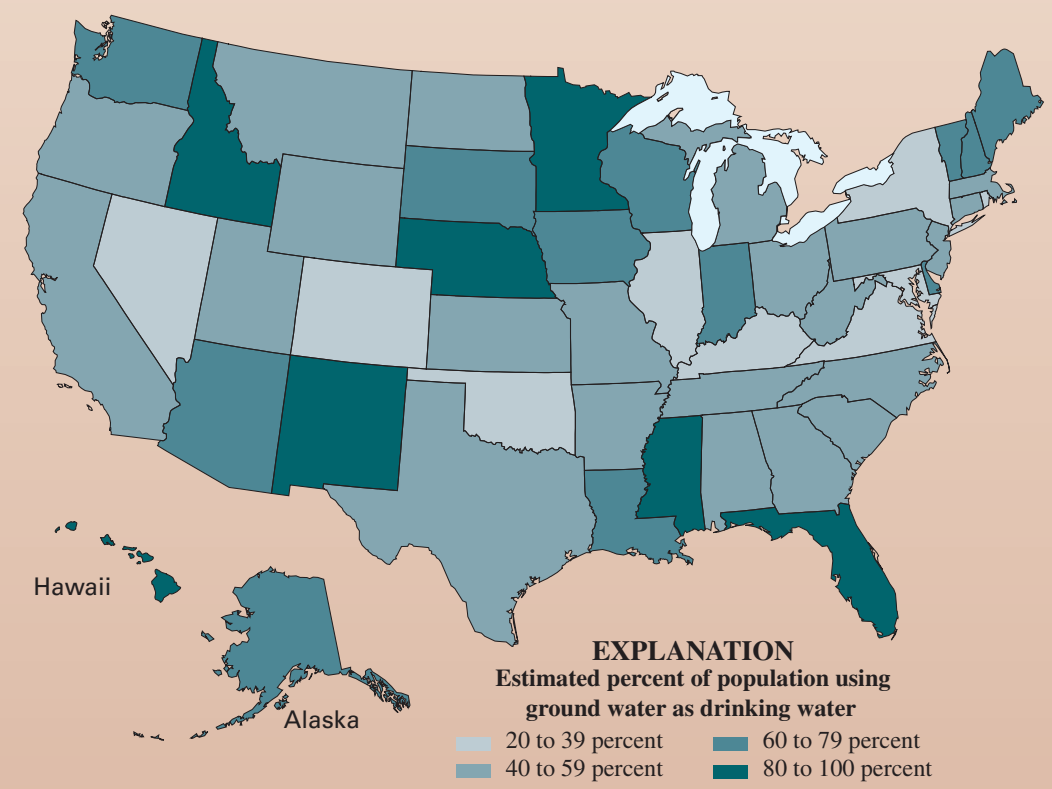

Estimated use of ground water for drinking water (adapted from data source ${ }^{(1)}$ )

Ground water is among the Nation's most important natural resources. Very large volumes of ground water are pumped each day for industrial, agricultural, and commercial use. Also, ground water is a drinking-water source for about one-half of the Nation's population, including almost all residents in rural areas. Ground water is important as a drinking-water supply in every State.

Information on the quality and quantity of ground water is important because of the Nation's increasing population and dependency on this resource. Although the population that used domestic wells for drinkingwater supplies decreased between 1950 and 2000, estimated withdrawal increased by about 70 percent during that time period. The population dependent on public water systems that used ground water for drinkingwater supplies increased between 1950 and 2000, and the estimated withdrawal increased about five-fold during that time period.

The quality and availability of ground water will continue to be an important environmental issue for the Nation's citizens. Long-term conservation, prudent development, and management of this natural resource are critical for preserving and protecting this priceless national asset. Continued research by scientists, guidance and regulation by governmental agencies, and pollution abatement programs by industry are necessary to preserve the Nation's ground-water quality and quantity for future generations. 


\section{National Water-Quality Assessment Program}

\section{Foreword}

The U.S. Geological Survey (USGS) is committed to serving the Nation with accurate and timely scientific information that helps enhance and protect the overall quality of life, and facilitates effective management of water, biological, energy, and mineral resources (http://www.usgs. gov/. Information on the quality of the Nation's water resources is of critical interest to the USGS because it is so integrally linked to the long-term availability of water that is clean and safe for drinking and recreation and that is suitable for industry, irrigation, and habitat for fish and wildlife. Escalating population growth and increasing demands for the multiple water uses make water availability, now measured in terms of quantity and quality, even more critical to the long-term sustainability of our communities and ecosystems.

The USGS implemented the National Water-Quality Assessment (NAWQA) Program (http:// water.usgs.gov/nawqa/ to support national, regional, and local information needs and decisions related to water-quality management and policy. Shaped by and coordinated with ongoing efforts of other Federal, State, and local agencies, the NAWQA Program is designed to answer: What is the condition of our Nation's streams and ground water? How are the conditions changing over time? How do natural features and human activities affect the quality of streams and ground water, and where are those effects most pronounced? By combining information on water chemistry, physical characteristics, stream habitat, and aquatic life, the NAWQA Program aims to provide science-based insights for current and emerging water issues and priorities. NAWQA results can contribute to informed decisions that result in practical and effective waterresource management and strategies that protect and restore water quality.

Since 1991, the NAWQA Program has implemented interdisciplinary assessments in more than 50 of the Nation's most important river basins and aquifers, referred to as Study Units (http:// water.usgs.gov/nawqa/nawqamap.htm/1'. Collectively, these Study Units account for more than 60 percent of the overall water use and population served by public water supply, and are representative of the Nation's major hydrologic landscapes, priority ecological resources, and agricultural, urban, and natural sources of contamination.

Each assessment is guided by a nationally consistent study design and methods of sampling and analysis. The assessments thereby build local knowledge about water-quality issues and trends in a particular stream or aquifer while providing an understanding of how and why water quality varies regionally and nationally. The consistent, multi-scale approach helps to determine if certain types of water-quality issues are isolated or pervasive, and allows direct comparisons of how human activities and natural processes affect water quality and ecological health in the Nation's diverse geographic and environmental settings. Comprehensive national assessments on pesticides, nutrients, volatile organic compounds, trace elements, and aquatic ecology are developed through national data analysis and comparative analysis of the Study-Unit findings (http://water.usgs.gov/nawqa/natsyn.htm).

The USGS places high value on the communication and dissemination of credible, timely, and relevant science so that the most recent and available knowledge about water resources can be 


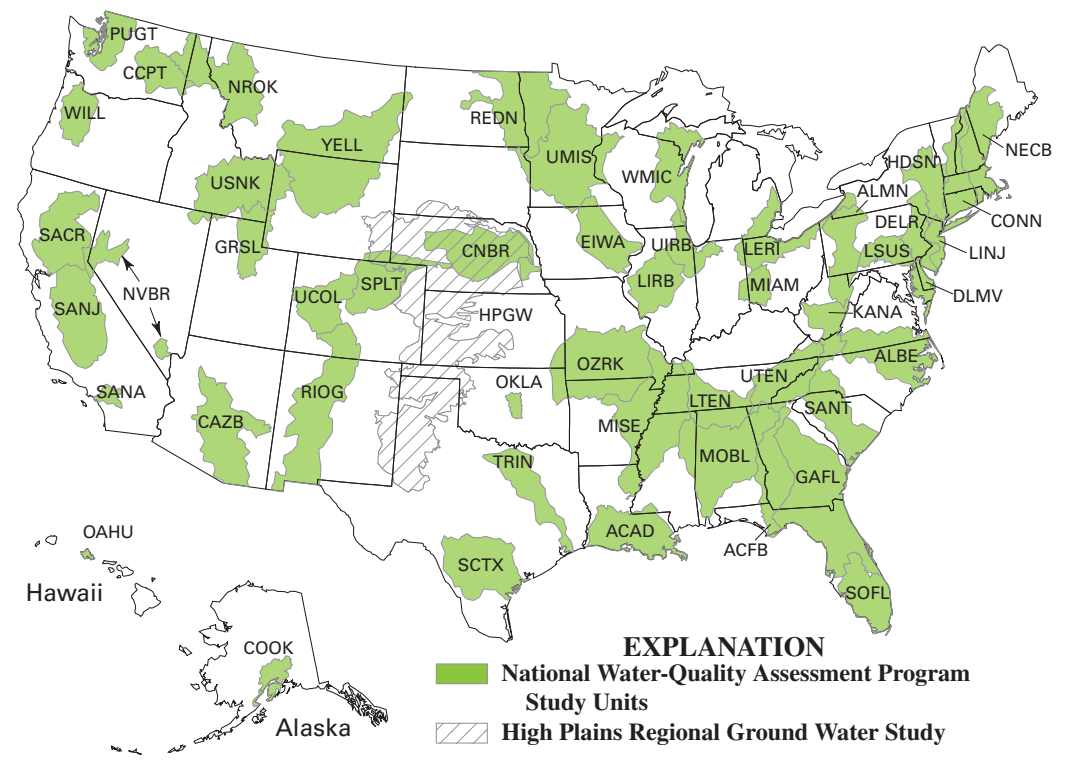

Study Units where the NAWQA Program has completed an occurrence study of volatile organic compounds in aquifers. ${ }^{2}$

applied in management and policy decisions. We hope this NAWQA publication will provide you the needed insights and information to meet your needs, and thereby foster increased awareness and involvement in the protection and restoration of our Nation's waters.

The NAWQA Program recognizes that a national assessment by a single program cannot address all water-resource issues of interest. External coordination at all levels is critical for a fully integrated understanding of watersheds and for cost-effective management, regulation, and conservation of our Nation's water resources. The Program, therefore, depends extensively on the advice, cooperation, and information from other Federal, State, interstate, Tribal, and local agencies, non-government organizations, industry, academia, and other stakeholder groups. The assistance and suggestions of all are greatly appreciated.

Robert M. Hirsch

Associate Director for Water

\footnotetext{
'Summaries of water-quality studies for the 51 Study Units assessed in the first decade of the NAWQA Program, as well as Study Units scheduled for assessments in the Program's second decade, are available at $h t t p: / / w a t e r . u s g s . g o v / n a w q a /$.

${ }^{2}$ The name of each Study Unit and other areas are given in Appendix 1.
} 


\section{Contents}

The first chapter provides an overview of major findings and conclusions for groundwater management, monitoring, and policies. The second chapter describes the assessment's purpose, scope, and approach. More detailed findings for ground water are given in the third chapter, and findings for samples from drinking-water supply wells are presented in the fourth chapter. Additional information for some frequently and widely detected compounds is presented in the fifth chapter.

1 Major findings and conclusions

2 Introduction

3 VOCs in ground water 16

VOCs in samples from drinking-water supply wells

5 Additional information for selected VOCs

- Chloroform and other trihalomethanes

- Chlorinated solvents-methylene chloride, perchlorethene, 1,1,1-trichloroethane, and trichloroethene

- Methyl tert-butyl ether and other gasoline oxygenates

- Gasoline hydrocarbons

References

Glossary. 62

Appendixes 66

A list of acronyms is included as Appendix 2. A glossary of common terms used in this report is included on p. 62-65. Beginning in Chapter 2, glossary terms are presented in boldface type when first used in the text. 


\section{Chapter 1-Major Findings and Conclusions}

\begin{tabular}{|c|c|}
\hline $\begin{array}{l}\text { his national assessment of } 55 \text { volatile organic } \\
\text { pounds (VOCs) in ground water gives emphasi } \\
\text { occurrence of VOCs in aquifers that are used as an } \\
\text { tant supply of drinking water. In contrast to the mor } \\
\text { of VOC contamination of ground water at point-sour } \\
\text { release sites, such as landfills and leaking undergrc } \\
\text { storage tanks (LUSTs), our investigations of aquifers } \\
\text { designed as large-scale resource assessments that } \\
\text { a general characterization of water-quality conditio } \\
\text { Nearly all of the aquifers included in this assessme } \\
\text { been identified as regionally extensive aquifers or a } \\
\text { systems. }{ }^{(2)} \text { The assessment of ground water (Chapte } \\
\text { included analyses of about 3,500 water samples co }\end{array}$ & $\begin{array}{l}\text { ns, decision makers, and } \\
\text { d information needs. } \\
\text { between domestic and } \\
\text { aarate issues for these } \\
\text { onmental setting, and } \\
\text { the occurrence of } 55 \\
\text { ples collected at the well } \\
\text { blending, from about } \\
100 \text { public wells. Findings } \\
\text { te earlier USGS studies } \\
\text { verage of sampled wells. } \\
\text { s important information } \\
\text { vell samples that may be } \\
\text {-indings for public well } \\
\text { nt understanding of the } \\
\text { OCs in untreated ground } \\
\text { ms (PWSs) across the } \\
\text { well water complements } \\
\text { tilities that typically focus } \\
\text { public. } \\
\text { nost relevant to the man- } \\
\text { ation's ground water and } \\
\text { mphasized in the following } \\
\text { is included in subsequent } \\
\text { ipporting Web site (http:// } \\
\text { onal_assessment). }\end{array}$ \\
\hline
\end{tabular}

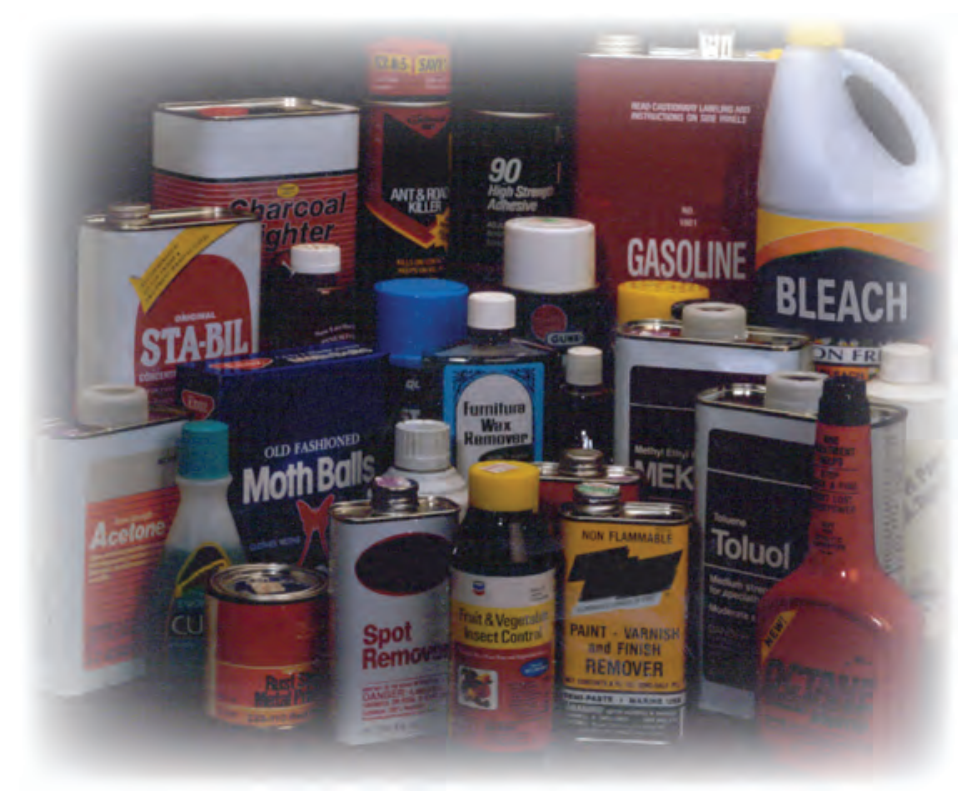

Some household products contain VOCs or chemicals that form VOCs when added to water. (Photograph courtesy of Joel Beamer, professional photographer.) 
VOCs were detected in many aquifers across the Nation. Almost 20 percent of the water samples from aquifers contained one or more of the 55 VOCs, at an assessment level of 0.2 microgram per liter $(\mu \mathrm{g} / \mathrm{L})$. This detection frequency increased to slightly more than 50 percent for the subset of samples analyzed with a low-level analytical method and for which an order-of-magnitude lower assessment level $(0.02 \mu \mathrm{g} / \mathrm{L})$ was applied. VOCs were detected in 90 of 98 aquifer studies completed across the Nation, with most of the largest detection frequencies in California, Nevada, Florida, and the New England and Mid-Atlantic States. Trihalomethanes (THMs), which may originate as chlorination by-products, and solvents were the most frequently detected VOC groups. Furthermore, detections of THMs and solvents and some individual compounds were geographically widespread; however, a few compounds, such as methyl tert-butyl ether (MTBE), ethylene dibromide (EDB), and dibromochloropropane (DBCP), had regional or local occurrence patterns. The widespread occurrence of VOCs indicates the ubiquitous nature of VOC sources and the vulnerability of many of the Nation's aquifers to low-level VOC contamination. The findings for VOCs indicate that other compounds with widespread sources and similar behavior and fate properties also may be occurring. (See p. 16, 18, 20, and 21.)

Many VOCs were detected, but typically at low concentrations. In water samples from aquifers, the concentrations of each VOC and the total concentration of all VOCs analyzed generally were low (defined in this report as concentrations less than $1 \mu \mathrm{g} / \mathrm{L}$ ). For example, 90 percent of the total VOC concentrations in samples were less than $1 \mu \mathrm{g} / \mathrm{L}$. Forty-two of the $55 \mathrm{VOCs}$ were detected in one or more samples at an assessment level of $0.2 \mu \mathrm{g} / \mathrm{L}$. Furthermore, VOCs in each of the seven VOC groups considered in this assessment were detected in the samples; these groups included fumigants, gasoline hydrocarbons, gasoline oxygenates, organic synthesis compounds, refrigerants, solvents, and THMs. The finding that most VOC concentrations in ground water are less than $1 \mu \mathrm{g} / \mathrm{L}$ is important because many previous monitoring programs did not use low-level analytical methods and therefore would not have detected such contamination. (See p. 16, 17, 23, and Appendixes 6 and 7.)

\section{CONCLUSIONS}

- Many of the Nation's aquifers are vulnerable to low-level VOC contamination, indicating the need to include VOCs in groundwater monitoring programs to track the trend of the low-level VOC contamination identified in this assessment.

- It is important to continue to control sources of VOCs, as well as to enhance information about the location, composi-

\section{CONCLUSION}

- VOC contamination in aquifers may be more prevalent than previously reported in

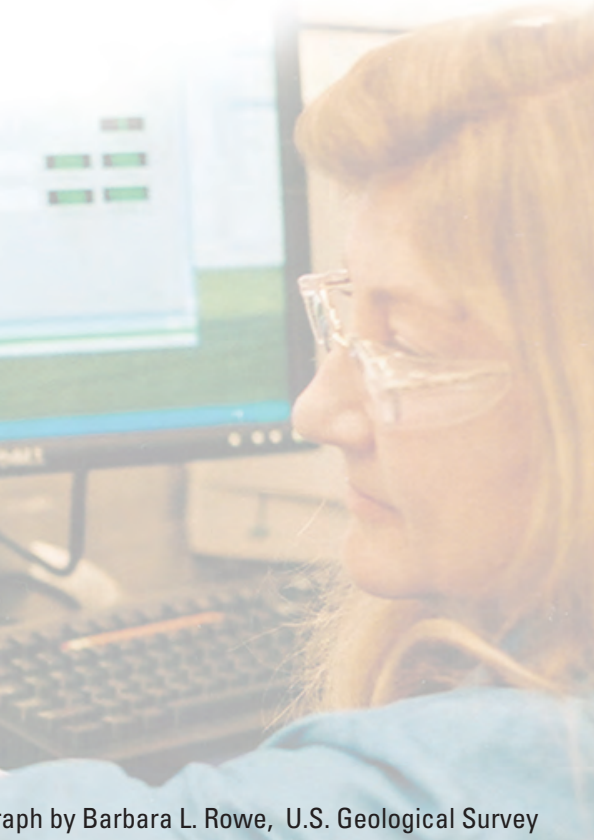


Some VOCs were detected more frequently than others. Although 42 VOCs were detected in aquifer samples, only 15 occurred in about 1 percent or more of the samples. The most frequently detected VOCs include 7 solvents, 4 THMs, 2 refrigerants, 1 gasoline oxygenate, and 1 gasoline hydrocarbon. The THM chloroform was the most frequently detected compound, and its source is attributed, in part, to the recycling of chlorinated waters to aquifers. The solvent perchloroethene (PCE) and the gasoline oxygenate MTBE were the second and third most frequently detected compounds, respectively. Overall, the 15 most frequently detected compounds comprise a large fraction of the low-level VOC contamination and provide a logical focus for future monitoring of aquifers and for follow-up studies to better understand their sources and pathways to aquifers. (See p. 22 and Appendix 6.)
VOCs found in about 1 percent or more of aquifer samples, at an assessment level of $0.2 \mu \mathrm{g} / \mathrm{L}$ (compounds listed by decreasing detection frequency)

\begin{tabular}{ll}
\hline \multicolumn{1}{c}{ Compound name } & \multicolumn{1}{c}{ VOC group } \\
\hline Chloroform & trihalomethane \\
Perchloroethene & solvent \\
Methyl tert-butyl ether & gasoline oxygenate \\
Trichloroethene & solvent \\
Toluene & gasoline hydrocarbon \\
Dichlorodifluoromethane & refrigerant \\
1,1,1-Trichloroethane & solvent \\
Chloromethane & solvent \\
Bromodichloromethane & trihalomethane \\
Trichlorofluoromethane & refrigerant \\
Bromoform & trihalomethane \\
Dibromochloromethane & trihalomethane \\
trans-1,2-Dichloroethene & solvent \\
Methylene chloride & solvent \\
1,1-Dichloroethane & solvent \\
\hline
\end{tabular}

\section{CONCLUSIONS}

- Future studies to understand how VOC contamination of aquifers is occurring can focus on relatively few compounds.

- Additional source control and/or remediation measures, if deemed warranted, also can focus on relatively few compounds, yet would address much of the low-level VOC contamination evident in this assessment.

\section{Explaining VOC contamination in aquifers is complex-VOC occurrence is determined not only by sources but also by natural and anthropogenic fac-} tors that affect the transport and fate of VOCs in aquifers. The complexity of explaining VOC contamination in aquifers was affirmed in this assessment through statistical models for 10 frequently detected compounds. Factors describing the source, transport, and fate of VOCs were all important in explaining the national occurrence of these VOCs. For example, the occurrence of PCE was statistically associated with the percentage of urban land use and density of septic systems near sampled wells (source factors), depth to top of well screen (transport factor), and presence of dissolved oxygen (fate factor). National-scale statistical analyses provide important insights about the factors that are strongly associated with the detection of specific VOCs, and this information may benefit many local aquifer investigations in selecting compound- and aquifer-specific information to be considered. Continued efforts to reduce or eliminate low-level VOC contamination will require enhanced knowledge of sources of contamination and aquifer characteristics. (See p. 24 and 25.)
Factors most commonly associated with VOCs in aquifers

- Septic systems

- Urban land

- Resource Conservation and Recovery Act (RCRA) hazardous-waste facilities

- Gasoline storage and release sites

- Climatic conditions

- Hydric (anoxic) soils

- Dissolved oxygen in ground water

- Type of well

- Depth to top of well screen

\section{CONCLUSIONS}

- The natural and anthropogenic factors important to VOC occurrence in a particular aquifer need to be understood in order to effectively manage and protect aquifers that are susceptible to VOC contamination.

- A careful review of the importance and feasibility of further reducing or eliminating VOC sources to aquifers also is needed to manage and protect these aquifers. 
Despite the short period of its extensive use, MTBE was one of the most frequently detected VOCs. As noted previously, MTBE was the third most frequently detected VOC in aquifers. MTBE production peaked in the 1990s with the majority of it used voluntarily by refineries for the Nation's Reformulated Gasoline (RFG) Program. Concentrations of MTBE in aquifer samples were rarely of concern relative to the U.S. Environmental Protection Agency's (USEPA) drinking-water advisory based on taste and odor; however, MTBE concentrations in ground water were detected more frequently in RFG Program areas than in other areas. The relatively frequent detection of MTBE in aquifers was not an anticipated outcome at the commencement of NAWQA's assessment because of MTBE's short and recent use. A period of only a decade or less was required for the detection of MTBE in some of the Nation's aquifers. MTBE findings demonstrate how quickly some anthropogenic chemicals, especially those that are mobile and persistent like MTBE, may reach aquifers that are especially susceptible to land-surface or atmospheric contamination. (See p. 22, 50-53.)

Some VOCs were not detected in aquifer samples. Thirteen of the VOCs included in this national assessment were not detected in any aquifer samples at a concentration of $0.2 \mu \mathrm{g} / \mathrm{L}$ or larger. The 13 compounds include 5 VOCs predominantly used in organic synthesis, 4 solvents, 2 fumigants, 1 gasoline hydrocarbon, and 1 gasoline oxygenate. The specific reason(s) why each of these compounds was not detected has not been ascertained; however, their lack of occurrence likely is attributed to one or more of the following factors: (1) limited use in industry, commerce, and household products; (2) small releases to water and land; (3) most use occurs in controlled industrial processes or in organic synthesis; (4) the compound degrades quickly to other compounds in the environment; and (5) insufficient time has elapsed to allow the compound to reach wells sampled in this assessment. (See Appendix 6.)
VOCs not detected in aquifer samples, at an assessment level of $0.2 \mu \mathrm{g} / \mathrm{L}$ (compounds listed by VOC group)

\begin{tabular}{ll}
\hline \multicolumn{1}{c}{ Compound name } & \multicolumn{1}{c}{ VOC group } \\
\hline Acrolein & organic synthesis compound \\
Acrylonitrile & organic synthesis compound \\
Hexachlorobutadiene & organic synthesis compound \\
1,2,3-Trichlorobenzene & organic synthesis compound \\
Vinyl bromide & organic synthesis compound \\
1,3-Dichlorobenzene & solvent \\
Hexachloroethane & solvent \\
\hline 1,2,4-Trichlorobenzene & solvent \\
1,1,2-Trichloroethane & solvent \\
cis-Dichloropropene & fumigant \\
trans-Dichloropropene & fumigant \\
\hline Styrene & gasoline hydrocarbon \\
Ethyl tert-butyl ether & gasoline oxygenate \\
\hline
\end{tabular}

\section{CONCLUSIONS}

- Some VOCs that are mobile and persistent may reach especially susceptible aquifers within a decade or less of extensive use, and potentially adversely affect groundwater quality.

- The environmental behavior and fate properties of anthropogenic compounds should be included in decision-making processes

\section{CONCLUSION}

- Some of these VOCs may not warrant continued inclusion in large-scale resource assessments, such as aquifer studies completed in the NAWOA Program, if it is confirmed that their use, release, and behavior and fate characteristics pose a small or negligible likelihood of ground-water contamination. 
Although VOCs were detected frequently in samples from domestic and public wells, only a small percentage of samples had VOC concentrations of potential human-health concern. One or more VOCs were detected in about 14 and 26 percent of domestic and public well samples, respectively, at an assessment level of $0.2 \mu \mathrm{g} / \mathrm{L}$. However, only about 1 to 2 percent of domestic and public well samples had concentrations of potential humanhealth concern (defined in this report as concentrations greater than a USEPA Maximum Contaminant Level (MCL) or concentrations greater than a Health-Based Screening Level (HBSL) for compounds without an MCL). Eight compounds were detected at concentrations of potential concern, and three of these compounds occurred in both domestic and public well samples. Most of the concentrations of potential concern were attributed to the fumigant DBCP (in domestic well samples only) and the solvents PCE and trichloroethene (TCE) in samples from both well types. Because NAWQA's assessment is based on samples collected at the wellhead, it is unknown if those domestic and public well samples with concentrations of potential concern actually result in concentrations greater than MCLs in drinking water. (See p. 30-35.)
VOCs found at concentration(s) of potential human-health concern (compounds listed by decreasing number of concentrations of potential concern).

\begin{tabular}{llll}
\hline \multicolumn{1}{c}{ Compound name } & \multicolumn{1}{c}{ VOC group } & $\begin{array}{c}\text { Domestic } \\
\text { wells }\end{array}$ & $\begin{array}{l}\text { Public } \\
\text { wells }\end{array}$ \\
\hline Trichloroethene & solvent & $\mathrm{X}$ & $\mathrm{X}$ \\
$\begin{array}{l}\text { Dibromochloropropane } \\
\text { fumigant } \\
\text { Perchloroethene }\end{array}$ & $\begin{array}{l}\text { X } \\
\text { solvent } \\
\text { organic synthesis } \\
\text { compound }\end{array}$ & $\mathrm{X}$ & $\mathrm{X}$ \\
1,1-Dichloroethene & $\begin{array}{l}\text { fumigant } \\
\text { fumigant }\end{array}$ & $\mathrm{X}$ & \\
$\begin{array}{l}\text { 1,2-Dichloropropane } \\
\text { Ethylene dibromide } \\
\text { Methylene chloride }\end{array}$ & $\begin{array}{l}\text { solvent } \\
\text { organic synthesis } \\
\text { compound }\end{array}$ & & $\mathrm{X}$ \\
Vinyl chloride & & $\mathrm{X}$ \\
\hline
\end{tabular}

\section{Additional VOCs may warrant inclusion in a low-concentration, trends-}

monitoring program. Nine VOCs that did not occur at concentrations of potential concern in samples from domestic and/or public wells were detected at concentrations below but within a factor of 10 of an MCL. The 9 compounds include 4 solvents, 4 THMs, and 1 gasoline hydrocarbon. These 9 VOCs, plus the 8 compounds with concentrations of potential concern, are important compounds to consider including in a low-concentration, trends-monitoring program, such as the NAWQA Program. Such programs seek to identify compounds in domestic and public well samples before concentrations reach levels of potential concern. Also noteworthy is the finding that the solvents PCE and TCE had, relative to other VOCs, a large number of concentrations in both domestic and public well samples below but within a factor of 10 of their MCLs. (See p. 32, 34, and Appendixes 9 and 11.)

\begin{tabular}{ll}
$\begin{array}{l}\text { Additional VOCs that may warrant inclusion in a } \\
\text { low-concentration, trends-monitoring program } \\
\text { (compounds listed by VOC group) }\end{array}$ \\
\hline \multicolumn{1}{c}{ Compound name } & \multicolumn{1}{c}{ VOC group } \\
\hline Benzene & gasoline hydrocarbon \\
Carbon tetrachloride & solvent \\
1,2-Dichloroethane & solvent \\
cis-1,2-Dichloroethene & solvent \\
1,1,1-Trichloroethane & solvent \\
Bromodichloromethane & trihalomethane \\
Bromoform & trihalomethane \\
Chloroform & trihalomethane \\
Dibromochloromethane & trihalomethane \\
\hline
\end{tabular}

\section{CONCLUSIONS}

- Most samples from domestic and public wells had VOC concentrations less than MCLs and HBSLs, indicating that these concentrations are not anticipated to cause adverse human-health effects.

- Some samples had VOC concentrations greater than MCLs, indicating possible adverse human-health effects if drinking water with these concentrations was consumed over a lifetime. However, there are uncertainties about actual drinkingwater exposure and health effects of water from these supply wells. Further study of these wells is warranted to understand contaminant sources and VOC concentrations in drinking water.

\section{CONCLUSIONS}

- Comparing concentrations to MCLs and HBSLs helps prioritize which compounds merit further study or monitoring. This assessment identified 17 VOCs that may warrant consideration for inclusion in a low-concentration, trends-monitoring program for domestic and public wells.

- NAWQA's occurrence information for these 17 compounds is important information considered in the USEPA's Contaminant Candidate List (CCL) Program.

- Because of the relatively large number of concentrations near and greater than their MCLs, the solvents PCE and TCE appear to warrant special emphasis to understand their sources and their capture by both domestic and public wells. 
In general, public wells are more vulnerable to low-level VOC contamination than are domestic wells. The detection frequencies of nearly all of the most frequently detected compounds and mixtures of VOCs were larger in samples from public wells than from domestic wells, at an assessment level of $0.2 \mu \mathrm{g} / \mathrm{L}$. Mixtures of 2 or more of the $55 \mathrm{VOCs}$ were found in about 13 percent of the public well samples-more than three times more frequently than in domestic well samples - and the likelihood of detecting a mixture of VOCs in public well samples was about the same as detecting a single compound. Furthermore, 10 of the 15 most frequently detected VOCs in public well samples were either THMs or solvents, and all but one of the most common VOC mixtures included THMs. The larger detection frequencies in public well samples than in domestic well samples is attributed, in part, to the larger withdrawal rates of public wells and their proximity to developed areas. The larger pumping rates may increase the capture and movement of VOC contamination to public wells. The proximity of public wells to developed areas increases the likelihood of VOC sources. (See p. 36-41.)

\section{Water that has been chlorinated or exposed to household products con- taining chlorine is an important source of chloroform and possibly other compounds in ground water supplying domestic and public wells. Chloro-} form was the most frequently detected VOC in domestic and public well samples. The chloroform detected in ground water may have potential sources associated with its use as a solvent and an extractant, and as an intermediate product in organic synthesis. Also, chloroform and other THMs are by-products of the chlorination of drinking waters and wastewaters, and the disinfection of domestic and public wells. These compounds also may be present in the effluent of septic systems from the use of household products containing chlorine, such as bleach. Furthermore, artificial recharge of chlorinated water containing THMs and potentially other compounds is becoming more common, especially in western States due to, in part, the limited supply of drinking water. The chlorination of water to control waterborne diseases has been a common practice in the United States for nearly a century. This long-term use has allowed ample time for the recharge of waters containing THMs to reach many of the sampled wells. Once introduced to ground water, chloroform and other THMs may persist and move long distances in some aquifers. The relative detection frequencies of the THMs in well samples, and the common occurrence of mixtures of THMs in public well samples, indicate that waters with a history of chlorination and that contain these compounds have reached some of the sampled wells. (See p. 42-45.)

\section{CONCLUSIONS}

- The frequent detection of VOCs in public well samples reinforces the critical importance of effective well-head protection programs for public wells and the need to further identify and control sources of VOC contamination in these programs.

- Toxicity testing of VOCs historically has focused on individual compounds, typically without consideration of compound mixtures. NAWQA studies contribute to toxicity studies for VOCs by identifying the most commonly occurring chemical mixtures in samples from drinking-water supply wells.

\section{CONCLUSIONS}

- The occurrence of THMs in samples from drinking-water supply wells, especially public wells, is attributed to anthropogenic sources, including most notably the capture of recycled water with a history of chlorination.

- The practice of artificial recharge of chlorinated waters to aquifers may require additional evaluation to understand the concentrations and potential concerns of THMs and other chlorination by-products, especially for those aquifers used for drinking-water supply. 


\section{Chapter 2-Introduction}

\section{Background and National Significance}

\section{What are VOCs?}

VOCs are a subset of organic compounds with inherent physical and chemical properties that allow these compounds to move between water and air. This behavior is the fundamental basis for the USGS's laboratory analysis of VOCs in water samples, in which compounds that are sufficiently volatile are purged from a water sample by an inert gas and then identified and quantified by gas chromatography/ mass spectrometry (GC/MS). In general, VOCs have high vapor pressures, low-to-medium water solubilities, and low molecular weights. Some VOCs may occur naturally in the environ ment, other compounds occur only as a result of manmade activities, and some compounds have both origins.
V olatile organic compounds (VOCs) are ground-water contaminants of concern because of very large environmental releases, human toxicity, and a tendency for some compounds to persist in and migrate with ground water to drinking-water supply wells (sidebar 1). Some VOCs, such as chlorinated solvents, have been used in commerce and industry for almost 100 years, ${ }^{(3)}$ and chloroform and other trihalomethanes (THMs) have undoubtedly been present in chlorinated drinking water since the first continuous municipal application of chlorination in $1908 .^{(4)}$ The production and use of manmade organic compounds, many of which are classified as VOCs, increased by an order of magnitude between 1945 and 1985. ${ }^{(5)}$ Some VOCs have had, and continue to have, very large and ubiquitous usage. An example is the widespread use of gasoline, which contains many VOCs. Furthermore, VOCs have had numerous uses in industry, commerce, households, and military sites (sidebar 2).

\section{The presence of elevated concentrations of VOCs in drinking water may be a concern to human health.}

The large-scale use of solutions of VOCs and products containing some VOCs has resulted in considerable quantities of VOCs released to the environment. Historically, many waste chemicals were disposed of indiscriminately. Because of this practice, VOCs often are the most frequently detected contaminants in soil and ground water at abandoned landfills and dumps, and at many industrial, commercial, and military sites across the Nation. Federal regulation of VOCs commenced in the 1970s with the passage of the Clean Air Act, Clean Water Act, Safe Drinking Water Act (SDWA), Resource Conservation and Recovery Act (RCRA), and other environmental acts. Collectively, much has been done in the past 30-plus years to mitigate pollution. Especially noteworthy examples for mitigating VOC ground-water contamination are (1) improved designs, operations, and disposal practices for the use of chlorinated solvents at industrial, commercial, and military sites; and (2) the cleanup of commercial gasoline release sites and the implementation of measures to minimize gasoline releases in the future. Despite these exemplary accomplishments, environmental releases of some VOCs from manufacturing facilities in the United States remain high. In 2001, for example, 4 of the 20 chemicals with the largest total on-site and off-site releases to the environment were VOCs, with a cumulative estimated release of more than 200 million pounds. ${ }^{(6)}$ 
The detection of VOCs in aquifers is important because of the widespread, large, and increasing use of ground water for drinking water. In 2000 , about 50 percent of the Nation's population obtained their supply of drinking water from ground water (p. 28 and 29).

The presence of elevated VOC concentrations in drinking water may be a concern to human health because of their potential carcinogenicity. In addition to cancer risk, VOCs may adversely affect the liver, kidney, spleen, stomach, and heart, as well as the nervous, circulatory, reproductive, and respiratory systems. Some VOCs may affect cognitive abilities, balance, or coordination, and some are eye, skin, and/or throat irritants. Because of known or suspected human-health concerns, the USEPA has established Maximum Contaminant Levels (MCLs) that apply to 29 VOCs in drinking water supplied by public water systems (PWSs). In addition, some States have set MCLs for additional VOCs and in some cases have established more stringent standards than the USEPA values. The human-health consequences of low-concentration exposure of VOCs in drinking water (that is, at concentrations less than MCLs) are uncertain.

\section{The detection of VOCs in ground water is a concern to officials involved in the management of aquifers because such an occurrence implies aquifer vulnerability.}

In addition to human-health concerns, scientists and engineers involved in the management of aquifers and water-supply development are concerned about the detection of VOCs in ground water because such an occurrence implies aquifer vulnerability. Identifying additional source-control strategies or enhancing existing measures may be warranted if anthropogenic compounds are detected frequently in ground water. The detection of a VOC in ground water also may be of concern because it denotes that a pathway exists by which other persistent and potentially toxic compounds may reach drinking-water supply wells.

\section{How are VOCs Used?}

VOCs have been used extensively in the United States since the 1940s. VOCs are common components or additives in many commercial and household products including gasoline, diesel fuel, other petroleum-based products, carpets, paints, varnishes, glues, spot removers, and cleaners. Example industrial applications include the manufacturing of automobiles, electronics, computers, wood products, adhesives, dyes, rubber products, and plastics, as well as in the synthesis of other organic compounds. VOCs also are used in the dry cleaning of clothing, in refrigeration units, and in the degreasing of equipment and home septic systems. VOCs are present in some personal care products such as perfumes, deodorants, insect repellents, skin lotions, and pharmaceuticals. Some VOCs also have been applied as fumigants in agriculture and in households to control insects, worms, and other pests.
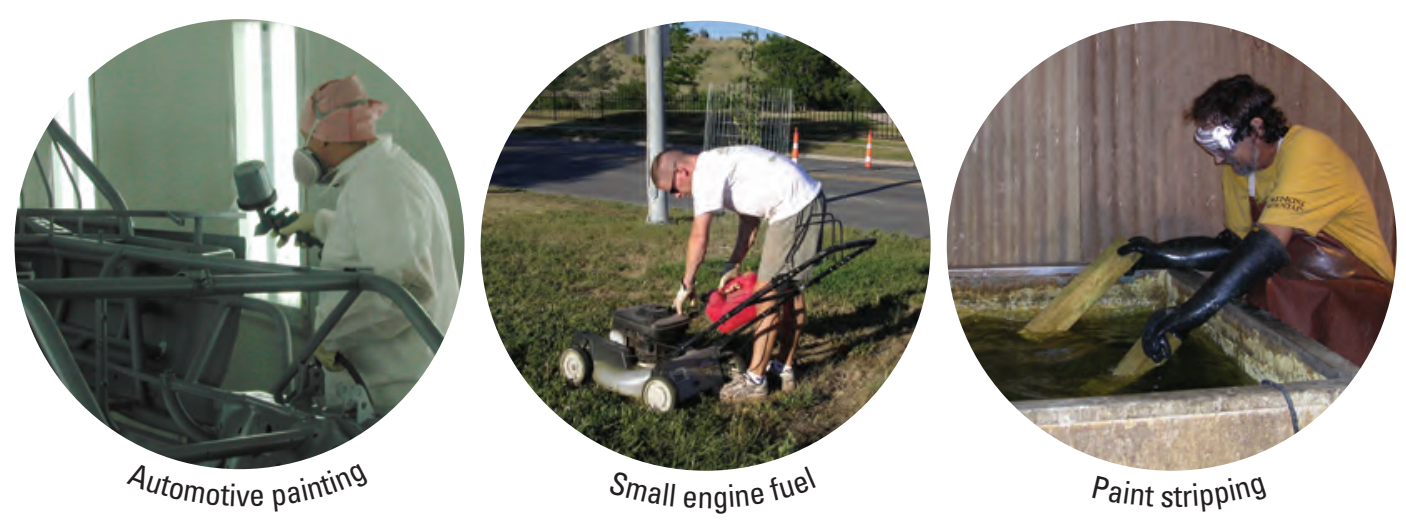

Products containing VOCs have many uses in commerce and households. (Photographs by: left, Connie J. Ross; middle, Janet M. Carter; right, Rika Lashley, U.S. Geological Survey.) 


\section{This Assessment's Purpose and Scope}

\section{Assessing the Quality of Ground Water \\ Ground water is an important supply of drink- ing water in the United States, and the study of aquifers is a large component of NAWQA's ground-water assessments. Aquifer studies have been completed in nearly every NAWOA Study Unit and have provided a comprehen- sive picture of the chemical quality of water in locally and regionally important aquifers. More information on specific aquifer studies is available on the Circular's Web site.}

Many pesticides, VOCs, nutrients, and naturally occurring chemicals are monitored in aquifer studies. Typically the aquifer (or portion thereof) selected for study is locally one of the most intensively used aquifers for drinking water. Aquifer studies are designed to provide an overall picture of the aquifer's water-quality condition and, as such, are considered resource assessments. To achieve this spatially large aquifer characterization, wells selected for sampling are randomly located but distributed approximately equally across the study area. A variety of well types with different water uses are included in the assessment of aquifer studies. None of the sampled wells were selected because of prior knowledge of nearby contamination.
$\mathrm{V}$ OCs were selected for emphasis in the USGS's NAWQA Program primarily because of the previously reported occurrence of some of these compounds in many of the Nation's water supplies. ${ }^{(3,7,8,9,10)}$ The overall intent of the Program's VOC assessment is to provide an improved understanding of the occurrence and geographical distribution of selected VOCs in the Nation's water resources, with emphasis on ground water. The assessment includes both new VOC data collected in the Program's Study-Unit investigations and VOC data from previous studies with a similar design.

Previous findings from the Program's assessment of VOCs were reported initially in 1999 with emphasis on (1) the occurrence of VOCs in samples from wells in urban and rural areas; and (2) the probability of detecting one or more VOCs in ground water on the basis of population density. ${ }^{(11)}$ Subsequently, the Program's scientists have reported nationalscale occurrence findings for (1) mixtures of VOCs, pesticides, and nitrate in samples from domestic and public wells; ${ }^{(12)}$ (2) VOCs in the water supply of selected community water systems (CWSs); ${ }^{(13,14)}$ (3) MTBE and gasoline hydrocarbons in ground water; ${ }^{(15)}$ and (4) VOCs in domestic well samples $^{(16)}$ and in shallow, urban ground water. ${ }^{(17)}$

\section{The overall intent of the NAWQA Program's VOC assessment is to provide an improved understanding of the occurrence and distribution of selected VOCs in the Nation's water resources.}

This report presents additional salient findings of the national VOC assessment and gives emphasis to the occurrence of VOCs in the Nation's ground water (sidebar 3) and in samples from drinking-water supply wells (sidebar 4). This includes information about the detection frequency, concentration, geographical distribution, and mixtures of VOCs. Also described are natural and anthropogenic factors that were found to be associated with the occurrence of some of the frequently detected VOCs. Additionally, this report presents information and more in-depth findings for selected VOCs including (1) chloroform and other THMs; (2) chlorinated solvents-methylene chloride, PCE, 1,1,1-trichloroethane (TCA), and TCE; (3) MTBE and other gasoline oxygenates; and (4) gasoline hydrocarbons.

Information on the occurrence of VOCs is presented separately in this report for ground water (Chapter 3) and drinking-water supply wells, specifically domestic and public wells (Chapter 4). It is recognized that various agencies, organizations, researchers, resource managers, decision makers, and the public have different interests and information needs regarding the use and management of ground-water resources and the protection and oversight of drinking-water supplies. NAWQA aquifer studies are large-scale resource assessments of ground water that provide a general characterization 
of water-quality conditions in locally important aquifers or portions thereof. When completed in many locations, these studies collectively provide an important national perspective on the current extent of VOC contamination and regional patterns of VOC occurrence in ground water. In addition, aquifer studies characterize the vulnerability of ground-water systems to VOCs, as well as to other contaminants with similar sources and environmental properties. This information may be especially valuable for national and regional decisions about the need for future ground-water protection and associated policies and regulations.

\section{The primary purpose of this report is to present impor- tant findings of the assessment of VOCs in the Nation's ground water and drinking-water supply wells.}

The occurrence of VOCs in samples from domestic and public wells is presented separately in order to distinguish the separate issues for these well types related to supply, environmental setting, and sources of VOCs. Samples from these wells provide information about VOC contamination that may reach tap water unless the supply is treated to remove any VOCs or is diluted with other water supplies. Occurrence information for individual VOCs provides important insights about the concentrations of potential human-health concern in drinking-water supply wells and the need for controlling their sources of contamination. This information often is sought by water utilities, public health agencies, the public, and rural citizens who rely on private wells for drinking water.

A total of 55 VOCs are included in this assessment, and a sample from each well was routinely analyzed for nearly all of these compounds. The selection procedure for the inclusion of these VOCs in NAWQA's routine monitoring is described elsewhere ${ }^{(18)}$ and included, for example, consideration of the feasibility of laboratory analysis, known or suspected humanhealth concerns, frequency of occurrence in water resources based on prior investigations, and potential for large-scale use.

\section{Example Key Questions About VOCs That NAWQA's Findings Address:}

- Which VOCs are detected most frequently in aquifers? In samples from domestic and public wells? At what concentrations?

- Which of the aquifers studied are most vulnerable to VOC contamination?

- Which natural and anthropogenic factors are associated with VOC occurrence in aquifers and samples from domestic and public wells?

- Are the frequently detected VOCs found everywhere in aquifers across the Nation or are local/regional occurrence patterns evident?

- Are specific mixtures of VOCs common? Which mixtures occur most frequently?

- Do domestic or public wells have more low-level VOC contamination? Why?

- Which VOCs are detected at concentrations of potential human-health concern in samples from domestic and public wells?

- Which VOC occurrence findings provide insights for future ground-water protection?
4. Assessing the Quality of Ground Water Captured by Drinking-Water Supply Wells

NAWQA's studies of drinking-water supply wells focus on the quality of ground water captured by domestic and public wells, in contrast to the quality of tap water (that is, drinking water). USGS field personnel collect samples of ground water from domestic and public wells at the wellhead and before any treatment or blending. As such, NAWQA's studies complement drinking-water-compliance-monitoring programs required by other agencies; these programs usually specify monitoring after treatment or blending. Comparisons of concentrations for domestic and public well samples to primary drinking-water standards and Health-Based Screening Levels (HBSLs) in this report are made only in the context of the quality of untreated and unblended ground water. Human exposure from tap water and other pathways is not quantified.

During NAWQA's first decade of assessments, many domestic wells and some public wells were sampled. During its second decade, additional emphasis has been placed on understanding the quality of drinking-water supplies including the monitoring of river intakes and production wells of large CWSs, as well as the continued sampling of domestic wells. In addition, major factors that influence the transport of chemicals to public wells are being studied.

Studies of drinking-water supplies are important because these studies (1) identify the presence and concentrations of those chemicals that may reach domestic and public wells (or surface-water intakes); and (2) provide information on the need for enhanced source control. Through these studies, the USGS will continue to collaborate with other agencies, organizations, and water utilities involved with the supply of the Nation's drinking water. 


\section{This Assessment's Approach}
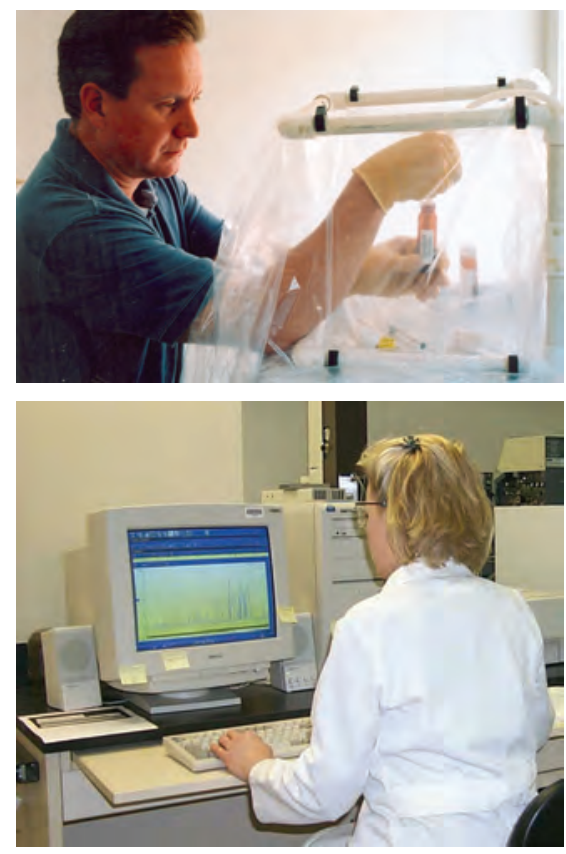

Samples for VOC determination are collected and analyzed by established methods that ensure highquality occurrence information. (Photographs by Barbara L. Rowe, U.S. Geological Survey.) his section describes some aspects of the assessment's approach.

Additional details are presented elsewhere ${ }^{(19)}$ and in Appendix 3. Two primary objectives of this assessment included determination of (1) VOCs in ambient ground water from aquifer studies; and (2) VOCs in samples from actively used domestic and public wells. Samples from 3,498 wells with a variety of water uses were selected for analysis of VOCs in aquifer studies (table 1). VOC data from 2,401 domestic wells and 1,096 public wells were available from aquifer studies, shallow ground-water studies, and a national source-water survey (table 2) to characterize the occurrence of VOCs in these two well types. One VOC analysis per well was included in the assessment. Well selection criteria and maps showing the locations of wells are presented in Appendix 3.

VOC data for domestic well samples are a large subset of data for aquifer studies because existing wells, including many domestic wells, were selected for sampling. Domestic wells commonly were chosen for aquifer studies because their distribution in most areas best fit the study objective of assessing the quality of aquifers using randomly selected and spatially distributed sampling points for a large area.

All samples for NAWQA studies were collected and analyzed by USGS personnel using approved USGS methods. For nearly all of the ground-water samples analyzed by the USGS, compounds were identified and concentrations were quantified using GC/MS. For data not collected or analyzed by USGS, laboratory certification and use of GC/MS methods were required for inclusion of data in this assessment.

Table 1. Number of wells with VOC data for aquifer studies by water use.

\begin{tabular}{lcc}
\hline \multirow{2}{*}{\multicolumn{1}{c}{ Use of water }} & \multicolumn{2}{c}{ Aquifer studies } \\
\cline { 2 - 3 } & Number of wells & Percent of wells \\
\hline Domestic supply & 2,138 & 61.1 \\
Public supply & 513 & 14.7 \\
Monitoring & 335 & 9.6 \\
Other & 461 & 13.2 \\
Unknown & 51 & 1.5 \\
\hline Total & 3,498 & 100 \\
\hline
\end{tabular}

Table 2. Number of domestic and public wells with VOC data by data source.

\begin{tabular}{lcccccc}
\hline \multirow{2}{*}{ Data source } & \multicolumn{2}{c}{ Domestic wells } & & \multicolumn{2}{c}{ Public wells } \\
\cline { 2 - 3 } & $\begin{array}{l}\text { Number } \\
\text { of wells }\end{array}$ & $\begin{array}{l}\text { Percent } \\
\text { of wells }\end{array}$ & & $\begin{array}{l}\text { Number } \\
\text { of wells }\end{array}$ & $\begin{array}{c}\text { Percent } \\
\text { of wells }\end{array}$ \\
\hline Aquifer studies & 12,138 & 89.0 & & 1513 & 46.8 \\
Shallow ground-water studies & 263 & 11.0 & & 8 & .7 \\
National source-water survey & 0 & 0 & & 575 & 52.5 \\
\hline Total & 2,401 & 100 & & 1,096 & 100 \\
\hline \multicolumn{1}{l}{ 'Same wells used in aquifer studies (table 1). } & & & &
\end{tabular}


As noted previously, 55 VOCs were included in this assessment. These VOCs were assigned to the following groups on the basis of their primary usage (or origin): (1) fumigants, (2) gasoline hydrocarbons, (3) gasoline oxygenates, (4) organic synthesis compounds, (5) refrigerants, (6) solvents, and (7) THMs (chlorination by-products). Other uses and additional information for the 55 VOCs can be found in Appendix 4.

\section{Various quality-control criteria were used to select wells and VOC data for this national assessment.}

Most detection frequencies were computed by applying an assessment level of $0.2 \mu \mathrm{g} / \mathrm{L}$ (sidebar 5). The assessment level of $0.2 \mu \mathrm{g} / \mathrm{L}$ was chosen to represent the laboratory reporting value for USGS prior to April 1996 and to be compatible with other agencies. For this assessment level, data from all sampled wells were used in the computation of detection frequencies. The number of samples with laboratory analyses varied among the 55 VOCs.

For some computations, an assessment level of $0.02 \mu \mathrm{g} / \mathrm{L}$ also was applied. This assessment level was selected to represent the occurrence of VOCs using a new, low-level analytical method developed by the USGS for natural waters. When applying this assessment level for aquifer studies, the samples from a subset of 1,687 wells that were analyzed using the new method were used in the computation of detection frequencies. Data from a subset of 1,208 wells were available for computations for domestic well samples; however, insufficient data were available for computations for public well samples at an assessment level of $0.02 \mu \mathrm{g} / \mathrm{L}$.

A variety of ancillary data and statistical models were used to relate the occurrence of VOCs to various hydrogeologic and anthropogenic variables. The hydrogeologic variables that were used in the relational analyses represented the transport and fate of VOCs in ground water. The anthropogenic variables used in the relational analyses represented some of the potential sources of VOCs to ground water. A listing of the ancillary data used in these analyses can be found elsewhere. ${ }^{(19)}$

For those compounds with Federal drinking-water standards, VOC concentrations in samples from domestic and public wells were compared to USEPA MCLs. Concentrations for 15 unregulated compounds were compared to HBSLs (p. 30), which were developed by the USGS in collaboration with the USEPA, New Jersey Department of Environmental Protection, and the Oregon Health \& Science University. HBSLs are not enforceable regulatory standards but are concentrations of contaminants in water that warrant scrutiny because they may be of potential human-health concern. ${ }^{(20)}$
5. What are Assessment Levels, and Why are They Used?

The detection frequency of VOCs in ground water is an important indicator of water quality in occurrence assessments. In order to compare detection frequencies for individual VOCs, groups of VOCs, or VOC data from different agencies with different reporting levels, an "assessment level" must be established. An assessment level is a fixed concentration that is the basis for computing detection frequencies

An assessment level is necessary because the detection frequency computed for a specific VOC depends on the laboratory reporting level for that compound. ${ }^{(21)}$ Laboratory reporting levels for VOCs may vary from compound to compound and from one laboratory to another due to differences in laboratory equipment, equipment sensitivity, experience and skill of equipment operators, or laboratory conditions. In addition, data sets collected for different monitoring objectives or analyzed by different laboratory methods also can have different reporting levels. Thus, different detection frequencies for VOC data sets with different reporting levels may not represent true differences in water quality, but rather they may only reflect the above noted factors. 
soluble VOCs like MTBE have a small sorption tendency and thus move as quickly as ground water, whereas other less soluble VOCs like carbon tetrachloride have a larger sorption tendency and may move slowly relative to the rate of ground-water flow. ${ }^{(25)}$

\section{Some VOCs, such as DBCP, TCA, and MTBE, can persist in ground water with little degradation over years or decades.}

The fate of VOCs in ground water is largely dependent on their persistence under the conditions present in the aquifer. VOCs that are persistent in water are more likely to be detected in ground water because they can travel greater distances from their source before degradation and dilution occur. In ground water, VOCs may undergo selective abiotic (not involving microorganisms) and biotic (involving microorganisms such as bacteria and fungi) degradation. An example of abiotic degradation is the degradation of TCA to 1,1-dichloroethene (1,1-DCE) by reaction with water. For most VOCs, biotic degradation generally is more important than abiotic degradation. Some VOCs can be degraded biotically under a range of redox conditions, ${ }^{(25)}$ whereas others may persist in ground water until a particular redox condition occurs. An example of biotic degradation is the degradation of PCE to TCE.

Bacteria may be unable to use VOCs as a sole source of food when the compounds are present at nanogram per liter or low microgram per liter concentrations. ${ }^{(26)}$ This may slow the degradation of VOCs in ground water. A decline in the degradation rate with decreasing concentration may account for the low VOC concentrations detected in this assessment for some VOCs that degrade quickly at larger concentrations.

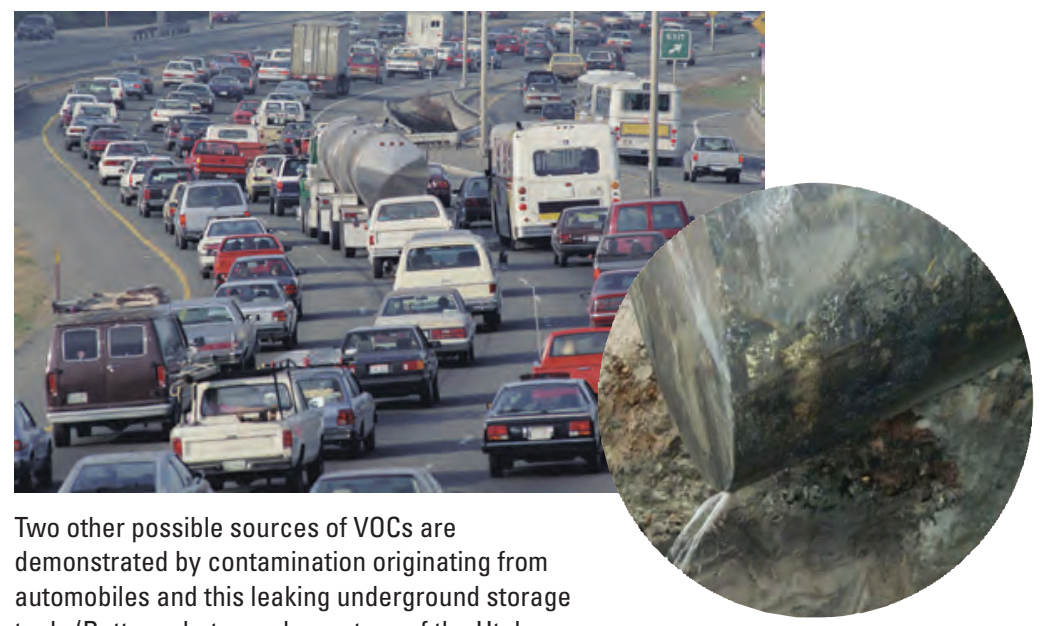

automobiles and this leaking underground storage tank. (Bottom photograph courtesy of the Utah Department of Environmental Quality.)

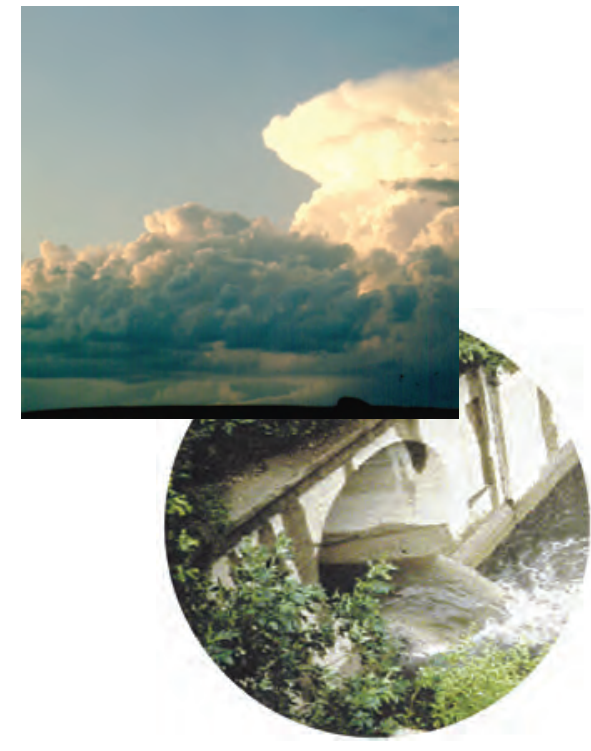

VOCs can be transported with precipitation to ground water and stormwater runoff. (Bottom photograph by Charles G. Crawford, U.S. Geological Survey.) 


\section{Chapter 3-VOCs in Ground Water}

\section{Occurrence of One or More VOCs in Aquifers}

\section{Occurrence Information Helps in Managing Ground-Water Resources}

The occurrence of VOCs in aquifers provides important information to those responsible for managing ground-water resources. Contamination of aquifers by one or more VOCs also is a national issue of potential concern because of the widespread and long-term use of many of these compounds.

Detecting one or more VOCs in aquifer samples provides evidence that conditions favor VOCs reaching the sampled wells. Contaminant occurrence depends on aquifer properties, the associated sources of water to the aquifer, and stresses on the aquifer such as pumping. Contamination also depends on the locations and types of VOC sources, the relative locations of wells, and the transport and fate of VOCs. ${ }^{(27)}$ Knowledge that VOC contamination is present in an aquifer provides the rationale for assessment of the human-health significance of the contamination, as well as the possible need for more in-depth studies to determine the source(s) of contamination and remedial action if concentrations are of potential concern. The occurrence of low-

level contamination of one or more VOCs in an aquifer also can provide managers with an early indication of the presence of VOCs that eventually might adversely affect the quality of water from domestic and public wells.

A bout 19 percent of the ground-water samples from 3,498 wells in aquifer studies (hereafter referred to as aquifer samples) contained one or more VOCs at an assessment level of $0.2 \mu \mathrm{g} / \mathrm{L}$. A larger percent occurrence of 51 percent was evident for a subset of samples from 1,687 wells that were analyzed using the low-level analytical method, for which an order-of-magnitude lower assessment level $(0.02 \mu \mathrm{g} / \mathrm{L})$ was applied.

Possible reasons why no VOCs were detected in some aquifer samples include (1) no VOC sources were present near the sampled wells, (2) the water sampled was recharged before VOCs were in use, (3) the water sampled was old enough that VOCs had time to undergo degradation, (4) the ground water sampled was a mix of water not containing VOCs with water containing VOCs, which resulted in any VOCs present being diluted to concentrations below detection levels, (5) VOCs were present in the aquifer but had not reached the wells yet, or (6) some combination of these and other reasons. VOC occurrence or non-occurrence could vary within different parts of an aquifer as well as among aquifers. At the local scale, additional studies are needed to help explain reasons for VOC occurrence or nonoccurrence.

\section{Detection of VOCs in aquifer samples demonstrates the vulnerability of many of the Nation's aquifers to VOC contamination.}

The finding that one or more VOCs were detected in about one-half of the samples analyzed using the low-level method demonstrates the vulnerability of many of the Nation's aquifers to low-level VOC contamination

Figure 1. Total VOC concentrations were less than 1 microgram per liter $(\mu \mathrm{g} / \mathrm{L})$ in about 90 percent of the 867 aquifer samples with VOC detections analyzed using the lowlevel method.

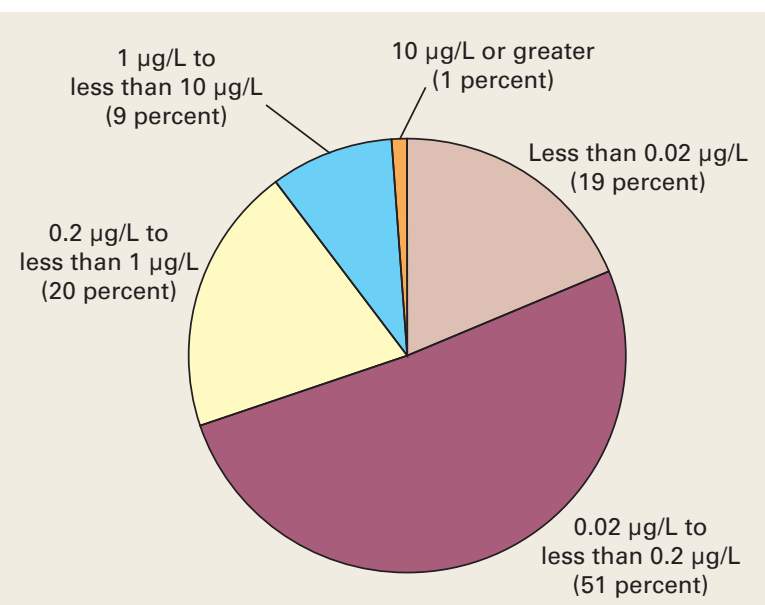


(sidebar 7). This finding also indicates that VOCs might be detected in other aquifers across the Nation if samples are analyzed using a low-level method.

Total concentrations of the 55 VOCs in samples provide an overall national perspective on the extent of VOC contamination in aquifers. About 90 percent of samples analyzed using the low-level method had total VOC concentrations less than $1 \mu \mathrm{g} / \mathrm{L}$ (fig. 1). Conversely, total VOC concentrations of $10 \mu \mathrm{g} / \mathrm{L}$ or greater were found in slightly more than 1 percent of all samples with VOC detections.

\section{Although infrequent, total VOC concentrations of $10 \mu \mathrm{g} / \mathrm{L}$ or greater were found in many States throughout the Nation.}

Nearly three-quarters (42 out of 55) of the VOCs in NAWQA's assessment were detected in one or more samples at a concentration of $0.2 \mu \mathrm{g} / \mathrm{L}$ or greater. The number of VOCs detected, however, did vary markedly among aquifer studies, ranging from 1 to 31 VOCs.

VOC contamination occurs in aquifers across the Nation, albeit over a large range of concentrations (fig. 2). Total concentrations of VOCs of $10 \mu \mathrm{g} / \mathrm{L}$ or greater occur infrequently but in many States throughout the Nation. Many factors, such as land use, hydrogeology of the aquifer, geochemistry of the ground water, and the transport and fate properties of VOCs, affect the occurrence of VOCs in ground water (sidebars 7 and 8, and p. 14 and 15).

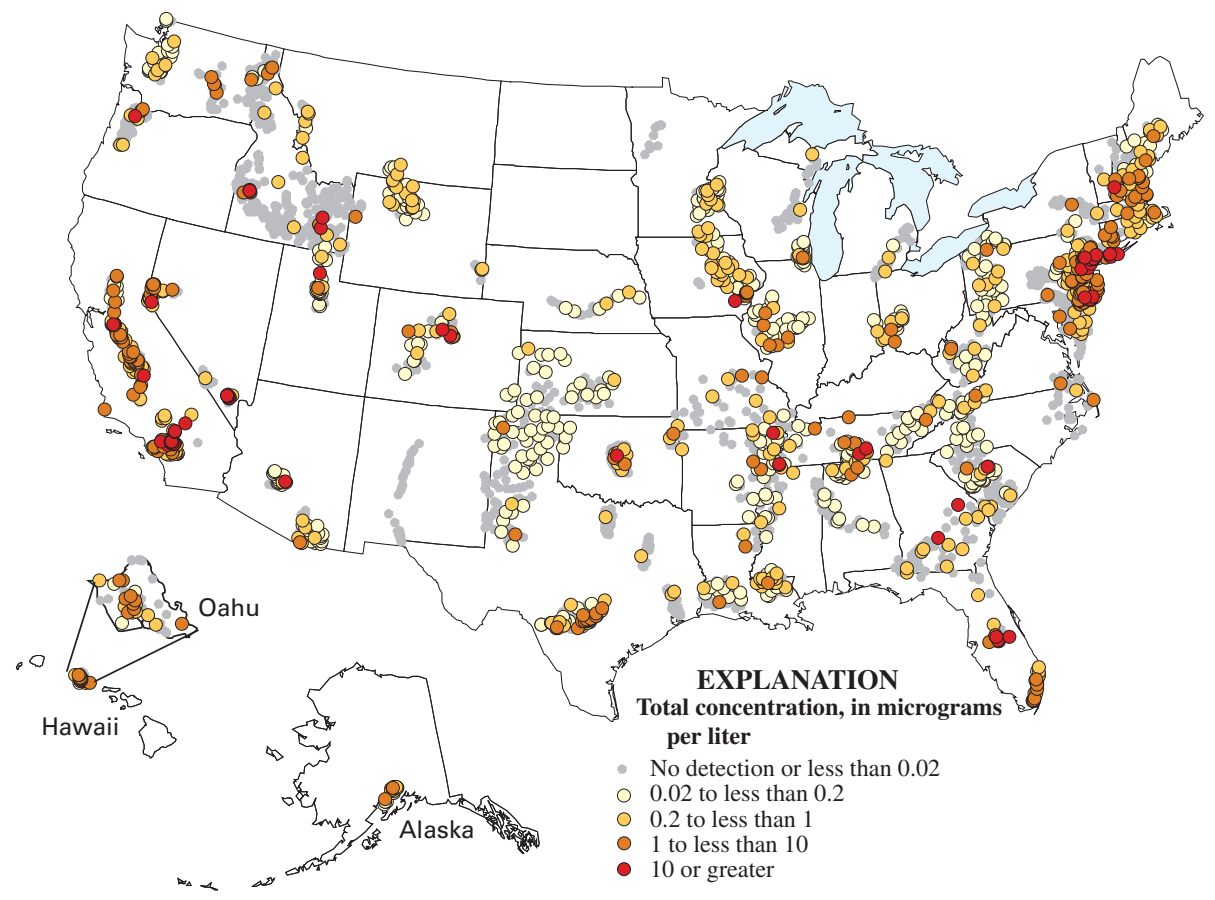

Figure 2. VOC contamination occurs in aquifers across the Nation, albeit over a large range of concentrations.
8. Urban Land Use Contributes More VOCs to Ground Water than Do Other Land Uses

Detection frequencies of 1 or more of the 55 VOCs differ in shallow ground water partly depending on the overlying land use-38 percent in residential/commercial urban settings and 11 percent in agricultural settings at an assessment level of $0.2 \mu \mathrm{g} / \mathrm{L}$. The residential/ commercial findings may be attributable to one or more of several factors related to VOC sources in the urban environment compared to other settings. For example, the urban setting may have more sources and releases of VOCs than other settings. Also, recharge of VOCs to ground water may be enhanced in urban areas by structures such as recharge basins and shallow injection wells. In addition differences in detection frequencies could be attributable to distance traveled by VOCs and to the transport and fate properties of the VOCs associated with the land-use setting.

The finding that urban settings contribute more VOCs to underlying ground water indicates that these waters generally are more vulnerable to VOC contamination than ground water underlying other settings. However, this is not always the case locally. In Oahu, Hawaii, for example, the largest VOC contamination occurs in the agricultural areas of central Oahu, where fumigants have been intensively applied but the aquifers are unconfined, as compared to the minimal contamination underlying urban Honolulu, where the aquifers are somewhat protected by a confining unit. ${ }^{(28)}$ 


\section{Occurrence of One or More VOCs by Aquifer Study, Principal Aquifer, and Aquifer Lithology}

\section{Hydrogeologic Conditions Can Partly Control the Occurrence of VOCs in an Aquifer \\ The Edwards aquifer is a sole-source carbonate aquifer used for drinking-water supply in south-central Texas. This aquifer demonstrates the control that hydrogeologic conditions can have on VOC occurrence in an aquifer. ${ }^{(29)}$ VOC detection frequencies in the Edwards aquifer for the unconfined recharge area (61 percent) differed from the confined area (38 percent). The aquifer's recharge area is a faulted and fractured limestone that allows unrestricted downward movement of water and contaminants into the aquifer. The confined part of the Edwards aquifer, however, is overlain by a unit composed of several hundred feet of low-permeability rocks (the Navarro-Del Rio confining unit). This unit restricts the downward movement of water and contaminants to the underlying confined part of the Edwards aquifer, resulting in a smaller VOC occurrence in the confined area than in the unconfined recharge area.}

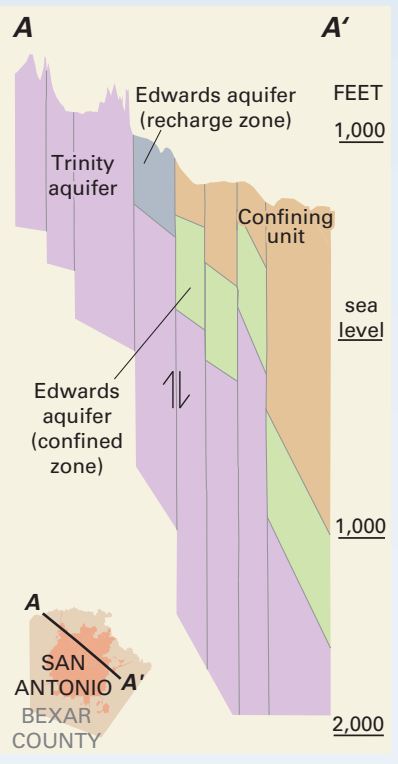

Cross section of the Edwards aquifer near San Antonio, Texas, showing the recharge zone and the confined zone of the Edwards aquifer. ${ }^{(29)}$
$\mathrm{T}$ he occurrence of 1 or more of the 55 VOCs in aquifers was reported collectively to provide an overall national perspective (p. 16 and 17) on the extent of VOC contamination. Additional insights about the variability in occurrence of at least one or more VOCs across the Nation, at aquifer or regional scales, and by aquifer characteristics, such as lithology and hydrogeologic conditions (sidebar 9), are presented here and are relevant to most regional and local ground-water managers.

\section{VOCs were detected throughout the Nation, with the largest detection frequencies generally in the West and the New England and Mid-Atlantic States.}

Detection frequencies of one or more VOCs for the 98 aquifer studies conducted as part of the Study-Unit investigations ranged from 0 to about 77 percent at an assessment level of $0.2 \mu \mathrm{g} / \mathrm{L}$ (fig. 3; Appendix 5). VOCs were detected in many studies throughout the Nation, with most of the largest detection frequencies in California, Nevada, Florida, and the New England and Mid-Atlantic States. No VOCs were detected in eight aquifer studies that were widely distributed across the Nation.

When the sampling was grouped by 33 principal aquifers and 3 other aquifers (sidebar 10), detection frequencies of one or more VOCs at an

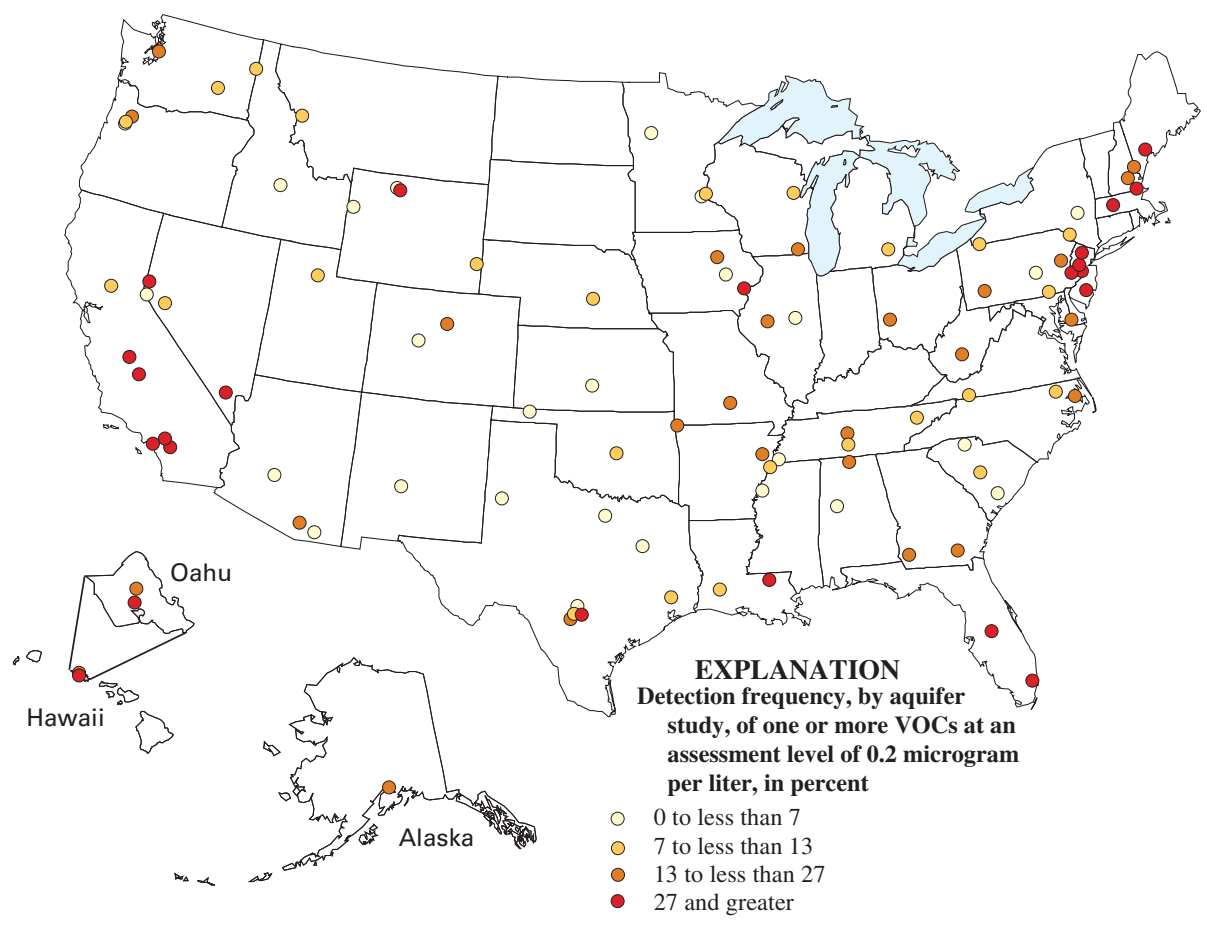

Figure 3. VOCs were detected in many aquifer studies throughout the Nation. 
assessment level of $0.2 \mu \mathrm{g} / \mathrm{L}$ varied from 0 to 51 percent (Appendix 5). This variability between principal aquifers is of the same order of magnitude as the variability within principal aquifers. For example, detection frequencies in the glacial deposit aquifers ranged from 0 to 43 percent.

\section{Detection of VOCs differed markedly between and within principal aquifers.}

The two clusters of relatively large detection frequencies (in the New England and Mid-Atlantic States and in California and Nevada) (fig. 3) include multiple principal aquifers. Large detection frequencies occurred in one or more aquifer studies within four principal or other aquifers in the Northeast - the New England part of the New York and New England crystalline rock aquifer, the glacial deposit aquifers, the Northern Atlantic Coastal Plain aquifer system, and the Early Mesozoic basin aquifers. Large detection frequencies occurred in one or more aquifer studies in two principal aquifers in California - the Central Valley aquifer system and the California Coastal basin aquifers in and near Los Angeles-and in the Basin and Range basin-fill aquifers in Nevada. The relatively large detection frequencies of VOCs in these principal aquifers likely are the result of a combination of factors such as long-term use of VOCs, high population densities, high rainfall (in the Northeast), artificial recharge (in California), and use of VOCs that are relatively persistent in ground water (such as DBCP in the Central Valley of California).

VOCs were detected in principal and other aquifer studies for all lithologic categories, and with the exception of the sandstone and carbonate aquifers, a wide range of detection frequencies were evident for each category (fig. 4). Noteworthy also is that VOCs were detected in nearly all studies. In general, lithology alone is not a good indicator of aquifer vulnerability nor of how frequently VOCs will be detected in a specific aquifer.

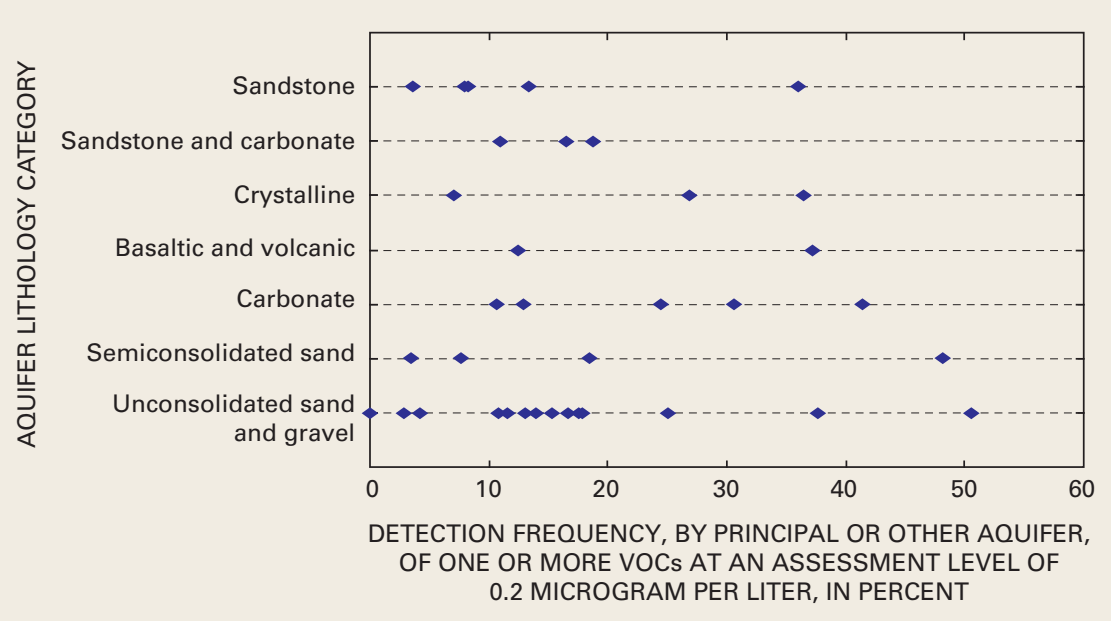

Figure 4. VOC detection frequencies in principal and other aquifers varied widely among lithologic categories.
10. Analysis and Reporting at the Principal-Aquifer Scale Help Link National and Local-Scale Findings

Analysis and reporting of NAWQA's first decade of sampling have focused on national and Study-Unit (local-scale) assessments. Future NAWQA efforts will expand this focus to include analysis and reporting at the principal-aquifer scale. National assessments provide summaries of the national occurrence and distribution of water-quality conditions. However, the large variability in hydrogeologic and other conditions across the Nation often confound the scientist's ability to sort out factors that affect water quality. Study-Unit assessments describe water-quality conditions locally, and often the scientist is able to determine the factors that affect water quality. Extrapolating those findings to beyond the study area often is problematic. Analysis and reporting at an intermediate regional scale, such as by principal aquifer, is intended to help link the findings between the national and local scales.

The principal aquifers used as the framework for this intermediate scale of analysis and reporting are located throughout the United States. Sixty-two principal aquifers have been identified as regionally extensive aquifers or aquifer systems that could potentially be used as a source of potable water. ${ }^{(2)}$ NAWQA sampled parts of 33 of these 62 principal aquifers during its first decade of assessments. The principal aquifers vary widely in size, thickness, hydrogeologic properties, yield, and use as drinking-water supplies. Basic descriptions of these principal aquifers and many of their characteristics are available at $h t t p: / / w w w$. nationalatlas.gov. 


\section{Occurrence of VOC Groups in Aquifers}

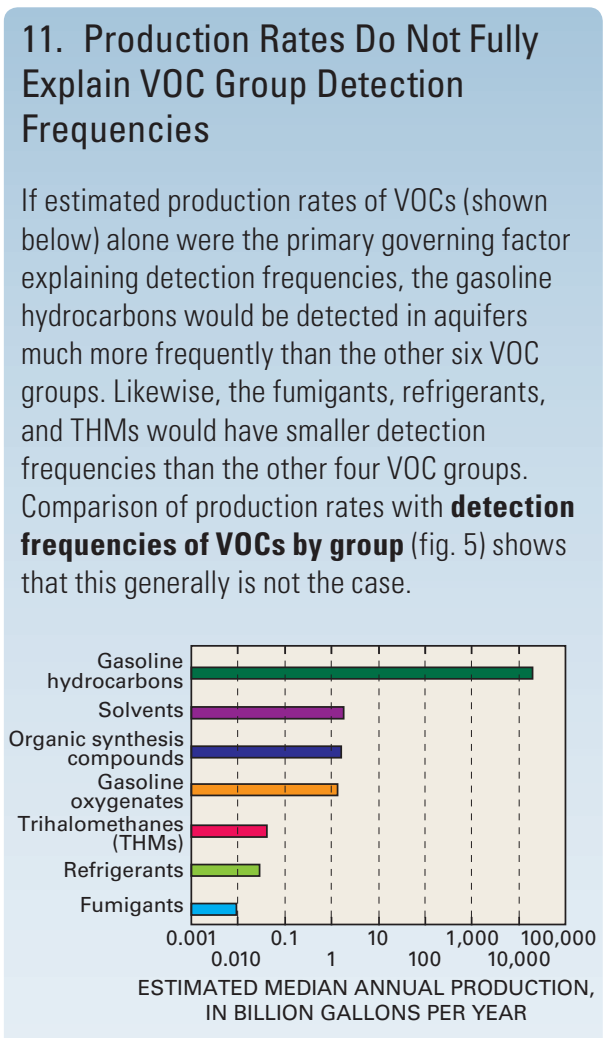

There are many possible reasons for this lack of correspondence between VOC production rates and detection frequency in aquifers. For example, production data (see Circular's Web site) are not available for all VOCs in each group, so actual production could be considerably more than the estimates shown above. In addition, even if the production data were complete, production is not necessarily an exact measure of a VOC source that is contributing a VOC to ground water. Although preferable in this analysis, national data sets of releases for all VOC groups are not available. Additionally, factors such as the hydrogeologic setting, geochemistry of the ground water, and transport and fate properties of VOCs can control the occurrence of VOCs in aquifers (p. 14 and 15). he most frequently detected VOC groups in aquifers were THMs and
solvents (fig. 5). Both groups were detected in about 8 percent of aquifer samples at an assessment level of $0.2 \mu \mathrm{g} / \mathrm{L}$. One or more compounds in each of the remaining five VOC groups also were detected, but at frequencies less than 4 percent. At an assessment level of $0.02 \mu \mathrm{g} / \mathrm{L}$, a detection of one or more THMs, solvents, and gasoline hydrocarbons occurred in about 1 out of every 5 wells. Production of the VOC groups alone does not fully explain VOC group occurrence (sidebar 11).

\section{THMs and solvents were the most frequently detected groups of VOCs in aquifers.}

Most total concentrations for each VOC group were less than $1 \mu \mathrm{g} / \mathrm{L}$, and more than one-half of the samples with detections had concentrations less than $0.2 \mu \mathrm{g} / \mathrm{L}$ for all groups. THMs, solvents, and gasoline hydrocarbons had the largest numbers of detections at concentrations less than $0.2 \mu \mathrm{g} / \mathrm{L}$.

Solvents (fig. 6), THMs, gasoline hydrocarbons, and, less frequently, refrigerants had a widespread distribution throughout the Nation. Fumigants, gasoline oxygenates, and organic synthesis compounds were not detected in many aquifers. Presumably, the spatial patterns of detections/non-detections may reflect, in part, the more spatially focused historical or continued use of particular VOC groups. For example, the association between fumigant use and occurrence in aquifers in Oahu, Hawaii, and the Central Valley of California illustrates effects from historical use and provides an example of how local and national detection frequencies of VOC groups can differ (sidebar 12; fig. 7). The gasoline oxygenates, specifically MTBE, also show spatial patterns of occurrence that are related to use (p. 52 and 53). Additional maps of the national occurrence patterns of VOC groups are available (see Circular's Web site).

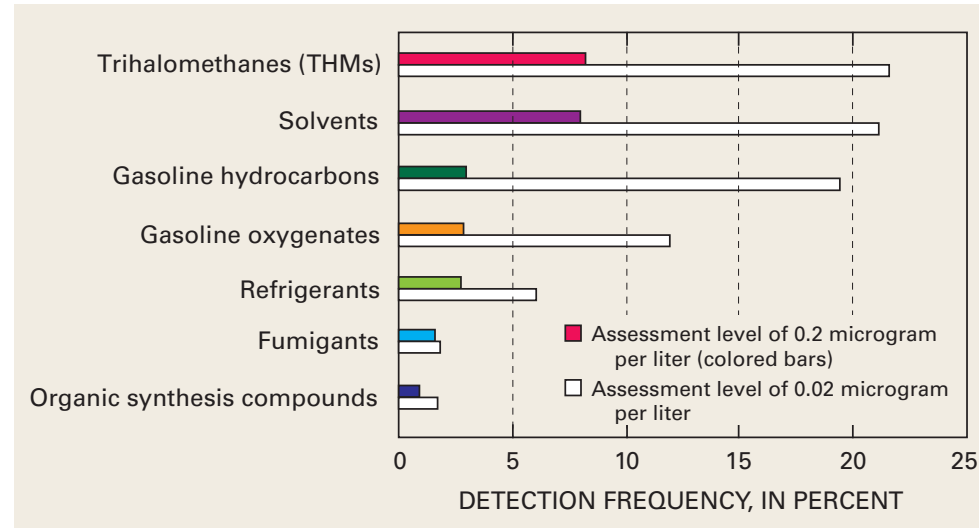

Figure 5. Detection frequencies in aquifers vary between VOC groups. 


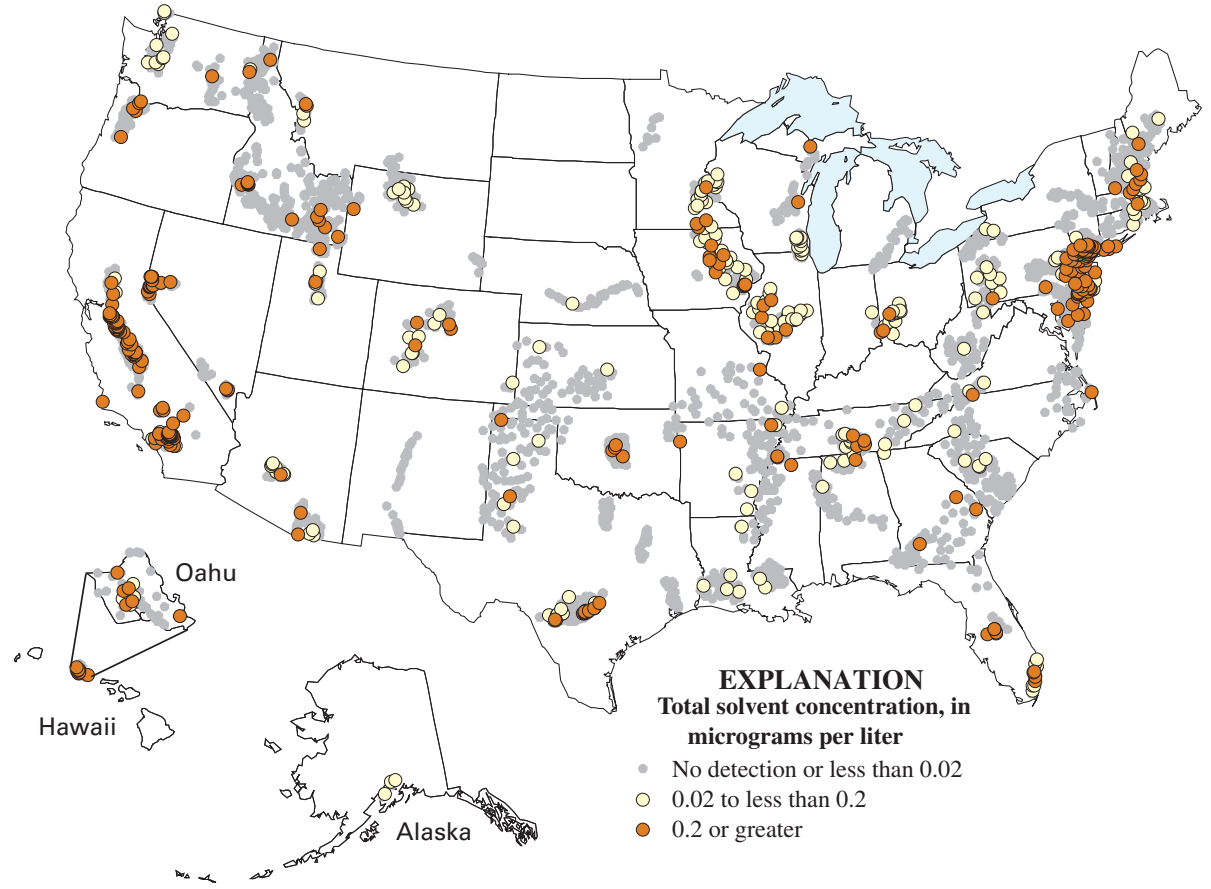

Figure 6. Solvents were detected in aquifers throughout the Nation.

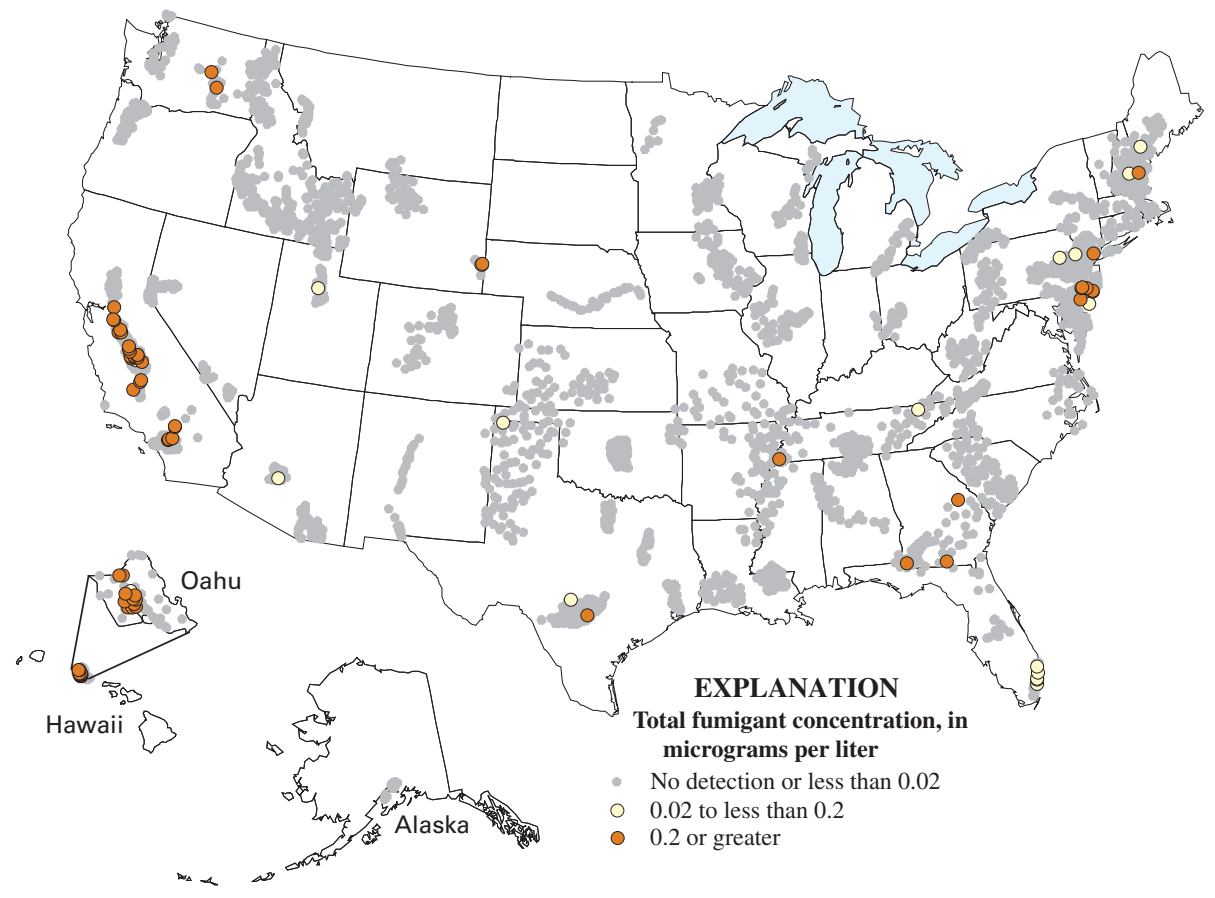

Figure 7. Fumigant detections in aquifers generally are related to areas of known fumigant use.
12. Local and National Detection Frequencies of VOC Groups Can Differ

Fumigant detections in aquifers on the Island of Oahu, Hawaii, and in the Central Valley of California provide examples of a VOC group with much higher local detection frequencies than the national detection frequency of about 2 percent (assessment level of $0.2 \mu \mathrm{g} / \mathrm{L}$ ). The fumigant detections in Oahu are the result of fumigant application to pineapple fields. In 1970, for example, about 1.8 million pounds of fumigants were applied to combat rootworms. ${ }^{(30)}$ Fumigant formulations containing 1,2-dichloropropane, 1,2,3-trichloropropane, and EDB were banned in the late 1970s-early 1980 s after about 20 to 30 years of use. ${ }^{(31,32)}$ In spite of the discontinuation of their use more than 20 years ago, fumigants were detected in more than 30 percent of wells sampled in NAWQA's aquifer study. Fumigants occur in ground water in Oahu because of a combination of factors, including extensive use in recharge areas of the unconfined aquifer in central Oahu, high rainfall that promotes infiltration from the surface, and slow rates of biodegradation. ${ }^{(28)}$

Fumigant detections in the Central Valley of California also are associated with the historical application of a fumigant-in this case, $\mathrm{DBCP}$ —on vineyards and almond orchards. $\mathrm{DBCP}$ was detected in shallow ground water beneath the vineyards and orchards as well as in the regional aquifer. Detection frequencies of DBCP were as large as 60 percent in shallow ground water beneath the vineyards and orchards and about 10 percent in the regional aquifer. ${ }^{(33)}$ 


\section{Occurrence of Individual VOCs in Aquifers}

13. Specific VOC Mixtures

Occurred Infrequently in Aquifer

\section{Samples}

Specific mixtures of VOCs in the 3,498 aquifer samples occurred relatively infrequently at an assessment level of $0.2 \mu \mathrm{g} / \mathrm{L}$. Of the 10 most common mixtures, the two most frequently detected VOC mixtures, PCE-TCE and PCE-chloroform, occurred in 1.5 percent of samples (table below). Only one other mixture, TCE-chloroform, occurred in more than 1 percent of the samples. Of the 55 VOCs measured, only 7 compounds ( 5 solvents and 2 THMs) were found in the 10 most frequently occurring mixtures. Although specific VOC mixtures are a relatively infrequent occurrence at an assessment level of $0.2 \mu \mathrm{g} / \mathrm{L}$, mixtures do occur more frequently when lower VOC concentrations are considered. ${ }^{(12)}$

[PCE, perchloroethene; TCE, trichloroethene; TCA, 1,1,1-trichloroethane; DCE, dichloroethene; DCA, dichloroethane]

\begin{tabular}{rlc}
\hline Rank & \multicolumn{1}{c}{ VoC mixture } & $\begin{array}{c}\text { Detection } \\
\text { frequency, } \\
\text { in percent }\end{array}$ \\
\hline 1 & PCE-TCE & 1.5 \\
1 & PCE-chloroform & 1.5 \\
3 & TCE-chloroform & 1.3 \\
4 & PCE-TCE-chloroform & .94 \\
5 & TCA-chloroform & .89 \\
5 & PCE-TCA & .89 \\
7 & TCE-TCA & .83 \\
8 & TCE-trans-1,2-DCE & .74 \\
9 & TCE-1,1-DCA & .71 \\
10 & Chloroform-chlorodi- & .69 \\
& bromomethane & \\
\hline
\end{tabular}

$\mathrm{P}$ orty-two of the 55 VOCs were detected in aquifers at an assessment level of $0.2 \mu \mathrm{g} / \mathrm{L}$ (Appendix 6). Of those $42 \mathrm{VOCs}, 12$ were detected in more than 1 percent of the samples, and 3 other VOCs had detection frequencies slightly less than 1 percent (fig. 8). Specific VOC mixtures also occur, but infrequently (sidebar 13). Some of the VOCs mixtures in aquifer samples may be the result of degradation of parent compounds (sidebar 14).

The 15 most frequently detected VOCs represent most of the use groups (fig. 8) and include 7 solvents, 4 THMs, 2 refrigerants, 1 gasoline oxygenate, and 1 gasoline hydrocarbon. Fumigants and organic synthesis compounds were not among the 15 most frequently detected VOCs.

\section{Forty-two of the 55 VOCs were detected in aquifers at an assessment level of $0.2 \mu \mathrm{g} / \mathrm{L}$; chloroform was the most frequently detected compound.}

In general, VOC detection frequencies were larger at an assessment level of $0.02 \mu \mathrm{g} / \mathrm{L}$ than at an assessment level of $0.2 \mu \mathrm{g} / \mathrm{L}$ (fig. 8). However, the same general pattern of occurrence among the 15 VOCs was observed. For example, chloroform, PCE, MTBE, and toluene were among the top five most frequently detected VOCs at both assessment levels.

Chloroform was the most frequently detected VOC in aquifers regardless of the assessment level. This finding has not been previously documented for ambient ground water nationally (p. 42-45). Like chloroform,

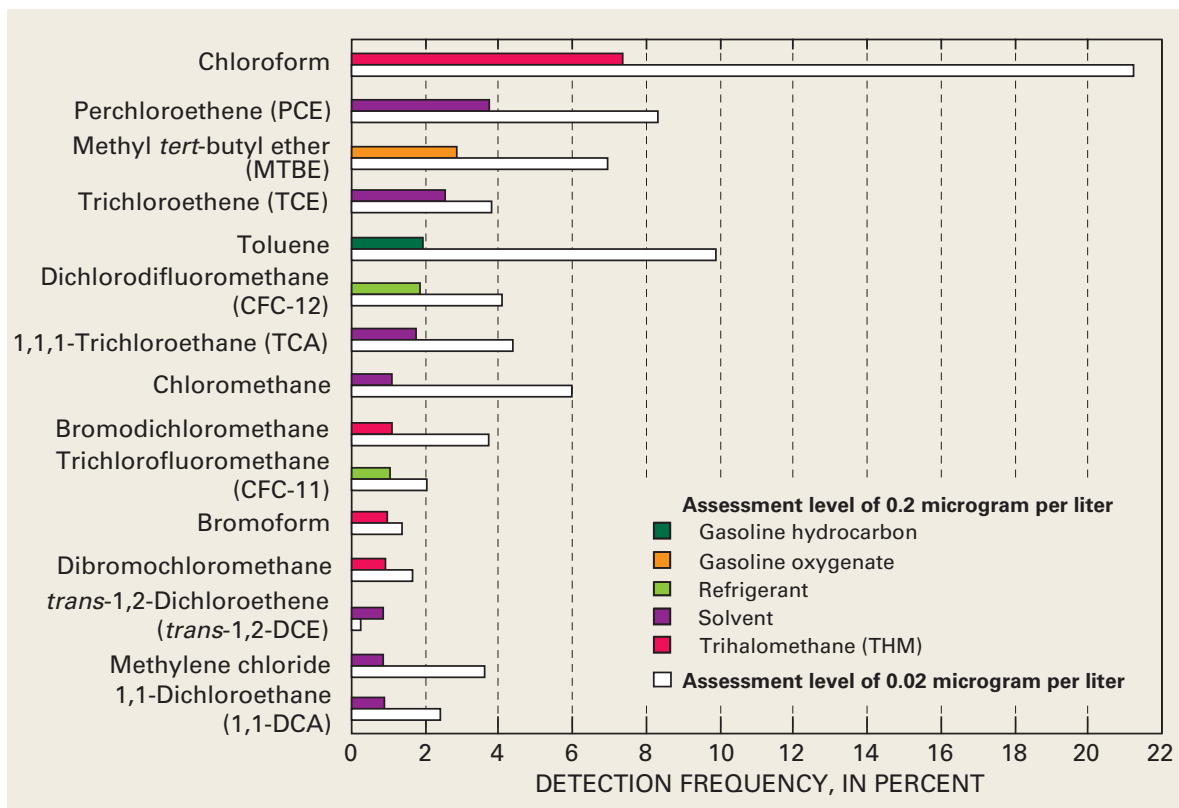

Figure 8. The 15 most frequently detected VOCs in aquifers are from 5 of the 7 VOC groups. 
most of the other frequently detected VOCs are halogenated aliphatic organic compounds (exceptions are toluene and MTBE).

Toluene was the only VOC of the gasoline hydrocarbon group that was among the 15 most frequently detected VOCs (fig. 8). Many of the gasoline hydrocarbons might be expected to be among the most frequently detected VOCs given the very high production and the large and long-term use of the gasoline hydrocarbons compared to other VOC groups. Additional discussion of gasoline hydrocarbons is included in Chapter 5 (p. 54 and 55).

\section{Most of the concentrations of the 15 most frequently detected VOCs were less than about $1 \mu \mathrm{g} / \mathrm{L}$.}

Concentrations reported by the laboratory for the 15 most frequently detected VOCs in aquifers ranged from about 0.002 to about $350 \mu \mathrm{g} / \mathrm{L}$ (fig. 9; Appendix 7). Most of the VOC concentrations, however, were less than about $1 \mu \mathrm{g} / \mathrm{L}$, and all 15 VOCs display this same general concentration pattern. However, the number of samples with concentrations in various concentration ranges differ among compounds. For example, concentrations less than $0.2 \mu \mathrm{g} / \mathrm{L}$ accounted for relatively large percentages of all of the concentrations for chloroform, toluene, and TCA. Conversely, concentrations less than $0.2 \mu \mathrm{g} / \mathrm{L}$ accounted for a relatively small percentage of all of the concentrations for some VOCs such as bromoform.

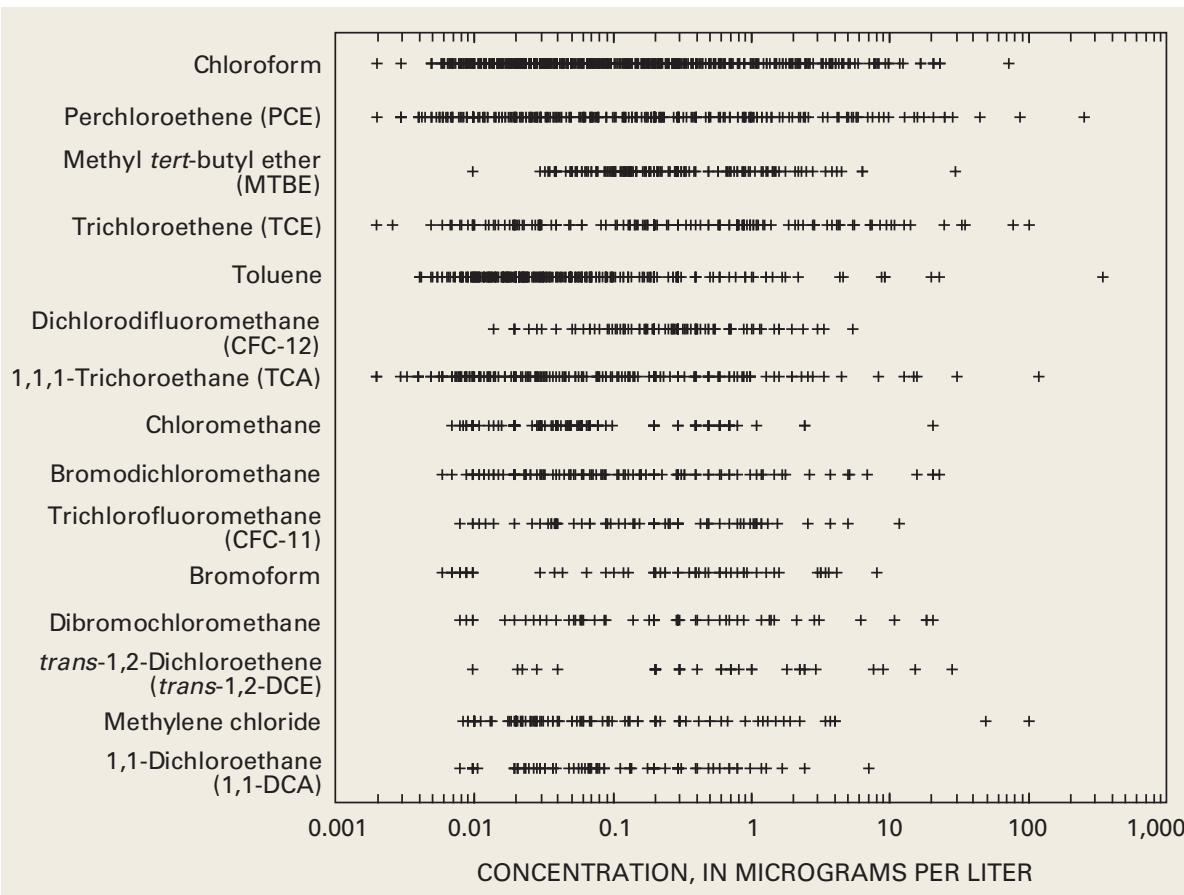

Figure 9. Concentrations varied widely for each of the 15 most frequently detected VOCs in aquifers.
14. Some VOC Detections Could be the Result of the Degradation of a Parent Compound

Some VOCs can degrade through abiotic or biotic processes to another VOC or other compound under oxic and/or anoxic conditions. Several possible degradation by-products are among the 15 most frequently detected VOCs in aquifers. Four of these are (1) methylene chloride from chloroform; (2) chloromethane from methylene chloride; (3) TCE from PCE; and (4) 1,1-dichloroethane (1,1-DCA) from TCA There is a high degree of co-occurrence of these four by-product/parent VOCs in aquifer samples where the parent compound was detected.

Some VOCs can originate both as degradation by-products and from industrial production for use in industrial, commercial, or domestic applications. For VOCs with these dual origins, information on the sources of both the parent and potential by-product to ground water would be helpful to determine whether a detected VOC was a degradation by-product or a result of anthropogenic use. 


\section{Natural and Anthropogenic Factors Associated with Selected VOCs in Aquifers}

15. How were Associations

Developed for the Occurrence of VOCs in Aquifers?

Many natural and anthropogenic factors were tested in individual logistic regression models, hereafter termed "statistical models," for 10 frequently detected VOCs. Numerous models were tested for each VOC, but one was selected as the final model on the basis of several statistical measures. Details of these measures and the general procedures for the modeling are described elsewhere. ${ }^{(19)}$ The detections of individual VOCs were significantly associated with particular natural or anthropogenic factors (table 4). In these models, numerous factors are considered together in a single model allowing one to account for differences in one factor (for example, sources) while testing for significance of other factors (for example, dissolved oxygen).

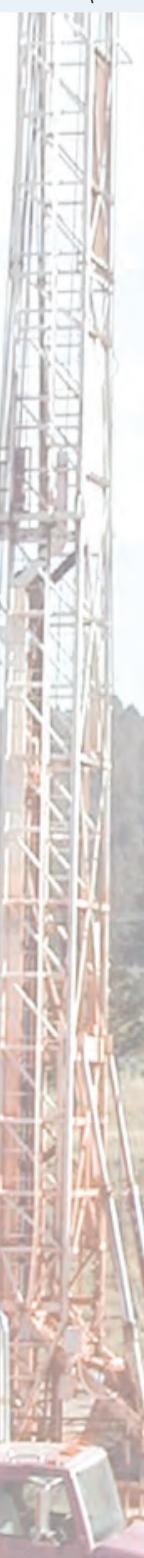

Managing the land area ground-water contamination. (Photograph by Larry D. Putnam, U.S. Geological Survey.)

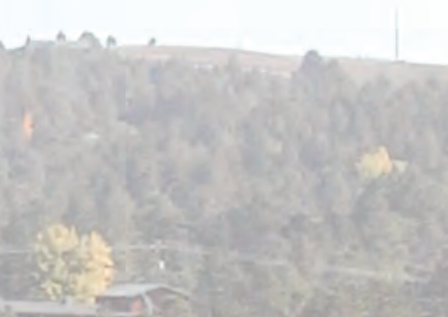
around a well helps to prevent
T en frequently detected VOCs were associated with natural or a mix of natural and anthropogenic factors that would affect their source, transport, and fate in ground water (table 3). Dissolved oxygen, which controls the fate of many compounds in ground water, was the most common explanatory factor for the occurrence of these 10 VOCs (sidebar 15; table 4). Other important factors included source factors of urban land use, RCRA hazardous-waste facilities, gasoline storage sites, and septic systems; transport factors of depth to top of well screen, climate, and soil characteristics; and the indeterminate factor of type of well.

Important similarities and differences are evident in factors that were associated with the occurrence of VOCs within three groups-gasoline hydrocarbons, solvents, and THMs - that are represented by nine of the VOCs considered in the statistical models. The number of LUST sites or underground storage tank (UST) sites was an important source factor associated with the gasoline hydrocarbons (1,2,4-trimethylbenzene and toluene) and also with the gasoline oxygenate MTBE. Subsurface leakage or surface runoff from these sites may be the source of these three VOCs. Cool climates, which tend to reduce volatilization of VOCs from land surfaces to the atmosphere, were associated with the occurrence of 1,2,4-trimethylbenzene, toluene, and MTBE in ground water. Toluene and MTBE were weakly associated with oxic conditions.

\section{Ten frequently detected VOCs were associated with factors that would affect their source, transport, and fate in ground water.}

Many factors that were associated with the occurrence of solvents (chloromethane, methylene chloride, TCA, TCE, and PCE) were similar. Septic system density, percentage of urban land use, and number of RCRA hazardous-waste facilities all were identified as sources associated with the occurrence of solvents. High silt, sparse sand, low organic content of soils, and shallow wells or screens are transport factors associated with the occurrence of solvents. High silt and sparse sand content of soils (indicating low permeability) were associated with the occurrence of chloromethane and methylene chloride. Under these conditions, the slower transport of recharge 
through the unsaturated zone may enhance the degradation of chloroform to methylene chloride and chloromethane (p. 26 and 27). The occurrence of methylene chloride, TCA, and PCE was associated with either shallow well depth or shallow well screen depth. The occurrence of TCA, TCE, and PCE was strongly related to oxic water conditions, whereas chloromethane occurrence was strongly related to anoxic conditions. These relations are not surprising given that TCA, TCE, and PCE are more stable under oxic conditions, and chloromethane is more stable under anoxic conditions.

The occurrence of THMs (bromodichloromethane and chloroform) was associated with oxic conditions and public wells. Bromodichloromethane was detected more frequently in areas with low ground-water recharge and in areas with sewer systems. In contrast, chloroform was detected more frequently in areas with wet climates (generally indicating high ground-water recharge) and in areas with several possible sources of contamination including urban land use, septic systems, and RCRA hazardous-waste facilities.

\section{The concentration of dissolved oxygen was the most common explanatory factor associated with the occurrence of many VOCs.}

The detection frequencies of many of the compounds were associated with a particular well type (domestic well or public well), but the reason for this association is not fully known. Noteworthy is the association of bromodichloromethane, chloroform, PCE, TCE, and MTBE with public wells. Plausible reasons for this association are the large pumping rates of public wells and their proximity to developed areas, where multiple sources or uses of those compounds may be present (p. 40 and 41).

Table 3. Factors most commonly associated with VOCs in aquifers.

\section{Source Factors}

- Septic systems

- Urban land

- Resource Conservation and Recovery Act (RCRA) hazardous-waste facilities

- Gasoline underground storage tank and leaking underground storage tank sites

\section{Transport Factors}

- Climatic conditions

- Depth to top of well screen

- Hydric (anoxic) soils

\section{Fate Factor}

- Oxic ground water (dissolved-oxygen concentration greater than or equal to 0.5 milligram per liter)

\section{Indeterminate}

- Type of well
Table 4. Positive associations, in order of decreasing importance, for 10 frequently detected VOCs in aquifers.

[TCA, 1,1,1-trichloroethane; TCE, trichloroethene; PCE, perchloroethene; MTBE, methyl tert-butyl ether; RCRA, Resource Conservation and Recovery Act; LUST, leaking underground storage tank; UST, underground storage tank; $\mathrm{F}$, fate; $\mathrm{S}$, source; $\mathrm{T}$, transport; I, indeterminate].

\begin{tabular}{|c|c|c|}
\hline Compound & $\begin{array}{c}\text { Occurrence } \\
\text { associated with: }\end{array}$ & $\begin{array}{c}\text { Type } \\
\text { of } \\
\text { variable }\end{array}$ \\
\hline \multicolumn{3}{|c|}{ Gasoline hydrocarbons } \\
\hline $1,2,4-$ & few septic systems & $\mathrm{S}$ \\
\hline \multicolumn{2}{|c|}{ Trimethyl- cool climates } & $\mathrm{T}$ \\
\hline \multirow[t]{2}{*}{ benzene } & dry climates & $\mathrm{T}$ \\
\hline & gasoline UST sites & $\mathrm{S}$ \\
\hline \multirow[t]{6}{*}{ Toluene } & cool climates & $\mathrm{T}$ \\
\hline & old construction & $\mathrm{S}$ \\
\hline & gasoline LUST sites & $\mathrm{S}$ \\
\hline & domestic wells & $\mathrm{I}$ \\
\hline & oxic water & $\mathrm{F}$ \\
\hline & hydric soils & $\mathrm{T}$ \\
\hline \multicolumn{3}{|c|}{ Gasoline oxygenate } \\
\hline \multirow[t]{7}{*}{ MTBE } & wet climates & $\mathrm{T}$ \\
\hline & MTBE use areas & $\mathrm{S}$ \\
\hline & $\begin{array}{l}\text { shallow depth to top of } \\
\text { well screen }\end{array}$ & $\mathrm{T}$ \\
\hline & public wells & $\mathrm{I}$ \\
\hline & cool climates & $\mathrm{T}$ \\
\hline & oxic water & $\mathrm{F}$ \\
\hline & gasoline LUST sites & $\mathrm{S}$ \\
\hline \multicolumn{3}{|c|}{ Solvents } \\
\hline \multirow{3}{*}{$\begin{array}{l}\text { Chloro- } \\
\text { methane }\end{array}$} & anoxic water & $\mathrm{F}$ \\
\hline & high silt in soil & $\mathrm{T}$ \\
\hline & undeveloped land & $\mathrm{S}$ \\
\hline \multirow{4}{*}{$\begin{array}{l}\text { Methylene } \\
\text { chloride }\end{array}$} & domestic wells & I \\
\hline & shallow well depth & $\mathrm{T}$ \\
\hline & septic systems & $\mathrm{S}$ \\
\hline & sparse sand in soil & $\mathrm{T}$ \\
\hline \multirow[t]{8}{*}{$\mathrm{TCA}$} & oxic water & $\mathrm{F}$ \\
\hline & $\begin{array}{l}\text { shallow depth to top of } \\
\text { well screen }\end{array}$ & $\mathrm{T}$ \\
\hline & low soil organic content & $\mathrm{T}$ \\
\hline & cool climates & $\mathrm{T}$ \\
\hline & septic systems & $\mathrm{S}$ \\
\hline & urban land & $\mathrm{S}$ \\
\hline & RCRA facilities & $\mathrm{S}$ \\
\hline & old construction & $\mathrm{S}$ \\
\hline \multirow[t]{7}{*}{ TCE } & urban land & $\mathrm{S}$ \\
\hline & oxic water & $\mathrm{F}$ \\
\hline & wet climates & $\mathrm{T}$ \\
\hline & public wells & $\mathrm{I}$ \\
\hline & sparse hydric soils & $\mathrm{T}$ \\
\hline & septic systems & $\mathrm{S}$ \\
\hline & RCRA facilities & $\mathrm{S}$ \\
\hline \multirow[t]{6}{*}{$\overline{\mathrm{PCE}}$} & $\begin{array}{l}\text { shallow depth to top of } \\
\text { well screen }\end{array}$ & $\mathrm{T}$ \\
\hline & oxic water & $\mathrm{F}$ \\
\hline & public wells & $\mathrm{I}$ \\
\hline & urban land & $\mathrm{S}$ \\
\hline & septic systems & $\mathrm{S}$ \\
\hline & Trihalomethanes (THMs) & \\
\hline \multirow{4}{*}{$\begin{array}{l}\text { Bromodi- } \\
\text { chloro- } \\
\text { methane }\end{array}$} & oxic water & $\mathrm{F}$ \\
\hline & sewer systems & $\mathrm{S}$ \\
\hline & low ground-water recharge & $\mathrm{T}$ \\
\hline & public wells & I \\
\hline \multirow[t]{7}{*}{ Chloroform } & urban land & $\mathrm{S}$ \\
\hline & oxic water & $\mathrm{F}$ \\
\hline & wet climates & $\mathrm{T}$ \\
\hline & public wells & $\mathrm{I}$ \\
\hline & sparse hydric soils & $\mathrm{T}$ \\
\hline & septic systems & $\mathrm{S}$ \\
\hline & RCRA facilities & $\mathrm{S}$ \\
\hline
\end{tabular}




\section{Dissolved Oxygen and VOC Occurrence in Aquifers}

16. Dissolved Oxygen Varies Along a Ground-Water Flowpath

Dissolved-oxygen concentrations in ground water can vary by location in an aquifer and with the age of the ground water. Young ground water usually has a larger dissolvedoxygen concentration compared to old ground water. This is because dissolved oxygen can become depleted along a flowpath through various abiotic and biotic processes.

Samples collected by NAWQA with age-date information indicate that water recharged after 1955 (referred to here as young ground water) had higher dissolved-oxygen concentrations compared to ground water recharged prior to 1955 (referred to here as old ground water). Because ground water in recharge areas of aquifers is younger than ground water farther along a flowpath, a comparison of detection frequencies of VOCs between young, oxic ground water and old, anoxic ground water should be similar to a comparison of ground water at points along a hypothetical flowpath (fig. 11).
D issolved oxygen in ground water was the factor most commonly associated with the occurrence of VOCs (p. 24 and 25). Oxygen is the electron acceptor preferred by many microorganisms in their respiration of organic compounds. ${ }^{(34)}$ Although the biodegradation of many VOCs can occur in either oxic or anoxic ground-water conditions, the rates of biodegradation usually are not equal. ${ }^{(35)}$ Because the rates of biodegradation of VOCs in oxic and anoxic conditions differ, the detection frequencies of VOCs also can be expected to vary with differences in the dissolved-oxygen condition of ground water.

The type of VOC (major chemical class) also is important in determining the rate of biodegradation in various dissolved-oxygen conditions. This is evident from the observation that, with the exception of MTBE and toluene, all of the other frequently detected VOCs in aquifers are halogenated aliphatic compounds (fig. 8). In general, halogenated aliphatic VOCs biodegrade more rapidly in anoxic conditions than in oxic conditions (see Circular's Web site). Because about three-quarters of the samples from aquifer studies were oxic, compounds that biodegrade more slowly in oxic ground water, like halogenated aliphatic VOCs, should be more persistent and more frequently detected than compounds that degrade quickly in oxic ground water, like many petroleum hydrocarbons.

\section{The detection frequencies of most VOCs were dependent on the dissolved-oxygen conditions of ground water and the type of VOC.}

The ratios of the detection frequencies of 10 frequently occurring VOCs in oxic ground water compared to their detection frequencies in anoxic ground water differ markedly (fig. 10). Some VOCs, such as TCA, chloroform, and PCE, were detected more frequently in oxic ground water than in anoxic ground water. Other VOCs, such as methylene chloride and chloromethane, were detected more frequently in anoxic ground water. The differences in detection frequencies for some of these VOCs are consistent with published rates of biodegradation for these VOCs under different dissolvedoxygen conditions. ${ }^{(35)}$ For example, TCA has an aerobic half-life that is nearly twice as long as its anaerobic half-life (see Circular's Web site). This indicates that TCA should be more persistent in oxic ground water than in anoxic ground water, which was confirmed by the relatively large detection frequency ratio of TCA.

A conceptual model illustrates how chloroform may undergo biodegradation along a hypothetical flowpath in an aquifer, along which dissolved oxygen becomes depleted (sidebar 16; fig. 11). A subset of samples from 


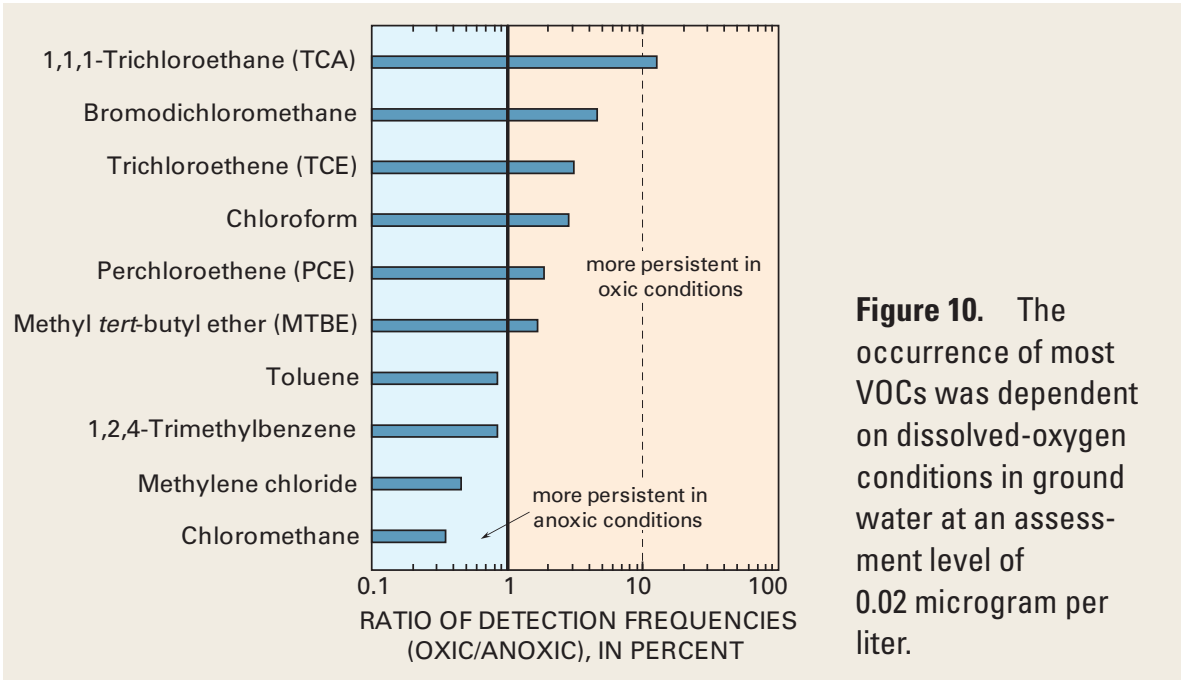

aquifers was used to represent this hypothetical flowpath and to characterize changes in the detection frequency of chloroform and two potential byproducts. The detection frequency of chloroform was lower in old, anoxic ground water compared to young, oxic ground water. In contrast, the detection frequencies of both chloromethane and methylene chloride, both potential by-products of chloroform degradation, were larger in old, anoxic ground water than in young, oxic ground water (fig. 11). These data support the conceptual model in which chloroform biodegrades along a groundwater flowpath.

Dissolved-oxygen concentration data from aquifer samples could be used to ascertain if VOCs of local interest would tend to persist in ground water or be degraded to a more or less toxic compound. Aquifer conditions that favor the persistence of the parent compound or formation of a toxic byproduct would warrant scrutiny.

Figure 11. Chloroform in young, oxic ground water biodegrades along a hypothetical groundwater flowpath to form methylene chloride and chloromethane in old, anoxic ground water.

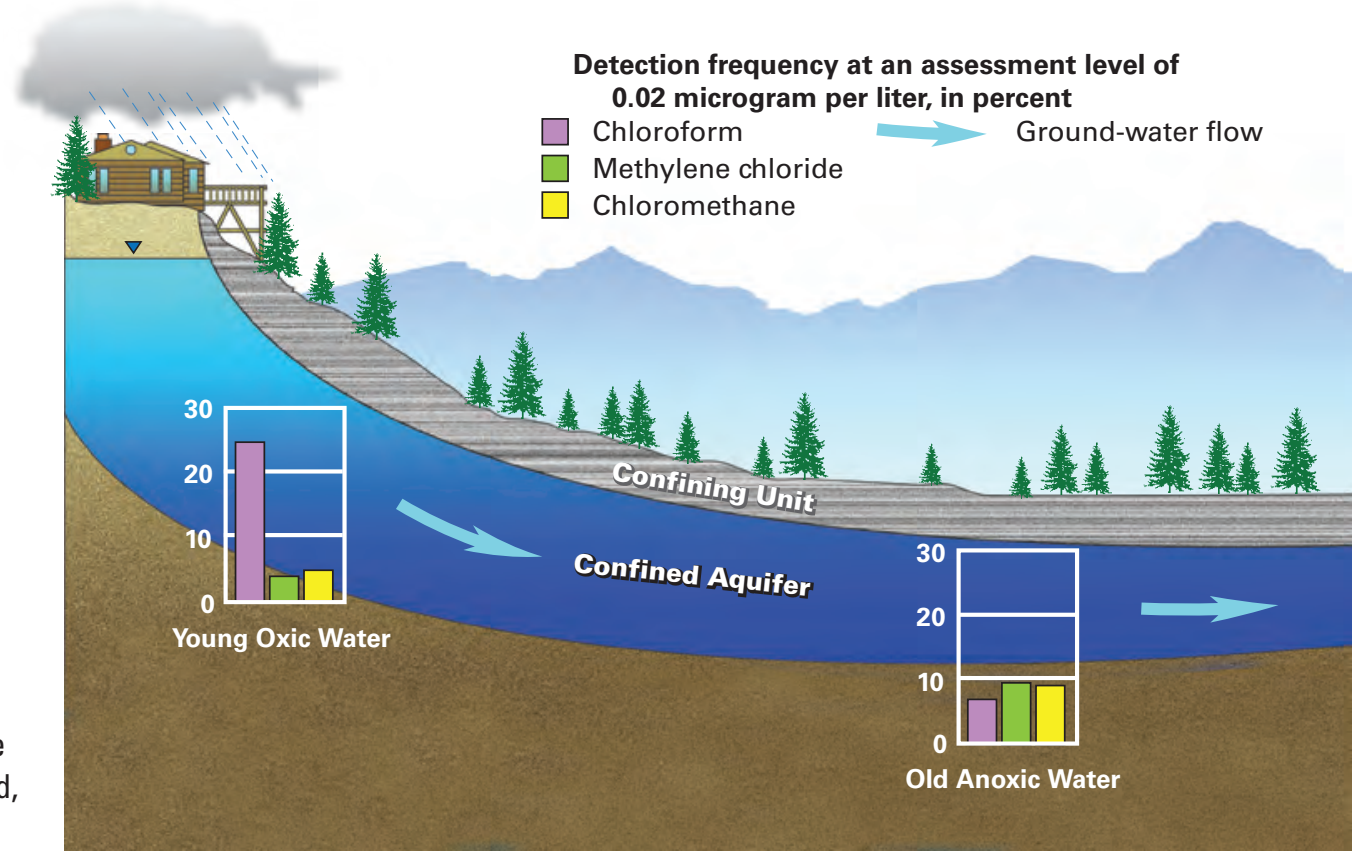




\section{Chapter 4—VOCs in Samples from Drinking-Water Supply Wells}

\section{Ground Water as a Drinking-Water Supply}

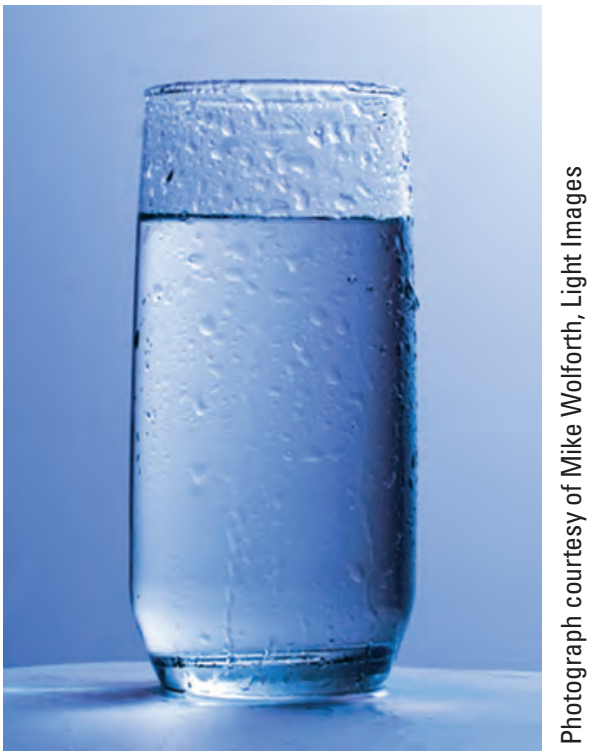

G round water provides a drinking-water supply for about one-half the Nation's population, including almost all of the people who reside in rural areas. ${ }^{(1)}$ Ground water supplies domestic wells and public wells in every State (fig. 12). Domestic wells are privately owned, self-supplied sources for domestic water use. ${ }^{(36)}$ Public wells are privately or publicly owned and supply ground water for PWSs. In this report, the discussion of public wells refers to the quality of water captured by wells that supply drinking water to PWSs. As defined by the USEPA, ${ }^{(37)}$ PWSs supply drinking water to at least 15 service connections or regularly serve at least 25 individuals daily at least 60 days a year.

\section{Ground water is used as a drinking-water supply for about one-half the Nation's population, including almost all people residing in rural areas.}

About 150 million people in the United States received their drinking water from domestic and public wells in 2000. ${ }^{(38,39)}$ Estimated withdrawals from domestic and public wells increased by about 60 and 100 percent, respectively, from 1965 to 2000 (fig. 13). In 2000, average daily withdrawal rates from domestic and public wells for drinking-water supply were 3.5 and 16 billion gallons per day (Bgal/d), respectively. ${ }^{(39)}$

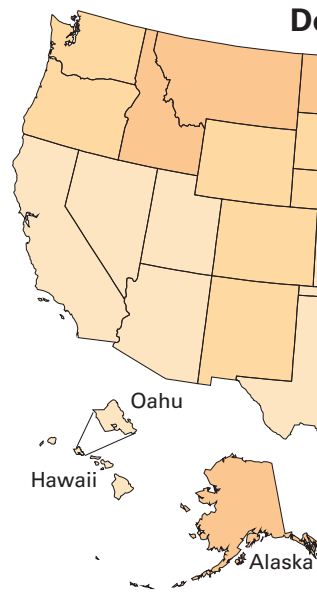

\section{Domestic Wells}

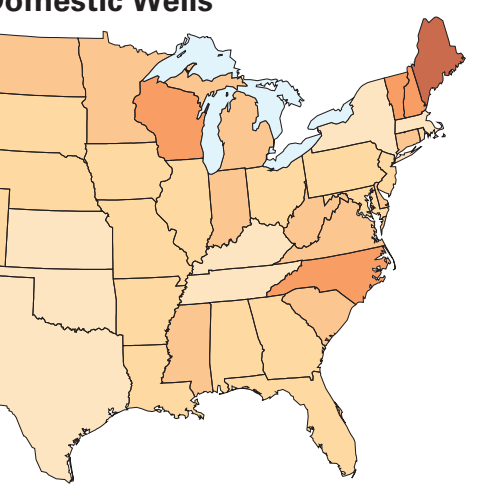

EXPLANATION

Percent of population that uses ground water for drinking water by State

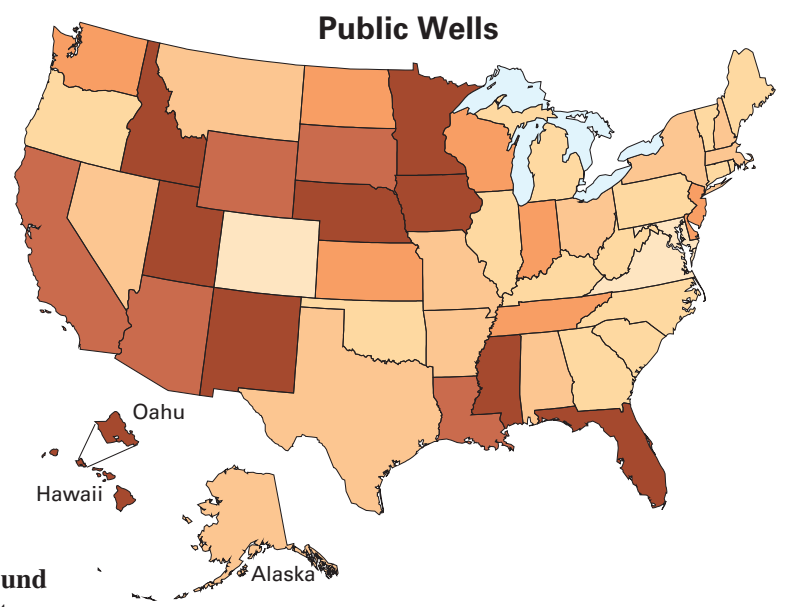

10 or less

Greater than 10 to $20 \square$ Greater than 30 to 40

Greater than 20 to $30 \square$ Greater than 50

Figure 12. In most States, a greater percentage of the population is dependent on public wells than on domestic wells as a drinking-water supply. 
For this NAWQA assessment, detection frequencies and concentrations of individual VOCs and VOC mixtures were examined to characterize the quality of ground water captured by drinking-water supply wells (sidebar 4). VOC detection frequencies for domestic well samples were determined using a two-tiered assessment level approach of $0.2 \mu \mathrm{g} / \mathrm{L}$ for 2,401 wells and $0.02 \mu \mathrm{g} / \mathrm{L}$ for a subset of 1,208 wells. Through a collaborative effort with researchers and water utilities, VOC detection frequencies also were determined for 1,096 public well samples at an assessment level of $0.2 \mu \mathrm{g} / \mathrm{L}$. All samples from domestic and public wells were collected at the well head before any treatment or blending of the water.

In this chapter, a three-step approach was used to assess the relevance of VOC concentrations in domestic and public well water to human health and to assess monitoring needs for VOCs. First, VOC concentrations were compared to USEPA's MCLs for regulated compounds (sidebar 17), and to HBSLs for unregulated compounds (sidebar 18). Comparison of VOC concentrations to benchmarks aids in identification of VOC concentrations that may be of potential human-health concern (hereafter referred to as concentrations of potential concern). The spatial distribution of VOC concentrations of potential concern also are examined in this step. Second, the relative proportions of concentrations of potential concern for individual VOCs were determined for both well types. Third, VOCs detected at concentrations less than but within a factor of 10 of MCLs and HBSLs were identified. These VOCs, along with the compounds determined in the first step, may warrant inclusion in a low-concentration, trends-monitoring strategy, such as the approach used by the NAWQA Program. This monitoring may provide an early indication of VOC concentrations approaching levels of potential concern.

In addition, sources of contamination to domestic and public wells are discussed, and anthropogenic and hydrogeologic factors associated with the detection of VOCs are described for each well type. Lastly, VOC occurrence findings for domestic wells and public wells are compared.
17. MCLs Serve as DrinkingWater-Quality Benchmarks for PWSs

Under the authority of the SDWA, the USEPA establishes drinking-water standards, such as MCLs, to limit the level of contaminants in the Nation's drinking water. An MCL is a legally enforceable standard that sets the maximum permissible level of a contaminant in water that is delivered to any user of a PWS. ${ }^{(40)}$ When setting an MCL, the USEPA also establishes a non-enforceable health goal or Maximum Contaminant Level Goal (MCLG). The MCLG is the maximum level of a contaminant in drinking water at which no known or anticipated adverse effect on human health would occur, and which allows an adequate margin of safety. ${ }^{(40)}$ The MCL is set as close to the MCLG as feasible, taking into account the best available technology, treatment techniques, and cost considerations, as well as expert judgment and public comments The USEPA reviews drinking-water standards every 6 years to determine if revisions are needed.

Established MCLs apply to 29 VOCs included in this NAWQA assessment. However, because MCLs apply to drinking water supplied to the public by PWSs, comparisons of VOC concentrations for samples collected at the well head in this assessment to MCLs are used only to indicate concentrations of potential humanhealth concern. Actual human exposure from drinking water is not described (sidebar 4).

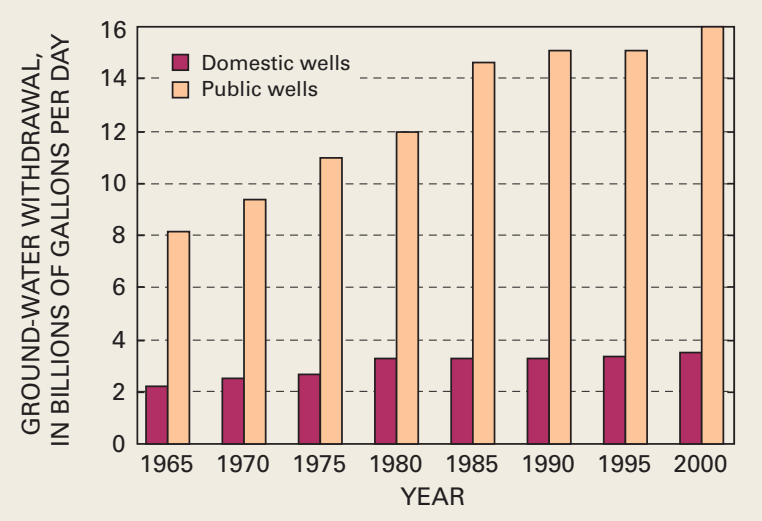

Figure 13. From 1965 to 2000, domestic well withdrawals increased by about 60 percent, whereas public well withdrawals increased nearly 100 percent. 


\section{VOCs in Domestic Well Samples}

18. HBSLs Can be Applied to VOCs with no MCLs

HBSLs are estimates of benchmark concentrations of contaminants in water that may be of potential human-health concern. HBSLs are based on health effects alone and have been calculated for unregulated contaminants (those with no MCLs) analyzed by the NAWQA Program. HBSLs were developed by the USGS in collaboration with others (p. 13) using (1) standard USEPA Office of Water methodologies; and (2) the most current, USEPA peer-reviewed, publically available human-health toxicity information. HBSLs are regularly reviewed and, as needed, revised to incorporate the most recent toxicity information and research findings.

HBSLs are not regulatory standards and are not legally enforceable. HBSLs were calculated for 15 of the 26 unregulated VOCs in this assessment, but were not calculated for the remaining 11 VOCs due to a lack of toxicity information. Measured contaminant concentrations may be compared to HBSLS to evaluate water-quality data in a humanhealth context. Such comparisons can provide an early indication of when contaminant concentrations in water resources may merit additional study or monitoring.

Since 1998, the USGS, in collaboration with others, has made substantial progress in providing additional information about the potential human-health implications of its water-quality findings. USGS will continue its research to develop and refine approaches to expand its ability to evaluate contaminant concentrations in a human-health context at the State and national scales.

Additional information about HBSLs and ongoing research is available in other pub-

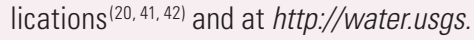
gov/nawqa/HBSL/.
$\mathrm{O}$ ne or more VOCs were detected in 14 percent of the 2,401 domestic well samples at an assessment level of $0.2 \mu \mathrm{g} / \mathrm{L}$. VOCs in these samples were not limited to a few compounds-more than two-thirds of the monitored VOCs were detected. In contrast, nearly one-half of 1,208 samples from a subset of these domestic wells had VOC detections using the low-level analytical method, for which an order-of-magnitude lower assessment level $(0.02 \mu \mathrm{g} / \mathrm{L})$ was applied. Furthermore, about 90 percent of the total VOC concentrations in samples with VOC detections were less than $1 \mu \mathrm{g} / \mathrm{L}$.

\section{Domestic well water may be vulnerable to low-level VOC contamination from many compounds.}

Six VOCs had detection frequencies of 1 percent or larger at an assessment level of $0.2 \mu \mathrm{g} / \mathrm{L}$ (fig. 14, Appendix 8). Chloroform had the largest detection frequency, almost double that of MTBE, the second most frequently detected VOC. The 15 most frequently detected VOCs in domestic well samples represent six groups (fig. 14), indicating multiple contaminant sources.

The gasoline oxygenate, refrigerant, solvent, and THM groups each were detected in more than 2 percent of the domestic well samples. VOCs with multiple uses and/or widespread sources, for example VOCs within the solvent group, were detected throughout the Nation. Gasoline oxygenates were detected most frequently in domestic well samples in the New England and Mid-Atlantic States. Few samples contained fumigants, and

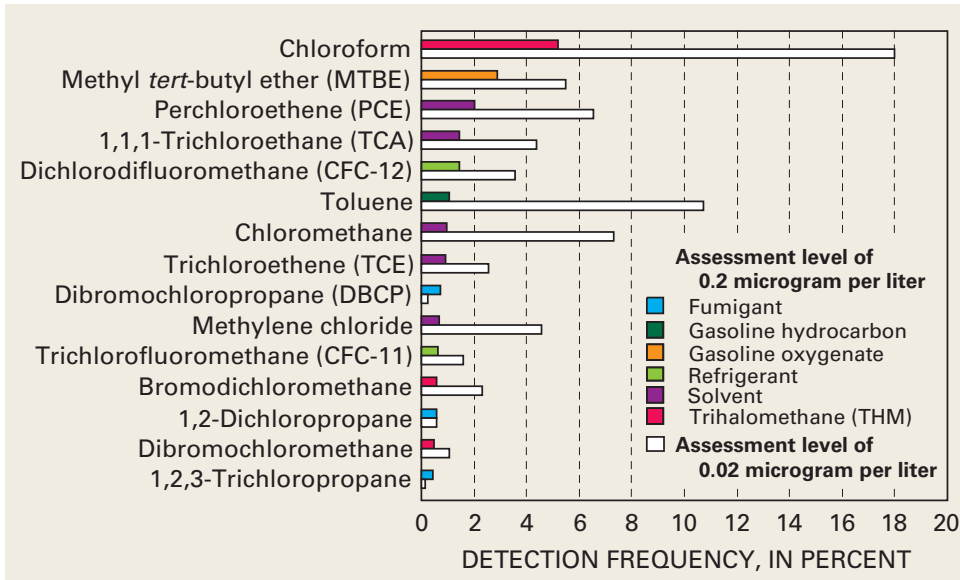

Figure 14. Detection frequencies in domestic well samples differed for the 15 most frequently occurring VOCs at assessment levels of 0.2 and 0.02 microgram per liter. 
most of these occurred in the Central Valley of California and in New Jersey, Arizona, and Washington. VOCs used in organic synthesis seldom were detected. Additional information about spatial occurrence of VOC groups and selected compounds is available from the Circular's Web site.

\section{About 1 percent of domestic well samples had VOC concentrations of potential human-health concern.}

Six VOCs had concentrations greater than MCLs-DBCP, 1,2-dichloropropane, EDB, 1,1-DCE, PCE, and TCE (fig. 15A). VOC concentrations of potential concern occurred in about 1 percent of the domestic well samples. Fumigants accounted for about two-thirds of the 32 VOC concentrations of potential concern, and DBCP comprised about one-half of these.

Samples with concentrations of potential concern were localized (fig. 15B) and may be associated with a specific VOC use, such as the historical application of DBCP on crops in the Central Valley of California from the late 1950s until the compound's ban in the late 1970s. ${ }^{(43)} \mathrm{DBCP}$

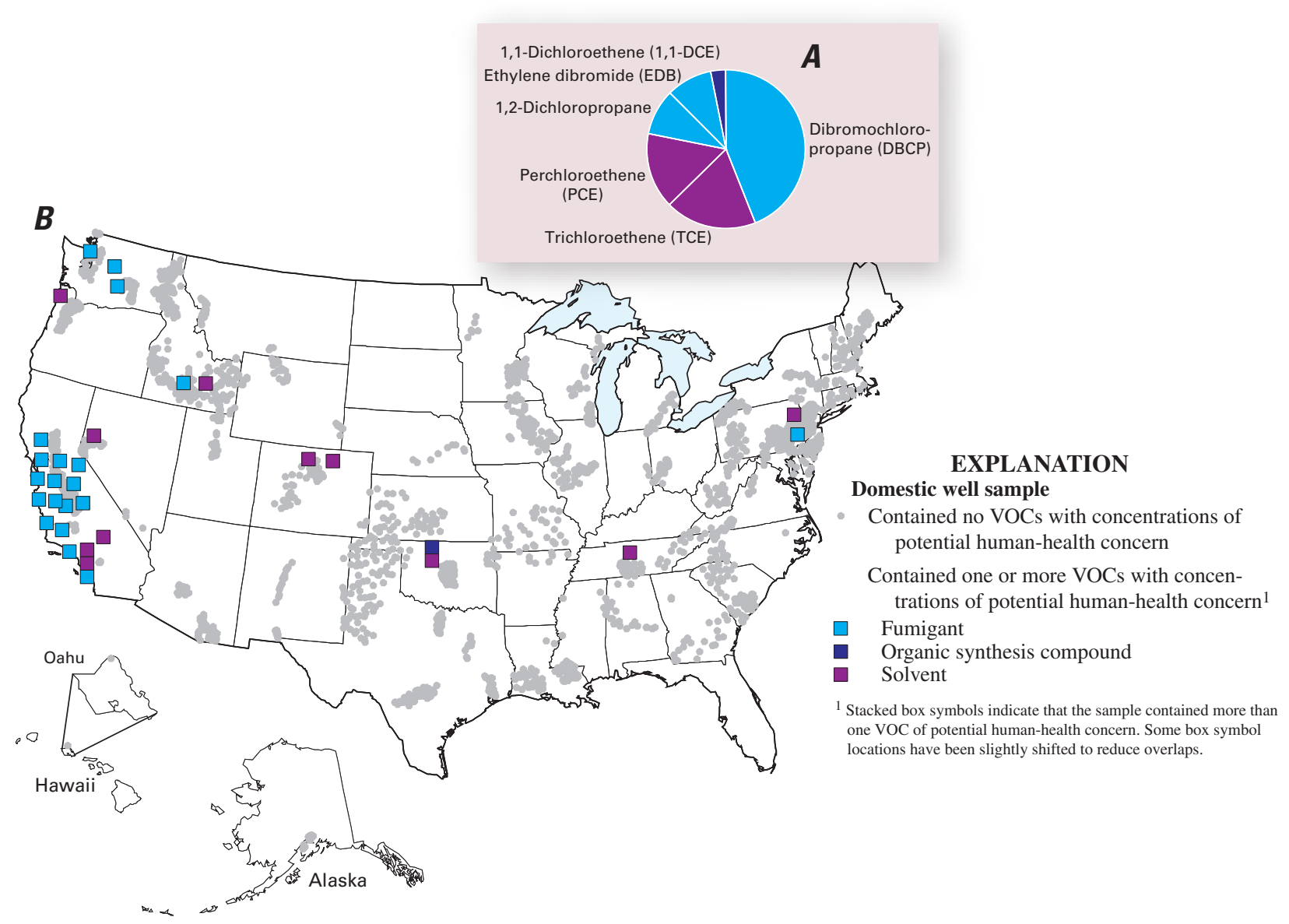

Figure 15. VOC concentrations of potential human-health concern in domestic well samples were predominantly for fumigants and solvents: $(A)$ the fumigant DBCP accounted for nearly one-half of all these concentrations; and $(B)$ concentrations of fumigants were most common in California. 


\section{VOCs in Domestic Well Samples-Continued}

19. Most Government Agencies Do Not Require Routine Monitoring of Water Quality for Domestic Wells

Although regulations vary by State, and also within States, the quality of water from privately owned domestic wells generally is the homeowner's responsibility. Routine monitoring is not required; however, most States and some local agencies provide guidance to domestic well owners through Web sites and printed materials. ${ }^{(45)}$

Raising awareness about the importance of regularly testing private wells is an important step towards ensuring a safe drinking-water supply for the population relying on domestic wells. As such, private well owners are advised by State and local agencies to test water annually to identify possible contaminants such as coliform bacteria, nitrate and nitrite, pesticides, radionuclides, heavy metals, and VOCs, and to compare test results to USEPA and State standards. No States currently require homeowners to take action to improve water quality if contaminants are detected in domestic well water. However, some States have introduced measures to assess water quality to aid in protection of human health. For example, in 2002 New Jersey passed a law that required "raw" or untreated water to be tested in wells included in real estate transactions. ${ }^{(46)}$ Additionally, landlords must test water every 5 years and provide the test results to new tenants. VOCs, including benzene and TCE, were among the required compounds to be tested in the well samples.

Because water from domestic wells usually is not treated prior to use, the VOC occurrence data provided by this NAWQA assessment may reflect the quality of tap water used by many rural households. Prior to NAWQA's assessment, no major national studies had been conducted for a large number of VOCs in domestic well samples. may have a half-life of about 6 years in ground water on the basis of an investigation in the eastern San Joaquin Valley, California. ${ }^{(43)}$ This persistence, when coupled with the intrinsic susceptibility of the sand and gravel aquifers in the Central Valley, has resulted in ground-water contamination in an area where about one-tenth of the population relies on domestic wells for drinking-water supplies.

All six of the previously mentioned VOCs that were detected at concentrations of potential concern warrant inclusion in low-concentration, trendsmonitoring programs. In addition, benzene, bromoform, carbon tetrachloride, chloroform, dibromochloromethane, 1,2-dichloroethane (1,2-DCA), methylene chloride, TCA, and vinyl chloride were detected at concentrations less than but within a factor of 10 of MCLs (Appendix 9). These VOCs also may warrant inclusion in such a monitoring program.

\section{Septic systems and USTs are important potential sources of VOC contamination to domestic wells.}

The finding that some VOC concentrations in domestic well samples were greater than or within a factor of 10 of an MCL is particularly noteworthy because testing of water from domestic wells is not federally mandated nor uniformly monitored (sidebar 19). Although HBSLs exist for 15 unregulated VOCs (sidebar 18), none of the compounds had concentrations greater than or within a factor of 10 of these benchmarks.

VOCs detected in domestic well samples could be from contaminant sources near the home, including septic systems, underground and aboveground storage tanks, fumigant applications, spills, pipelines, and sewer lines. Household septic systems are important potential sources of contamination to domestic wells (p. 45). USTs used to store fuels also are recognized as potential contaminant sources to domestic wells. ${ }^{(4)}$

Leaking gasoline, heating oil, and diesel fuel from storage tanks can result in lowlevel VOC contamination in ground water that serves as a domestic drinking-water supply. (Photograph by Connie J. Ross, U.S. Geological Survey.)

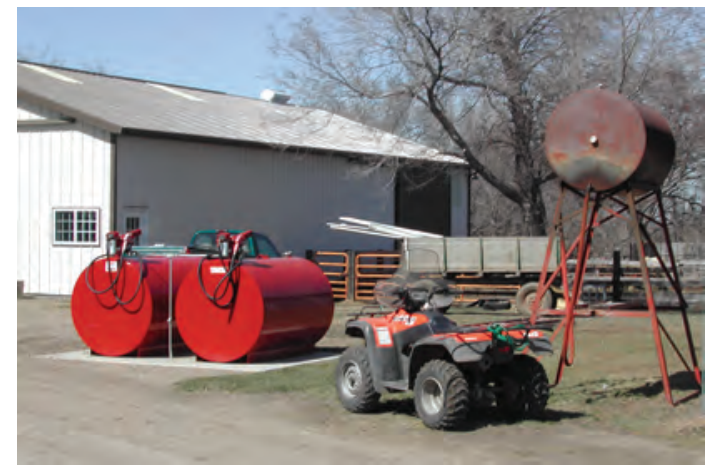




\section{VOCs in Public Well Samples}

ne or more VOCs were detected in about one-fourth of the 1,096 public well samples at an assessment level of $0.2 \mu \mathrm{g} / \mathrm{L}$. Total VOC concentrations in about one-half of the samples with detections were less than $1 \mu \mathrm{g} / \mathrm{L}$. Furthermore, about three-fourths of the 55 monitored VOCs were detected (Appendix 10), indicating that many VOCs are potential contaminants in public well water. Because the public well samples were collected before any treatment or blending of the water, these findings do not necessarily reflect the quality of drinking water ultimately supplied by the large number of PWSs that use ground water as a drinking-water supply (sidebar 20).

\section{About one-fourth of the public well samples contained VOCs; however, total VOC concentrations generally were less than $1 \mu \mathrm{g} / \mathrm{L}$.}

Fifteen VOCs had detection frequencies of 1 percent or larger (fig. 16). Chloroform was the most frequently detected VOC in public well samples with a frequency of about 11 percent. Additionally three other THMs-bromoform, dibromochloromethane, and bromodichloromethane-each were detected in about 4 percent of public well samples. MTBE was the second most frequently detected VOC. The solvents PCE, TCE, TCA, 1,1-dichloroethane (1,1-DCA), and cis- and trans-1,2-dichloroethene (cis- and trans1,2-DCE) were detected in 1 to 5 percent of the public well samples. In a national survey conducted by the USEPA (1981-1982), these solvents were among the most frequently detected VOCs in treated water from PWSs. ${ }^{(8)}$
20. Ground Water is Used by Many PWSs

Nearly 145,000 PWSs provide ground water for human consumption to about 112 million people in the United States. ${ }^{(38)}$ PWS categories established by the USEPA include CWSs and non-community water systems (NCWSs) CWSs serve a residential population such as a municipality, mobile home park, or nursing home. NCWSs are divided into non-transient, non-community water systems (NTNCWSs), such as schools, hospitals, and factories; and transient non-community water systems (TNCWSs), such as campgrounds, motels, and gasoline stations. Nearly 60 percent of PWSs are TNCWSs, but more than 80 percent of the U.S. population is served by CWSs. ${ }^{(38)}$

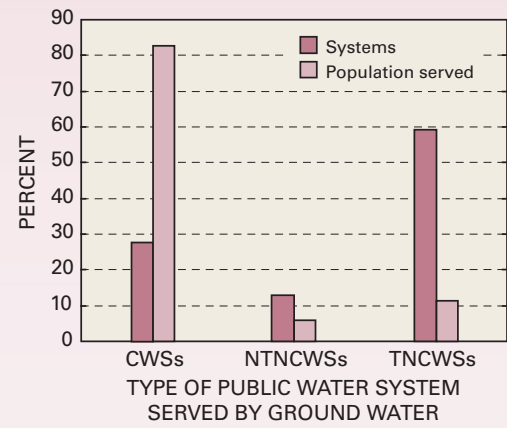

Ownership and size of population served by PWSs may vary from very small, privately owned systems whose primary business is something other than water supply (such as mobile home parks) to large, publicly owned water utilities that serve millions of people. ${ }^{(47)}$

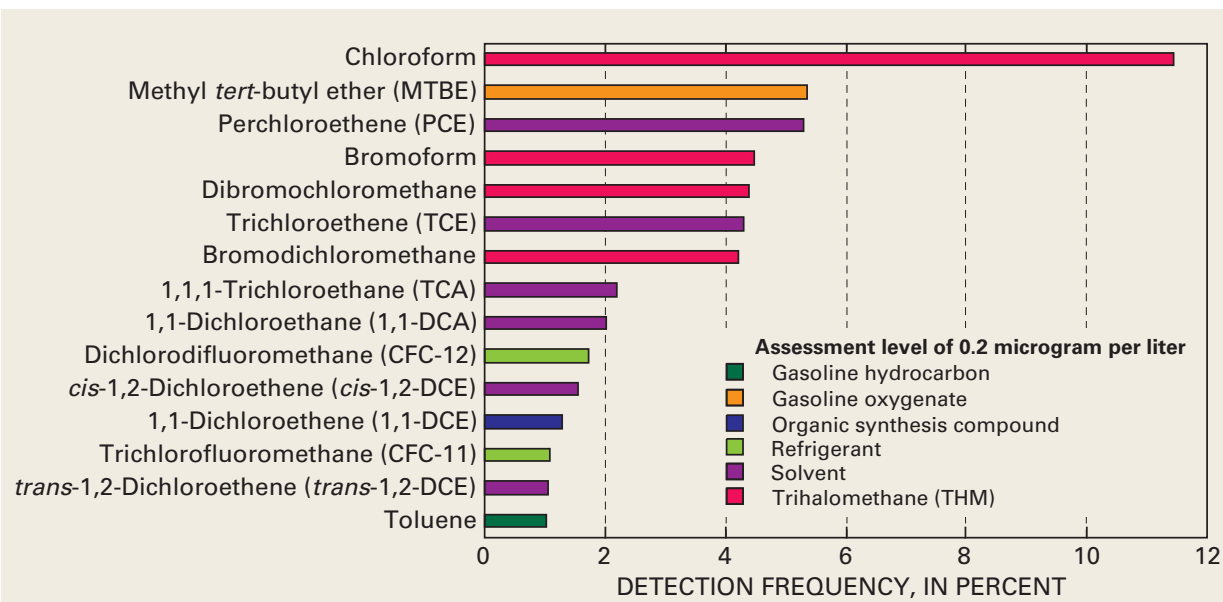

Figure 16. Trihalomethanes, solvents, and the gasoline oxygenate MTBE were among the 15 most frequently detected VOCs in public well samples. 


\section{VOCs in Public Well Samples-Continued}

\author{
21. Unregulated Contaminants, \\ Including VOCs, are Monitored in \\ PWSs \\ The 1996 SDWA Amendments require \\ the USEPA to identify and publish a list of \\ unregulated contaminants (referred to as \\ the CCL) that are known or anticipated to \\ occur in PWSs and that may require regula- \\ tion with a national primary drinking-water \\ standard. ${ }^{(49)}$ In making regulatory determina- \\ tions for compounds on the CCL, USEPA must \\ determine whether (1) the contaminant may \\ have an adverse effect on human health; \\ (2) the contaminant is known to occur or there \\ is substantial likelihood that the contaminant \\ will occur in PWSs with a frequency and at \\ levels of public health concern; and (3) in the \\ sole judgment of the Administrator, regulation \\ of such contaminant presents a meaningful \\ opportunity for health risk reduction for people \\ served by PWSs. ${ }^{(50)}$ SDWA requires that the \\ USEPA publish the CCL every 5 years and \\ make regulatory determinations for at least \\ five contaminants (also every 5 years). \\ The Unregulated Contaminant Monitoring \\ (UCM) Program is the mechanism used to \\ collect data for unregulated contaminants sus- \\ pected to occur in drinking water. ${ }^{(51)}$ The UCM \\ list is revised every 5 years by the USEPA and \\ is based primarily on the CCL.
}

Five VOCs monitored by NAWQA are currently listed on the second CCL published by the USEPA $^{(52)}$ and are prioritized for research and data collection efforts by the USEPA. These VOCs include bromomethane (methyl bromide), 1,1-DCA, 1,3-dichloropropene, MTBE, and 1,2,4-trimethylbenzene. ${ }^{(52)}$ In public well samples collected for this national assessment, the isomers cis- and trans-1,3-dichloropropene were not detected, and bromomethane and 1,2,4-trimethylbenzene were detected in less than 1 percent of the samples. MTBE and 1,1-DCA had the largest detection frequencies of these five VOCs, 5.4 percent and 2.0 percent, respectively (Appendix 10).
THMs and solvents had the largest detection frequencies among VOC groups in public well samples (15 and 10 percent, respectively). In addition, gasoline oxygenates, predominantly MTBE, occurred in about 5 percent of the samples. All other groups were detected in about 3 percent or less of the samples. Spatial patterns of occurrence differed for VOC groups (see Circular's Web site). Detections of solvents, THMs, and gasoline hydrocarbons were distributed throughout the Nation. Gasoline oxygenates were detected primarily in the New England and Mid-Atlantic States, and in Florida and California. Detections of fumigants were predominantly in Hawaii and in the eastern coastal area of the United States.

Drinking water from PWSs is monitored for regulated contaminants and also for selected unregulated contaminants that may be considered for new drinking-water standards (sidebar 21). Five of the 29 regulated VOCs had one or more concentrations greater than MCLs (fig. 17A). These VOCs with concentrations of potential concern are 1,1-DCE, methylene chloride, PCE, TCE, and vinyl chloride and generally occurred in highly populated areas of the Nation (fig. 17B). None of the 15 unregulated VOCs with HBSLs had concentrations greater than these benchmarks. The solvents PCE and TCE comprised about three-quarters of the concentrations of potential concern.

\section{About 2 percent of public well samples had VOC concentrations of potential human-health concern.}

The regulated compounds benzene, bromodichloromethane, bromoform, carbon tetrachloride, chloroform, dibromochloromethane, 1,2-DCA, 1,2-dichloropropane, and cis-1,2-DCE were detected at concentrations less than but within a factor of 10 of MCLs (Appendix 11). In contrast, none of the 15 unregulated VOCs with HBSLs had concentrations within a factor of 10 of these benchmarks. The 5 VOCs with concentrations greater than their MCLs and the 9 VOCs within a factor of 10 of their benchmarks may warrant inclusion in a low-concentration, trends-monitoring program.

Potential sources of VOC contamination to public wells include leaking aboveground and underground storage tanks, sewer lines, effluent from septic systems, landfills, industrial sites, accidental spills, and areas where chemicals have been disposed of improperly. ${ }^{(48)}$ Additionally, businesses associated with populated areas, such as dry cleaners, gasoline stations, auto repair and re-painting shops, and industrial fabricators that use VOCs 
to clean and degrease material and equipment or complete other processes, may be potential contaminant sources. Other possible VOC sources include industrial and motor vehicle emissions to the atmosphere, ${ }^{(53)}$ highway runoff, and urban stormwater runoff. ${ }^{(54)}$

The detection of VOCs in public well samples has been shown to be associated with the CWS size (sidebar 22). VOCs were detected more frequently and at greater concentrations in samples from very large systems than from smaller systems. ${ }^{(13)}$ A study by the USEPA Office of Drinking Water (1981-1982) also found that samples from large PWSs had more frequent VOC detections and greater VOC concentrations than small systems. ${ }^{(8)}$

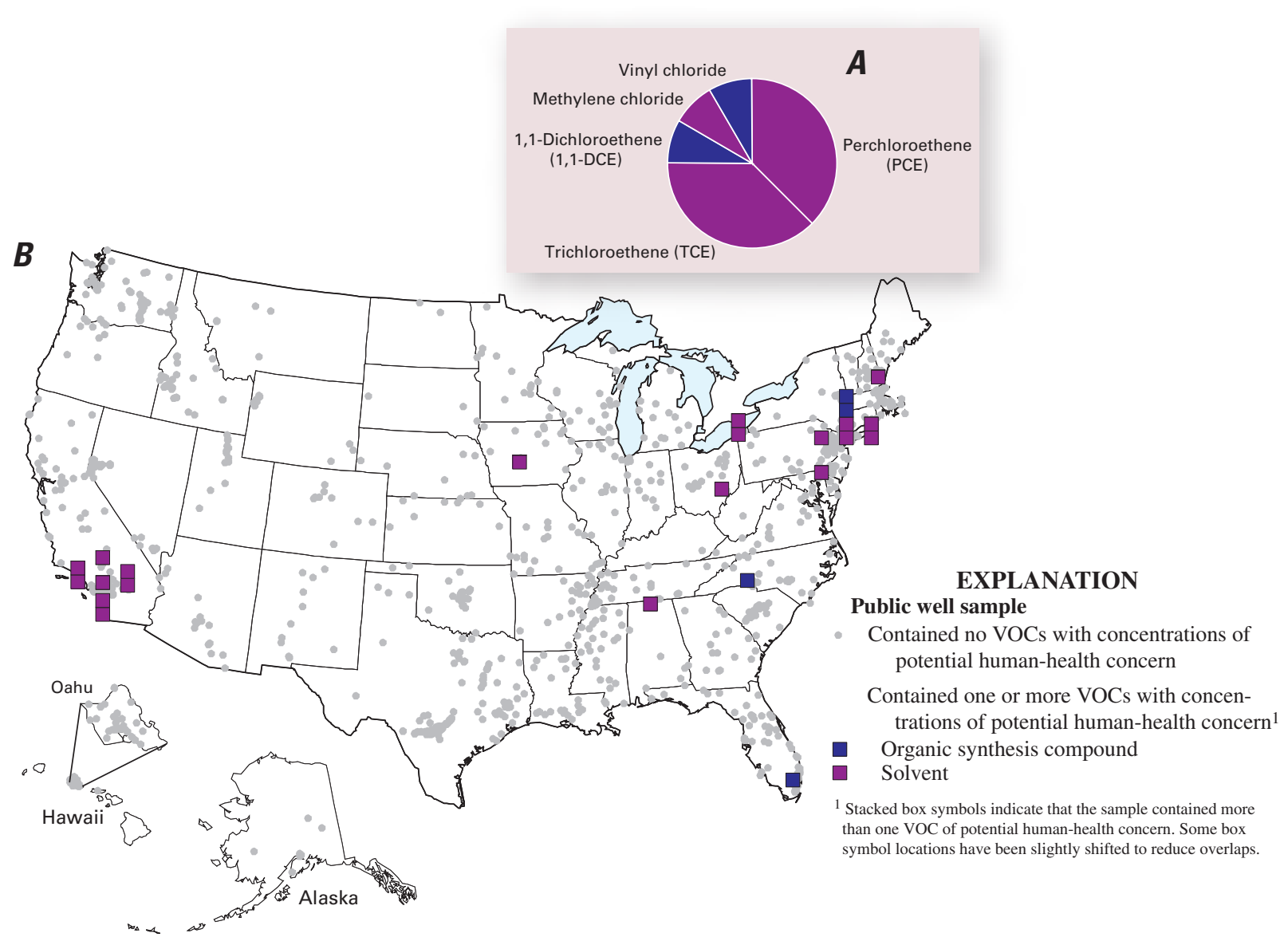

Figure 17. VOC concentrations of potential human-health concern in public well samples included solvents and compounds used in organic synthesis: $(A)$ solvents accounted for about 85 percent of these concentrations; and $(B)$ these concentrations occurred predominantly in the highly populated areas of southern California and the New England and Mid-Atlantic States. 


\section{Comparison of VOCs in Samples from Domestic and Public Wells}

22. VOCs Occur More Frequently in the Water Supply of Very Large CWSs than Other System Sizes

The USGS assisted in a nationwide survey (1999-2002) to characterize the occurrence of VOCs in ground water that served as a drinking-water supply for CWSs. ${ }^{(13)}$ The survey used a statistically stratified design for sampling 575 public wells from randomly selected CWSs representative of the five size categories as follows:

CWS Size Population Served

Very small less than 500

Small $\quad 501$ to 3,300

Medium 3,301 to 10,000

Large $\quad 10,001$ to 50,000

Very large more than 50,000

In general, VOCs were detected most frequently in the very large CWSs. As of 1998, very large CWSs using ground water collectively provided drinking water to about 26 million people. VOC detections were significantly related to urban land use and population density associated with large systems. ${ }^{(13)}$ In particular, detections of gasoline hydrocarbons, solvents, and refrigerants were detected more frequently in ground-water supplies from very large CWSs than from smaller sized systems.

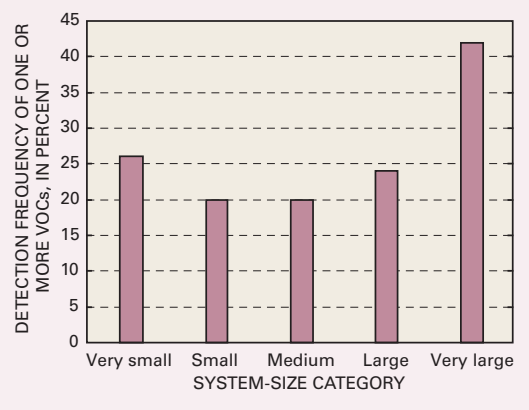

$\mathrm{V}$ OC occurrence in samples from domestic and public wells is compared in this section. Additionally, VOC data for public well samples are compared to the findings of previous investigations (sidebar 23). Domestic well samples had fewer compounds and mixtures, lower detection frequencies, and smaller VOC concentrations than public well samples.

\section{VOCs were detected more frequently and had more concentrations of potential human-health concern in public well samples than in domestic well samples.}

The 10 most frequently detected VOCs for each well type are shown in figure 18. The three most frequently detected VOCs were the same for samples from domestic and public wells - chloroform, MTBE, and PCE. Some of the 55 VOCs were not detected at the $0.2 \mu \mathrm{g} / \mathrm{L}$ assessment level (table 5) in any domestic or public well samples (18 and 14 VOCs, respectively). VOCs within the organic synthesis group had the greatest proportion of compounds with no detections for both well types. In contrast, all of the VOCs in the THM and refrigerant groups were detected in samples from both well types. All of the VOCs in the gasoline hydrocarbon group were detected in public well samples, whereas four of these VOCs were not detected in domestic well samples (table 5).

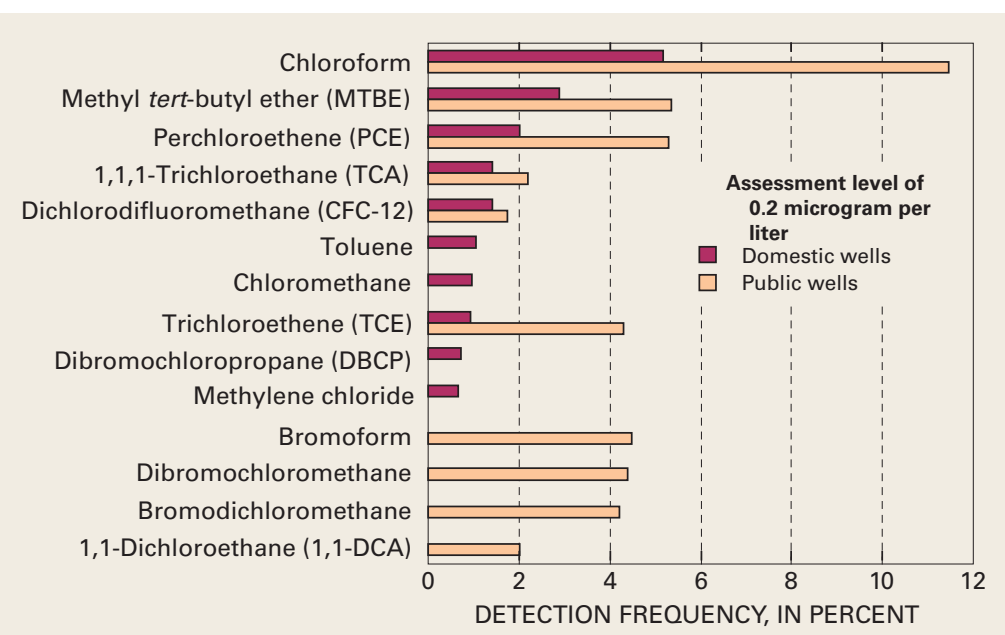

Figure 18. Although the top 3 of the 10 most frequently detected VOCs were the same for samples from domestic and public wells, the overall signature of VOC detections associated with domestic and public wells differed. 
Table 5. VOCs with no detections in samples from domestic or public wells at an assessment level of 0.2 microgram per liter.

[ND, VOC not detected; --, VOC detected]

\begin{tabular}{|c|c|c|}
\hline \multirow{2}{*}{ Compound } & \multicolumn{2}{|c|}{ Well type } \\
\hline & Domestic & Public \\
\hline \multicolumn{3}{|c|}{ Fumigants } \\
\hline Bromomethane & $\mathrm{ND}^{1}$ & -- \\
\hline Dibromochloropropane (DBCP) & -- & ND \\
\hline cis-1,3-Dichloropropene & $\mathrm{ND}^{1}$ & ND \\
\hline trans-1,3-Dichloropropene & $\mathrm{ND}^{1}$ & ND \\
\hline Ethylene dibromide (EDB) & -- & ND \\
\hline \multicolumn{3}{|c|}{ Gasoline hydrocarbons } \\
\hline$n$-Butylbenzene & ND & -- \\
\hline Styrene & ND & -- \\
\hline$o$-Xylene & ND & -- \\
\hline$m$ - and $p$-Xylenes ${ }^{2}$ & ND & -- \\
\hline \multicolumn{3}{|c|}{ Gasoline oxygenate } \\
\hline Ethyl tert-butyl ether (ETBE) & $\mathrm{ND}^{1}$ & -- \\
\hline \multicolumn{3}{|c|}{ Organic synthesis compounds } \\
\hline Acrolein & $\mathrm{ND}^{1}$ & ND \\
\hline Acrylonitrile & $\mathrm{ND}^{1}$ & ND \\
\hline Hexachlorobutadiene & $\mathrm{ND}^{1}$ & ND \\
\hline 1,2,3-Trichlorobenzene & $\mathrm{ND}^{1}$ & ND \\
\hline Vinyl bromide & $\mathrm{ND}^{1}$ & ND \\
\hline \multicolumn{3}{|c|}{ Solvents } \\
\hline 1,3-Dichlorobenzene & ND & ND \\
\hline Hexachloroethane & $\mathrm{ND}^{1}$ & ND \\
\hline$n$-Propylbenzene & -- & ND \\
\hline 1,2,4-Trichlorobenzene & $\mathrm{ND}^{1}$ & ND \\
\hline 1,1,2-Trichloroethane & ND & ND \\
\hline
\end{tabular}

${ }^{1} \mathrm{VOC}$ also was not detected in a subset of domestic well samples analyzed using a low-level method and with no assessment level applied.

${ }^{2}$ Considered as 2 of the 55 compounds included in this assessment.
23. NAWQA's VOC Assessment Can Be Placed in the Context of Other Studies for Public Wells

This NAWQA study provides one of the few existing national assessments of VOCs in public well samples. The few previous studies of VOC occurrence generally were based on samples of drinking water. One such study was completed by the USEPA during 1981-1982 and focused on 29 VOCs in treated water from CWSs. ${ }^{\left({ }^{8}\right)}$ In this study, VOC concentrations greater than $5 \mu \mathrm{g} / \mathrm{L}$ were found in 2.9 percent of samples from CWSs serving less than 10,000 people and in 6.5 percent of the samples from CWSs serving more than 10,000 people. Although untreated water was sampled for this NAWOA assessment, VOC occurrence in these size categories was similar, 2.4 and 7.8 percent, respectively.

A recent study completed in 2002 by the USEPA, (55) based on compliance monitoring data, also provided information on the quality of drinking water from PWSs. In the USEPA study, nine VOCs - benzene, carbon tetrachloride, 1,2-DCA, 1,1-DCE, methylene chloride, 1,2-dichloropropane, PCE, 1,1,2-trichloroethane, and TCE - each had concentrations greater than their MCL in less than 0.7 percent of the PWSs sampled. In public wells sampled by the NAWOA Program, only four of these VOCs-1,1-DCE, methylene chloride, PCE, and TCE - each had concentrations greater than their MCL in less than 0.9 percent of the samples.
The 15 most frequently detected VOCs in domestic well samples represented all VOC groups with the exception of organic synthesis compounds (fig. 14), whereas VOCs in public well samples were predominantly THMs, solvents, and the gasoline oxygenate MTBE (fig. 16). Total concentrations for each VOC group were summed for each sample with detections. For domestic well samples, organic synthesis compounds had the greatest median total concentration $(1.1 \mu \mathrm{g} / \mathrm{L})$, and refrigerants had the lowest $(0.3 \mu \mathrm{g} / \mathrm{L})$. For public well samples, solvents had the greatest median total concentration $(0.7 \mu \mathrm{g} / \mathrm{L})$, and gasoline hydrocarbons had the lowest $(0.4 \mu \mathrm{g} / \mathrm{L})$. 


\section{Comparison of VOCs in Domestic and Public Well Samples-Continued}

\begin{tabular}{|c|c|c|}
\hline \\
\hline \multicolumn{3}{|c|}{$\begin{array}{l}\text { 24. Specific VOC Mixtures } \\
\text { Occurred Infrequently, But Were } \\
\text { More Common in Public Well } \\
\text { Samples }\end{array}$} \\
\hline \multicolumn{3}{|c|}{$\begin{array}{l}\text { All specific mixtures of VOCs occurred in less } \\
\text { than } 1 \text { percent of domestic well samples, and } \\
\text { in less than } 4 \text { percent of public well samples } \\
\text { at an assessment level of } 0.2 \mu \mathrm{g} / \mathrm{L} \text {. The table } \\
\text { below ranks the } 10 \text { most common VOC mix- } \\
\text { tures by their detection frequency in domestic } \\
\text { well samples and in public well samples, } \\
\text { and shows the more common occurrence of } \\
\text { mixtures in public well samples. }\end{array}$} \\
\hline \multicolumn{3}{|c|}{$\begin{array}{l}\text { [MTBE, methyl tert-butyl ether; PCE, perchloroethene; } \\
\text { TCA, 1,1,1-trichloroethane; TCE, trichloroethene] }\end{array}$} \\
\hline Rank & VOC mixture & $\begin{array}{l}\text { Detection } \\
\text { frequency, } \\
\text { in percent }\end{array}$ \\
\hline \multicolumn{3}{|c|}{ Domestic well samples } \\
\hline 1 & PCE-TCA & 0.62 \\
\hline 2 & Chloroform-PCE & .50 \\
\hline 2 & Chloroform-MTBE & .50 \\
\hline 2 & PCE-TCE & .50 \\
\hline 5 & $\begin{array}{l}\text { Dibromochloromethane- } \\
\text { chloroform }\end{array}$ & .42 \\
\hline 6 & Chloroform-TCA & .37 \\
\hline 6 & TCA-TCE & .37 \\
\hline 8 & PCE-MTBE & .33 \\
\hline 9 & $\begin{array}{l}\text { Bromoform- } \\
\text { dibromochloromethane }\end{array}$ & .29 \\
\hline 9 & Bromoform-chloroform & .29 \\
\hline \multicolumn{3}{|c|}{ Public well samples } \\
\hline 1 & $\begin{array}{l}\text { Bromodichloromethane- } \\
\text { dibromochloromethane }\end{array}$ & 3.4 \\
\hline 2 & $\begin{array}{l}\text { Bromodichloromethane- } \\
\text { chloroform }\end{array}$ & 3.2 \\
\hline 3 & $\begin{array}{l}\text { Bromoform- } \\
\quad \text { dibromochloromethane }\end{array}$ & 2.9 \\
\hline 4 & $\begin{array}{l}\text { Dibromochloromethane- } \\
\text { chloroform }\end{array}$ & 2.5 \\
\hline 5 & $\begin{array}{l}\text { Bromodichloromethane- } \\
\text { dibromochloromethane- } \\
\text { chloroform }\end{array}$ & 2.4 \\
\hline 6 & PCE-TCE & 2.3 \\
\hline 7 & $\begin{array}{l}\text { Bromodichloromethane- } \\
\text { bromoform }\end{array}$ & 2.0 \\
\hline 7 & $\begin{array}{l}\text { Bromodichloromethane- } \\
\text { bromoform-dibromo- } \\
\text { chloromethane }\end{array}$ & 2.0 \\
\hline 9 & Bromoform-chloroform & 1.7 \\
\hline 10 & $\begin{array}{l}\text { Bromoform- } \\
\text { dibromochloromethane- } \\
\text { chloroform }\end{array}$ & 1.6 \\
\hline
\end{tabular}

Samples from domestic and public wells had about the same number of VOCs with concentrations of potential concern (6 and 5 VOCs, respectively) (table 6). VOCs with concentrations of potential concern in both well types included 1,1-DCE, PCE, and TCE. Domestic wells had three additional VOCs with concentrations of potential concern-DBCP, 1,2-dichloropropane, and EDB; and public wells had two additional VOCs with concentrations of potential concern-methylene chloride and vinyl chloride (Appendixes 9 and 11). Overall, domestic well samples had a smaller percentage of samples with VOC concentrations of potential concern than public well samples (1.2 and 1.5 percent, respectively).

VOCs with the largest proportion of concentrations of potential concern differed between well types (figs. 15A and 17A). For domestic well samples, fumigants and solvents had the most concentrations of potential concern, with DBCP having the greatest proportion. For public well samples, solvents and compounds used for organic synthesis had the most concentrations of potential concern, with PCE and TCE each having the greatest and equal proportions. VOC concentrations of potential concern for domestic wells were located predominantly in the Central Valley and other areas of California, whereas concentrations of potential concern for public wells generally occurred in southern California and in the New England and Mid-Atlantic States.

\section{VOC mixtures were detected more frequently in public well samples than in domestic well samples.}

Occurrence of mixtures may result from persistence of VOCs in the environment, co-occurrence of parent compounds with their degradation byproducts, multiple compounds sharing the same source, and wide distributions of VOCs that may have overlapping sources. ${ }^{(12)}$ VOC mixtures occurred less frequently in domestic well samples (3.9 percent) than in public well samples (13.4 percent) at an assessment level of $0.2 \mu \mathrm{g} / \mathrm{L}$. Furthermore, a single VOC occurred more frequently than multiple VOCs in domestic well samples, whereas detections of single VOCs and multiple VOCs were about equal in public well samples (table 6). Also, concentrations of individual VOCs in mixtures generally were greater than the compound's concentration when detected alone in a sample.

Solvents, THMs, and the gasoline oxygenate MTBE comprised the 10 most frequently detected VOC mixtures for domestic well samples (sidebar 24). In contrast, all but 1 of the 10 most frequently occurring VOC mixtures for public well samples were mixtures of THMs; the exception was the 
Table 6. Statistics for VOC occurrence in samples from domestic and public wells at an assessment level of 0.2 microgram per liter.

[MCL, Maximum Contaminant Level; HBSL, Health-Based Screening Level; $\mu \mathrm{g} / \mathrm{L}$, micrograms per liter]

\begin{tabular}{|c|c|c|}
\hline \multirow{2}{*}{ Occurrence information } & \multicolumn{2}{|c|}{ Well type } \\
\hline & Domestic & Public \\
\hline \multicolumn{3}{|c|}{ Detections } \\
\hline Number of VOCs detected & 37 & 41 \\
\hline Frequency of one or more VOCs, in percent & 14.0 & 26.2 \\
\hline Frequency of VOC groups, in percent & $\begin{array}{l}\text { trihalomethanes (THMs), } 5.3 \\
\text { solvents, } 4.9 \\
\text { gasoline oxygenates, } 2.9 \\
\text { refrigerants, } 2.1 \\
\text { gasoline hydrocarbons, } 1.5 \\
\text { fumigants, } 1.2 \\
\text { organic synthesis compounds, } 0.2\end{array}$ & $\begin{array}{l}\text { trihalomethanes (THMs), } 14.7 \\
\text { solvents, } 9.9 \\
\text { gasoline oxygenates, } 5.3 \\
\text { refrigerants, } 2.6 \\
\text { gasoline hydrocarbons, } 2.2 \\
\text { fumigants, } 1.3 \\
\text { organic synthesis compounds, } 1.4\end{array}$ \\
\hline Most frequently detected VOCs, in percent & $\begin{array}{l}\text { chloroform, } 5.2 \\
\text { methyl tert-butyl ether (MTBE), } 2.9 \\
\text { perchloroethene (PCE), } 2.0\end{array}$ & $\begin{array}{l}\text { chloroform, } 11.4 \\
\text { methyl tert-butyl ether (MTBE), } 5.4 \\
\text { perchloroethene (PCE), } 5.3\end{array}$ \\
\hline \multicolumn{3}{|c|}{ Concentrations } \\
\hline Total VOC concentrations less than $1 \mu \mathrm{g} / \mathrm{L}$, in percent & 62.2 & 49.8 \\
\hline Total VOC concentrations greater than $10 \mu \mathrm{g} / \mathrm{L}$, in percent & 6.6 & 8.4 \\
\hline $\begin{array}{l}\text { Median concentration of samples with detections for the three most } \\
\text { frequently detected VOCs, in } \mu \mathrm{g} / \mathrm{L}\end{array}$ & $\begin{array}{l}\text { chloroform, } 0.5 \\
\text { methyl tert-butyl ether (MTBE), } 0.6 \\
\text { perchloroethene (PCE), } 0.4\end{array}$ & $\begin{array}{l}\text { chloroform, } 0.6 \\
\text { methyl tert-butyl ether (MTBE), } 0.6 \\
\text { perchloroethene (PCE), } 0.7\end{array}$ \\
\hline
\end{tabular}

\begin{tabular}{lcc}
\multicolumn{1}{c}{ Detections and concentrations of potential human-health concern } & perchloroethene (PCE), 0.7 \\
\hline $\begin{array}{l}\text { Number of VOCs with concentrations greater than their MCL } \\
\text { Frequency of concentrations greater than their MCL, in percent }\end{array}$ & 5 & 5 \\
\hline $\begin{array}{l}\text { Number of VOCs with concentrations greater than their HBSL } \\
\text { Frequency of concentrations greater than their HBSL, in percent }\end{array}$ & 1.2 & 0 \\
\hline $\begin{array}{l}\text { Total number of VOCs with concentrations of potential human-health } \\
\text { concern }\end{array}$ & 0 & 0 \\
\hline & \multicolumn{1}{c}{ Multiple VOCs } & 5 \\
\hline Total number of VOCs that occurred in mixtures & 38 & 40 \\
\hline Number of VOCs occurring only in mixtures & 16 & 18 \\
\hline Frequency of well samples with a single VOC detection, in percent & 10.1 & 12.8 \\
\hline Frequency of mixtures in all wells, in percent & 3.9 & 13.4 \\
\hline Frequency of mixtures in well samples with VOC detections, in percent & 27.7 & 51.2 \\
\hline
\end{tabular}

solvent mixture PCE-TCE. Solvents, however, were common components of VOC mixtures in public well samples that occurred at detection frequencies lower than those for the mixtures listed in sidebar 24 .

\section{Generally, public wells are more vulnerable to low- level VOC contamination than domestic wells.}

As previously described for ground water in general (p. 24 and 25), many factors can be associated with the source, transport, and fate of VOCs. Results of statistical models used in this assessment indicated that for samples from both domestic and public wells, hydrogeologic factors 


\section{Comparison of VOCs in Domestic and Public Well Samples-Continued}

associated with an increased probability of detecting VOCs included high aquifer recharge and high soil permeability. Furthermore, dissolved-oxygen concentration in samples from domestic and public wells was an important factor associated with the occurrence of individual VOCs.

Anthropogenic factors strongly associated with the increased probability of VOC detections in both well types included population density and percentage of urban land use near the sampled wells. Additionally, the probability of detecting VOCs was associated with the number of nearby RCRA hazardous-waste facilities. For public well samples, increased MTBE occurrence was associated with local use of this VOC in gasoline.

Although hydrogeologic and anthropogenic factors associated with VOC occurrence were similar for both well types, findings from this assessment indicate that public well water has the potential for more frequent detections of individual VOCs and mixtures and for greater concentrations than domestic well water. These findings are apparent despite the much deeper median depth of sampled public wells (303 feet) than domestic wells (104 feet). In general, deep public wells are presumed to be less vulnerable than shallow domestic wells to anthropogenic contaminants that originate on or near the land surface. However, several factors including large withdrawal rates from public wells and proximity to developed areas explain, at least in part, why public wells have a larger vulnerability to VOC contamination despite their typically greater depths.

Two recently completed NAWQA Study-Unit investigations explain, and figure 19 illustrates, reasons for the differences in VOC occurrence between domestic and public wells. A study of paired domestic and public wells within the High Plains aquifer system in the central part of the United States indicated that water containing surface-derived anthropogenic compounds from near the water table was drawn more quickly to the higher 


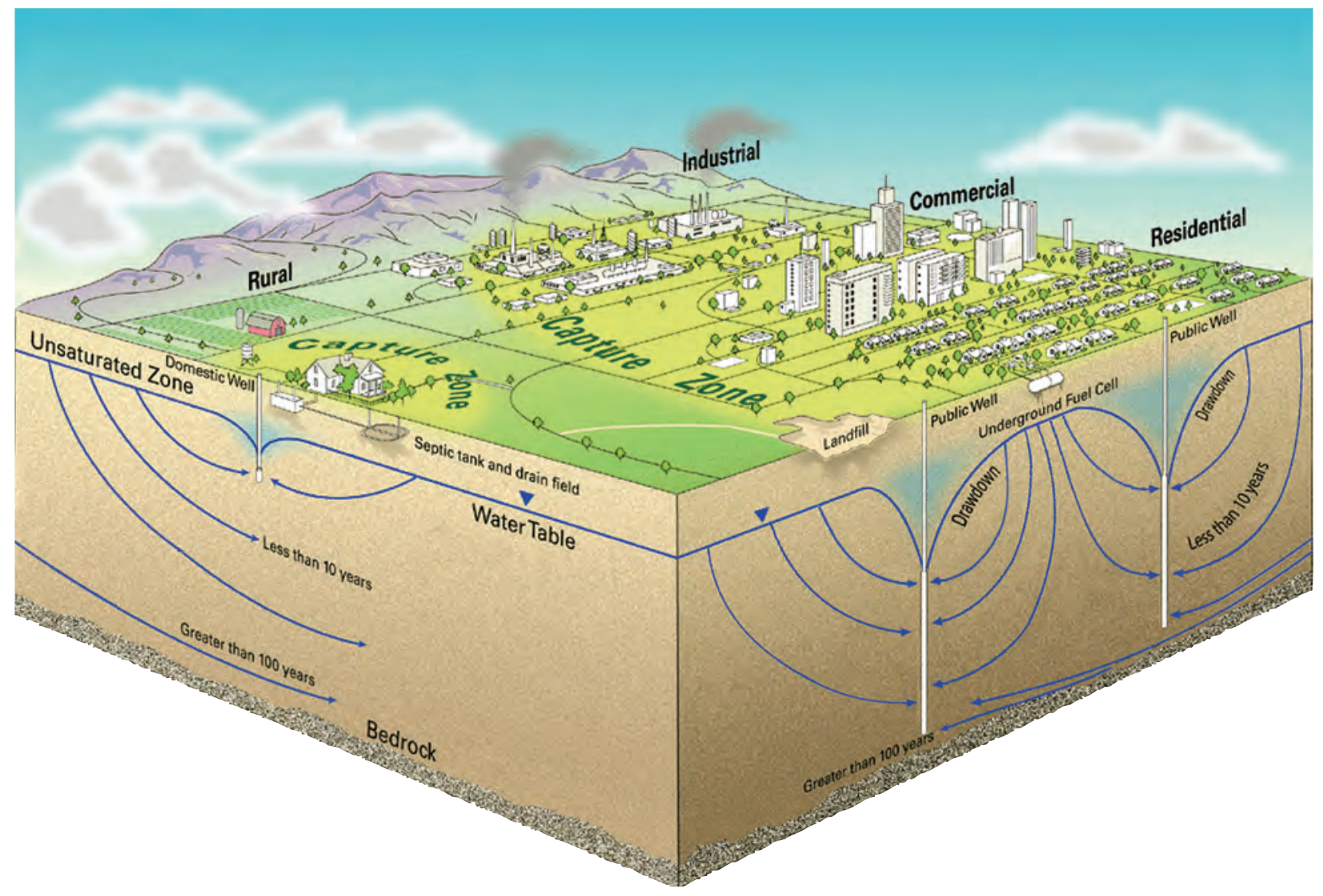

Figure 19. Differences in hydrogeologic and anthropogenic factors can affect the quality of ground water that supplies domestic and public wells.

volume pumping systems. ${ }^{(56)}$ Production rates of public wells create a larger capture zone, greater drawdown, and faster movement of water from the top of the water table to the well screen than the comparatively low production rates of domestic wells.

Relatively young water in recently recharged ground water can be intercepted by both domestic and public wells (fig. 19). The frequent occurrence of MTBE in samples from public wells in the Kirkwood-Cohansey aquifer system in southern New Jersey was attributed to the capture of young ground water through the interception of flowpaths with short traveltimes. ${ }^{(57)}$ Furthermore, for the same aquifer system, public wells intercepted VOCs from multiple land uses and point sources within a large contributing area. ${ }^{(48,58)}$ Additionally, deep public wells also can intercept ground water flowing along extensive paths associated with long residence times. This water may contain degradation by-products from parent compounds. VOCs that had substantial historical use, but whose use has been reduced or phased out, may be potential contaminants in ground water with relatively long flowpaths. 


\section{Chapter 5-Additional Information for Selected VOCs}

\section{Chloroform and Other THMs}

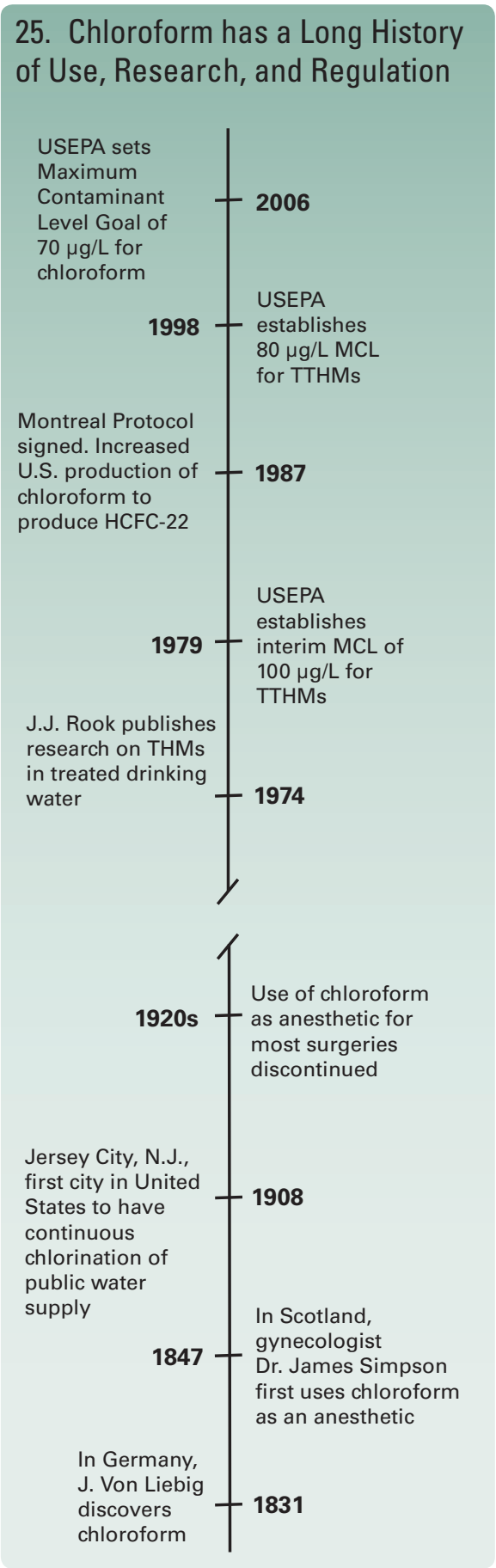

T he THM chloroform was the most frequently detected VOC in aquifers (fig. 8), in 7 percent of all samples at an assessment level of $0.2 \mu \mathrm{g} / \mathrm{L}$. The other three THMs - bromodichloromethane, dibromochloromethane, and bromoform-were each detected in about 1 percent of aquifer samples. Concentrations of chloroform and other THMs generally were less than $1 \mu \mathrm{g} / \mathrm{L}$. Of samples with detections, the median concentration was $0.08 \mu \mathrm{g} / \mathrm{L}$ for chloroform, and the median total trihalomethane (TTHM) concentration was $0.09 \mu \mathrm{g} / \mathrm{L}$ (Appendix 6).

\section{Chloroform was the most frequently detected VOC in the Nation's aquifers; however, concentrations of chloroform generally were less than $1 \mu \mathrm{g} / \mathrm{L}$.}

Chloroform has a long history of use, research, and regulation (sidebar 25). In 1999, 98 percent of chloroform produced by industry (fig. 20) was used in the production of the refrigerant hydrochlorofluorocarbon-22 (HCFC-22) to replace dichlorodifluoromethane (CFC-12) for home air conditioners and commercial freezers. The remaining 2 percent of chloroform was used for other purposes, including reagents and extraction solvents, ${ }^{(59,60)}$ fumigants, insecticides, and a precursor for dyes and pesticides. ${ }^{(61,62)}$ In 1998, the most recent year with production data, about 46 million gallons of chloroform were produced by industry.

In contrast to chloroform, the production of the other three THMs has been relatively small; for example, only about 46,000 gallons of bromoform were produced in 1977, the most recent year for which production data are available. ${ }^{(63)}$ Furthermore, there is no information on the U.S. production of bromodichloromethane and chlorodibromomethane, presumedly because of the limited or non-existent use of these compounds. Examples of limited current or prior use(s) of these three THMs are as solvents for fats, waxes and resins, heavy liquid for geological assays, fire-extinguisher agents, and as an intermediate in chemical synthesis.

Chloroform and other THMs are commonly produced during the chlorination of water and wastewater (sidebar 26). Chlorination of water and wastewater produces an estimated 0.37 million gallons of chloroform in the United States annually, ${ }^{(64)}$ which includes the treatment of drinking water, wastewater from municipalities and the bleaching process of pulp and paper, and rinse water from domestic and commercial cleaning and laundry operations. In addition, some THMs occur naturally in the environment (sidebar 27). 


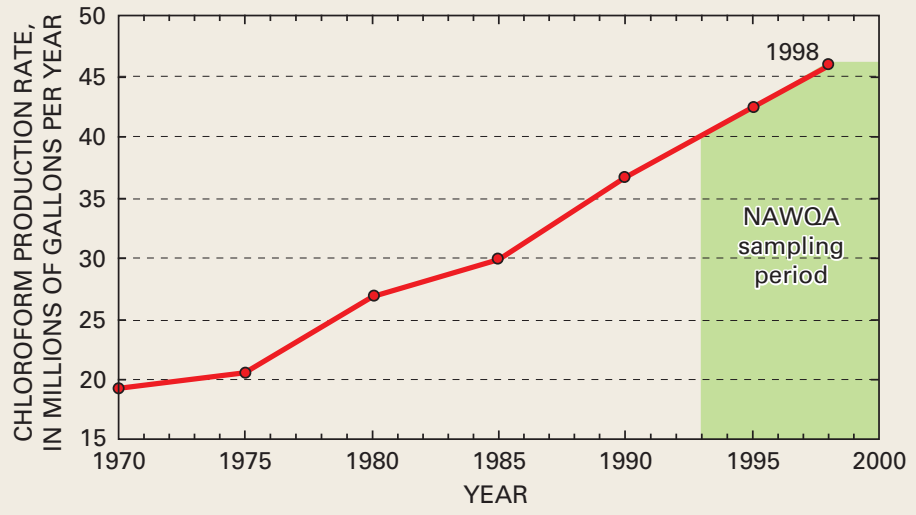

Figure 20.

Industrial production of chloroform continues to increase in the United States.

In studies of the formation of multiple THMs during water chlorination, it has been shown that the relative concentrations (and their relative detection frequencies) usually decrease with increasing bromine content (chloroform $>$ bromodichloromethane $>$ dibromochloromethane $>$ bromoform) ${ }^{(65,66)}$ This occurrence pattern also was noted in the NAWQAcollected data, ${ }^{(11,13,36,67,68,69,70)}$ and indicates that chlorinated water is an important source of chloroform and other THMs to ground water. ${ }^{(71)}$ Sources of chlorinated water to ground water may include irrigation of lawns, gardens, golf courses, and parks; leaking drinking-water distribution and sewer pipes; artificial recharge of wastewater; regulated discharges of cooling process blowdown water from electric power-generating plants; combined sewer overflows; ${ }^{(62,72)}$ and unintended backflow of chlorinated water to supply wells.

\section{Trihalomethanes (THMs) are produced during water and wastewater treatment when chlorine is added for disinfection.}

Chloroform has been detected in urban air ${ }^{(73)}$ and in rainwater. ${ }^{(74)}$ In studies of chloroform occurrence in shallow ground water in Indiana ${ }^{(75)}$ and New Jersey, ${ }^{(76)}$ however, the concentrations of chloroform in the atmosphere and rainwater were not high enough to account for all the mass of chloroform measured in shallow ground water. The sources of the chloroform frequently detected in ground water in the New Jersey study were attributed to use of chlorinated drinking water and the associated recharge from septic tanks or from the irrigation of crops and lawns. ${ }^{(76)}$

Chloroform has been detected in ground water beneath a variety of land-use settings. ${ }^{(11,68)}$ In NAWQA's assessments, THMs were detected more frequently beneath urban residential areas than beneath agricultural areas (fig. 21). Furthermore, the percentage of urban land, the number of RCRA hazardous-waste facilities, and septic system density were shown to be

26. THMs Result from Water Chlorination

THMs are a group of VOCs classified as disinfection by-products. THMs in drinking water were first identified by Rook ${ }^{(77)}$ and are formed as a result of the haloform reaction when dissolved chlorine combines with dissolved organic matter, such as humic and fulvic acids. The disinfection of drinking water in the United States by chlorination commonly uses chlorine gas, sodium hypochlorite, and calcium hypochlorite. The chemistry associated with the chlorination of water and the formation of chloroform and the brominated THMs are described elsewhere. ${ }^{(71)}$ The primary purpose of chlorination of drinking water is to prevent the spread of waterborne diseases, which can include such fatal diseases as cholera and typhoid. Another advantage of chlorination is that a chlorine residual is retained, which provides ongoing disinfection within the distribution system. ${ }^{(78)}$ Although the chlorination of drinking water provides many advantages, THMs remain a human-health concern (sidebar 28). Because of this concern, the USEPA has established an MCL of $80 \mu \mathrm{g} / \mathrm{L}$ for the combined concentrations of four THMs (chloroform, bromodichloromethane, dibromochloromethane, and bromoform), also known as TTHMs.

\section{Some THMs Occur Naturally}

Chloroform was originally considered solely of anthropogenic origins; however, several natural sources of chloroform recently have been identified. These include volcanic gases, ${ }^{(79)}$ soil fungi, ${ }^{(64)}$ and marine algae. ${ }^{(80,81)}$ Although natural sources contribute approximately 90 percent of the total global chloroform flux, ${ }^{(64)}$ evidence in the NAWOA-collected data is inconclusive about whether natural sources contribute to chloroform in ground water. Marine algae have been identified as a natural source for bromodichloromethane, dibromochloromethane, and bromoform. ${ }^{(80)}$ 


\section{Chloroform and Other THMs-Continued}

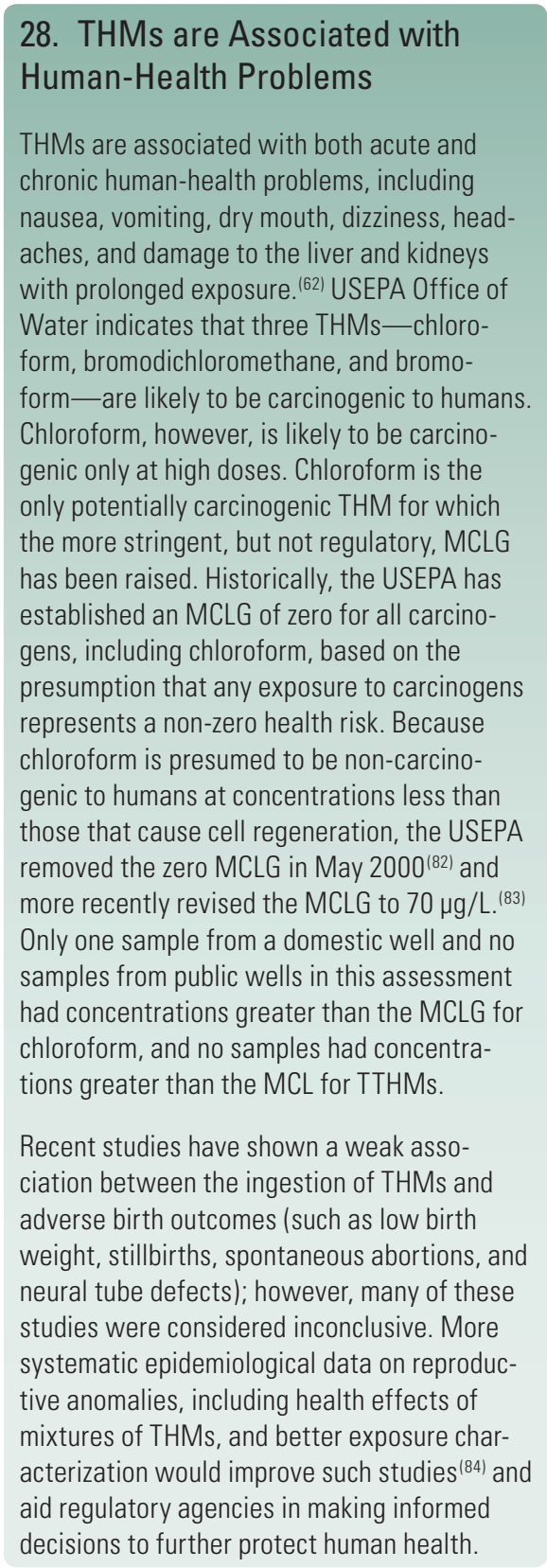

Figure 21. Detection frequencies of chloroform in shallow ground water were larger beneath urban areas than beneath agricultural areas.

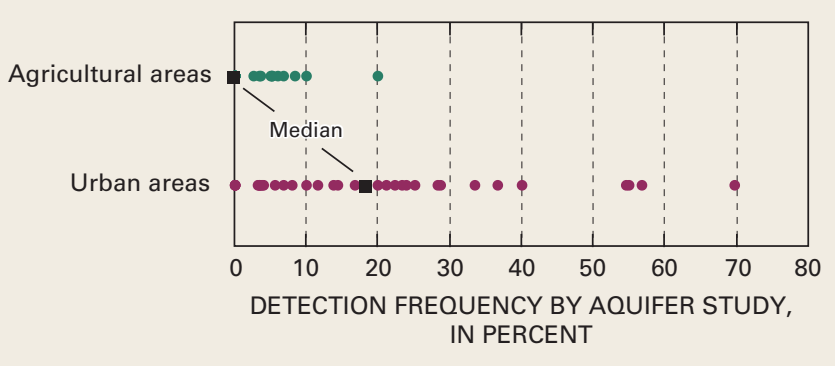

IN PERCENT

statistically associated with chloroform in aquifers, whereas sewer systems were associated with the occurrence of bromodichloromethane (table 4).

Chloroform was the most frequently detected VOC in samples from domestic and public wells. Detection frequencies of chloroform were about 5 percent in domestic well samples and about 11 percent in public well samples at an assessment level of $0.2 \mu \mathrm{g} / \mathrm{L}$ (fig. 22). As previously mentioned, this difference may be a consequence of the higher pumping rates of public wells and their proximity to developed areas, compared to domestic wells (p. 40 and 41). A pattern of detection frequencies (chloroform > bromodichloromethane $>$ dibromochloromethane $>$ bromoform) is apparent for domestic well samples (fig. 22). This pattern indicates that chlorinated water is an important source of THMs in domestic well water. The frequent occurrence of brominated THMs and THM mixtures in public well samples supports the importance of chlorinated water as a source of THMs to these wells.

\section{Chlorinated water is an important source of chloroform to ground water.}

Although chloroform was detected frequently, most TTHM concentrations were two orders of magnitude lower than the USEPA MCL of $80 \mu \mathrm{g} / \mathrm{L}$. No TTHM concentrations in samples from domestic or public wells were

Figure 22. Detection frequencies of trihalomethanes (THMs), especially the brominated species, were much greater in public well samples than in domestic well samples.

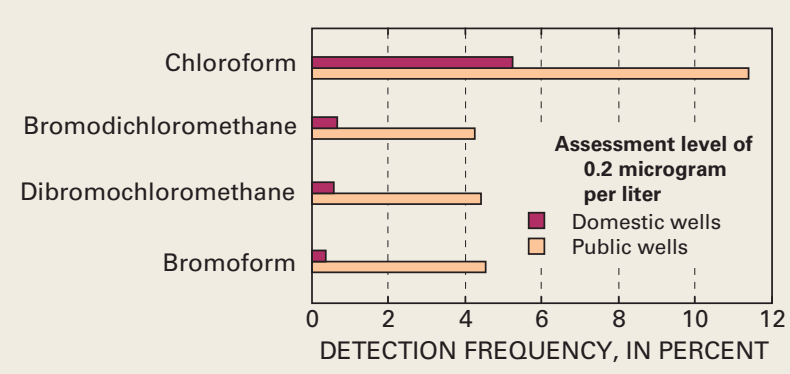


greater than the MCL (Appendixes 9 and 11). However, each of the four THMs had concentrations less than but within a factor of 10 of the TTHM MCL.

THMs have been detected in septic tank effluent, ${ }^{(85,86)}$ and in improperly designed, maintained, or operated septic systems, resulting in shallow ground-water contamination in the vicinity of the septic system. ${ }^{(82)}$ Water from a domestic well may be contaminated if the well is drawing contaminated water from the vicinity of an improperly operating septic system.

Other potential sources of chloroform and other THMs to domestic wells are laundry wastewater containing bleach and the well disinfection practice of shock chlorination. In both cases, chloroform and other THMs are produced through the haloform reaction of the chlorine in bleach with organic matter.

\section{Detection frequencies of THMs were larger in public well samples than in domestic well samples; however, no concentrations were greater than the USEPA drinking-water standard.}

Chloroform and other THMs are persistent under oxic conditions and have relatively low tendencies to sorb to soil and aquifer organic carbon. Because of these properties, THMs are expected to persist and may migrate substantial distances through the subsurface, especially in aquifers with detectable concentrations of dissolved oxygen and low amounts of organic carbon. ${ }^{(71,87)}$ These properties are important considerations in the western United States where drinking-water sources are sparse, and the injection of chlorinated wastewater into aquifers for future supply and to reduce land subsidence may become a more common practice (sidebar 29).

Monitoring chloroform and other THMs in samples from domestic and public wells is important because these compounds likely are indicators of sources of contamination. It also is important to evaluate trends in the occurrence of these compounds and to better understand the origin and humanhealth relevance of the low concentrations in water supplies.
29. THMs Persist in an Aquifer in the Western United States

Chlorinated surface water was injected into an oxic, unconsolidated sand and gravel aquifer in Antelope Valley, California, as part of a program to assess the long-term feasibility of using injection, storage, and recovery as a water-supply method and to reduce waterlevel declines and land subsidence in Antelope Valley. ${ }^{(88)}$ In the sand and gravel aquifer, THM formation continued after the treated water was injected. Once all the residual chlorine reacted, the concentrations of THMs were controlled primarily by mixing and dilution with native ground water. Potential for natural THM attenuation in the aquifer by biodegradation and sorption was low because the aquifer has oxic conditions and low organic matter content.

A model used to forecast the effects of repeated cycles of injection, storage, and recovery indicated that the cycles increased concentrations of THMs in the aquifer. These repeated cycles could yield aquifer THM concentrations approaching 100 percent of the injection-water THM concentration within 10 annual cycles, provided mixing within the aquifer does not lower concentrations markedly.

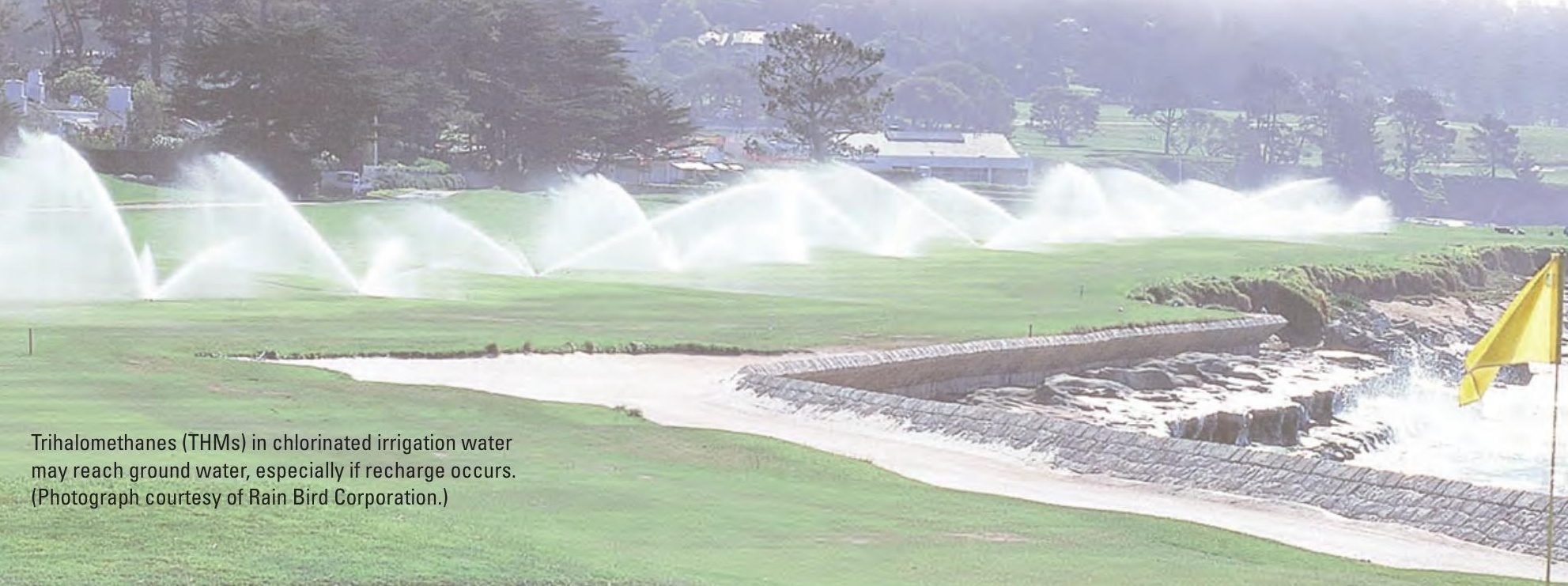




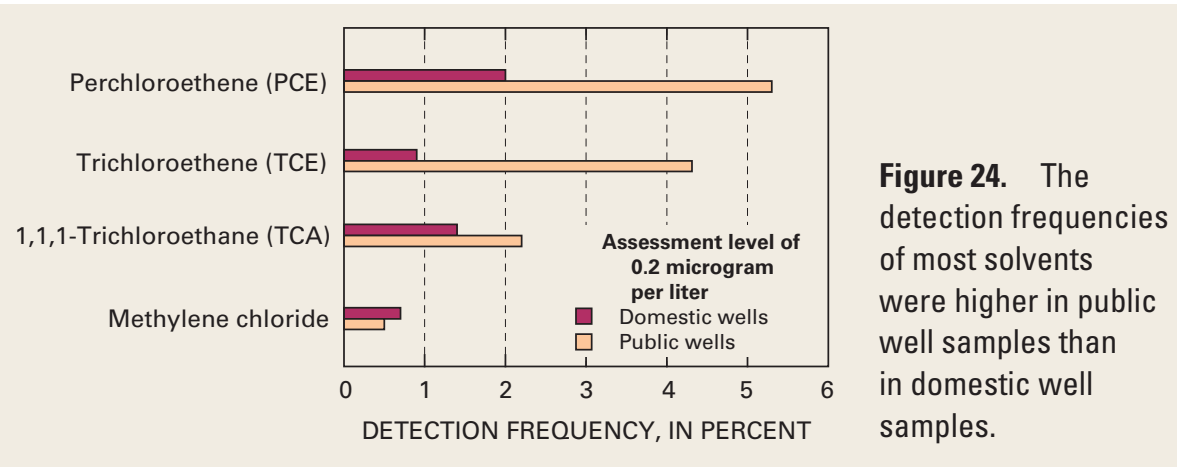

except for methylene chloride, were higher in public well samples than in domestic well samples (fig. 24). Solvents also were detected frequently in drinking water supplied by CWSs (sidebar 32).

The median concentrations of detections of all four solvents in aquifer samples were less than $0.2 \mu \mathrm{g} / \mathrm{L}$ (fig. 25). TCE had the highest median concentration of detections, followed by PCE, TCA, and methylene chloride. If all laboratory analyses (including non-detections) are considered, the ranking of solvents by concentration is the same as the ranking by detection frequency.

\section{In samples from domestic and public wells, solvents were among the VOCs that most frequently had concentrations greater than USEPA MCLs.}

In samples from domestic and public wells, the concentrations of 8 VOCs were greater than their MCL, and 3 of these were the solvents PCE, TCE, and methylene chloride. In domestic well samples, TCE and PCE were ranked second and third among VOCs with concentrations that were greater than their MCLs. In public well samples, PCE and TCE were both ranked first, and methylene chloride was ranked third among VOCs with concentrations that were greater than their MCLs. In addition, PCE and TCE had,

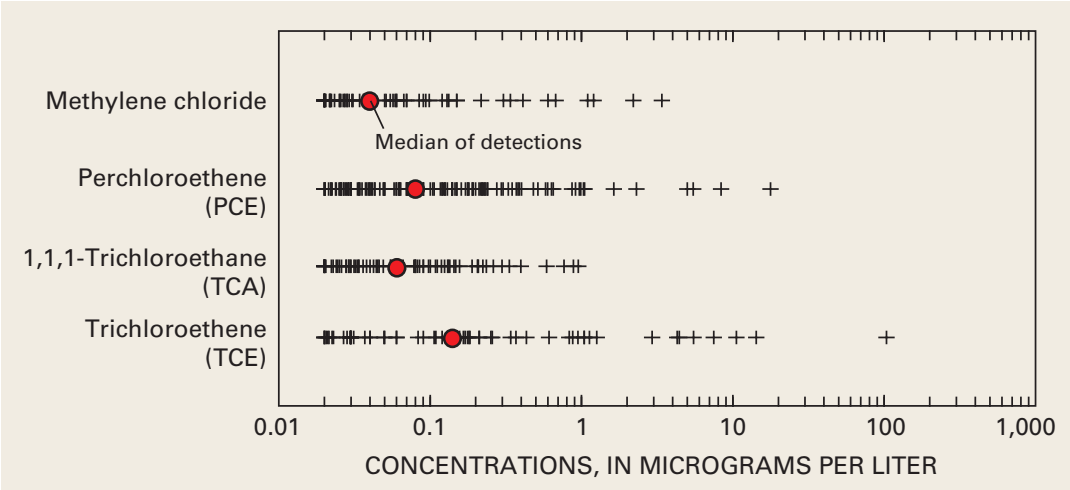

Figure 25. Concentrations of solvents in aquifers typically were less than 1 microgram per liter.
31. Some Solvents are Associated with Human-Health Problems

Chlorinated solvents have been associated with both cancer and non-cancer humanhealth problems. USEPA Office of Water indicates that both methylene chloride and TCE are probable human carcinogens, although the cancer classification of TCE is under review. TCA is not classifiable for carcinogenicity by the USEPA because of the lack of reported human data and the inadequacy of the available animal studies. The USEPA has not issued any qualitative judgment on the carcinogenicity of PCE. ${ }^{(83)}$ The USEPA currently is reassessing the health effects of all four solvents. The final drafts of the reassessments are expected during 2006-2008. ${ }^{(93)}$

MCLs for drinking water (Appendix 9) have been set for all the solvents considered here. ${ }^{(82)}$ The potential of solvents to affect drinking water is large, in part, because the water solubilities of the solvents are much greater than their MCLs. This means that even small spills can result in ground-water concentrations of potential human-health concern.

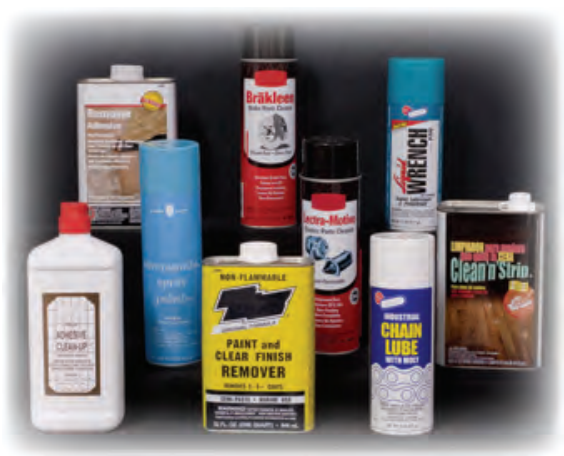

A variety of household products contain chlorinated solvents. (Photograph courtesy of Mike Wolforth, Light Images.) 


\section{Chlorinated Solvents-Continued}

\section{Solvents 0 ccur Frequently in \\ Drinking Water Supplied by CWSs}

Drinking water supplied by CWSs sampled during 1993-1998 in 12 New England and Mid-Atlantic States for a previous study had a larger occurrence of solvents compared to samples from domestic wells in the same 12 -State area ${ }^{(70)}$. One or more solvents were detected in about 10 percent of samples from CWSs that supply drinking water from ground water and in about 6 percent of domestic well samples. Individual solvents also were detected more frequently in CWS samples than in domestic well samples with the exception of methylene chloride.

Individual solvents were detected much more frequently in large CWSs than in small CWSs. The differences in detection frequencies by CWS size probably are related to larger pumping rates and to more urban land use and higher population density in areas surrounding the supply wells of large CWSs compared to small ones.

In drinking water from CWSs, concentrations of three solvents were greater than MCLs more often than other VOCs. Concentrations of PCE, TCE, and methylene chloride were greater than their MCLs in 1.5 percent, 1.2 percent, and 0.2 percent, respectively, of CWS samples. relative to other VOCs, a large number of concentrations less than but within a factor of 10 of their MCLs in samples from public and domestic wells (Appendixes 9 and 11).

The four solvents occurred together in any mixture in 5 percent of aquifer samples at an assessment level of $0.2 \mu \mathrm{g} / \mathrm{L}$. The most frequently occurring two-solvent mixture, PCE-TCE, probably represents the degradation of PCE to TCE, which occurs through a process called "reductive dechlorination." (94) In reductive dechlorination, a chlorine atom in PCE is replaced by a hydrogen atom producing TCE and is mediated by microbes (fig. 26). Several lines of evidence indicate that at least some PCE is being degraded in aquifers with anoxic conditions (sidebar 33).

\section{PCE degrades to TCE in aquifers with anoxic conditions.}

A statistical model of solvents in aquifers and shallow ground water indicated that the occurrence of one or more of the four solvents increased with dissolved-oxygen concentrations (table 7). The probability of occurrence of the four solvents also increased with increasing percentage of urban land use, population density, number of RCRA hazardous-waste facilities, and septic system density. Conversely, the probability of occurrence of the four solvents decreased with increasing sand content of soil and depths to the top of the screen/open interval in the well.

The sources of solvents to ground water are numerous and include releases associated with the production, transport, or use of these chemicals. Urban land-use practices, regulated hazardous-waste facilities, and dry-cleaning businesses are likely sources of solvents. Conditions such as recharge, vertical soil permeability, and dissolved oxygen control the transport and fate of the solvents. Although solvents occur in air in urban areas, concentrations are not large enough for atmospheric deposition to account for all the mass of solvents detected in ground water. ${ }^{(76)}$

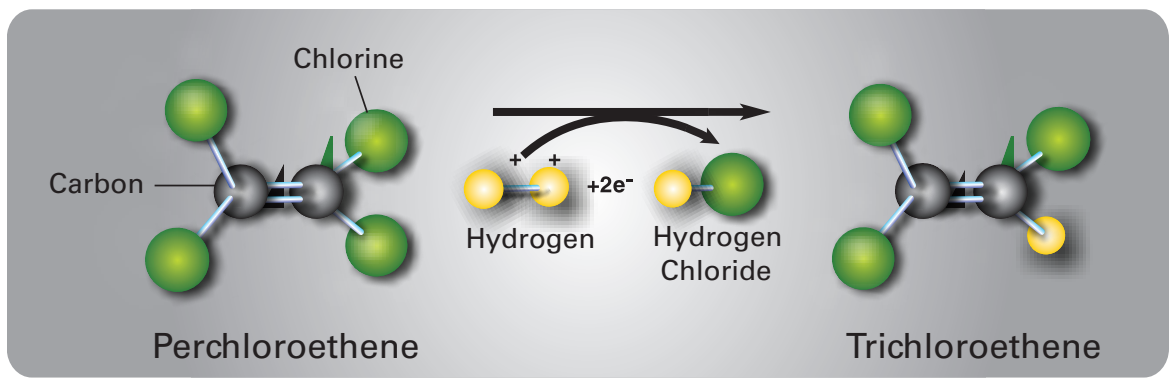

Figure 26. Perchloroethene (PCE) degrades to trichloroethene (TCE) under anoxic conditions through reductive dechlorination. 
Table 7. Explanatory factors associated with the occurrence in ground water of one or more of the four solvents - methylene chloride, perchloroethene (PCE), 1,1,1trichloroethane (TCA), and trichloroethene (TCE).

[RCRA, Resource Conservation and Recovery Act]

\begin{tabular}{lcc}
\hline \multicolumn{1}{c}{ Explanatory factor } & Rank & $\begin{array}{c}\text { Positive }(+) \text { or } \\
\text { negative }(-) \text { association }\end{array}$ \\
\hline Sand content of soil & 1 & - \\
Percentage of urban land use & 2 & + \\
Dissolved-oxygen concentration & 3 & + \\
Population density & 4 & + \\
Depth to screen/open interval & 5 & - \\
Number of RCRA facilities within 1 kilometer & 6 & + \\
Septic system density within 1 kilometer & 7 & + \\
\hline
\end{tabular}

\section{In some cases, concentrations of PCE and TCE increase with depth in an aquifer.}

Because of their physical and chemical properties, different solvents move through and react in ground water in unique ways (sidebar 33). In some cases, the concentrations of PCE and TCE have been shown to increase with increasing depth of the water in the aquifer. ${ }^{(95)}$ Because pure solvents are denser than water, they can penetrate the water table and collect in pools on top of less permeable layers in an aquifer. In this way, they become a source of contamination at the bottom of the aquifer. Through dissolution, diffusion, and dispersion, the solvent mass can then move upward in an aquifer and produce a concentration gradient that increases with depth (fig. 27).

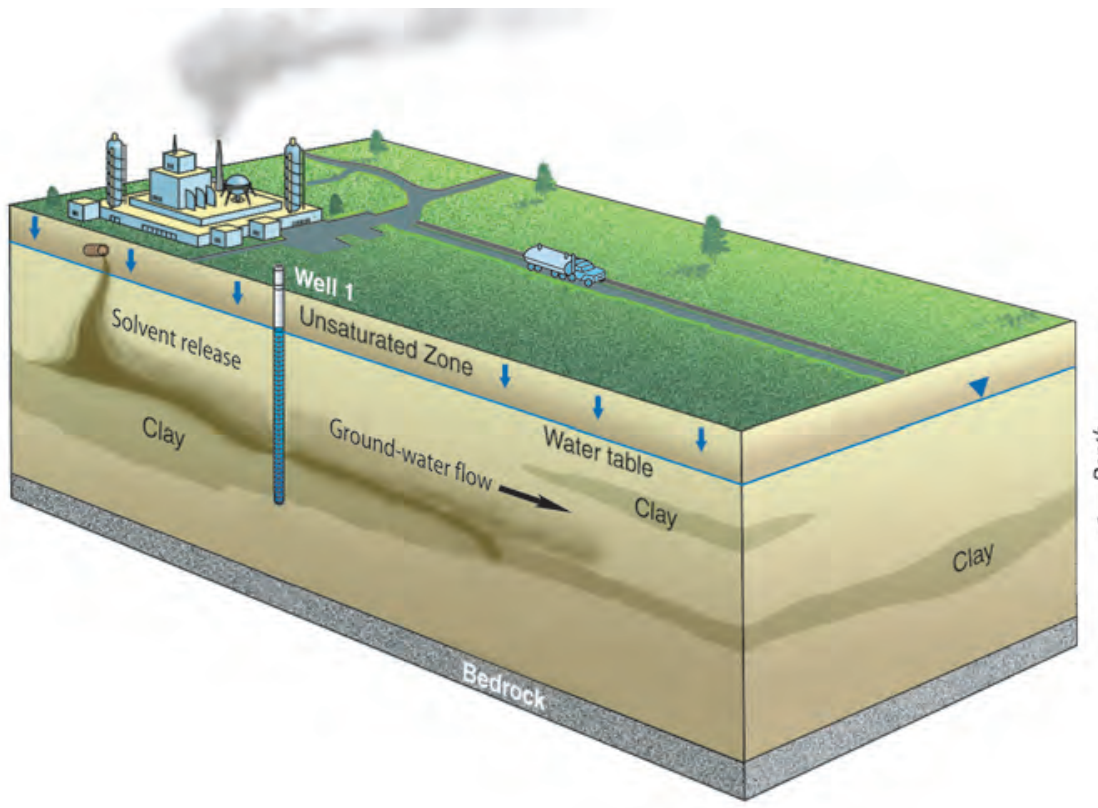

33. What are the Properties of Solvents?

In general, chlorinated solvents, as pure liquids, have relatively high densities, vapor pressures, and solubilities. In ground water, they also have relatively long half-lives. All solvents considered here have densities greater than 1 . This means that they are denser than water and that releases of pure solvents can penetrate the water table (fig. 27). The relatively high vapor pressures of the four solvents means that these compounds can volatilize when spilled onto a surface or exposed to the atmosphere. The aqueous solubilities of the four solvents also generally are high. ${ }^{(96)}$ Consequently, some mass of solvents exposed to land surfaces can move in solution to the water table. Finally, the biotic half-lives of solvents in ground water are longer than those of other commonly used VOCs, like the gasoline hydrocarbons. ${ }^{(97)}$ This means that solvents biodegrade slowly and therefore can persist for long periods of time in certain aquifers.

For more highly chlorinated molecules, the biodegradation of one chlorinated solvent can result in a by-product that also is a chlorinated solvent. For example, PCE can degrade to TCE (fig. 26), especially under anoxic conditions. If this occurs, the detection frequencies and concentrations of PCE should be larger in oxic ground water compared to anoxic ground water. PCE was detected in about 13 percent of samples from oxic ground water, but in only about 6 percent of samples from anoxic ground water. In addition, the concentration ratios of $\mathrm{PCE}$ to TCE were three times larger in oxic ground water compared to anoxic ground water. These lines of evidence indicate that some PCE may be degraded to TCE in aquifers with anoxic conditions.

Figure 27. The concentration of a chlorinated solvent may increase with depth in an aquifer. 


\section{MTBE and Other Gasoline Oxygenates}

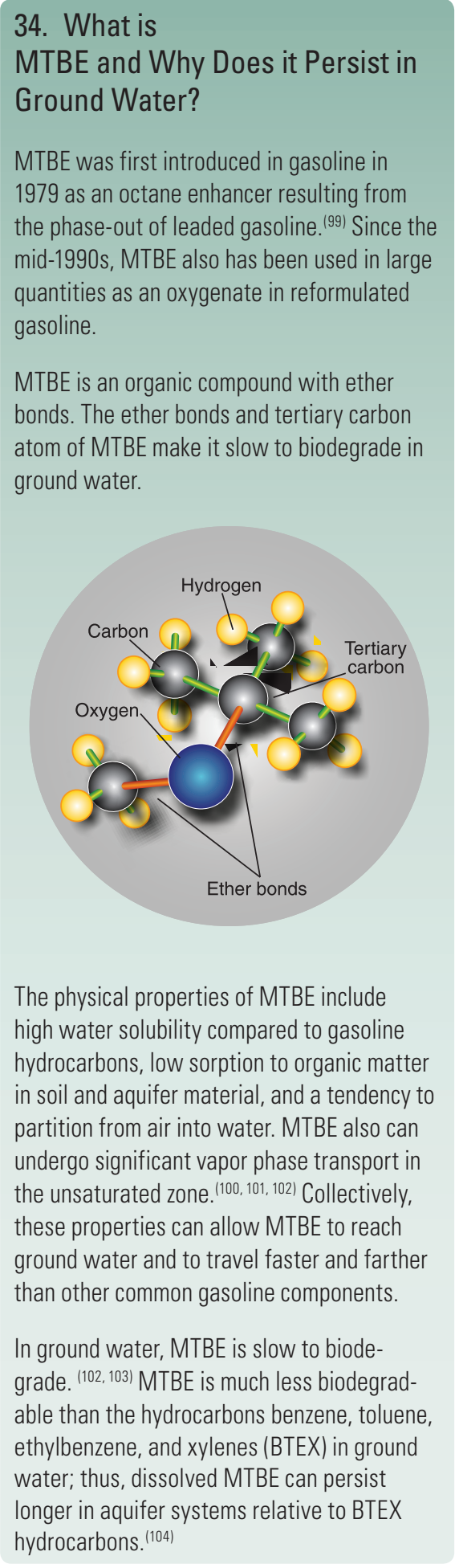

$\mathrm{M}$ TBE, a gasoline oxygenate, was the second most frequently detected VOC in samples from domestic and public wells at an assessment level of $0.2 \mu \mathrm{g} / \mathrm{L}$. The detection frequency of MTBE was about 3 percent in domestic well samples and about 5 percent in public well samples (fig. 28). Public wells generally have larger pumping rates than domestic wells, draw water from larger areas, and thus are more likely to be affected by releases of MTBE. Because of the large overlap in samples between studies of aquifers and domestic wells, the detection frequency of MTBE in aquifers is the same as for domestic well samples.

The NAWQA Program also analyzed samples for three other ether gasoline oxygenates-tert-amyl methyl ether (TAME), diisopropyl ether (DIPE), and ethyl tert-butyl ether (ETBE). These VOCs were detected infrequently in samples from domestic and public wells (fig. 28).

\section{MTBE was the second most frequently detected VOC in samples from domestic and public wells despite its relatively short production and use history.}

Gasoline oxygenates are compounds that contain oxygen and are added to gasoline to improve combustion and reduce harmful motor vehicle emissions. Since the 1990s, oxygenates have been used in gasoline in areas where certain air-quality standards have not been attained. In 2004, MTBE was the most commonly used gasoline oxygenate (sidebar 34); however, MTBE has been completely or partially banned in some States (sidebar 35). The Energy Policy Act of 2005 eliminated the oxygen requirement in gasoline. ${ }^{(98)}$

Potential point sources of MTBE include leaking storage tanks and associated piping, tank overflow spills, leaks from transport pipelines or bulk

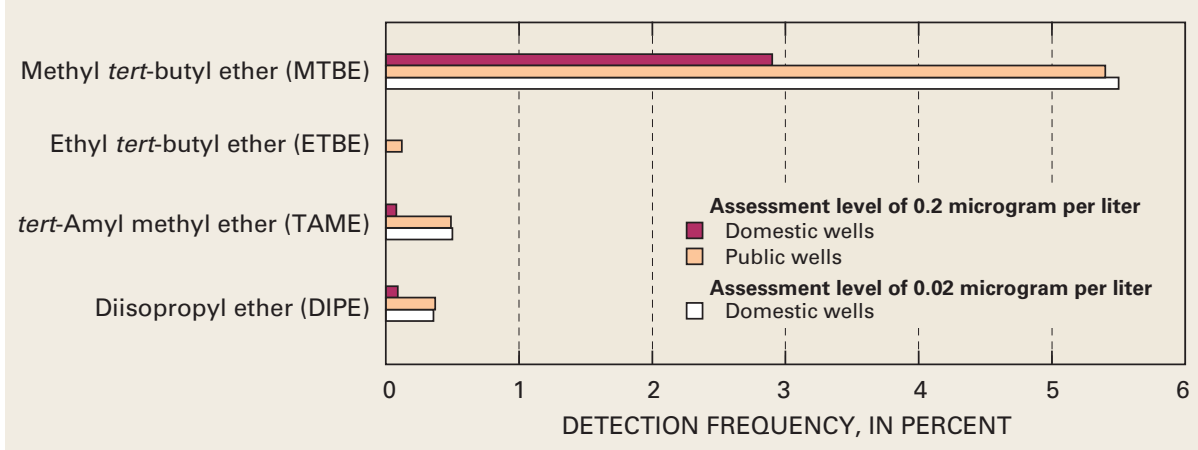

Figure 28. Compared to methyl tert-butyl ether, other gasoline oxygenates were detected infrequently in samples from domestic and public wells. 
gasoline stations, and automobile and truck accidents. Potential nonpoint sources of MTBE include evaporative losses from tanks or pipelines, incomplete combustion in automobile engines, urban stormwater runoff, exhaust from motorized watercraft, and leaks from watercraft tanks. MTBE has been detected in used motor oil, which also could be a source of MTBE in ground water. ${ }^{(105)}$ In some situations, the atmosphere can be a source of MTBE to ground water. This source of MTBE to shallow ground water was studied in a network of sites in southern New Jersey. At some sites, concentrations of MTBE in ambient air and in shallow ground water indicated that the atmosphere was a possible source of MTBE in ground water. ${ }^{(76)}$ At other sites, the concentrations of MTBE in ground water indicated that other sources, such as leaking tanks or road runoff, were the dominant source of MTBE. ${ }^{(106)}$ In California, artificial recharge in some areas may be a source of MTBE to aquifers (sidebar 36).

Production of MTBE has increased markedly since 1985, with large volumes of MTBE produced in the United States since about 1990 (fig. 29). The locations of ground-water samples analyzed for MTBE, as collected or compiled by the NAWQA Program, and samples where MTBE was detected are shown in figure 30. The locations include samples from studies of aquifers, domestic wells, and public wells. As is evident in this figure, many of the detections of MTBE were in the New England and Mid-Atlantic States.

MTBE has been detected in drinking water of some CWSs (sidebar 37). The current concern with MTBE in drinking water is primarily taste and odor because the human-health effects of MTBE have not yet been clearly established. Because of its chemical properties, MTBE can be smelled and tasted at low concentrations by some people. In 1997, the USEPA issued a Drinking-Water Advisory for MTBE. ${ }^{(107)}$ The advisory indicates that keeping MTBE concentrations in drinking water below the range of 20 to $40 \mu \mathrm{g} / \mathrm{L}$ will likely avert unpleasant taste and odor effects and also be protective of human health. The USEPA currently (2005) is conducting a risk assessment on the health effects of MTBE.

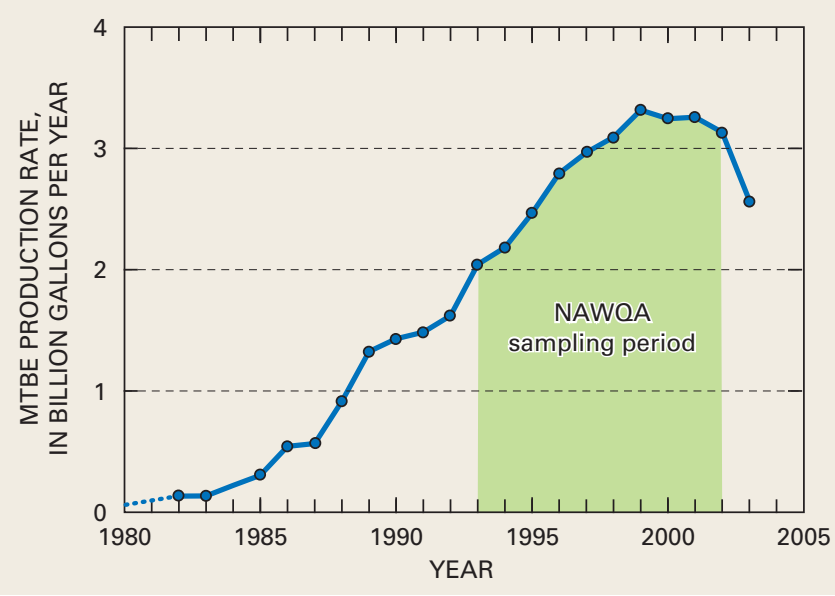

Figure 29. The annual production rate of methyl tert-butyl ether (MTBE) in the United States generally has increased until 1999 , but has since decreased. ${ }^{(89,108,109,110)}$
35. MTBE has been Completely or Partially Banned in Some States

As of June 2004, 19 States had enacted legislation to completely or partially ban MTBE use in gasoline. ${ }^{(111)}$ Also, several Federal bills and resolutions have been introduced in Congress that would ban or limit the use of MTBE nationwide. As of 2004, however, none of the Federal legislation to restrict MTBE use had been enacted.

After 1995, most of the gasoline in California contained 2 percent oxygen by weight (11 percent by volume) in order to comply with Federal regulations. ${ }^{(112)}$ Because of its favorable blending and transfer characteristics in gasoline, MTBE was used as the oxygenate in gasoline in California to comply with air-quality standards. However, because of concerns about the occurrence of MTBE in water supplies, an Executive Order was issued by the Governor of California in 1999 to ban the use of MTBE in gasoline by the end of 2002. In 2002, implementation of the ban was extended to the end of 2003.(112)

In 2005, Congress passed the Energy Policy Act that eliminated the oxygen requirement in gasoline as established by the Clean Air Act Amendments (CAAA) of 1990. ${ }^{(98)}$ Application of the elimination of the oxygen requirement in gasoline can begin as of the date of the Act (Aug. 8, 2005) for States that received a waiver under the CAAA. Application of the elimination of the oxygen requirement for any other State can begin 270 days after the date of the Act. ${ }^{(98)}$ The elimination of an oxygen requirement is expected to result in less use of oxygenates, such as MTBE, in reformulated gasoline. 
greater persistence in ground water relative to common gasoline hydrocarbons.

In statistical analyses reported previously, ${ }^{(113)}$ the probability of detecting MTBE in ground water was greater in areas with high population density, in areas where MTBE is used as an oxygenate in gasoline, and in areas with high ground-water recharge, compared to other areas of the Nation. Public well water and shallow ground water underlying urban land-use areas had a greater probability of containing detectable levels of MTBE than domestic well water and ground water underlying rural land-use areas. ${ }^{(113)}$

When MTBE use in gasoline was applied as a surrogate for MTBE release to the environment, the detection frequency of MTBE was significantly larger in areas of high use than in areas of low use. ${ }^{(113)}$ These results indicate that the use of MTBE in large amounts in gasoline in some areas of the Nation has resulted in increased detection frequencies of MTBE in ground water. ${ }^{(113)}$ MTBE was detected in some low MTBE-use areas presumedly as a result of its small volume in gasoline for octane enhancement.

\section{Public well water and shallow ground water underlying urban land-use areas had the highest probability of MTBE contamination.}

The quick arrival of MTBE in ground water relative to its production history (fig. 29) indicates that MTBE is an important concern with respect to ground-water management. Aquifers that may be vulnerable to MTBE contamination warrant evaluation with consideration given to the development of strategies to reduce the likelihood of contamination. Continued groundwater monitoring is warranted to evaluate trends in the occurrence of MTBE and to better understand the sources and transport of MTBE to ground water and to domestic and public wells.

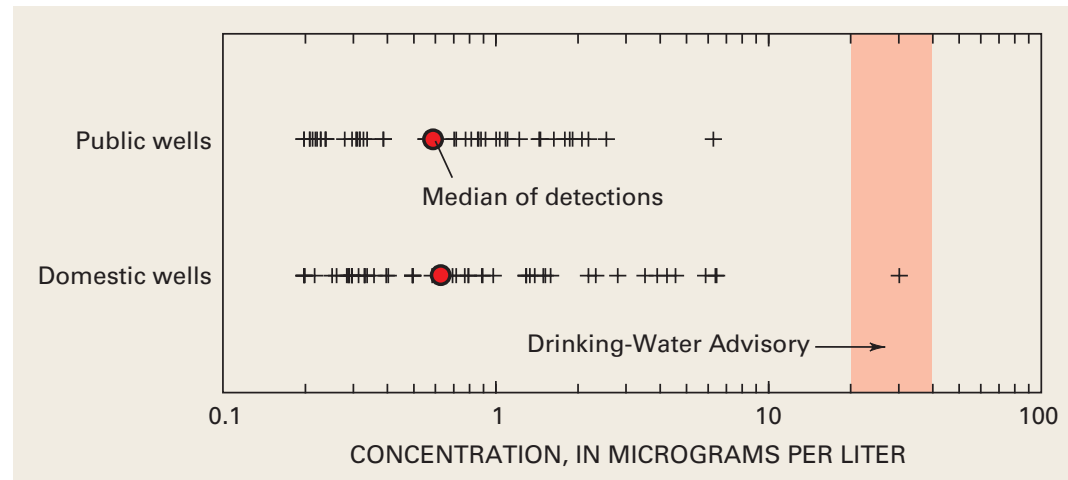

Figure 31. Most concentrations of methyl tert-butyl ether (MTBE) in samples from domestic and public wells are much less than the U.S. Environmental Protection Agency's Drinking-Water Advisory level.
37. MTBE has been Detected in Drinking Water of Some CWSs

MTBE was the fifth most frequently detected VOC in CWS samples collected during 19931998 for a previous study in 10 New England and Mid-Atlantic States. ${ }^{(70)}$ It was detected in about 9 percent of 985 CWS samples. However, only 0.9 percent of CWSs reported MTBE concentrations greater than $20 \mu \mathrm{g} / \mathrm{L}$, the lower limit of the USEPA's Drinking-Water Advisory. Most MTBE concentrations in drinking water were less than $5.0 \mu \mathrm{g} / \mathrm{L}$.

The USEPA required monitoring of MTBE in drinking water provided by public water systems under the UCM, which was designed to support drinking-water regulations. As of January 2005, 1,859 public water systems with ground-water sources have been sampled for MTBE under the UCM. Only four systems reported MTBE concentrations greater than $20 \mu \mathrm{g} / \mathrm{L}^{(116)}$

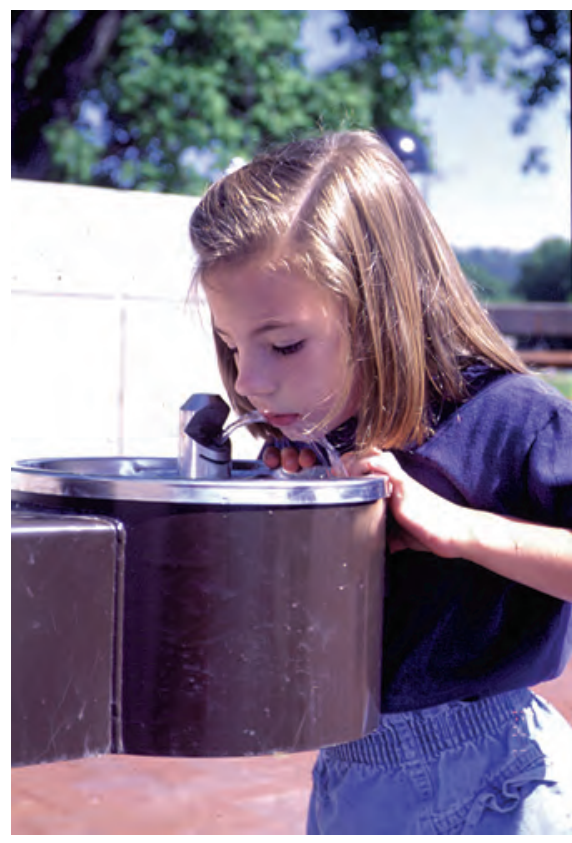

MTBE in drinking water has been a public concern because of its low taste and odor threshold and uncertain human-health effects. (Photograph by Paul J. Squillace, U.S. Geological Survey.) 


\section{Gasoline Hydrocarbons}

\begin{abstract}
38. Why are Gasoline Hydrocarbons Detected Infrequently in Aquifers?

A variety of physical and chemical properties can limit the movement of gasoline hydrocarbons to and transport by ground water. In ground water, a compound's solubility is one of the most important chemical properties. The median solubility of gasoline hydrocarbons is the lowest of any VOC group. ${ }^{(118)}$ Thus, gasoline hydrocarbons have less chance to reach ground water if released because less mass can be dissolved in recharge water.

At a gasoline release site in Beaufort, South Carolina, aerobic biodegradation and volatilization were found to be important in limiting the transport and occurrence of gasoline hydrocarbons in the unsaturated zone. ${ }^{(119)}$ This could help to explain, in part, the lower detection frequency of gasoline hydrocarbons relative to other VOC groups.

Another important property of organic chemicals is their ability to adsorb to organic carbon in soil and aquifer material. A good measure of the sorption potential is the organic carbon partitioning coefficient. Gasoline hydrocarbons have the highest median organic carbon partitioning coefficient of any other VOC group. ${ }^{(118)}$ Because of this, once in the subsurface the movement of gasoline hydrocarbons will be retarded with respect to the velocity of ground water. Also, less mass is left in ground water as sorption occurs.
\end{abstract}

Finally, and perhaps most importantly, biodegradation can reduce the mass of gasoline hydrocarbons in the unsaturated zone and in ground water. For aerobic biodegradation, gasoline hydrocarbons have some of the shortest half-lives of VOCs (see Circular's Web site). This means that gasoline hydrocarbons biodegrade quickly in oxic ground water relative to other VOCs.
T he gasoline hydrocarbon group is defined here as aromatic hydrocarbons or alkyl benzenes whose predominant use is in motor vehicle gasoline. Eleven of the 55 VOCs analyzed by NAWQA are in this group: benzene, $n$-butylbenzene, ethylbenzene, isopropylbenzene, naphthalene, styrene, toluene, 1,2,4-trimethylbenzene, $o$-xylene, $m$-xylene, and $p$-xylene.

Gasoline hydrocarbons are among the most intensively and widely used VOCs. Compared to other VOC groups, production of gasoline hydrocarbons has been extremely large. From 1980 to 2000, the median annual production of these compounds for all uses (including motor gasoline) was about 20 trillion gallons. ${ }^{(117)}$ This production number was at least four orders of magnitude larger than other VOC groups (sidebar 11) and comprised 99.9 percent of the total production of all VOC groups for the time period.

\section{Gasoline hydrocarbons were detected infrequently in aquifers at an assessment level of $0.2 \mu \mathrm{g} / \mathrm{L}$.}

Although the production of gasoline hydrocarbons from 1980 to 2000 was substantially larger than that of any other VOC group, it was not the most frequently detected VOC group in aquifers. Both THMs and solvents were detected more frequently than gasoline hydrocarbons at an assessment level of $0.2 \mu \mathrm{g} / \mathrm{L}$ (fig. 5). The smaller detection frequency of gasoline hydrocarbons relative to these other VOC groups probably is attributed to their transport and fate properties (sidebar 38).

Gasoline hydrocarbons were detected most frequently at concentrations less than $0.2 \mu \mathrm{g} / \mathrm{L}$ and comprised a substantial fraction ( 24 percent) of all low-level VOC detections. The frequent occurrence of low concentrations explains why the median concentration of samples with detections of gasoline hydrocarbons was among the lowest of any VOC group (fig. 32). In drinking water from CWSs, few concentrations of gasoline hydrocarbons were greater than MCLs (sidebar 39).

Individual gasoline hydrocarbons were detected infrequently in aquifers. Only one gasoline hydrocarbon, toluene, was detected in more than 1 percent of aquifer samples (fig. 8). No individual gasoline hydrocarbons were in the top 10 mixtures of VOCs in aquifers (sidebar 13). Furthermore, gasoline hydrocarbons occurred more frequently alone than as mixtures. Two or more gasoline hydrocarbons occurred together in only about 15 percent of samples in which gasoline hydrocarbons were detected.

The sources of most gasoline hydrocarbons in aquifers probably are releases of gasoline or other finished fuel products. However, in addition to their use in gasoline, many of the compounds identified as gasoline hydrocarbons have other uses (Appendix 4) and thus may have other sources to ground water. Gasoline hydrocarbons have been detected in used motor oil, which could be a source for some of these VOCs in ground water. ${ }^{(105)}$ 


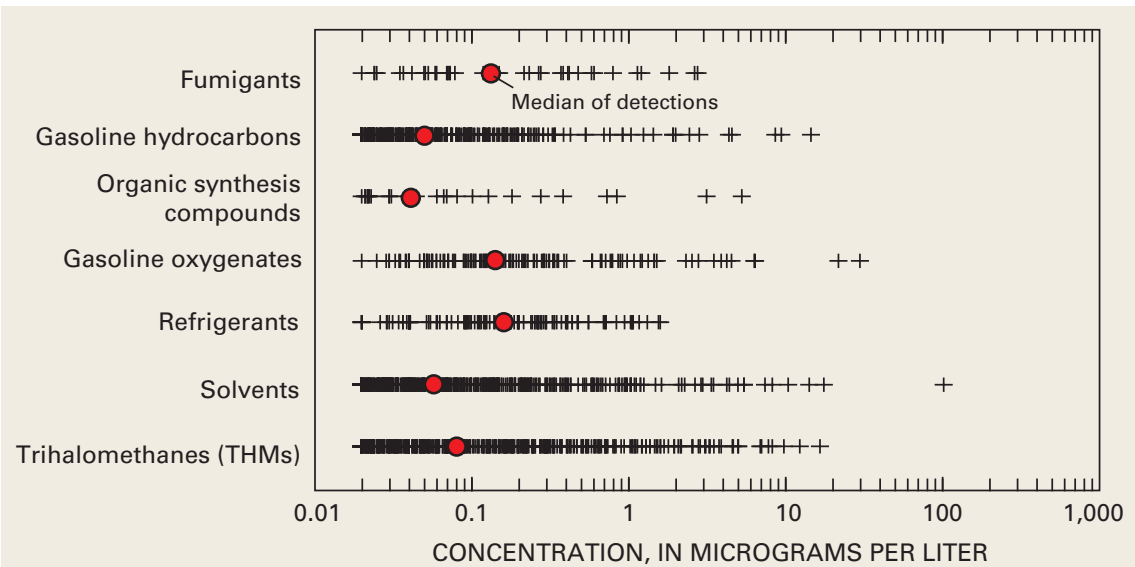

Figure 32. The median concentration of gasoline hydrocarbons in aquifer samples with detections was the second lowest of all seven VOC groups.

Because of the infrequent detection of individual gasoline hydrocarbons in aquifers, few associations with anthropogenic or hydrogeologic factors that might control their occurrence could be made in this assessment. The likelihood of detecting either toluene or 1,2,4-trimethylbenzene, however, was determined to be larger in areas with higher density of gasoline storage tanks (table 4).

In a study of the occurrence of MTBE and gasoline hydrocarbons in ground water of the United States, the detection frequencies of individual gasoline hydrocarbons were smaller than the detection frequency of MTBE. ${ }^{(113)}$ Although both are components of gasoline, the smaller detection frequencies of gasoline hydrocarbons were believed to be the result of differences in transport and fate properties of these compounds compared to those of MTBE.

\section{The median concentration of gasoline hydrocarbons was among the lowest of any VOC group.}

In the Reformulated Gasoline (RFG) Program, the content of benzene was limited to 1 percent by volume. Normally, gasoline contains between 1 and 1.5 percent benzene by volume. ${ }^{(120)}$ RFG usually contains the oxygenate MTBE. The limitation of benzene content in RFG should have resulted in smaller detection frequencies of benzene in areas of high MTBE use compared to areas of low MTBE use. An examination of ground-water data from across the United States revealed that this was the case. ${ }^{(113)}$ The smaller detection frequency of benzene, a known human carcinogen, in high MTBE-use areas could be a result of the lower benzene content in RFG and, if so, would be an important change for improving ground-water quality, especially for ground water that is used as a supply for drinking water.
39. Gasoline Hydrocarbons Occur More Frequently in Drinking Water from CWSs than in Domestic Wells

Drinking water from CWSs sampled during 1993-1998 for a previous study in 12 New England and Mid-Atlantic States ${ }^{(70)}$ had a more frequent occurrence of one or more gasoline hydrocarbons compared to domestic well samples in the same 12-State area. One or more gasoline hydrocarbons were detected in about 8 percent of CWSs deriving drinking water from ground water compared to about 2 percent of domestic well samples. Individual gasoline hydrocarbons also were detected more frequently in CWSs than in domestic well samples, with the exception of isopropylbenzene. The larger detection frequency of gasoline hydrocarbons in CWSs than in domestic well samples is likely due to several factors as discussed previously (p. 40 and 41).

Few concentrations of gasoline hydrocarbons in drinking water from CWSs or in domestic well samples were greater than MCLs. One CWS had a concentration of one gasoline hydrocarbon-benzene - that was greater than its MCL. In domestic well samples from the same 12-State area, no concentrations of gasoline hydrocarbons were greater than MCLs.

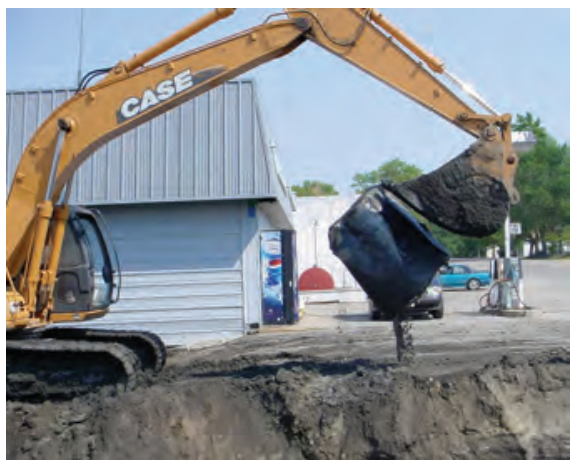

More than 1.5 million storage tanks have been removed from service since 1984 to protect soil and ground water from gasoline contamination. (Photograph courtesy of South Dakota Petroleum Release Compensation Fund.) 


\section{References}

1. Alley, W.M., Reilly, T.L., and Franke, O.H., 1999, Sustainability of ground-water resources: U.S. Geological Survey Circular 1186, $79 \mathrm{p}$.

2. U.S. Geological Survey, comp., 2003, Principal aquifers of the United States: prepared by the U.S. Geological Survey for The National Atlas, scale 1:5,000,000.

3. Pankow, J.F., and Cherry, J.A., 1996, Dense chlorinated solvents and other DNAPLs in ground water-History, behavior, and remediation: Portland, Oreg., Waterloo Press, $522 \mathrm{p}$.

4. American Water Works Association, Inc., 1971, Water quality and treatment-A handbook of public water supplies: New York, McGraw Hill Book Co., 654 p.

5. Ashford, N.A., and Miller, C.S., 1991, Chemical exposures-Low levels and high stakes (1st ed.): New York, Van Nostrand Reinhold, 214 p.

6. U.S. Environmental Protection Agency, 2004, 2001 TRI data release: accessed April 19, 2004, at http://www.epa.gov/tri/tridata/tri01/.

7. Office of Technology Assessment, 1984, Protecting the Nation's groundwater from contamination-Volume I: Washington, D.C., U.S. Congress, Office of Technology Assessment, Chapters 1 and 2, OTA-O-233.

8. Westrick, J.J., Mello, J.W., and Thomas, R.F., 1984, The groundwater supply survey: Journal of the American Water Works Association, v. 76, no. 5, p. 52-59.

9. Westrick, J.J., 1990, National surveys of volatile organic compounds in ground and surface waters, in Ram, N.M., Christman, R.F., and Cantor, K.P., eds., Significance and treatment of volatile organic compounds in water supplies: Chelsea, Mich., Lewis Publishers, p. 103-125.

10. Tennant, P.A., Norman, C.G., and Vicory, A.H., Jr., 1992, The Ohio River Valley Water Sanitation Commission's Toxic Substances Control Program for the Ohio River: Water Science and Technology, v. 26, no. 7-8, p. 17791788 .

11. Squillace, P.J., Moran, M.J., Lapham, W.W., Price, C.V., Clawges, R.M., and Zogorski, J.S., 1999, Volatile organic compounds in untreated ambient groundwater of the United States, 1985-1995: Environmental Science \& Technology, v. 33 , no. 23 , p. $4176-4187$.

12. Squillace, P.J., Scott, J.C., Moran, M.J., Nolan, B.T., and Kolpin, D.W., 2002, VOCs, pesticides, nitrate, and their mixtures in groundwater used for drinking water in the United States: Environmental Science \& Technology, v. 36, no. 9, p. 1923-1930.
13. Grady, S.J., 2003, A national survey of methyl tert-butyl ether and other volatile organic compounds in drinkingwater sources-Results of the Random Survey: U.S. Geological Survey Water-Resources Investigations Report 02-4079, $85 \mathrm{p}$.

14. Delzer, G.C., and Ivahnenko, Tamara, 2003, Occurrence and temporal variability of methyl tert-butyl ether (MTBE) and other volatile organic compounds in select sources of drinking water-Results of the Focused Survey: U.S. Geological Survey Water-Resources Investigations Report 02-4084, 65 p.

15. Moran, M.J., Zogorski, J.S., and Squillace, P.J., 2005, Occurrence and distribution of MTBE and gasoline hydrocarbons in ground water of the United States: Ground Water, v. 43, no. 4, p. 615-627.

16. Moran, M.J., Lapham, W.W., Rowe, B.L., and Zogorski, J.S., 2004, Volatile organic compounds in ground water from rural private wells, 1986 to 1999: Journal of the American Water Resources Association, v. 40, no. 5, p. 1141-1157.

17. Squillace, P.J., Moran, M.J., and Price, C.V., 2004, VOCs in shallow groundwater in new residential/commercial areas of the United States: Environmental Science \& Technology, v. 38 , no. 20 , p. $5327-5338$.

18. Bender, D.A., Zogorski, J.S., Halde, M.J., and Rowe, B.L., 1999, Selection procedure and salient information for volatile organic compounds emphasized in the National WaterQuality Assessment Program: U.S. Geological Survey Open-File Report 99-182, 32 p.

19. Moran, M.J., Zogorski, J.S., and Rowe, B.L., 2006, Approach to an assessment of volatile organic compounds in the Nation's ground water and drinking-water supply wells: U.S. Geological Survey Open-File Report 2005-1452, 36 p.

20. Toccalino, P.L., Zogorski, J.S., and Norman, J.E., 2005, Health-Based Screening Levels and their application to water-quality data: U.S. Geological Survey Fact Sheet 05-3059, 2 p.

21. Lapham, W.W., Moran, M.J., and Zogorski, J.S., 2000, Enhancement of nonpoint source monitoring of volatile organic compounds in ground water: Journal of the American Water Resources Association, v. 36, no. 6, p. 1321-1334.

22. U.S. Environmental Protection Agency, 1998, TRI data summary information-Top 20 chemicals with largest onsite and off-site releases, 1998, original industries: accessed August 2, 2001, at http://www.epa.gov/tri/tridata/tri98/data/ rlmc98atold2.pdf 
23. Pankow, J.F., Thomson, N.R., Johnson, R.L., Baehr, A.L., and Zogorski, J.S. 1997, The urban atmosphere as a non-point source for the transport of MTBE and other volatile organic compounds (VOCs) to shallow groundwater: Environmental Science \& Technology, v. 31, no. 10, p. 2821-2828.

24. Reilly, T.E., and Pollock, D.W., 1995, Effect of seasonal and long-term changes in stress on sources of water to wells: U.S. Geological Survey Water-Supply Paper 2445, $25 \mathrm{p}$.

25. Wiedemeier, T.H., Rifai, H.S., Newell, C.J., and Wilson, J.T., 1999, Natural attenuation of fuels and chlorinated solvents in the subsurface: New York, John Wiley and Sons, Inc., 617 p.

26. Roch, François, and Alexander, Martin, 1997, Inability of bacteria to degrade low concentrations of toluene in water: Environmental Toxicology and Chemistry, v. 16, no. 7, p. 1377-1383.

27. Focazio, M.J., Reilly, T.E., Rupert, M.G., and Helsel, D.R., 2002, Assessing ground-water vulnerability to contamination-Providing scientifically defensible information for decision makers: U.S. Geological Survey Circular 1224, $33 \mathrm{p}$.

28. Anthony, S.S., Hunt, C.D., Jr., Brasher, A.M.D., Miller, L.D., and Tomlinson, M.S., 2004, Water quality on the island of Oahu, Hawaii, 1999-2001: U.S. Geological Survey Circular 1239, 31 p.

29. Bush, P.W., Ardis, A.F., Fahlquist, Lynne, Ging, P.B., Hornig, C.E., and Lanning-Rush, Jennifer, 2000, Water quality in south-central Texas, Texas, 1996-98: U.S. Geological Survey Circular 1212, 32 p.

30. Pacific Biomedical Research Center, 1975, Hawaii epidemiologic studies program: Honolulu, University of Hawaii, Annual report no. 8, January through December 1974, 176 p.

31. Oki, D.S., and Giambelluca, T.W., 1987, DBCP, EDB, and TCP contamination of ground water in Hawaii: Ground Water, v. 25, no. 6, p. 693-702.

32. Orr, Shlomo, and Lau, L.S., 1987, Trace organic (DBCP) transport simulation of Pearl Harbor aquifer, Oahu, Hawaii-Multiple mixing-cell model, Phase I: Honolulu, University of Hawaii Water Resources Research Center Technical Report No. 174, 60 p.

33. Dubrovsky, N.M., Kratzer, C.R., Brown, L.R., Gronberg, J.M., and Burow, K.R., 1998, Water quality in the San Joaquin-Tulare Basins, California, 1992-95: U.S. Geological Survey Circular 1159, 38 p.
34. Reineke, Walter, 2001, Chapter 1, Aerobic and anaerobic biodegradation potentials of microorganisms, in Huntzinger, Otto, ed., The handbook of environmental chemistry, Beek, B., ed., Volume 2, Part K, Reactions and Processes-Biodegradation and persistence: Heidelberg, Germany, Springer-Verlag, p. 1-161.

35. Suarez, M.P., and Rifai, H.S., 1999, Biodegradation rates for fuel hydrocarbons and chlorinated solvents in groundwater: Bioremediation Journal, v. 3, no. 4, p. 337-362.

36. Moran, M.J., Lapham, W.W., Rowe, B.L., and Zogorski, J.S., 2002, Occurrence and status of volatile organic compounds in ground water from rural, untreated, self-supplied domestic wells in the United States, 1986-99: U.S. Geological Survey Water-Resources Investigations Report 02-4085, 51 p.

37. U.S. Environmental Protection Agency, 2005, Public Drinking Water Systems Programs: accessed November 2, 2005, at http://www.epa.gov/safewater/pws/index.html

38. U.S. Environmental Protection Agency, 2001, FactoidsDrinking water and ground water statistics for 2000: Office of Water, EPA 816-K-01-004, 10 p.

39. Hutson, S.S., Barber, N.L., Kenny, J.F., Linsey, K.S., Lumia, D.S., and Maupin, M.A., 2004, Estimated use of water in the United States in 2000: U.S. Geological Survey Circular 1268, 46 p.

40. U.S. Environmental Protection Agency, 2005, Setting standards for safe drinking water: accessed November 2, 2005, at http://www.epa.gov/safewater/standard/setting.html

41. Toccalino, Patricia; Nowell, Lisa; Wilber, William; Zogorski, John; Donohue, Joyce; Eiden, Catherine; Krietzman, Sandra and Post, Gloria, 2003, Development of HealthBased Screening Levels for use in State or local-scale water-quality assessments: U.S. Geological Survey WaterResources Investigations Report 03-4054, 22 p. [Available online at http://pubs.water.usgs.gov/wri03-4054]

42. Toccalino, P.L., Norman, J.E., Phillips, R.H., Kauffman, L.J., Stackelberg, P.E., Nowell, L.H., Krietzman, S.J., and Post, G.B., 2004, Application of Health-Based Screening Levels to ground-water quality data in a State-scale pilot effort: U.S. Geological Survey Scientific Investigations Report 2004-5174, 64 p. [Available online at http://pubs. water.usgs.gov/sir2004-5174]

43. Burow, K.R., Panshin, S.Y., Dubrovsky, N.M., VanBrocklin, David, and Fogg, G.E., 1999, Evaluation of processes affecting 1,2-dibromo-3-chloropropane (DBCP) concentrations in ground water in the eastern San Joaquin Valley, California-Analysis of chemical data and ground-water flow and transport simulations: U.S. Geological Survey Water-Resources Investigations Report 99-4059, 57 p. 
44. Wisconsin Department of Natural Resources, 1998, Volatile organic chemicals in drinking water: accessed July 12, 2001, at http://www.dnr.state.wi.us/org/water/dwg/voc.htm

45. U.S. Environmental Protection Agency, 2005, Private drinking water wells: accessed November 2, 2005, at http://www.epa.gov/safewater/privatewells/whereyoulive_ state.html

46. New Jersey Department of Environmental Protection, 2005, Private Well Testing Act: accessed January 5, 2005, at http://www.state.nj.us/dep/pwta/

47. U.S. Environmental Protection Agency, 2002, Community Water System Survey 2000, Vol. 1, Overview: Office of Water, EPA 815-R-02-OO5A, 48 p.

48. Stackelberg, P.E., Kauffman, L.J., Baehr, A.L., and Ayers, M.A., 2000, Comparison of nitrate, pesticides, and volatile organic compounds in samples from monitoring and publicsupply wells, Kirkwood-Cohansey aquifer system, southern New Jersey: U.S. Geological Survey Water-Resources Investigations Report 00-4123, 78 p.

49. U.S. Enviromental Protection Agency, 2005, Drinking water Contaminant Candidate List-Frequently asked questions: accessed November 2, 2005, at http://www.epa. gov/safewater/ccl/frequentquestions. $\mathrm{htm}$

50. U.S. Environmental Protection Agency, 2005, 1996 Amendments to the Safe Drinking Water Act-Public Law 104-182 104th Congress: accessed November 8, 2005, at http://www.epa.gov/safewater/sdwa/text.html

51. U.S. Environmental Protection Agency, 2005, Unregulated Contaminant Monitoring Rule 1 (UCMR 1): accessed November 2, 2005, at http://www.epa.gov/safewater/ucmr/ ucmrl/index.html

52. U.S. Environmental Protection Agency, 2005, Drinking water Contaminant Candidate List (CCL)_drinking water Contaminant Candidate List 2: accessed November 2, 2005, at http://www.epa.gov/safewater/ccl/ccl2_list.html

53. Squillace, P.J., Pankow, J.F., Korte, N.E., and Zogorski, J.S., 1996, Environmental behavior and fate of methyl tertbutyl ether (MTBE): U.S. Geological Survey Fact Sheet 203-96, 6 p.

54. Lopes, T.J., and Dionne, S.G., 1998, A review of semivolatile and volatile organic compounds in highway runoff and urban stormwater: U.S. Geological Survey Open-File Report 98-409, 67 p.

55. U.S. Environmental Protection Agency, 2002, Occurrence summary and use support document for the six-year review of national primary drinking water regulations: Office of Water, EPA-815-D-02-006, 449 p., accessed December 7, 2005, at http://www.epa.gov/safewater/review. html\#completion
56. Bruce, B.W., and Oelsner, G.P., 2001, Contrasting water quality from paired domestic/public supply wells, Central High Plains: Journal of the American Water Resources Association, v. 37, no. 5, p. 1389-1403.

57. Baehr, A.L., Kauffman, L.J., Charles, E.G., Baker, R.J., Stackelberg, P.E., Ayers, M.A., and Zapecza, O.S., 1999, Sampling throughout the hydrologic cycle to characterize sources of volatile organic compounds in ground water, in Morganwalp, D.W., and Buxton, H.T., eds., U.S. Geological Survey Toxic Substances Hydrology Program-Proceedings of the Technical Meeting, Charleston, South Carolina, March 8-12, 1999, v. 3: U.S. Geological Survey WaterResources Investigations Report 99-4018C, p. 21-35.

58. Stackelberg, P.E., Kauffman, L.J., Ayers, M.A., and Baehr, A.L., 2001, Frequently co-occurring pesticides and volatile organic compounds in public supply and monitoring wells, southern New Jersey, USA: Environmental Toxicology and Chemistry, v. 20, no. 4, p. 853-865.

59. Budavari, Susan, ed., 1989, The Merck Index: Rahway, N.J., Merck and Company, Inc. [variously paged].

60. Mannsville Chemical Products Corporation, 1999, Chemical products synopsis, chloroform: Adams, N.Y., Mannsville Chemical Products Corporation, 2 p.

61. Lucius, J.E., Olhoeft, G.R., Hill, P.L., and Duke, S.K., 1992, Properties and hazards of 108 selected substances (1992 ed.): U.S. Geological Survey Open-File Report 92-527, p. 191-195.

62. Agency for Toxic Substances and Disease Registry, 1997, Toxicological profile for chloroform: U.S. Department of Health and Human Services, Public Health Service, Agency for Toxic Substances and Disease Registry, 293 p.

63. Agency for Toxic Substances and Disease Registry, 2005, Bromoform and dibromochloromethane: accessed October 24, 2005, at http://www.atsdr.cdc.gov/toxprofiles/tp130c5.pdf

64. McCulloch, A., 2003, Chloroform in the environmentOccurrence, sources, sinks and effects: Chemosphere, v. 50, no. 10 , p. $1291-1308$.

65. Minear, R.A., and Bird, J.C., 1980, TrihalomethanesImpact of bromide ion concentration on yield, species distribution, rate of formation and influence of other variables, in Jolley, R.L., ed., Water chlorination-Environmental impact and health effects, v. 3: Ann Arbor, Mich., Ann Arbor Science Publishers Inc., p. 151-160.

66. Chellam, Shankararaman, 2000, Effects of nanofiltration on trihalomethane and haloacetic acid precursor removal and speciation in waters containing low concentrations of bromide ion: Environmental Science \& Technology, v. 34, no. 9, p. 1813-1820. 
67. Kolpin, D.W., and Thurman, E.M., 1995, Postflood occurrence of selected agricultural chemicals and volatile organic compounds in near-surface unconsolidated aquifers in the Upper Mississippi River Basin, 1993: U.S. Geological Survey Circular 1120-G, 20 p.

68. Stackelberg, P.E., Hopple, J.A., and Kauffman, L.J., 1997, Occurrence of nitrate, pesticides and volatile organic compounds in the Kirkwood-Cohansey aquifer system, southern New Jersey: U.S. Geological Survey Water-Resources Investigations Report 97-4241, 8 p.

69. Thiros, S.A., 2000, Anaylsis of nitrate and volatile organic compound data for ground water in the Great Salt Lake Basins, Utah, Idaho, and Wyoming 1980-98, National Water Quality Assessment Program: U.S. Geological Survey Water-Resources Investigations Report 00-4043, 20 p.

70. Grady, S.J., and Casey, G.D., 2001, Occurrence and distribution of methyl tert-butyl ether and other volatile organic compounds in drinking water in the Northeast and Mid-Atlantic regions of the United States, 1993-98: U.S. Geological Survey Water-Resources Investigations Report 00-4228, 123 p.

71. Ivahnenko, Tamara, and Barbash, J.E., 2004, Chloroform in the hydrologic system-Sources, transport, fate, occurrence, and effects on human health and aquatic organisms: U.S. Geological Survey Scientific Investigations Report 2004-5137, 34 p.

72. California Air Resources Board, 1990, Chloroform: accessed June 10, 1999, at http://www.arb.ca.gov/toxics/ summary/chlorfor.pdf

73. Pankow, J.F., Luo, Wentia, Bender, D.A., Isabelle, L.M., Hollingsworth, J.S., Cehn, Cai, Asher, W.E., and Zogorski, J.S., 2003, Concentrations and co-occurrence correlations of 88 volatile organic compounds (VOCs) in ambient air of 13 semi-rural to urban locations in the United States: Atmospheric Environment, v. 37, no. 36, p. 5023-5046.

74. Adachi, Atsuko, and Kobayashi, Tadashi, 1994, Volatile chlorinated organic compound levels in rain water from Kobe City, Japan: Bulletin of Environmental Contamination and Toxicology, v. 52, no. 1, p. 9-12.

75. Fenelon, J.M., and Moore, R.C., 1996, Occurrence of volatile organic compounds in ground water in the White River Basin, Indiana, 1994-95: U.S. Geological Survey Fact Sheet 138-96, 4 p.

76. Baehr, A.L., Stackelberg, P.E., Baker, R.J., 1999, Evaluation of the atmosphere as a source of volatile organic compounds in shallow groundwater: Water Resources Research, v. 35 , no. 1 , p. 127-136.
77. Rook, J.J., 1974, Formation of haloforms during chlorination of natural waters: Water Treatment and Examination, v. 23 , p. 234-243.

78. Weber, W.J., Jr., 1972, Physiochemical processes for water quality control: New York, John Wiley and Sons, 640 p.

79. Isidorov, V.A., Zenkevich, I.G., and Ioffe, B.V., 1990, Volatile organic compounds in solfataric gases: Journal of Atmospheric Chemistry, v. 10, p. 329-340.

80. Gribble, G.W., 1994, The natural production of chlorinated compounds: Environmental Science \& Technology, v. 28, no. 7 , p. 310A-319A.

81. Laturnus, Frank, Haselmann, K.F., Borch, Thomas, and Gron, Christian, 2002, Terrestrial natural sources of trichloromethane (chloroform, $\mathrm{CHCl} 3$ )_An overview: Biochemistry, v. 60 , no. 2 , p. 121-139.

82. U.S. Environmental Protection Agency, 2000, National water quality inventory, 1998 Report to Congress: Washington, D.C., Office of Water Quality, EPA 841-R-00-001, $413 \mathrm{p}$.

83. U.S. Environmental Protection Agency, 2006, Federal Register Document January 4, 2006: U.S. Environmental Protection Agency, v. 71, no. 2, p. 478.

84. Nieuwenhuijsen, M.J., Toledano, M.B., Eaton, N.E., Falwell, John, and Elliot, Paul, 2000, Chlorination disinfection by-products in water and their association with adverse reproductive outcomes-A review: Occupational and Environmental Medicine, v. 57, no. 2, p. 73-85.

85. DeWalle, F.B., Kalman, D., Norman, D., Sung, J., and Plews, G., 1985, Determination of toxic chemicals in effluent from household septic tanks: EPA 600/2-85/050, 25 p.

86. Ayres Associates, 1993, Onsite sewage disposal system research in Florida-An evaluation of current onsite sewage disposal system (OSDS) practices in Florida: Tampa, Fla., Ayres Associates, $191 \mathrm{p}$

87. McCarty, P.L., Reihard, Martin, and Rittman, B.E., 1981, Trace organics in groundwater: Environmental Science \& Technology, v. 15, no. 1, p. 40-51.

88. Fram, M.S., Bergamaschi, B.A., Goodwin, K.D., Fujii, Roger, and Clark, J.F., 2003, Processes affecting the trihalomethane concentrations associated with the third injection, storage, and recovery test at Lancaster, Antelope Valley, California, March 1998 through April 1999: U.S. Geological Survey Water-Resources Investigations Report 03-4062, $72 \mathrm{p}$.

89. Chemical Manufacturers Association, 1997, U.S. Chemical industry statistical handbook, 1997: Arlington, Va., Chemical Manufacturers Association, 185 p. 
90. Chemical Manufacturers Association, 1998, U.S. Chemical industry statistical handbook, 1998: Arlington, Va., Chemical Manufacturers Association, 113 p.

91. Halogenated Solvents Industry Alliance, 2004, Solvent applications: accessed May 7, 2004, at http://www.hsia. org/applications.htm

92. U.S. Environmental Protection Agency, 1980, Sources of toxic compounds in household wastewater: Washington, D.C., Office of Research and Development, EPA 600/2-80 $128,84 \mathrm{p}$.

93. U.S. Environmental Protection Agency, 2005, IRIS chemical assessment tracking system: accessed October 4, 2005, at http://cfpub.epa.gov/iristrac/index.cfm?fuseaction= listChemicals. showList\&letter $=A L L$

94. Nyer, E.K., and Duffin, M.E., 1997, The state of the art of bioremediation: Ground Water Monitoring \& Remediation, v. 17, no. 2, p. 64-69.

95. Mullaney, J.R., and Grady, S.J., 1997, Hydrogeology and water quality of a surficial aquifer underlying an urban area, Manchester, Connecticut: U.S. Geological Survey WaterResources Investigations Report 97-4195, 40 p.

96. Mackay, Donald, Shiu, W.Y., and Ma, K.C., 1993, Illustrated handbook of physical-chemical properties and environmental fate for organic chemicals, Volume III, Volatile organic chemicals: Chelsea, Mich., Lewis Publishers, $916 \mathrm{p}$.

97. Howard, P.H., Boethling, R.S., Jarvis, W.F., Meylan, W.M., and Michalenko, E.M., 1991, Handbook of Environmental Degradation Rates: Chelsea, Mich., Lewis Publishers, $725 \mathrm{p}$.

98. U.S. Congress, 2005, Energy Policy Act of 2005: Washington, D.C., 109th Congress of the United States, Public Law 109-58, August 8, 2005, 551 p.

99. U.S. Environmental Protection Agency, 2005, Gasoline: accessed October 3, 2005, at http://www.epa.gov/mtbe/ gas.htm

100. Squillace, P.J., Pankow, J.F., Korte, N.E., and Zogorski, J.S., 1997, Review of the environmental behavior and fate of methyl tert-butyl ether: Environmental Toxicology and Chemistry, v. 16, no. 9, p. 1836-1844.

101. Moran, M.J., Zogorski J.S., and Squillace P.J., 1999, MTBE in ground water of the United States-Occurrence, potential sources and long-range transport, in Water Resources Conference, Proceedings: Norfolk, Va., American Water Works Association Conference, Sept. 26-29, 1999 [CD-ROM].
102. Dakhel, Nathalie; Pasteris, Gabriele; Werner, David; and Höhener, Patrick, 2003, Small-volume releases of gasoline in the vadose zone-Impact of the additives MTBE and ethanol on groundwater quality: Environmental Science \& Technology, v. 37, no. 10, p. 2127-2133.

103. Pasteris, Gabriele; Werner, David; Kaufmann, Karin; and Höhener, Patrick, 2002, Vapor phase transport and biodegradation of volatile fuel compounds - A large scale lysimeter experiment: Environmental Science \& Technology, v. 36, no. 1 , p. 30-39.

104. Zogorski, J.S., Morduchowitz, Abraham, Baehr, A.L., Bauman, B.J., Conrad, D.L., Drew, R.T., Korte, N.E., Lapham, W.W., Pankow, J.F., and Washington, E.R., 1997, Fuel oxygenates and water quality, in Interagency Assessment of Oxygenated Fuels: Washington, D.C., Office of Science and Technology Policy, Executive Office of the President, chap. 2, 80 p.

105. Baker, R.J., Best, E.W., and Baehr, A.L., 2002, Used motor oil as a source of MTBE, TAME, and BTEX to ground water: Ground Water Monitoring \& Remediation, v. 22 , no. 4 , p. $46-51$.

106. Baehr, A.L., Charles, E.G., and Baker, R.J., 2001, Methyl tert-butyl ether degradation in the unsaturated zone and the relation between MTBE in the atmosphere and shallow groundwater: Water Resources Research, v. 37, no. 2, p. 223-234.

107. U.S. Environmental Protection Agency, 1997, Drinking water advisory-Consumer acceptability advice and health effects analysis on methyl tertiary-butyl ether: Washington, D.C., U.S. Environmental Protection Agency, Office of Water, EPA-822-F-97-009.

108. American Chemical Society, 1993, Chemical production resumed growth in 1992: Chemical and Engineering News, June 28, 1993, v. 71, no. 26, p. 40-46.

109. American Chemical Society, 1995, Production soared in most chemical sectors: Chemical and Engineering News, June 26, 1995, v. 73, no. 26, p. 38-44.

110. Department of Energy, 2004, Monthly oxygenate report: Department of Energy, accessed May 6, 2004, at http://www. eia.doe.gov/oil_gas/petroleum/data_publications/monthly_ oxygenate_telephone_report/motr_historical.html

111. U.S. Environmental Protection Agency, 2004, State actions banning MTBE (Statewide): EPA-420-B-04-009, accessed November 22, 2004, at http://www.epa.gov/mtbe/ 420b04009.pdf

112. California Air Resources Board, 2003, The California Reformulated Gasoline Regulations: accessed January 3, 2004, at http://www.arb.ca.gov/fuels/gasoline/carfg3_ 090904.pdf 
113. Moran, M.J., Zogorski, J.S., and Squillace, P.J., 2004, Occurrence and implications of methyl tert-butyl ether and gasoline hydrocarbons in ground water and source water in the United States and in drinking water in 12 Northeast and Mid-Atlantic States, 1993-2002: U.S. Geological Survey Water-Resources Investigations Report 03-4200, 26 p.

114. Shelton, J.L., Burow, K.R., Belitz, Kenneth, Dubrovsky, N.M., Land, Michael, and Gronberg, JoAnn, 2001, Lowlevel volatile organic compounds in active public supply wells as ground-water tracers in the Los Angeles physiographic basin, California, 2000: U.S. Geological Survey Water-Resources Investigations Report 01-4188, 29 p.

115. Dawson, B.J.M.; Belitz, Kenneth; Land, Michael; and Danskin, W.R., 2003, Stable isotopes and volatile organic compounds along seven ground-water flow paths in divergent and convergent flow systems, southern California, 2000: U.S. Geological Survey Water-Resources Investigations Report 03-4059, 79 p.

116. U.S. Environmental Protection Agency, 2004, Accessing unregulated contaminant monitoring data: U.S. Environmental Protection Agency, accessed November 3, 2005, at http://www.epa.gov/safewater/ucmr/data.html

117. U.S. Department of Energy Information Administration, 2003, U.S. Gasoline data: accessed March 20, 2003, at http://www.eia.doe.gov/oil_gas/petroleum/info_glancel gasoline.html

118. Mackay, Donald, Shiu, W.Y., and Ma, K.C., 1992, Illustrated handbook of physical-chemical properties of environmental fate for organic chemicals, Volume I, Monoaromatic hydrocarbons, chlorobenzenes, and PCBs: Chelsea, Mich., Lewis Publishers, 697 p.

119. Lahvis, M.A., Baehr, A.L., and Baker, R.J., 1999, Quantification of aerobic biodegradation and volatilization rates of gasoline hydrocarbons near the water table under natural attenuation conditions: Water Resources Research, v. 35, no. 3, p. 753-765.

120. U.S. Environmental Protection Agency, 1990, The Clean Air Act Amendments: Washington, D.C., U.S. Congress, $101^{\text {st }}$, Sec. 219, p. S.1630-1938: accessed January 15, 2003, at http://www.epa.gov/oar/caa/caaa.txt

The following references apply to the glossary and appendixes.

121. U.S. Environmental Protection Agency, 1986, Guidelines for carcinogen risk assessment: Washington, D.C., EPA/630/R-00/004, p. 19-21.

122. U.S. Environmental Protection Agency, 2005, Guidelines for Carcinogen Risk Assessment: Washington D.C., EPA/630/P-03/001F [variously paged].
123. U.S. Environmental Protection Agency, 2005, List of drinking water contaminants and MCLs (includes potential health effects, sources of contaminant in drinking water): accessed June 10, 2005, at http://www.epa.gov/safewater/ mcl.html

124. U.S. Environmental Protection Agency, 2004, Technical factsheets on drinking water contaminants: accessed July 28, 2004, at http://www.epa.gov/safewater/hfacts.html

125. Department of Energy, 2004, Risk Assessment Information System (RAIS): accessed July 28, 2004, at http://risk. lsd.ornl.gov/index.shtml

126. Agency for Toxic Substances and Disease Registry (ATSDR), 1992, Toxicological profile for 1,3-dichloropropene: U.S. Department of Health and Human Services, p. 81 .

127. Agency for Toxic Substances and Disease Registry (ATSDR), 2003, ATSDR tox profiles 2003 (2003 ed.): Atlanta, Ga., U.S. Department of Health and Human Services [CD-ROM].

128. Agency for Toxic Substances and Disease Registry (ATSDR), 2004, ATSDR Tox Profiles 2004 (2004 ed.): Atlanta, Ga., U.S. Department of Health and Human Services [CD-ROM].

129. Sittig, Marshall, 1991, Handbook of toxic and hazardous chemicals and carcinogens ( $3 \mathrm{~d}$ ed.), Vol. 1 and 2: Park Ridge, N.J., Noyes Publications, 1,685 p. 


\section{Glossary}

Abiotic Pertaining to the nonliving parts of a system.

Abiotic degradation The transformation of a compound without involvement of living organisms.

Advection Transport of contaminants due only to the flow of water.

Aerobic biodegradation The breakdown of organic contaminants by microorganisms when oxygen is present. Aerobic biodegradation also is known as aerobic respiration.

Ambient ground water Untreated ground water that is characteristic of the aquifer resource. Studies of ambient ground water by the NAWQA Program typically exclude contaminated ground water at regulated point-source release sites.

Anoxic Ground water that has no dissolved oxygen or a very low concentration of dissolved oxygen (that is, less than 0.5 milligrams per liter).

Anthropogenic Derived from, or caused by human activity.

Anthropogenic compound A compound that occurs in the environment primarily as a result of human activity.

Aquifer A geologic formation, group of formations, or part of a formation that contains sufficient saturated permeable material (soil, sand, gravel and/or rock) to yield significant quantities of water to wells and springs.

Aquifer sample As used in this report, a water sample collected as part of an aquifer study.

Aquifer study A study to assess the general water quality of an aquifer, a part of an aquifer, or an aquifer system by sampling primarily existing wells. Typically 20 to 30 wells are sampled once. Wells are randomly selected using a stratified, areally distributed design. Wells are distributed over a large area, and the study constitutes a resource assessment.

Assessment level A concentration selected by a hydrologist and applied to water-quality data that have variable laboratory reporting levels either for a specific compound or between individual compounds. The assessment level is applied to data received from the laboratory and is applied subsequent to the laboratory reporting level. Concentrations reported by the laboratory but below the assessment level are considered as "non-detections" in the calculation of occurrence statistics. The primary purpose of the assessment level is for accurate comparison of detection frequencies and median concentrations between individual VOCs, groups of VOCs, and to previous studies.

Atmospheric deposition The process by which chemical constituents are deposited from the atmosphere to the earth's surface by rain, sleet, and snow.

Biodegradation See definition for biotic degradation.
Biotic Pertaining to the living parts of a system.

Biotic degradation As used in this report, the conversion of a parent VOC to a by-product by microorganisms. Also known as biodegradation.

By-product A compound that results from the degradation of another (that is, parent) compound.

Chlorinated solvent An organic compound that contains chlorine and is used in a variety of industrial, commercial, and domestic applications. In general, chlorinated solvents have relatively high densities, relatively high vapor pressures and solubilities, and relatively long half-lives in ground water.

Community water system (CWS) A public water system that supplies water to the same population year-round. A CWS serves a residential population, such as a municipality, mobile home park, or nursing home.

Concentration The amount or mass of a substance present in a given volume or mass of sample. Concentrations in this report generally are expressed in micrograms per liter, but are also expressed in milligrams per liter and nanograms per liter.

Concentration of potential human-health concern As used in this report: (1) for a regulated compound with a U.S. Environmental Protection Agency drinking-water standard, a concentration greater than the Maximum Contaminant Level; and (2) for an unregulated compound, a concentration greater than the Health-Based Screening Level.

Degradation The breakdown of substances like VOCs through abiotic or biotic processes.

Detection frequency The frequency of detection of an individual VOC that was computed as the number of samples with a detection of an individual VOC divided by the number of samples in which the VOC was analyzed, times 100. In most cases, the detection frequency reported in this assessment was computed at a prescribed assessment level.

Detection frequency of VOCs by group The frequency of detection of one or more VOCs from a particular use group that was computed as the number of samples with a detection of one or more VOCs from a particular use group divided by the number of samples analyzed for the particular use group, times 100. In all cases, the detection frequency of VOCs by group was computed at a prescribed assessment level.

Dispersion The process whereby solutes are mixed and spread during advective transport due to velocity variations.

Domestic well A privately owned well that typically serves one home and supplies water for human consumption and other homeowner uses.

Domestic well water Self-supplied water that is withdrawn from a private well and used for human consumption and other 
homeowner uses. Water supplied for domestic wells often is untreated and is not subject to federally enforceable drinkingwater standards.

Drinking water Water for human consumption that meets all applicable Federal, State, and local requirements.

Fifteen most frequently detected VOCs The 15 compounds with the largest detection frequency in samples from aquifers, domestic wells, or public wells, based on samples from all wells and an assessment level of 0.2 microgram per liter.

Fumigant A compound or mixture of compounds that produces a gas, vapor, fumes, or smoke intended to destroy, repel, or control organisms such as insects, bacteria, or rodents. Bromomethane is an example of a fumigant used for large-scale strawberry farming.

Gasoline hydrocarbon A straight, branched, and (or) cyclic structured organic compound containing only carbon and hydrogen atoms that is a common ingredient in gasoline and other petroleum product formulations. Benzene, toluene, ethylbenzene, and xylenes, commonly referred to as BTEX, are a subset of the gasoline hydrocarbons.

Gasoline oxygenate A compound that contains oxygen and was added to gasoline in order to meet the requirements of the 1990 Clean Air Act Amendments. As used in this report, gasoline oxygenates include the four ethers MTBE, TAME, DIPE, and ETBE.

Ground water Water beneath the land surface in the saturated zone.

Half-life The time required for the concentration of a compound in a given environmental medium to be reduced to one-half of its original value by one or more processes, such as degradation or transport into another environmental medium.

Halogenated aliphatic organic compound A compound belonging to a group of compounds that consist of carbon and hydrogen atoms, and any of the five nonmetalic elements including bromine, chlorine, fluorine, iodine, or astatine. Atoms are linked in an open chain.

Health-Based Screening Level (HBSL) An estimate of concentration (for a noncarcinogen) or concentration range (for a carcinogen) in water that (1) may be of potential human-health concern; (2) can be used as a threshold value against which measured concentrations of contaminants in ambient groundwater samples can be compared; and (3) is consistent with USEPA Office of Water methodologies.

Hydric soil Soil that formed under conditions of saturation, flooding, or ponding long enough during the growing season to develop anoxic conditions in the upper part of the soil profile.

Intrinsic susceptibility A measure of the ease with which a contaminant in water enters and moves through an aquifer. It is a characteristic of the aquifer and overlying material and hydrologic conditions, and is independent of the chemical characteristics of the contaminant and its sources.

Laboratory reporting level A level of reporting concentrations of VOCs in a water sample that is set by the laboratory to minimize the rate of false positives and false negatives. Concentrations below the laboratory reporting level are denoted by a less than designation, " $<$," preceding a concentration value.

Lithology The physical character of a rock based on such characteristics as color, structure, mineralogical composition, and grain size.

Low-level (analytical) method A new GC/MS method for the analysis of VOCs in ambient water samples, USGS method 0-4127-96, which was implemented in 1996.

Low-level contamination As used in this report, concentrations of individual VOCs or VOC groups, and total VOC concentrations less than 1 microgram per liter. Although arbitrary, this concentration is approximately the laboratory reporting level for VOCs by many agencies. The USGS lowlevel method identifies VOCs at concentrations 2-3 orders of magnitude below this benchmark.

Maximum Contaminant Level (MCL) As used in this report, a USEPA drinking-water standard that is legally enforceable, and that sets the maximum permissible level of a contaminant in water that is delivered to any user of a public water system.

Maximum Contaminant Level Goal (MCLG) As established by the USEPA, a non-enforceable health goal that is set at a level at which no known or anticipated adverse effect on the health of persons occurs and which allows an adequate margin of safety. ${ }^{(121)}$

Median A compound's concentration for which 50 percent of the laboratory analyses, when arranged in order of magnitude, lie on each side. In this report, this median is based on samples from all wells.

Median (concentrations) of detections A compound's concentration for which 50 percent of the detections, when arranged in order of magnitude, lie on each side. For the 0.02-microgram per liter assessment level, this median for this report is based on the subset of wells for which samples were analyzed by the low-level (analytical) method.

Non-aqueous-phase liquid An organic liquid that can exist in a separate phase in equilibrium with water after the dissolved concentration in water has reached the saturation limit for water.

Occurrence The presence, frequencies of detection, concentrations, and ranges of concentrations of VOCs and the locations (areal patterns) of VOC detections in ground water.

Old ground water As used in this report, ground water recharged prior to 1955 . 
Organic synthesis compound A compound that is used in the formation of other organic compounds. Chloroethene is an example of an organic synthesis compound used in the production of polyvinyl chloride plastics.

0xic Ground water that has a concentration of dissolved oxygen greater than or equal to 0.5 milligrams per liter.

Permeability A measure of the relative ease with which a porous medium can transmit a fluid.

Primary drinking-water standard A regulation that (1) applies to public water systems; (2) specifies contaminants that may have any adverse effect on the health of persons; (3) specifies for each contaminant a maximum contaminant level or treatment technique; and (4) contains criteria and procedures to ensure compliance.

Principal aquifer A regionally extensive aquifer or aquifer system that has the potential to be used as a source of potable water.

Probable human carcinogen Under the USEPA's cancer classification, an agent that is likely to be carcinogenic to humans. ${ }^{(122)}$ Probable human carcinogens also have been expressed as a USEPA cancer "group" and included agents for which the weight of evidence of human carcinogenicity based on epidemiologic studies was limited ("Group B1"), and those for which the weight of evidence of carcinogenicity based on animal studies was "sufficient" ("Group B2"). ${ }^{(121)}$

Public water system (PWS) Any publicly or privately owned water system that provides water for human consumption if such system has 15 connections or regularly serves at least 25 people for at least 60 days out of the year. PWSs include (1) community water systems, such as municipalities, mobile home parks, or nursing homes; (2) transient non-community water systems, such as campgrounds, motels, and gasoline stations; and (3) non-transient, non-community systems, such as schools, factories, and hospitals.

Public well As used in this report, a privately or publicly owned well that provides water to a public water system (PWS).

Public well water As used in this report, water provided by a public water system that is for human consumption and other homeowner uses. Water may be treated or blended prior to distribution.

RCRA Hazardous-Waste Facilities As used in this report, includes treatment, storage, and disposal facilities regulated under the Resource Conservation and Recovery Act.

Recharge The process involved in the addition of water to the saturated zone. Also, the amount of water added.

Redox condition As used in this report, redox condition refers to the position that a system is in for the redox scale between very oxidizing and very reducing.
Reductive dechlorination A reductive process, usually mediated by bacteria, in which chlorine atoms on a chlorinated aliphatic hydrocarbon are replaced sequentially with hydrogen. Also known as dehalogenation, hydrogenolysis, and hydrogenolytic dehalogenation.

Reformulated Gasoline (RFG) Program A program applied to an area established under the Clean Air Act Amendments in which gasoline contained 2 percent oxygen by weight yearround to control levels of tropospheric ozone.

Refrigerant A compound used for producing refrigeration, either as a working substance in a refrigerator or by direct absorption of heat. The chlorofluorocarbons (CFCs) are classified as refrigerants for the purposes of this report.

Regulated compound As used in this report, a compound for which a Federal drinking-water standard has been established.

Respiration The metabolic processes whereby certain organisms obtain energy from organic molecules.

Rural area An area that has a population density of less than 386 persons $/ \mathrm{km}^{2}$ (1,000 persons $/ \mathrm{mi}^{2}$ or 1.56 persons/acre).

Saturated zone The region in the subsurface in which all the interstices or voids are filled with water under a pressure exceeding that of the atmosphere.

Shallow ground-water study An investigation of the concentrations and distribution of water-quality constituents in recently recharged ground water (generally less than 10 years old) associated with a particular land use. For each study, usually about 20-30 shallow monitoring wells are sampled.

Solvent A compound that is used to dissolve other substances. Two of the more common solvents are trichloroethene (TCE) and perchloroethene (PCE).

Sorption The interaction, through binding or association, of a solute ion or molecule with a solid.

Source of contamination Includes any natural or anthropogenic chemical or physical property of the ground-water resource that is not desirable from a health or other perspective such as interference with water-treatment practices.

Study Unit A major hydrologic system of the United States in which NAWQA studies are focused, geographically defined by surface- or ground-water features and usually encompassing more than $10,000 \mathrm{~km}^{2}$ of land area. The NAWQA studies during the first decade of assessments included 51 of these systems, collectively covering a large part of the Nation, encompassing the majority of population and water use, and including diverse hydrologic settings that differ widely in the natural and human factors that affect water quality.

Study-Unit investigation The systematic study of water quality in a NAWQA Study Unit. Study Units are organized into three groups that are studied on a rotational schedule, with 3 -year intensive study periods repeated about every decade.

Susceptibility See definition for intrinsic susceptibility. 
Total trihalomethane concentration The sum of all quantified concentrations for bromodichloromethane, bromoform, chloroform, and dibromochloromethane in a water sample.

Total VOC concentration The sum of all quantified concentrations for all VOCs analyzed in a sample.

Total xylene concentration The sum of all quantified concentrations for $m$-xylene, $o$-xylene, and $p$-xylene in a water sample.

Trihalomethane (THM) As used in this report, a compound belonging to a group of VOCs that includes bromodichloromethane, bromoform, chloroform, and dibromochloromethane. These compounds are known by-products of water chlorination.

Unregulated compound As used in this report, a compound for which no Federal drinking-water standard has been established. Note that a compound that is unregulated under the Safe Drinking Water Act may be regulated in other contexts and under other statutes.

Unsaturated zone The subsurface region above the water table in which the pore spaces may contain a combination of air and water.

Urban area An area that has a population density of 386 persons $/ \mathrm{km}^{2}$ (1,000 persons $/ \mathrm{mi}^{2}$ or 1.56 persons/acre) or greater.

VOC mixture The co-occurrence of two or more VOCs in a water sample.

Volatile organic compound (VOC) An organic chemical that has a high vapor pressure relative to its water solubility. VOCs include components of gasoline, fuel oils, and lubricants, as well as organic solvents, fumigants, some inert ingredients in pesticides, refrigerants, some compounds used in organic synthesis, and some by-products of water chlorination.

Vulnerability The tendency or likelihood for contaminants to reach a specified position in the ground-water system after introduction at some location above the uppermost aquifer. The vulnerability of a ground-water resource to contamination depends on its intrinsic susceptibility as well as the locations and types of sources of naturally occurring and anthropogenic contamination, relative location of wells, and the fate and transport of the contaminant(s). As used in this report, an aquifer is considered vulnerable if at least one VOC was detected in aquifer samples.

Well sample As used in this report, water collected (prior to treatment and blending) from a domestic or public well built into or drilled into the zone of saturation.

Young ground water As used in this report, ground water recharged after 1955. 


\section{Appendixes}

\section{Appendix 1. Key to NAWQA Study Units that Completed Aquifer Studies for VOCs}

\begin{tabular}{|c|c|c|c|}
\hline ACAD & Acadian-Pontchartrain Drainages & OAHU & Oahu \\
\hline ACFB & Apalachicola-Chattahoochee-Flint River & OKLA & Oklahoma Ground-Water Pilot Study \\
\hline & & OZRK & Ozark Plateaus \\
\hline ALBE & Albemarle-Pamlico Drainage Basin & PUGT & Puget Sound Basin \\
\hline ALMN & Allegheny and Monongahela River Basin & REDN & Red River of the North Basin \\
\hline CAZB & Central Arizona Basins & RIOG & Rio Grande Valley \\
\hline СCPT & Central Columbia Plateau & SACR & Sacramento River Basin \\
\hline CNBR & Central Nebraska Basins & SANA & Santa Ana Basin \\
\hline CONN & $\begin{array}{l}\text { Connecticut, Housatonic, and Thames River } \\
\text { Basins }\end{array}$ & SANJ & San Joaquin-Tulare Basins \\
\hline $\mathrm{COOK}$ & Cook Inlet Basin & SANT & Santee River Basin and Coastal Drainages \\
\hline DELR & Delaware River Basin & SCTX & South-Central Texas \\
\hline DLMV & Delmarva Peninsula & SOFL & Southern Florida \\
\hline EIWA & Eastern Iowa Basins & SPLT & South Platte River Basin \\
\hline GAFL & Georgia-Florida Coastal Plain & TRIN & Trinity River Basin \\
\hline GRSL & Great Salt Lake Basins & UCOL & Upper Colorado River Basin \\
\hline HDSN & Hudson River Basin & UIRB & Upper Illinois River Basin \\
\hline HPGW & High Plains Regional Ground Water Study & UMIS & Upper Mississippi River Basin \\
\hline KANA & Kanawha-New River Basins & USNK & Upper Snake River Basin \\
\hline LERI & Lake Erie-Lake Saint Clair Drainages & UTEN & Upper Tennessee River Basin \\
\hline LINJ & Long Island-New Jersey Coastal Drainages & WILL & Willamette Basin \\
\hline LIRB & Lower Illinois River Basin & WMIC & Western Lake Michigan Drainages \\
\hline LSUS & Lower Susquehanna River Basin & YELL & Yellowstone River Basin \\
\hline LTEN & Lower Tennessee River Basin & & \\
\hline MIAM & Great and Little Miami River Basins & & \\
\hline MISE & Mississippi Embayment & & \\
\hline MOBL & Mobile River Basin & & \\
\hline NECB & New England Coastal Basins & & \\
\hline NROK & Northern Rockies Intermontane Basins & & \\
\hline NVBR & Nevada Basin and Range & & \\
\hline
\end{tabular}




\section{Appendix 2. Abbreviations and Acronyms}

\begin{tabular}{|c|c|}
\hline $\mathrm{Bgal} / \mathrm{d}$ & billion gallons per day \\
\hline $\mathrm{km}$ & kilometer \\
\hline$\mu \mathrm{g} / \mathrm{L}$ & micrograms per liter \\
\hline BTEX & Benzene, Toluene, Ethylbenzene, and Xylenes \\
\hline CAAA & Clean Air Act Amendments \\
\hline CAS & Chemical Abstract Services \\
\hline $\mathrm{CCL}$ & Drinking-Water Candidate Contaminant List \\
\hline CFC-11 & Trichlorofluoromethane \\
\hline CFC-12 & Dichlorodifluoromethane \\
\hline CFC-113 & Trichlorotrifluoroethane \\
\hline CWS & Community Water System \\
\hline $\mathrm{DBCP}$ & Dibromochloropropane \\
\hline DCA & Dichloroethane \\
\hline DCE & Dichloroethene \\
\hline DIPE & Diisopropyl Ether \\
\hline EDB & Ethylene Dibromide \\
\hline ETBE & Ethyl tert-Butyl Ether \\
\hline GC/MS & Gas Chromatography/Mass Spectrometry \\
\hline HBSL & Health-Based Screening Level \\
\hline HCFC-22 & Hydrochlorofluorocarbon-22 \\
\hline IUPAC & $\begin{array}{l}\text { International Union of Pure and Applied } \\
\text { Chemistry }\end{array}$ \\
\hline LUST & Leaking Underground Storage Tank \\
\hline MCL & Maximum Contaminant Level \\
\hline MCLG & Maximum Contaminant Level Goal \\
\hline MTBE & Methyl tert-Butyl Ether \\
\hline NAWQA & $\begin{array}{l}\text { U.S. Geological Survey National Water- } \\
\text { Quality Assessment Program }\end{array}$ \\
\hline NTNCWS & $\begin{array}{l}\text { Non-Transient, Non-Community Water } \\
\text { System }\end{array}$ \\
\hline NCWS & Non-Community Water System \\
\hline PCE & Perchloroethene \\
\hline PWS & Public Water System \\
\hline
\end{tabular}

RCRA Resource Conservation and Recovery Act

RFG Reformulated Gasoline

SDWA Safe Drinking Water Act

TAME tert-Amyl Methyl Ether

TCA 1,1,1-Trichloroethane

TCE Trichloroethene

THM Trihalomethane (includes bromodichloromethane, bromoform, chloroform, and dibromochloromethane)

TNCWS Transient, Non-Community Water System

TTHM Total Trihalomethane

UCM Unregulated Contaminant Monitoring

USEPA U.S. Environmental Protection Agency

USGS U.S. Geological Survey

UST Underground Storage Tank

VOC Volatile Organic Compound 


\section{Appendix 3. Additional Information on the Approach of this Assessment}

The following maps show the locations of wells sampled in aquifer studies (fig. 33) and of domestic wells (fig. 34) and public wells (fig. 35) sampled for this national assessment of VOCs. The VOC occurrence information from these wells came from three sources: (1) the NAWQA Program that sampled aquifers throughout the United States from 1993 to 2002; (2) local, State, and Federal agencies that sampled aquifers in various parts of the United States from 1985 to 1997 (referred to as retrospective data); and (3) a collaborative study by several entities including the USGS, that sampled ground waters used by community water systems throughout the United States from 1999 to 2000.

Various criteria were used to select wells for inclusion in this assessment including: study type, number of wells in the study, intended purpose of the sample, minimum number of compounds analyzed in each well sample, analytical method, laboratory reporting levels, and minimum distance between wells. Additional information on the sources of the data and the procedures used to select wells can be found elsewhere. ${ }^{(19)}$

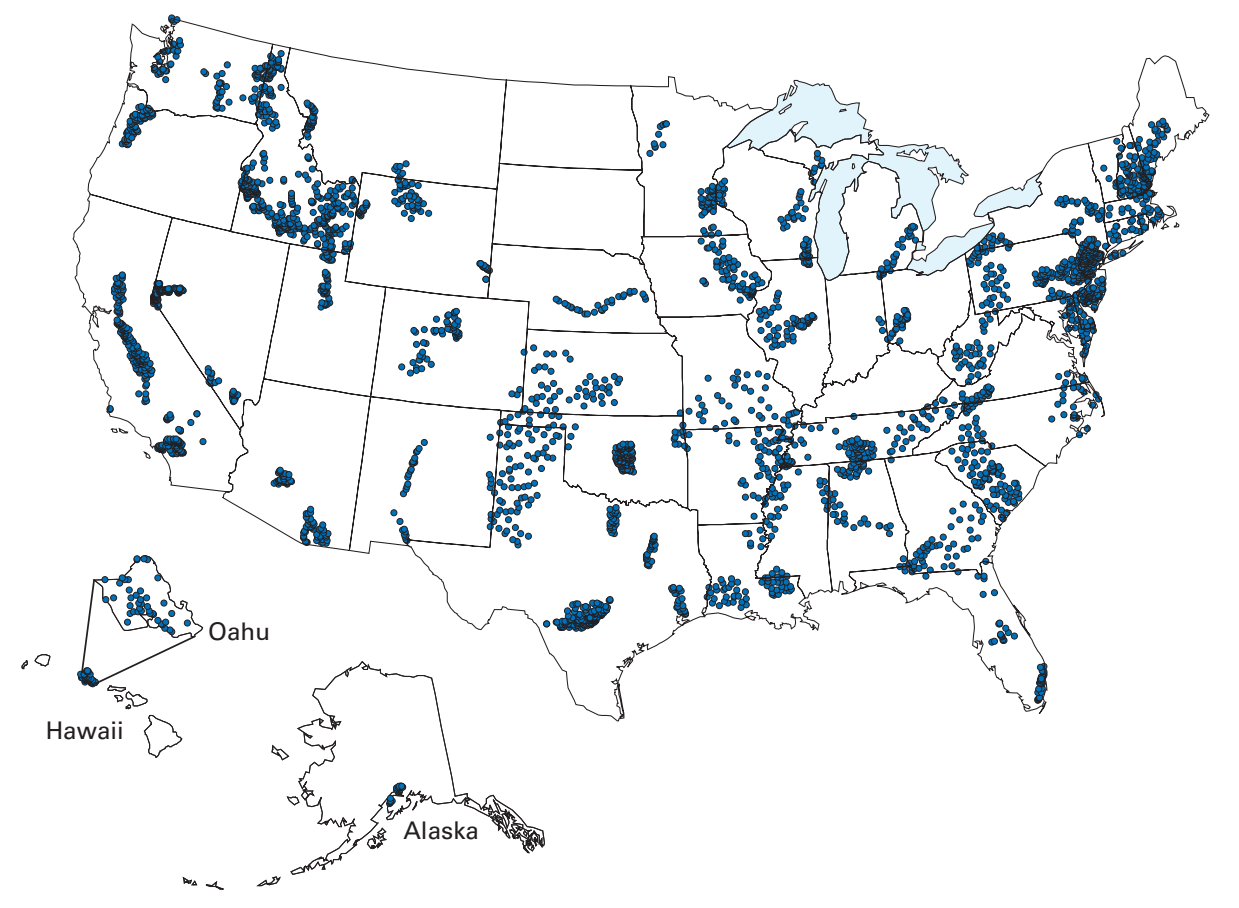

Figure 33. Locations of wells sampled in aquifer studies for the national assessment of VOCs. 


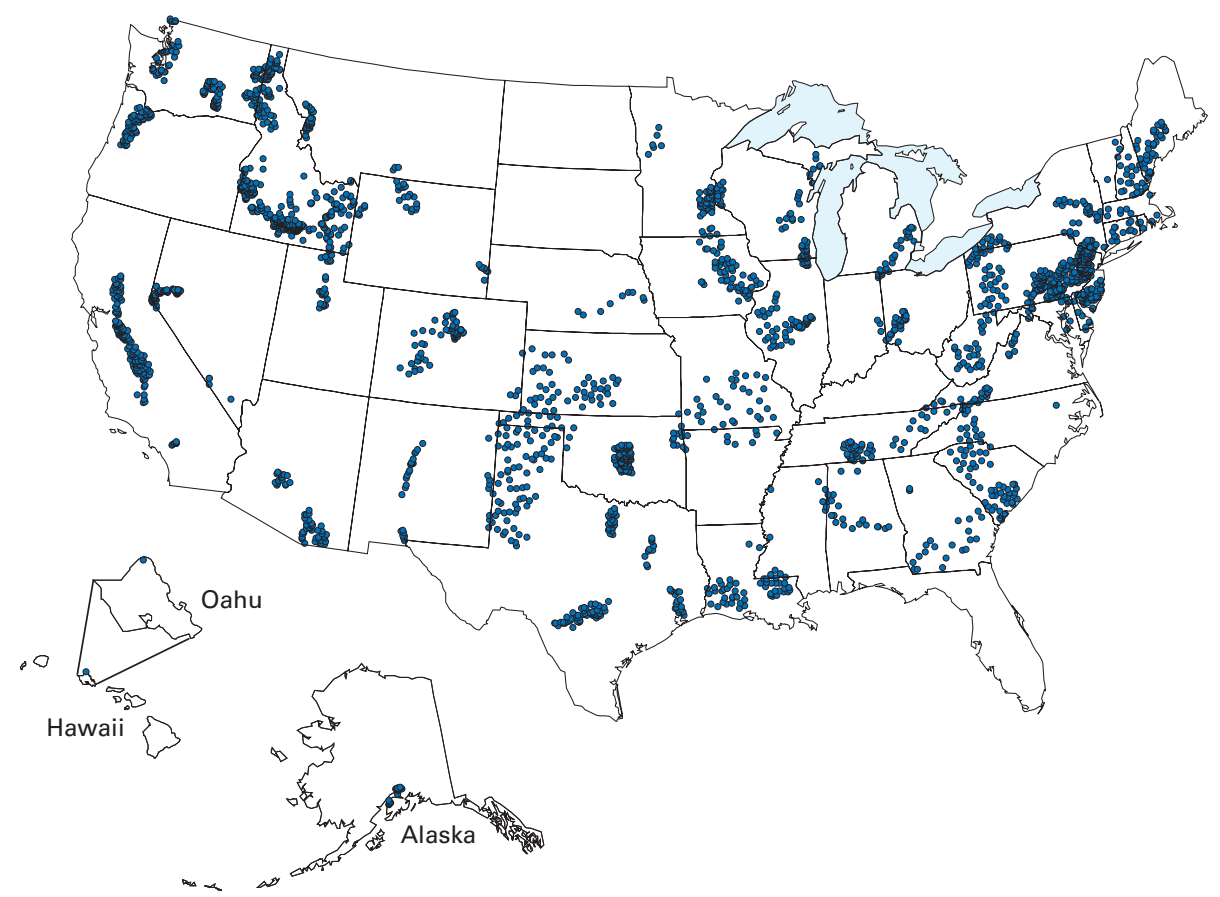

Figure 34. Locations of domestic wells sampled for the national assessment of VOCs.

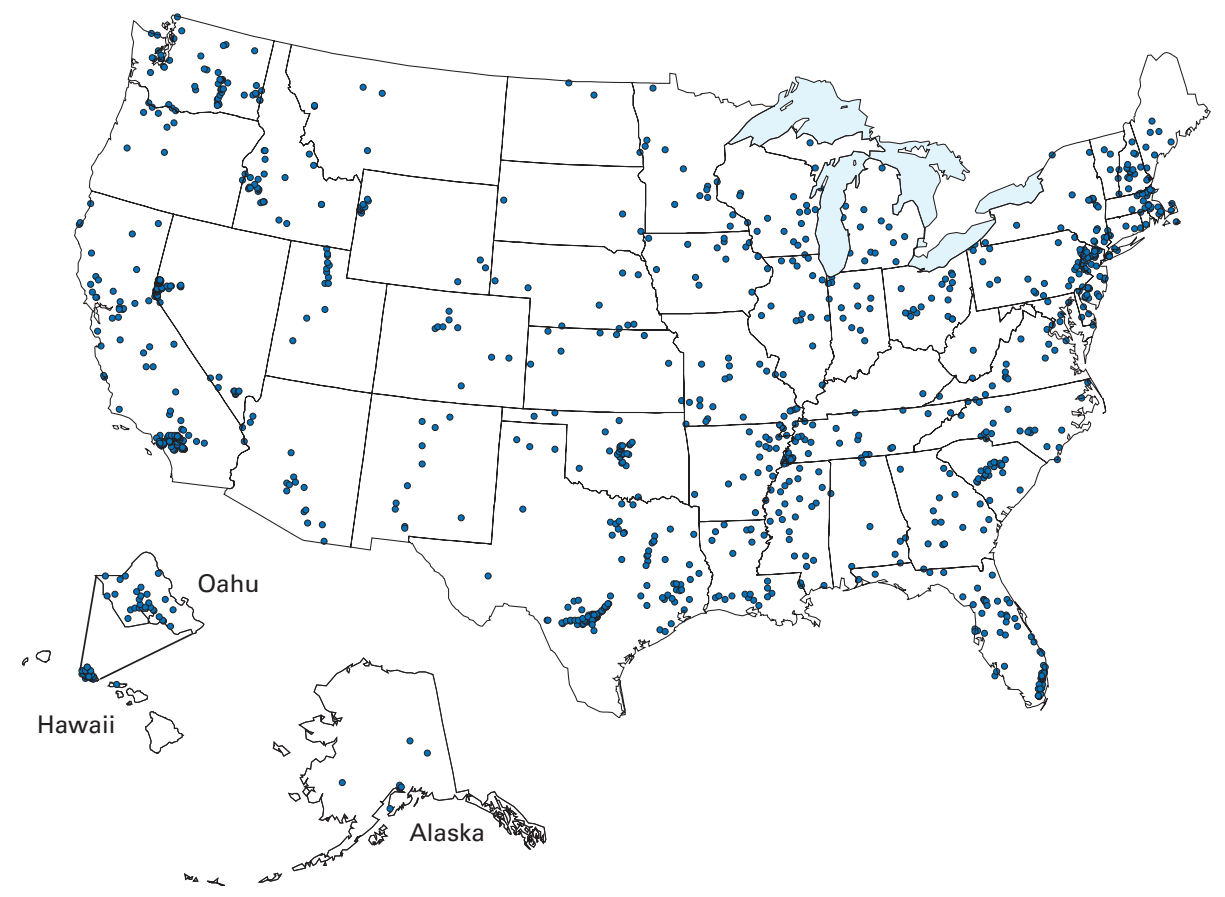

Figure 35. Locations of public wells sampled for the national assessment of VOCs. 
Appendix 4. Compound names used in this report, International Union of Pure and Applied Chemistry (IUPAC) names, Chemical Abstract Service (CAS) numbers, predominant use group, and other use information in alphabetical order.

[--, not applicable or no information available]

\begin{tabular}{|c|c|c|c|c|}
\hline Compound name & $\begin{array}{l}\text { IUPAC name } \\
\text { (If different from } \\
\text { this report's } \\
\text { name) }\end{array}$ & CAS number & $\begin{array}{l}\text { Predominant use } \\
\text { group (or source) }\end{array}$ & $\begin{array}{l}\text { Other uses as parent compound } \\
\text { or additive and remarks }{ }^{1}\end{array}$ \\
\hline Acrolein & 2-Propenal & $107-02-8$ & Organic synthesis & $\begin{array}{l}\text { Herbicide; algicide; biocide; leather tanning; } \\
\text { protein supplements in poultry feed }\end{array}$ \\
\hline tert-Amyl methyl ether (TAME) & $\begin{array}{l}\text { 2-Methoxy-2- } \\
\text { methylbutane }\end{array}$ & $994-05-8$ & Gasoline oxygenate & -- \\
\hline Bromodichloromethane & -- & $75-27-4$ & $\begin{array}{l}\text { Trihalomethane (chlorina- } \\
\text { tion by-product) }\end{array}$ & Organic synthesis \\
\hline Bromoform & $\begin{array}{l}\text { Tribromo- } \\
\text { methane }\end{array}$ & $75-25-2$ & $\begin{array}{l}\text { Trihalomethane (chlorina- } \\
\text { tion by-product) }\end{array}$ & $\begin{array}{l}\text { Solvent; pharmaceutical manufacturing; } \\
\text { ingredient of fire resistant chemicals and } \\
\text { gauge fluid }\end{array}$ \\
\hline Bromomethane & -- & $74-83-9$ & Fumigant & Chemical intermediate; solvent \\
\hline$n$-Butylbenzene & -- & $104-51-8$ & Gasoline hydrocarbon & -- \\
\hline
\end{tabular}

\begin{tabular}{|c|c|c|c|c|}
\hline Carbon tetrachloride & $\begin{array}{c}\text { Tetrachloro- } \\
\text { methane }\end{array}$ & $56-23-5$ & Solvent & $\begin{array}{l}\text { Manufacture of chlorofluorocarbons; dry } \\
\text { cleaning; fire extinguishers; organic syn- } \\
\text { thesis; agriculture }\end{array}$ \\
\hline
\end{tabular}

\begin{tabular}{|c|c|c|c|c|}
\hline Chloroethane & -- & $75-00-3$ & Solvent & $\begin{array}{l}\text { Used in the production of tetraethyl lead } \\
\text { for gasoline, cellulose, chemicals, and } \\
\text { pharmaceuticals }\end{array}$ \\
\hline Chloromethane & -- & $74-87-3$ & Solvent & $\begin{array}{l}\text { Chemical intermediate for production of } \\
\text { silicones, agricultural chemicals, and } \\
\text { cellulose }\end{array}$ \\
\hline Dibromochloromethane & -- & $124-48-1$ & $\begin{array}{l}\text { Trihalomethane (chlorina- } \\
\text { tion by-product) }\end{array}$ & $\begin{array}{l}\text { Chemical intermediate for manufacture of } \\
\text { aerosol propellants, refrigerants, pesti- } \\
\text { cides, fire extinguishing agents }\end{array}$ \\
\hline
\end{tabular}


Appendix 4. Compound names used in this report, International Union of Pure and Applied Chemistry (IUPAC) names, Chemical Abstract Service (CAS) numbers, predominant use group, and other use information in alphabetical order.-Continued

[--, not applicable or no information available]

\begin{tabular}{|c|c|c|c|c|}
\hline Compound name & $\begin{array}{l}\text { IUPAC name } \\
\text { (If different from } \\
\text { this report's } \\
\text { name) }\end{array}$ & CAS number & $\begin{array}{l}\text { Predominant use } \\
\text { group (or source) }\end{array}$ & $\begin{array}{l}\text { Other uses as parent compound } \\
\text { or additive and remarks }{ }^{1}\end{array}$ \\
\hline Dibromochloropropane (DBCP) & $\begin{array}{l}\text { 1,2-Dibromo-3- } \\
\text { chloropropane }\end{array}$ & $96-12-8$ & Fumigant & $\begin{array}{l}\text { Nematocide; fumigant used until } 1979 \text { ex- } \\
\text { cept on pineapples in Hawaii until } 1985\end{array}$ \\
\hline 1,2-Dichlorobenzene & -- & $95-50-1$ & Solvent & $\begin{array}{l}\text { Intermediate for making herbicides and } \\
\text { insecticides }\end{array}$ \\
\hline 1,3-Dichlorobenzene & -- & $541-73-1$ & Solvent & -- \\
\hline 1,4-Dichlorobenzene & -- & $106-46-7$ & Fumigant & $\begin{array}{l}\text { Insecticide and fungicide; organic synthesis; } \\
\text { garbage and restroom deodorant }\end{array}$ \\
\hline $\begin{array}{l}\text { Dichlorodifluoromethane } \\
\text { (CFC-12) }\end{array}$ & -- & $75-71-8$ & Refrigerant & -- \\
\hline 1,1-Dichloroethane (1,1-DCA) & -- & $75-34-3$ & Solvent & $\begin{array}{l}\text { Manufacture of plastic wrap, adhesives, and } \\
\text { synthetic fiber }\end{array}$ \\
\hline 1,2-Dichloroethane (1,2-DCA) & -- & $107-06-2$ & Solvent & $\begin{array}{l}\text { Chemical intermediate for manufacture of } \\
\text { vinyl chloride, solvents, and fluorocar- } \\
\text { bons; fumigant; ingredient in paints and } \\
\text { leaded gasoline }\end{array}$ \\
\hline 1,1-Dichloroethene (1,1-DCE) & -- & $75-35-4$ & Organic synthesis & PVC (plastics); adhesives; refrigerants \\
\hline $\begin{array}{l}\text { cis-1,2-Dichloroethene } \\
\quad \text { (cis-1,2-DCE) }\end{array}$ & -- & $156-59-2$ & Solvent & $\begin{array}{l}\text { Refrigerant; pharmaceutical manufacture; } \\
\text { artificial pearl manufacture; extraction of } \\
\text { fats from fish and meat; organic synthesis }\end{array}$ \\
\hline $\begin{array}{l}\text { trans-1,2-Dichloroethene } \\
\quad(\text { trans-1,2-DCE) }\end{array}$ & -- & $156-60-5$ & Solvent & $\begin{array}{l}\text { Refrigerant; pharmaceutical manufacture; } \\
\text { artificial pearl manufacture; extraction of } \\
\text { fats from fish and meat; organic synthesis }\end{array}$ \\
\hline 1,2-Dichloropropane & -- & $78-87-5$ & Fumigant & $\begin{array}{l}\text { Organic synthesis; former soil fumigant; } \\
\text { stain remover; ingredient in gasoline }\end{array}$ \\
\hline cis-1,3-Dichloropropene & -- & $10061-01-5$ & Fumigant & Solvent; chemical intermediate \\
\hline
\end{tabular}

\begin{tabular}{|c|c|c|c|c|}
\hline trans-1,3-Dichloropropene & -- & $10061-02-6$ & Fumigant & Solvent; chemical intermediate \\
\hline Diisopropyl ether (DIPE) & $\begin{array}{l}\text { 2,2-Oxybis[pro- } \\
\text { pane] }\end{array}$ & $108-20-3$ & Gasoline oxygenate & $\begin{array}{l}\text { Solvent; chemical intermediate in organic } \\
\text { synthesis }\end{array}$ \\
\hline
\end{tabular}


Appendix 4. Compound names used in this report, International Union of Pure and Applied Chemistry (IUPAC) names, Chemical Abstract Service (CAS) numbers, predominant use group, and other use information in alphabetical order.-Continued

[--, not applicable or no information available]

\begin{tabular}{lllll}
\hline \multicolumn{1}{c}{ Compound name } & $\begin{array}{c}\text { IUPAC name } \\
\text { (If different from } \\
\text { this report's } \\
\text { name) }\end{array}$ & CAS number & $\begin{array}{c}\text { Predominant use } \\
\text { group (or source) }\end{array}$ & $\begin{array}{c}\text { Other uses as parent compound } \\
\text { or additive and remarks }\end{array}$ \\
\hline Ethyl tert-butyl ether (ETBE) & $\begin{array}{c}\text { 2-Ethoxy-2- } \\
\text { methylpropane }\end{array}$ & $637-92-3$ & Gasoline oxygenate & - \\
\hline Ethylbenzene & -- & $100-41-4$ & Gasoline hydrocarbon & Solvent; production of styrene
\end{tabular}

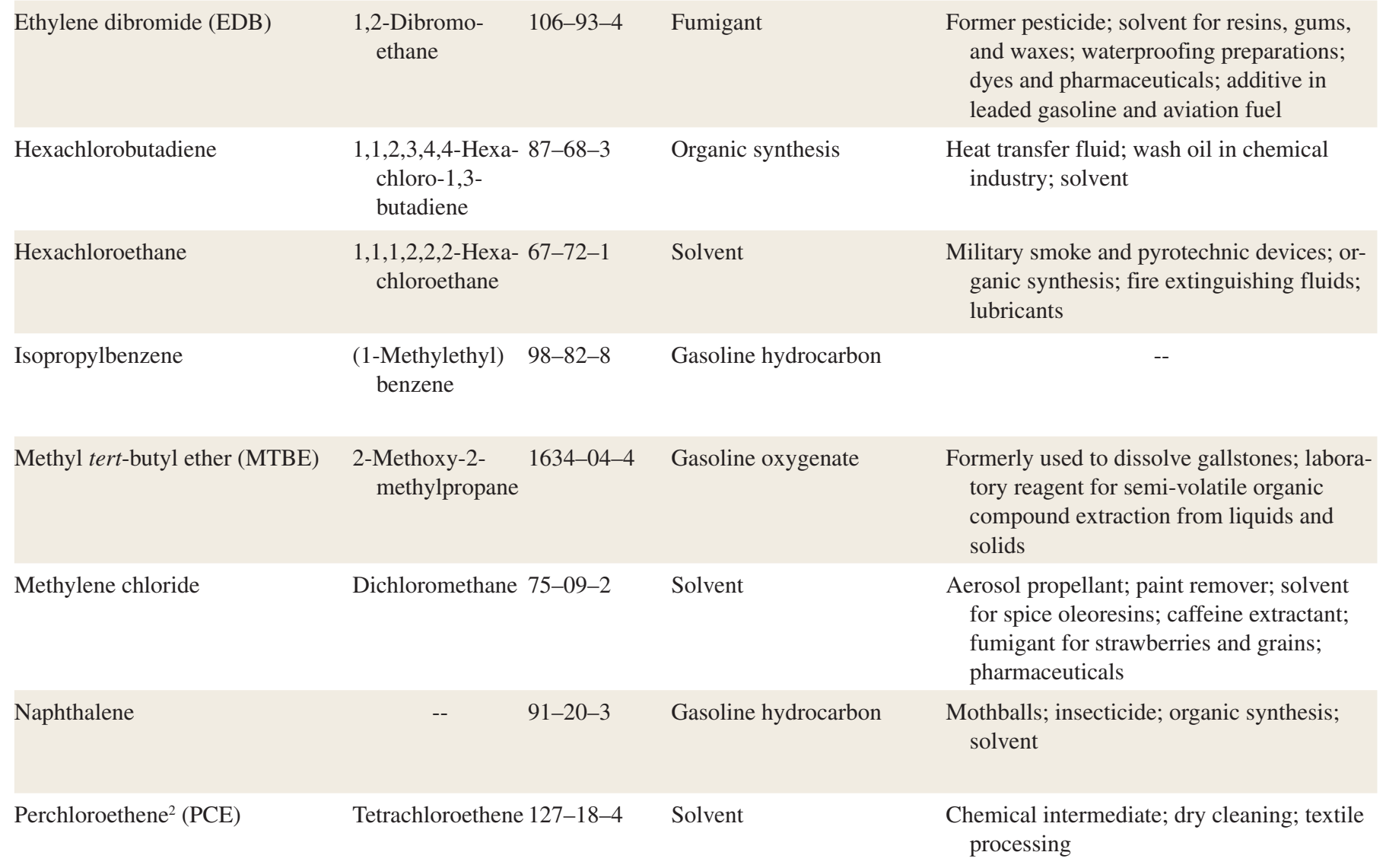

$\begin{array}{lllll}n \text {-Propylbenzene } & -- & 103-65-1 & \text { Solvent } & -- \\ \text { Styrene } & \text { Ethenylbenzene } \quad 100-42-5 \quad \text { Gasoline hydrocarbon } \quad \text { Coatings; paint; rubber; adhesives }\end{array}$

Toluene $\quad$ Methylbenzene $\quad 108-88-3 \quad$ Gasoline hydrocarbon $\quad$ Solvents; production of urethane

1,2,3-Trichlorobenzene $\quad$-- $\quad 87-61-6 \quad$ Organic synthesis


Appendix 4. Compound names used in this report, International Union of Pure and Applied Chemistry (IUPAC) names, Chemical Abstract Service (CAS) numbers, predominant use group, and other use information in alphabetical order.-Continued

[--, not applicable or no information available]

\begin{tabular}{|c|c|c|c|c|}
\hline Compound name & $\begin{array}{l}\text { IUPAC name } \\
\text { (If different from } \\
\text { this report's } \\
\text { name) }\end{array}$ & CAS number & $\begin{array}{l}\text { Predominant use } \\
\text { group (or source) }\end{array}$ & $\begin{array}{l}\text { Other uses as parent compound } \\
\text { or additive and remarks }{ }^{1}\end{array}$ \\
\hline 1,2,4-Trichlorobenzene & -- & $120-82-1$ & Solvent & $\begin{array}{l}\text { Dye carrier; herbicides; wood preservatives; } \\
\text { former soil treatment for termite control }\end{array}$ \\
\hline 1,1,2-Trichloroethane & -- & $79-00-5$ & Solvent & $\begin{array}{l}\text { Manufacture of vinylidene chloride, an } \\
\text { intermediate for making synthetic fibers } \\
\text { and plastic wraps }\end{array}$ \\
\hline $\begin{array}{l}\text { Trichlorofluoromethane } \\
\text { (CFC-11) }\end{array}$ & -- & $75-69-4$ & Refrigerant & Foaming agent; aerosol propellant \\
\hline 1,2,3-Trichloropropane & -- & $96-18-4$ & Fumigant & Solvent; degreaser \\
\hline
\end{tabular}

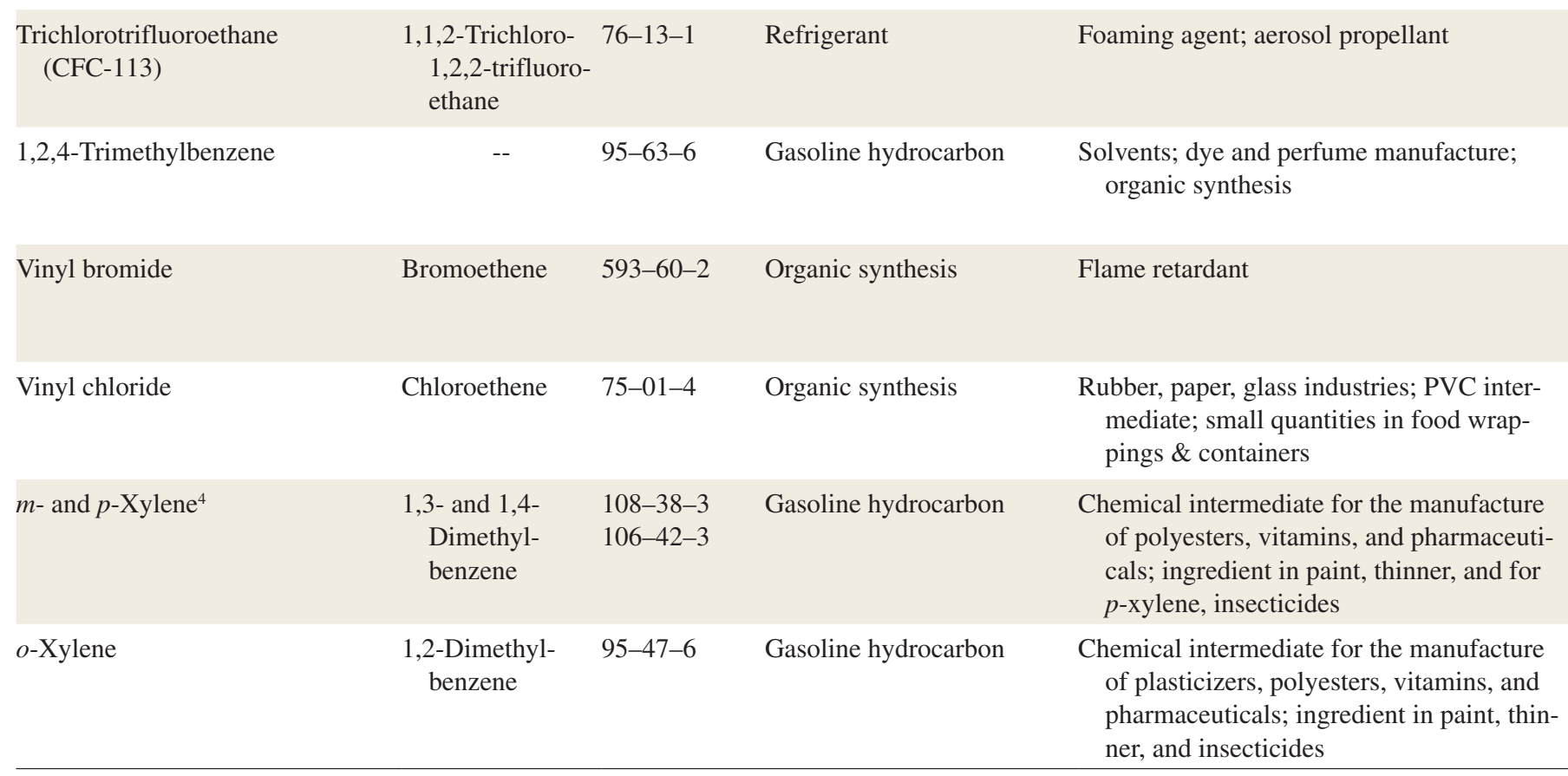

${ }^{1}$ Sources of information on other uses. ${ }^{(123,124,125,126,127,128,129)}$

${ }^{2}$ Also known as tetrachloroethylene, perchloroethylene, and perc.

${ }^{3}$ Also known as trichloroethylene.

${ }^{4}$ Considered as 2 of the 55 compounds included in this assessment. 
Appendix 5. Detection frequency of at least one volatile organic compound (VOC) by principal or other aquifer and by aquifer study at two assessment levels (in order of overall decreasing detection frequency).

$[\mu \mathrm{g} / \mathrm{L}$, micrograms per liter; --, not applicable; US\&G, unconsolidated sand and gravel; S Sand, sand and (or) semiconsolidated sand; Carb, carbonate rocks; B\&V, basaltic and (or) volcanic rocks; SS, sandstone; Cryst, crystalline rocks; SS\&Carb, sandstone and carbonate rocks; ND, no detections]

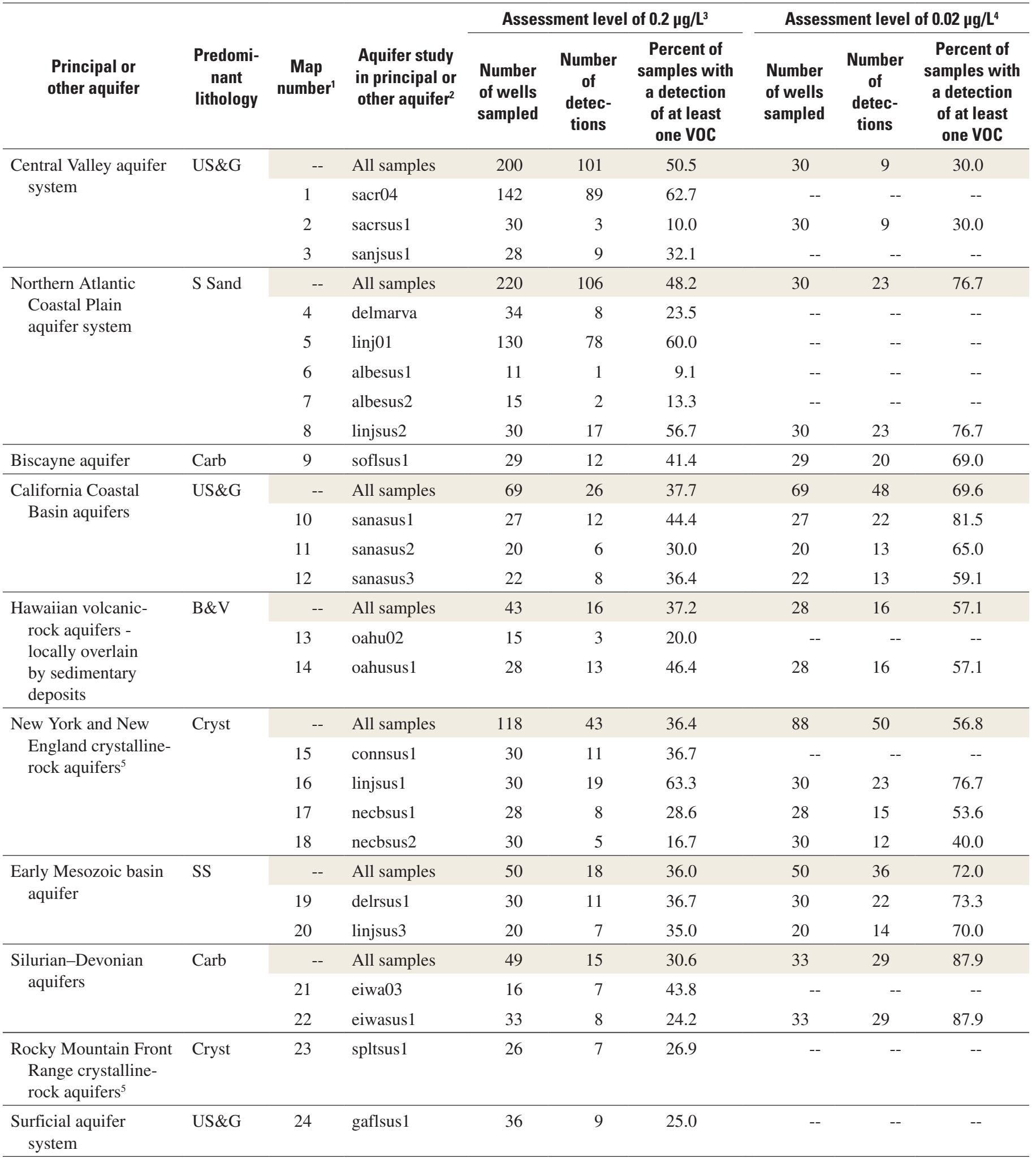


Appendix 5. Detection frequency of at least one volatile organic compound (VOC) by principal or other aquifer and by aquifer study at two assessment levels (in order of overall decreasing detection frequency).-Continued

[ $\mu \mathrm{g} / \mathrm{L}$, micrograms per liter; --, not applicable; US\&G, unconsolidated sand and gravel; S Sand, sand and (or) semiconsolidated sand; Carb, carbonate rocks; B\&V, basaltic and (or) volcanic rocks; SS, sandstone; Cryst, crystalline rocks; SS\&Carb, sandstone and carbonate rocks; ND, no detections]

\begin{tabular}{|c|c|c|c|c|c|c|c|c|c|}
\hline \multirow[b]{2}{*}{$\begin{array}{l}\text { Principal or } \\
\text { other aquifer }\end{array}$} & \multirow[b]{2}{*}{$\begin{array}{l}\text { Predomi- } \\
\text { nant } \\
\text { lithology }\end{array}$} & \multirow[b]{2}{*}{$\begin{array}{c}\text { Map } \\
\text { number }^{1}\end{array}$} & \multirow[b]{2}{*}{$\begin{array}{l}\text { Aquifer study } \\
\text { in principal or } \\
\text { other aquifer }^{2}\end{array}$} & \multicolumn{3}{|c|}{ Assessment level of $0.2 \mu \mathrm{g} / \mathrm{L}^{3}$} & \multicolumn{3}{|c|}{ Assessment level of $0.02 \mu \mathrm{g} / \mathrm{L}^{4}$} \\
\hline & & & & $\begin{array}{l}\text { Number } \\
\text { of wells } \\
\text { sampled }\end{array}$ & $\begin{array}{c}\text { Number } \\
\text { of } \\
\text { detec- } \\
\text { tions }\end{array}$ & $\begin{array}{l}\text { Percent of } \\
\text { samples with } \\
\text { a detection } \\
\text { of at least } \\
\text { one VOC }\end{array}$ & $\begin{array}{l}\text { Number } \\
\text { of wells } \\
\text { sampled }\end{array}$ & $\begin{array}{c}\text { Number } \\
\text { of } \\
\text { detec- } \\
\text { tions }\end{array}$ & $\begin{array}{l}\text { Percent of } \\
\text { samples with } \\
\text { a detection } \\
\text { of at least } \\
\text { one VOC }\end{array}$ \\
\hline \multirow{2}{*}{$\begin{array}{l}\text { Ozark Plateaus } \\
\text { aquifer system }\end{array}$} & \multirow[t]{2}{*}{ Carb } & -- & All samples & 49 & 12 & 24.5 & -- & -- & -- \\
\hline & & 26 & ozrksus3a & 16 & 4 & 25.0 & -- & -- & -- \\
\hline Mississippian aquifers & SS\&Carb & 27 & ltensus $1^{6}$ & 32 & 6 & 18.8 & 32 & 23 & 71.9 \\
\hline \multirow{2}{*}{$\begin{array}{l}\text { Coastal Lowlands } \\
\text { aquifer system }\end{array}$} & \multirow[t]{2}{*}{ S Sand } & -- & All samples & 81 & 15 & 18.5 & 57 & 29 & 50.9 \\
\hline & & 28 & acadsus1 & 29 & 3 & 10.3 & 29 & 10 & 34.5 \\
\hline \multirow{7}{*}{$\begin{array}{l}\text { Other sand and gravel } \\
\text { aquifers }^{5}\end{array}$} & \multirow[t]{7}{*}{ US\&G } & -- & All samples & 142 & 25 & 17.6 & 53 & 28 & 52.8 \\
\hline & & 32 & mise 07 & 30 & 2 & 6.7 & -- & -- & -- \\
\hline & & 33 & sofl03 & 13 & 10 & 76.9 & -- & -- & -- \\
\hline & & 34 & yell01 & 19 & 2 & 10.5 & -- & -- & -- \\
\hline & & 35 & cnbrsus2 & 27 & 2 & 7.4 & -- & -- & -- \\
\hline & & 36 & ucolsus1 & 29 & 2 & 6.9 & 29 & 11 & 37.9 \\
\hline & & 37 & yellsus1 & 24 & 7 & 29.2 & 24 & 17 & 70.8 \\
\hline \multirow{2}{*}{$\begin{array}{l}\text { Edwards-Trinity } \\
\text { aquifer system }\end{array}$} & \multirow{2}{*}{ SS\&Carb } & 42 & sctxsus3 & 29 & 4 & 13.8 & 29 & 11 & 37.9 \\
\hline & & 43 & trinsus 1 & 24 & 1 & 4.2 & -- & -- & -- \\
\hline \multirow{9}{*}{$\begin{array}{l}\text { Glacial deposit } \\
\text { aquifers }^{7}\end{array}$} & \multirow[t]{9}{*}{ US\&G } & -- & All samples & 367 & 56 & 15.3 & 253 & 146 & 57.7 \\
\hline & & 44 & nneb05 & 69 & 15 & 21.7 & -- & -- & -- \\
\hline & & 45 & almnsus2 & 30 & 3 & 10.0 & 30 & 12 & 40.0 \\
\hline & & 46 & delrsus3 & 16 & 2 & 12.5 & 16 & 6 & 37.5 \\
\hline & & 47 & eiwasus2 & 32 & 1 & 3.1 & 32 & 16 & 50.0 \\
\hline & & 48 & hdsnsus 1 & 35 & 2 & 5.7 & -- & -- & -- \\
\hline & & 49 & lerisus1 & 28 & 2 & 7.1 & 28 & 3 & 10.7 \\
\hline & & 50 & lirbsus1 & 30 & ND & ND & 30 & 16 & 53.3 \\
\hline & & 51 & lirbsus2 & 30 & 8 & 26.7 & 30 & 26 & 86.7 \\
\hline
\end{tabular}


Appendix 5. Detection frequency of at least one volatile organic compound (VOC) by principal or other aquifer and by aquifer study at two assessment levels (in order of overall decreasing detection frequency).-Continued

$[\mu \mathrm{g} / \mathrm{L}$, micrograms per liter; --, not applicable; US\&G, unconsolidated sand and gravel; S Sand, sand and (or) semiconsolidated sand; Carb, carbonate rocks; B\&V, basaltic and (or) volcanic rocks; SS, sandstone; Cryst, crystalline rocks; SS\&Carb, sandstone and carbonate rocks; ND, no detections]

\begin{tabular}{|c|c|c|c|c|c|c|c|c|c|}
\hline \multirow[b]{2}{*}{$\begin{array}{l}\text { Principal or } \\
\text { other aquifer }\end{array}$} & \multirow[b]{2}{*}{$\begin{array}{l}\text { Predomi- } \\
\text { nant } \\
\text { lithology }\end{array}$} & \multirow[b]{2}{*}{$\begin{array}{c}\text { Map } \\
\text { number }\end{array}$} & \multirow[b]{2}{*}{$\begin{array}{l}\text { Aquifer study } \\
\text { in principal or } \\
\text { other aquifer }^{2}\end{array}$} & \multicolumn{3}{|c|}{ Assessment level of $0.2 \mu \mathrm{g} / \mathrm{L}^{3}$} & \multicolumn{3}{|c|}{ Assessment level of $0.02 \mu \mathrm{g} / \mathrm{L}^{4}$} \\
\hline & & & & $\begin{array}{l}\text { Number } \\
\text { of wells } \\
\text { sampled }\end{array}$ & $\begin{array}{c}\text { Number } \\
\text { of } \\
\text { detec- } \\
\text { tions }\end{array}$ & $\begin{array}{c}\text { Percent of } \\
\text { samples with } \\
\text { a detection } \\
\text { of at least } \\
\text { one VOC }\end{array}$ & $\begin{array}{l}\text { Number } \\
\text { of wells } \\
\text { sampled }\end{array}$ & $\begin{array}{l}\text { Number } \\
\text { of } \\
\text { detec- } \\
\text { tions }\end{array}$ & $\begin{array}{c}\text { Percent of } \\
\text { samples with } \\
\text { a detection } \\
\text { of at least } \\
\text { one VOC }\end{array}$ \\
\hline \multirow{4}{*}{$\begin{array}{l}\text { Glacial deposit } \\
\text { aquifers }{ }^{7}- \\
\text { Continued }\end{array}$} & & 52 & miamsus1 & 30 & 6 & 20.0 & 30 & 19 & 63.3 \\
\hline & & 53 & necbsus3 & 30 & 13 & 43.3 & 30 & 28 & 93.3 \\
\hline & & 54 & rednsus2 & 10 & 4 & 40.0 & -- & -- & -- \\
\hline & & 55 & uirbsus 1 & 27 & ND & ND & 27 & 20 & 74.1 \\
\hline \multirow{9}{*}{$\begin{array}{l}\text { Basin and Range } \\
\text { basin-fill aquifers }\end{array}$} & US\&G & -- & All samples & 328 & 46 & 14.0 & 127 & 50 & 39.4 \\
\hline & & 56 & carson & 148 & 18 & 12.2 & -- & -- & -- \\
\hline & & 57 & cazbsus1a & 30 & 2 & 6.7 & 30 & 13 & 43.3 \\
\hline & & 58 & cazbsus 2 & 27 & 5 & 18.5 & 27 & 7 & 25.9 \\
\hline & & 59 & cazbsus3 & 18 & ND & ND & 18 & 13 & 72.2 \\
\hline & & 60 & grslsus1 & 52 & 5 & 9.6 & 52 & 17 & 32.7 \\
\hline & & 61 & nvbrsus1 & 21 & 11 & 52.4 & -- & -- & -- \\
\hline & & 62 & nvbrsus 2 & 16 & 5 & 31.2 & -- & -- & -- \\
\hline & & 63 & nvbrsus3 & 16 & ND & ND & -- & -- & -- \\
\hline \multirow[t]{3}{*}{ Pennsylvanian aquifers } & SS & -- & All samples & 60 & 8 & 13.3 & 60 & 32 & 53.3 \\
\hline & & 64 & almnsus1 & 30 & 4 & 13.3 & 30 & 22 & 73.3 \\
\hline & & 65 & kanasus1 & 30 & 4 & 13.3 & 30 & 10 & 33.3 \\
\hline \multirow{3}{*}{$\begin{array}{l}\text { Mississippi River } \\
\text { Valley alluvial } \\
\text { aquifer }\end{array}$} & US\&G & -- & All samples & 54 & 7 & 13.0 & 54 & 28 & 51.9 \\
\hline & & 66 & misesus1 & 29 & 7 & 24.1 & 29 & 17 & 58.6 \\
\hline & & 67 & misesus 3 & 25 & ND & ND & 25 & 11 & 44.0 \\
\hline Ordovician aquifers & Carb & 68 & 1tensus2 & 31 & 4 & 12.9 & 31 & 15 & 48.4 \\
\hline $\begin{array}{l}\text { Columbia Plateau } \\
\text { basaltic-rock } \\
\text { aquifers }\end{array}$ & $\mathrm{B} \& \mathrm{~V}$ & 69 & ccptsus 1 & 32 & 4 & 12.5 & -- & -- & -- \\
\hline \multirow{3}{*}{$\begin{array}{l}\text { Northern Rocky } \\
\text { Mountains Inter- } \\
\text { montane Basins } \\
\text { aquifer system }\end{array}$} & US\&G & -- & All samples & 61 & 7 & 11.5 & 61 & 13 & 21.3 \\
\hline & & 70 & nroksus1 & 31 & 4 & 12.9 & 31 & 7 & 22.6 \\
\hline & & 71 & nroksus2 & 30 & 3 & 10.0 & 30 & 6 & 20.0 \\
\hline \multirow{5}{*}{$\begin{array}{l}\text { Valley and Ridge } \\
\text { aquifers }\end{array}$} & SS\&Carb & -- & All samples & 101 & 11 & 10.9 & 60 & 28 & 46.7 \\
\hline & & 72 & uten02 & 12 & 3 & 25.0 & -- & -- & -- \\
\hline & & 73 & delrsus2 & 30 & 5 & 16.7 & 30 & 11 & 36.7 \\
\hline & & 74 & lsussus 1 & 29 & ND & ND & -- & -- & -- \\
\hline & & 75 & utensus1 & 30 & 3 & 10.0 & 30 & 17 & 56.7 \\
\hline \multirow{4}{*}{$\begin{array}{c}\text { Willamette Lowland } \\
\text { basin-fill aquifers }\end{array}$} & US\&G & -- & All samples & 65 & 7 & 10.8 & -- & -- & -- \\
\hline & & 76 & willlusag1 & 15 & 1 & 6.7 & -- & -- & -- \\
\hline & & 77 & willlusag2 & 25 & 2 & 8.0 & -- & -- & -- \\
\hline & & 78 & willsus1 & 25 & 4 & 16.0 & -- & -- & -- \\
\hline
\end{tabular}


Appendix 5. Detection frequency of at least one volatile organic compound (VOC) by principal or other aquifer and by aquifer study at two assessment levels (in order of overall decreasing detection frequency).-Continued

[ug/L, micrograms per liter; --, not applicable; US\&G, unconsolidated sand and gravel; S Sand, sand and (or) semiconsolidated sand; Carb, carbonate rocks; B\&V, basaltic and (or) volcanic rocks; SS, sandstone; Cryst, crystalline rocks; SS\&Carb, sandstone and carbonate rocks; ND, no detections]

\begin{tabular}{|c|c|c|c|c|c|c|c|c|c|}
\hline \multirow[b]{2}{*}{$\begin{array}{l}\text { Principal or } \\
\text { other aquifer }\end{array}$} & \multirow[b]{2}{*}{$\begin{array}{l}\text { Predomi- } \\
\text { nant } \\
\text { lithology }\end{array}$} & \multirow[b]{2}{*}{$\begin{array}{c}\text { Map } \\
\text { number }\end{array}$} & \multirow[b]{2}{*}{$\begin{array}{l}\text { Aquifer study } \\
\text { in principal or } \\
\text { other aquifer }^{2}\end{array}$} & \multicolumn{3}{|c|}{ Assessment level of $0.2 \mu \mathrm{g} / \mathrm{L}^{3}$} & \multicolumn{3}{|c|}{ Assessment level of $0.02 \mu \mathrm{g} / \mathrm{L}^{4}$} \\
\hline & & & & $\begin{array}{l}\text { Number } \\
\text { of wells } \\
\text { sampled }\end{array}$ & $\begin{array}{l}\text { Number } \\
\text { of } \\
\text { detec- } \\
\text { tions }\end{array}$ & $\begin{array}{l}\text { Percent of } \\
\text { samples with } \\
\text { a detection } \\
\text { of at least } \\
\text { one VOC }\end{array}$ & $\begin{array}{l}\text { Number } \\
\text { of wells } \\
\text { sampled }\end{array}$ & $\begin{array}{c}\text { Number } \\
\text { of } \\
\text { detec- } \\
\text { tions }\end{array}$ & $\begin{array}{l}\text { Percent of } \\
\text { samples with } \\
\text { a detection } \\
\text { of at least } \\
\text { one VOC }\end{array}$ \\
\hline \multirow{3}{*}{$\begin{array}{l}\text { Floridan aquifer } \\
\text { system }\end{array}$} & \multirow[t]{3}{*}{ Carb } & -- & All samples & 56 & 6 & 10.7 & 30 & 4 & 13.3 \\
\hline & & 79 & acfbsus1 & 26 & 4 & 15.4 & -- & -- & -- \\
\hline & & 80 & santsus2 & 30 & 2 & 6.7 & 30 & 4 & 13.3 \\
\hline $\begin{array}{l}\text { Central Oklahoma } \\
\text { aquifer }\end{array}$ & SS & 81 & oklahoma & 120 & 10 & 8.3 & -- & -- & -- \\
\hline \multirow{4}{*}{$\begin{array}{l}\text { Cambrian-Ordovician } \\
\text { aquifer system }\end{array}$} & \multirow[t]{4}{*}{ SS } & -- & All samples & 76 & 6 & 7.9 & 50 & 28 & 56.0 \\
\hline & & 82 & umissus3 & 25 & 3 & 12.0 & 25 & 18 & 72.0 \\
\hline & & 83 & umissus4 & 25 & 1 & 4.0 & 25 & 10 & 40.0 \\
\hline & & 84 & wmicsus 1 & 26 & 2 & 7.7 & -- & -- & -- \\
\hline \multirow{3}{*}{$\begin{array}{l}\text { Mississippi } \\
\text { Embayment-Texas } \\
\text { Coastal Uplands } \\
\text { aquifer system }\end{array}$} & \multirow[t]{3}{*}{ S Sand } & -- & All samples & 52 & 4 & 7.7 & 30 & 14 & 46.7 \\
\hline & & 85 & misesus2 & 30 & 3 & 10.0 & 30 & 14 & 46.7 \\
\hline & & 86 & trinsus2 & 22 & 1 & 4.5 & -- & -- & -- \\
\hline \multirow{4}{*}{$\begin{array}{l}\text { Piedmont and Blue } \\
\text { Ridge crystalline- } \\
\text { rock aquifers }\end{array}$} & \multirow[t]{4}{*}{ Cryst } & -- & All samples & 70 & 5 & 7.1 & 60 & 23 & 38.3 \\
\hline & & 87 & kanasus2 & 30 & 3 & 10.0 & 30 & 12 & 40.0 \\
\hline & & 88 & lsussus2 & 10 & 1 & 10.0 & -- & -- & -- \\
\hline & & 89 & santsus3 & 30 & 1 & 3.3 & 30 & 11 & 36.7 \\
\hline \multirow{3}{*}{$\begin{array}{l}\text { Snake River Plain } \\
\text { basin-fill aquifers }\end{array}$} & \multirow[t]{3}{*}{ US\&G } & -- & All samples & 405 & 17 & 4.2 & -- & -- & -- \\
\hline & & 90 & id01 & 385 & 16 & 4.2 & -- & -- & -- \\
\hline & & 91 & usnksus3 & 20 & 1 & 5.0 & -- & -- & -- \\
\hline $\begin{array}{l}\text { Lower Tertiary } \\
\text { aquifers }\end{array}$ & SS & 92 & yellsus2 & 28 & 1 & 3.6 & 28 & 20 & 71.4 \\
\hline \multirow{3}{*}{$\begin{array}{l}\text { Southeastern Coastal } \\
\text { Plain aquifer system }\end{array}$} & \multirow[t]{3}{*}{ S Sand } & -- & All samples & 57 & 2 & 3.5 & 57 & 24 & 42.1 \\
\hline & & 93 & moblsus1 & 30 & ND & ND & 30 & 7 & 23.3 \\
\hline & & 94 & santsus1 & 27 & 2 & 7.4 & 27 & 17 & 63.0 \\
\hline \multirow[t]{4}{*}{ High Plains aquifer } & \multirow[t]{4}{*}{ US\&G } & -- & All samples & 141 & 4 & 2.8 & 141 & 55 & 39.0 \\
\hline & & 95 & hpgwsus1a & 74 & 1 & 1.4 & 74 & 39 & 52.7 \\
\hline & & 96 & hpgwsus1b & 47 & 2 & 4.3 & 47 & 9 & 19.1 \\
\hline & & 97 & hpgwsus2 & 20 & 1 & 5.0 & 20 & 7 & 35.0 \\
\hline $\begin{array}{l}\text { Rio Grande aquifer } \\
\text { system }\end{array}$ & US\&G & 98 & riogsus1 & 28 & ND & ND & -- & -- & -- \\
\hline
\end{tabular}

${ }^{1}$ The map number refers to a corresponding map on the Circular's Web site.

${ }^{2}$ The name of each aquifer study is unique and can be used to find more detailed information about the aquifer study on the Circular's Web site.

${ }^{3}$ Detection frequencies are for all samples included in this assessment, regardless of the analytical method.

${ }^{4}$ Detection frequencies are for the subset of samples that were analyzed with the U.S. Geological Survey's low-level method 0-4127-96. At this assessment level, detection frequencies are estimates. ${ }^{(19)}$

${ }^{5}$ Other aquifer.

${ }^{6}$ Regolith overlying bedrock.

${ }^{7}$ Sand and gravel aquifers north of the limit of Quaternary continental glaciation and east of the Rocky Mountains. 
Appendix 6. Detection frequencies and median concentrations for selected volatile organic compounds in samples from aquifer studies.

[ $\mu \mathrm{g} / \mathrm{L}$, micrograms per liter; ND, compound not detected; <, less than; --, not applicable]

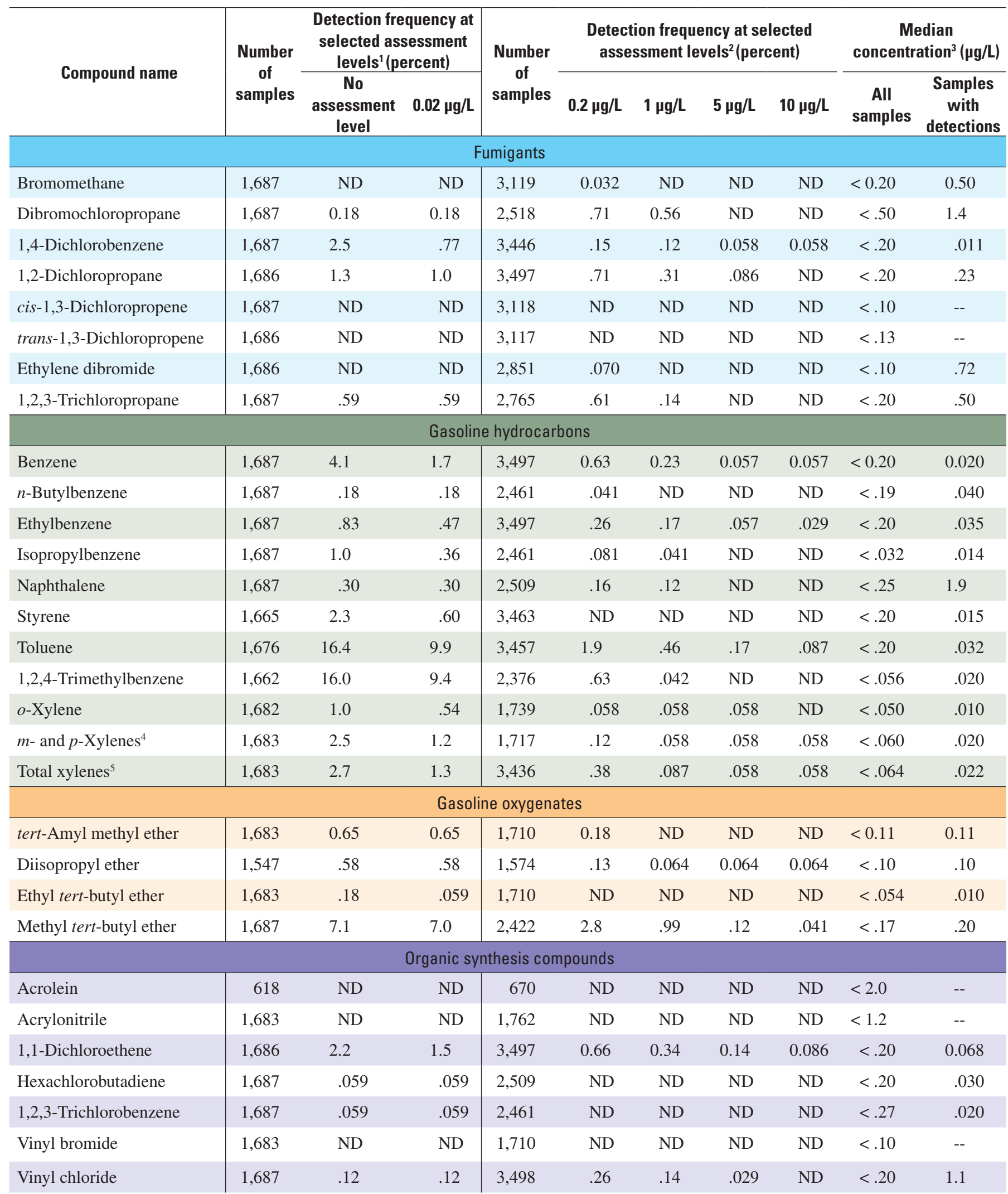


Appendix 6. Detection frequencies and median concentrations for selected volatile organic compounds in samples from aquifer studies.-Continued

[ug/L, micrograms per liter; ND, compound not detected; <, less than; --, not applicable]

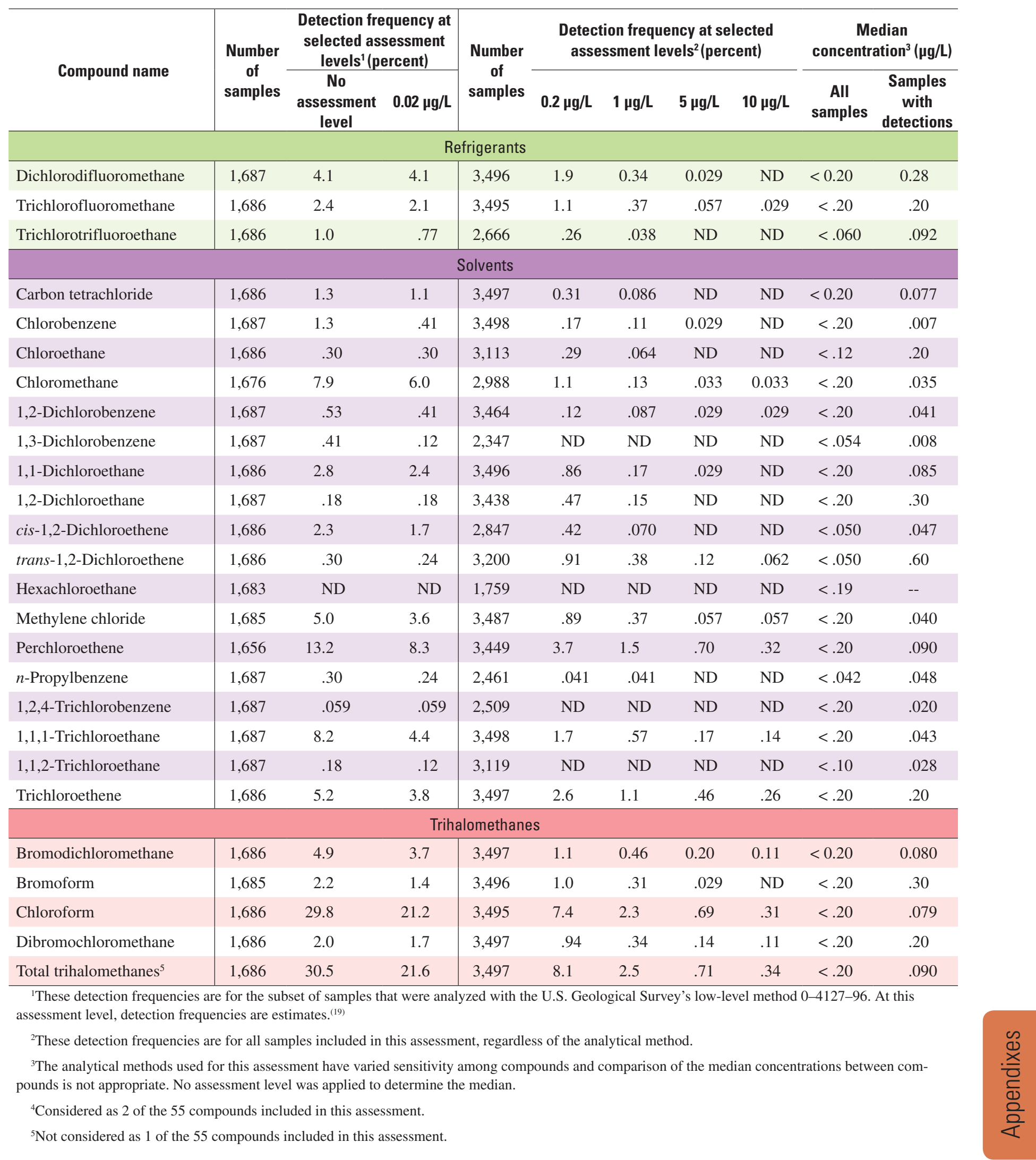


Appendix 7. Concentrations of selected volatile organic compounds (VOCs) in samples of untreated ground water.

\section{EXPLANATION}

+ VOC concentration for a sample-Multiple samples of equal concentration will appear as a single cross. Concentrations are shown for all samples and without the application of an assessment level

Median of concentrations for two or more detections, considering all samples and without the application of an assessment level-Several analytical methods, with differing sensitivity for a specific VOC with time, as well as between VOCs, were used in this assessment. Because of the differing analytical sensitivities, comparison of the median concentrations (shown in the charts) between study type, well type, and VOCs is not appropriate

0.1 Detection frequency, in percent, at an assessment level of $\mathbf{0 . 2}$ microgram per liter-For detection frequency information at other assessment levels refer to Appendixes 6, 8, and 10

1 Number of detections at or above the assessment level of $\mathbf{0 . 2}$ microgram per liter

1,078 Number of samples

Study types

Aquifers

Shallow ground water in urban areas

Shallow ground water in agricultural areas

Ground water supplying domestic and public wells

Domestic wells

Public wells

Domestic and public wells

Drinking-water standards and screening levels

I U.S. Environmental Protection Agency (USEPA) Maximum Contaminant Level (MCL)

| Health-Based Screening Level (HBSL) 
Appendix 7. Concentrations of selected volatile organic compounds (VOCs) in samples of untreated ground water.-Continued
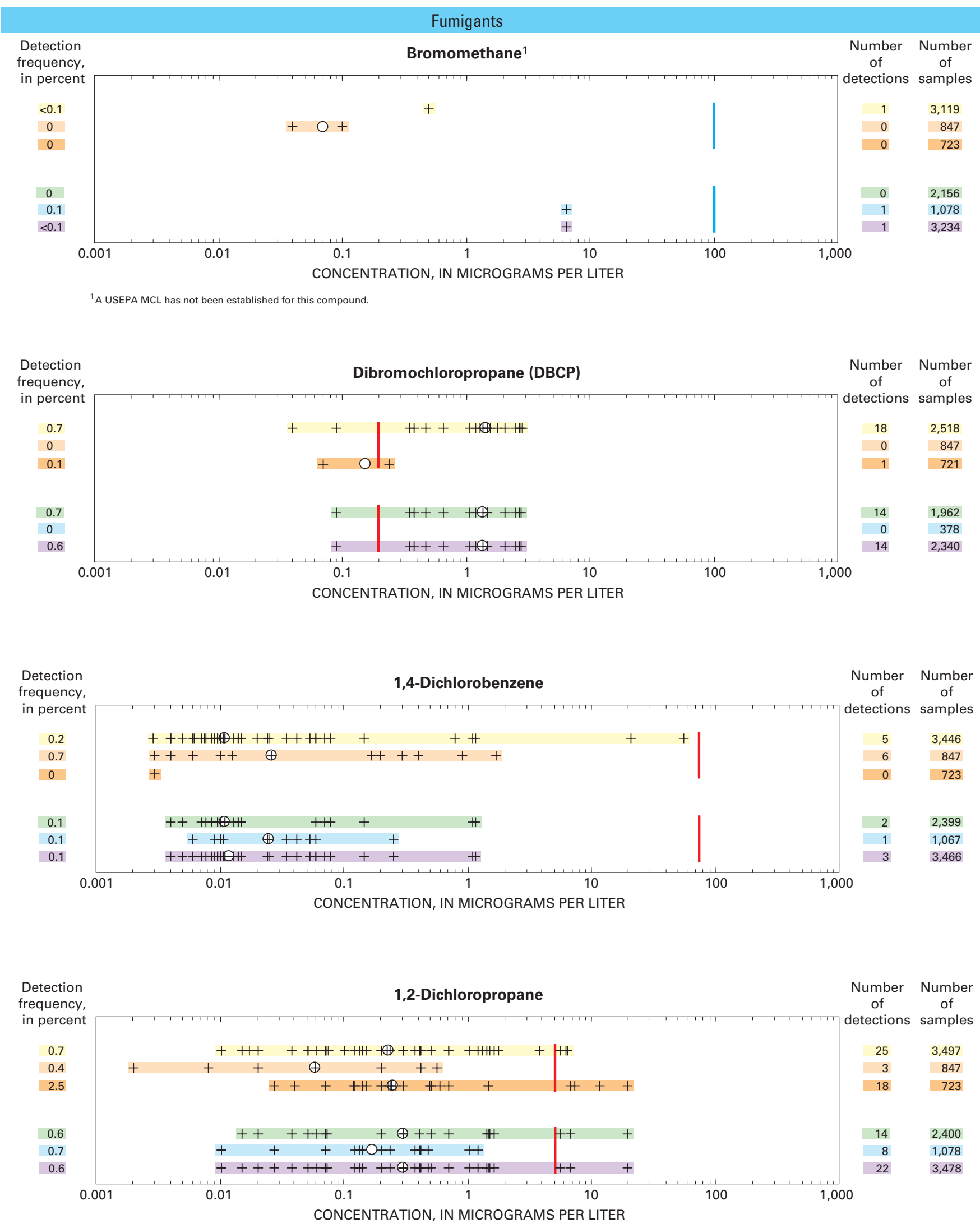
Appendix 7. Concentrations of selected volatile organic compounds (VOCs) in samples of untreated ground water.-Continued
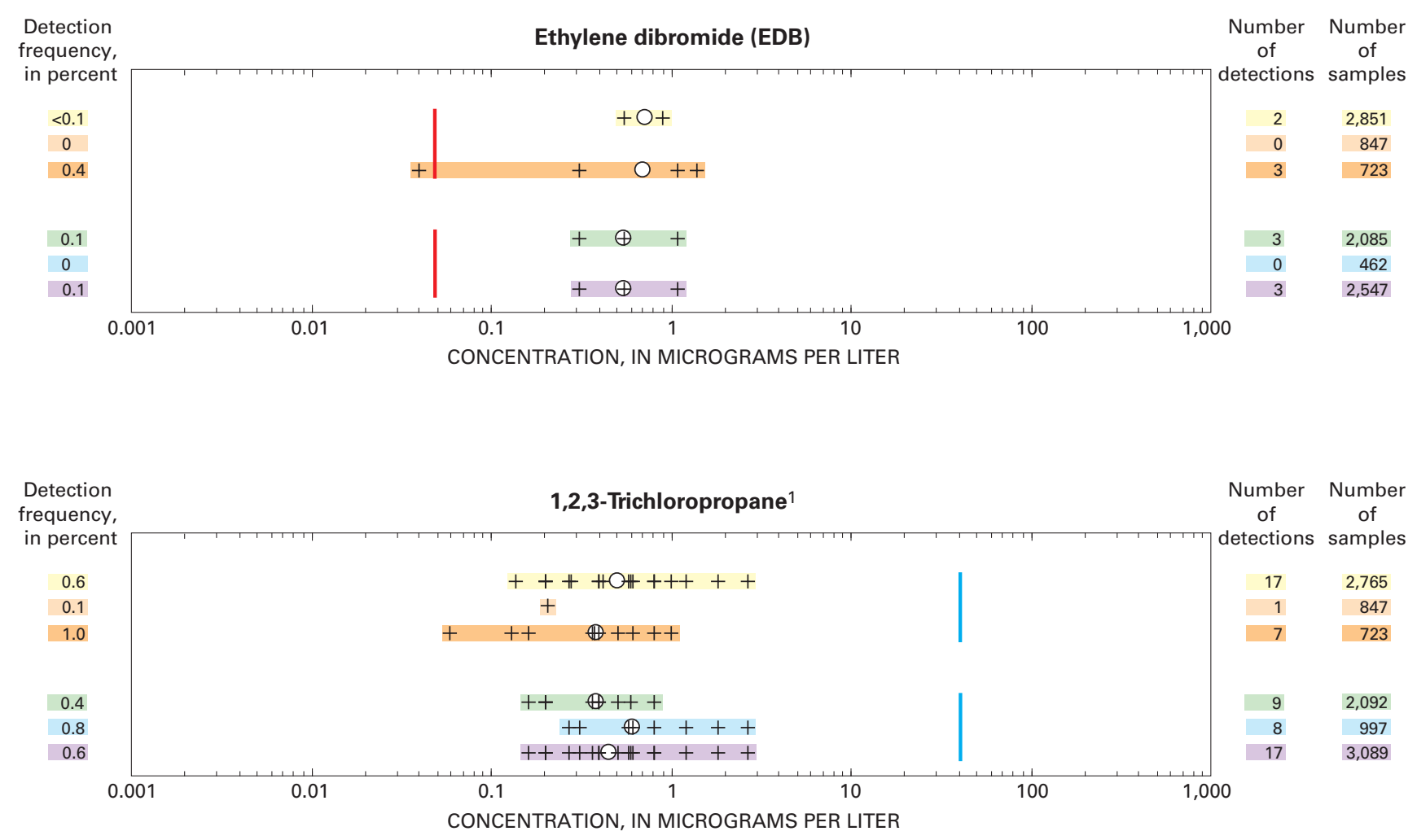

${ }^{1}$ A USEPA MCL has not been established for this compound.

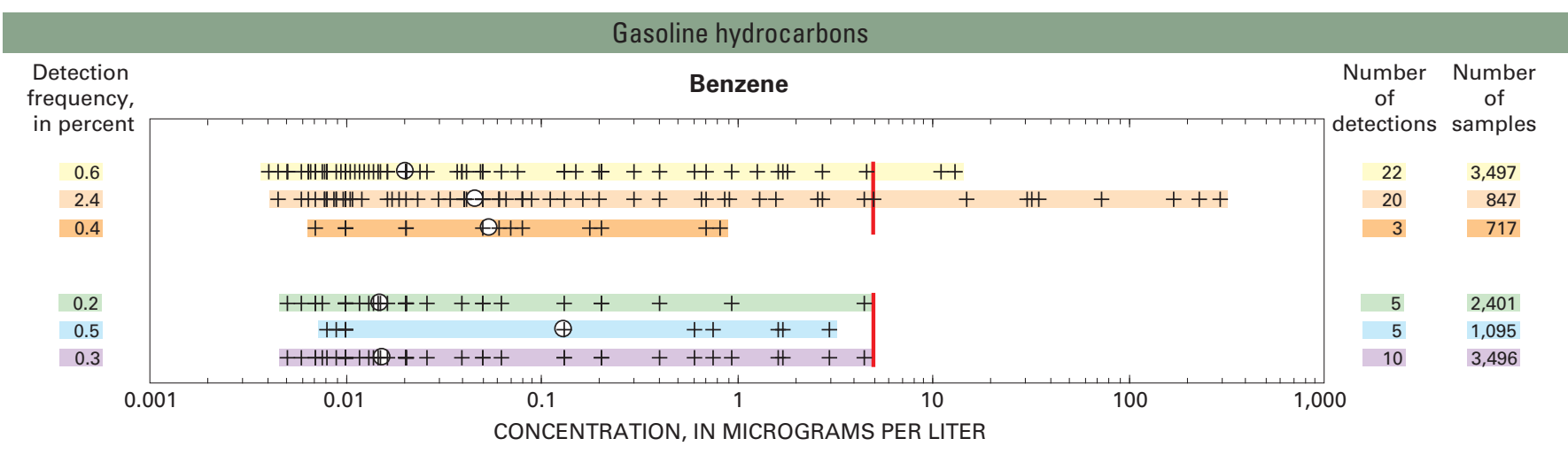

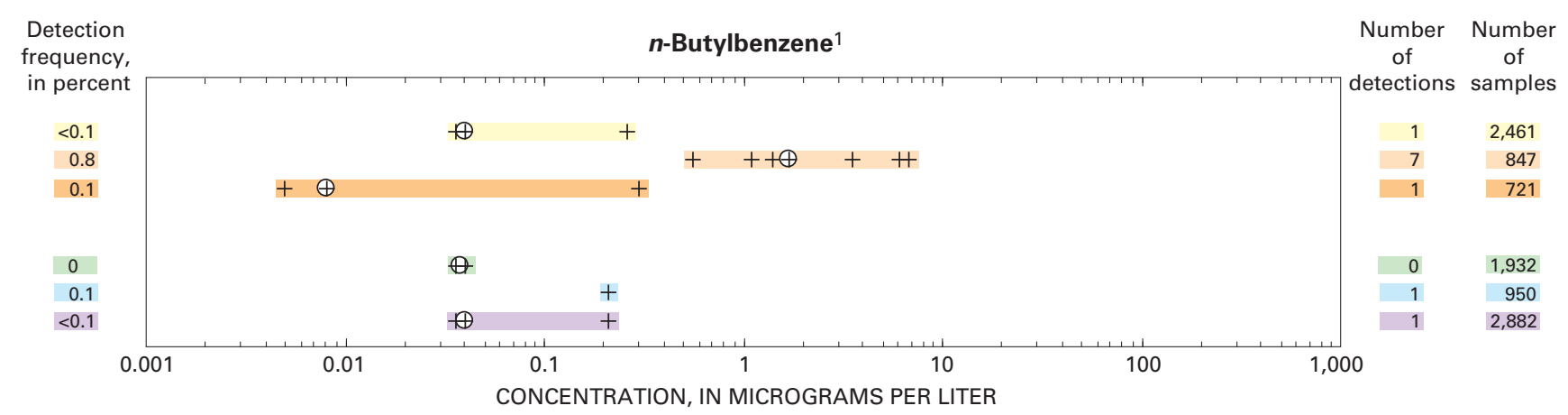

${ }^{1}$ Neither an MCL nor HBSL has been established for this compound. 
Appendix 7. Concentrations of selected volatile organic compounds (VOCs) in samples of untreated ground water.-Continued
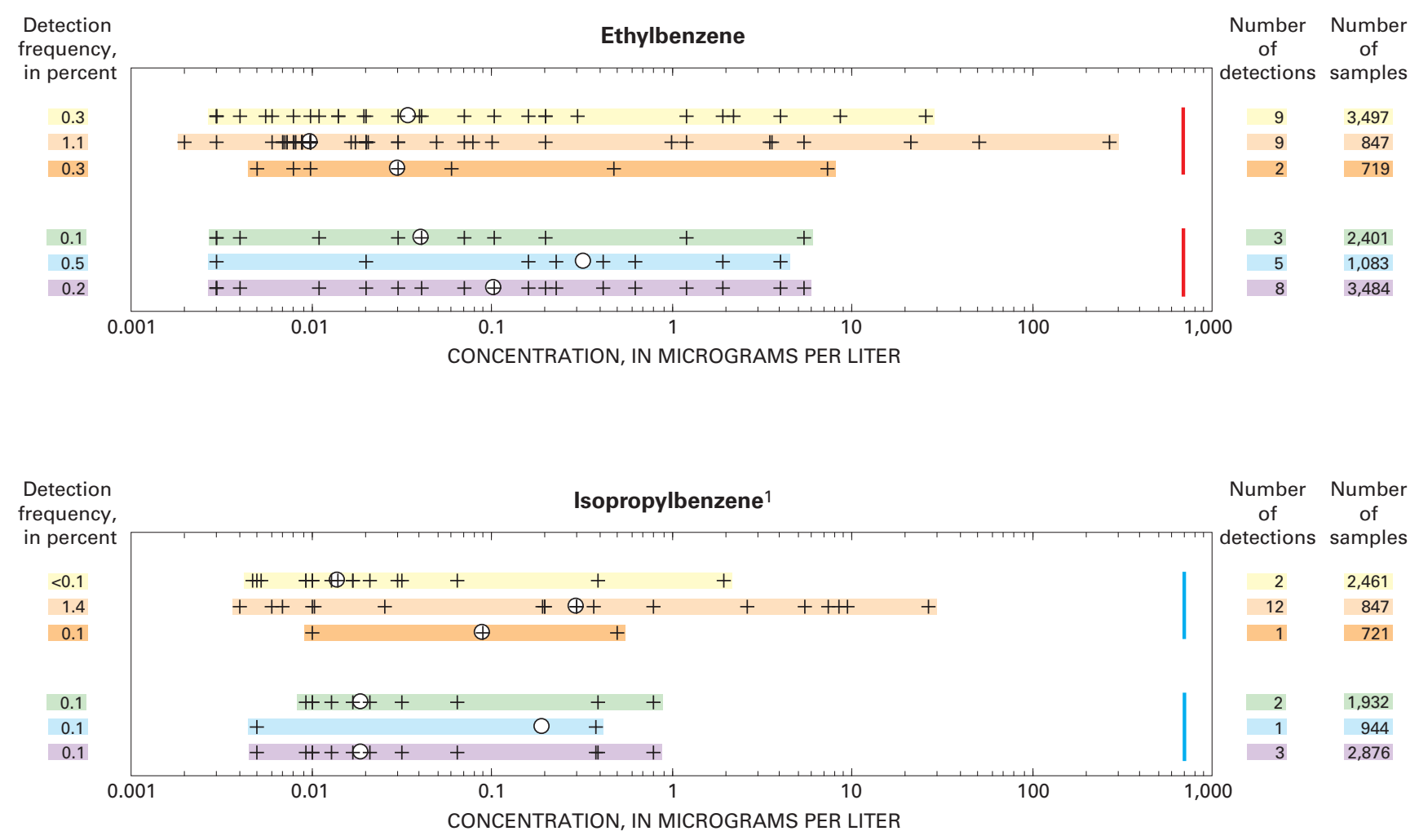

${ }^{1}$ A USEPA MCL has not been established for this compound.

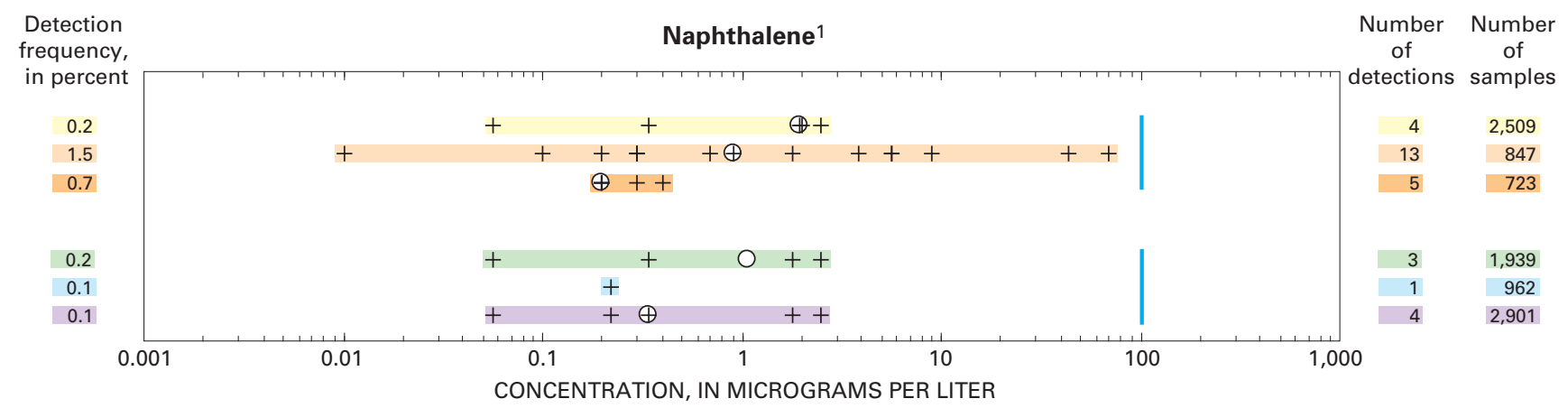

${ }^{1}$ A USEPA MCL has not been established for this compound.

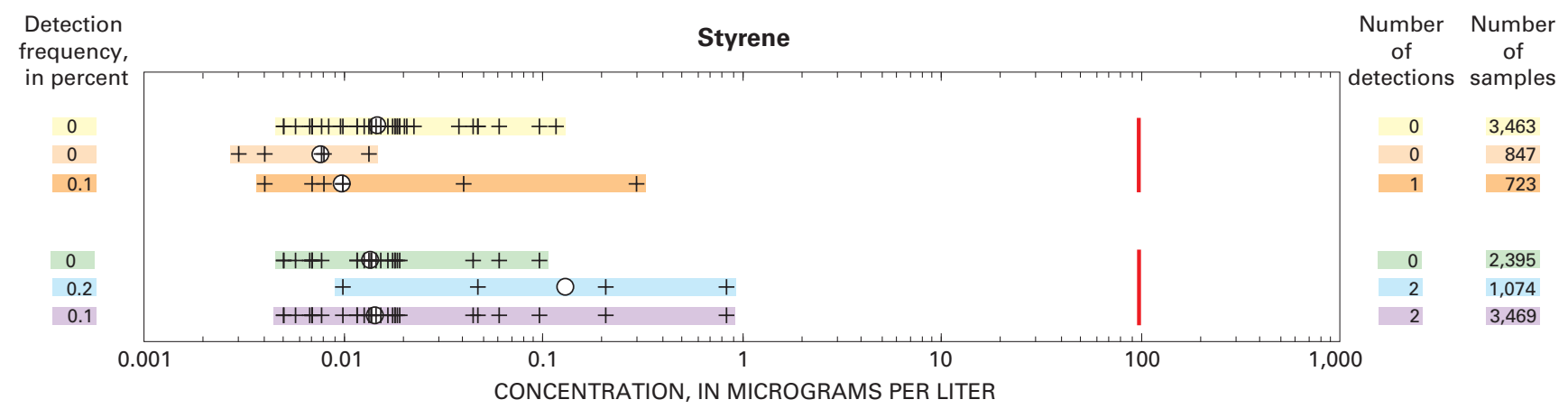


Appendix 7. Concentrations of selected volatile organic compounds (VOCs) in samples of untreated ground water-Continued
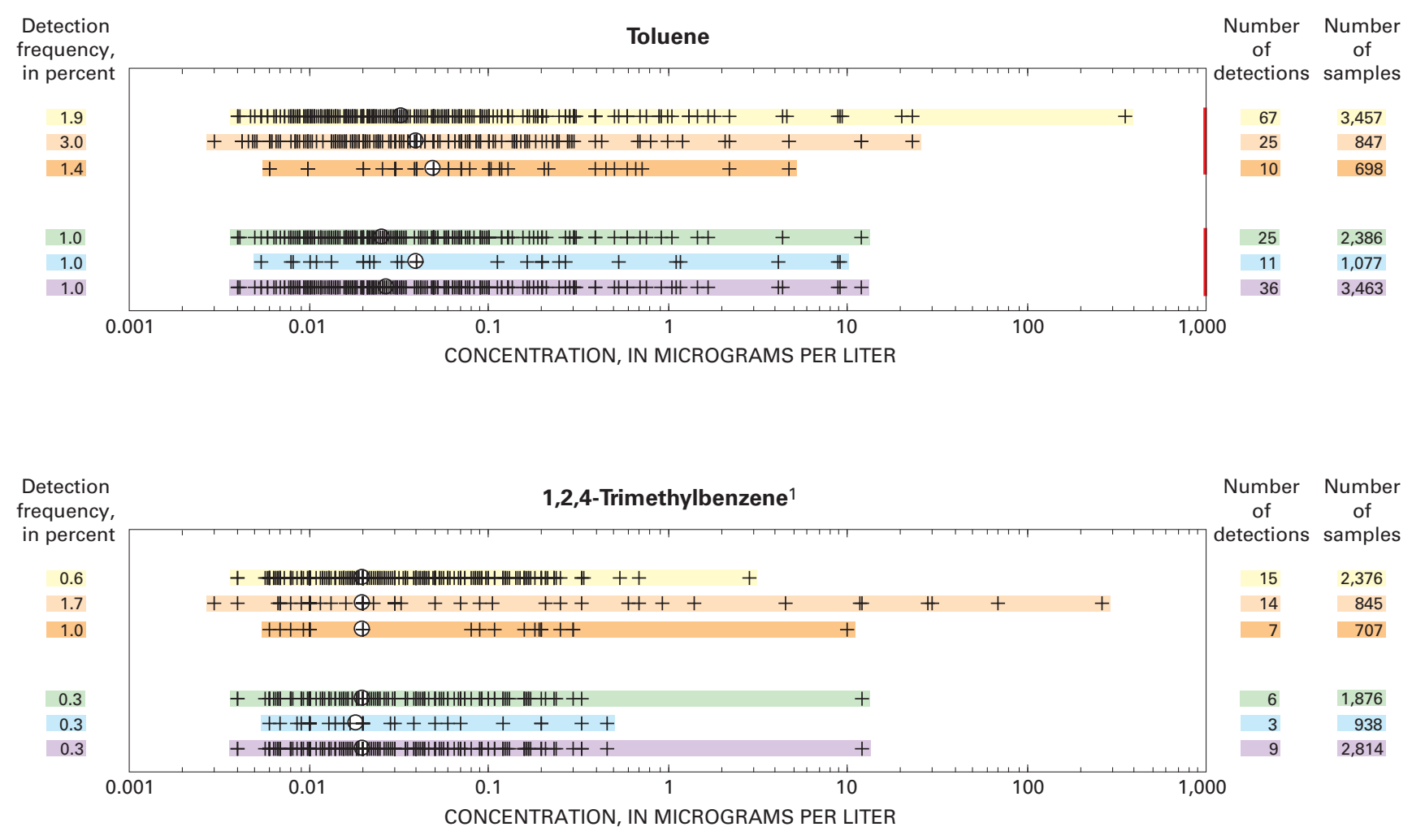

${ }^{1}$ Neither an MCL nor HBSL has been established for this compound.

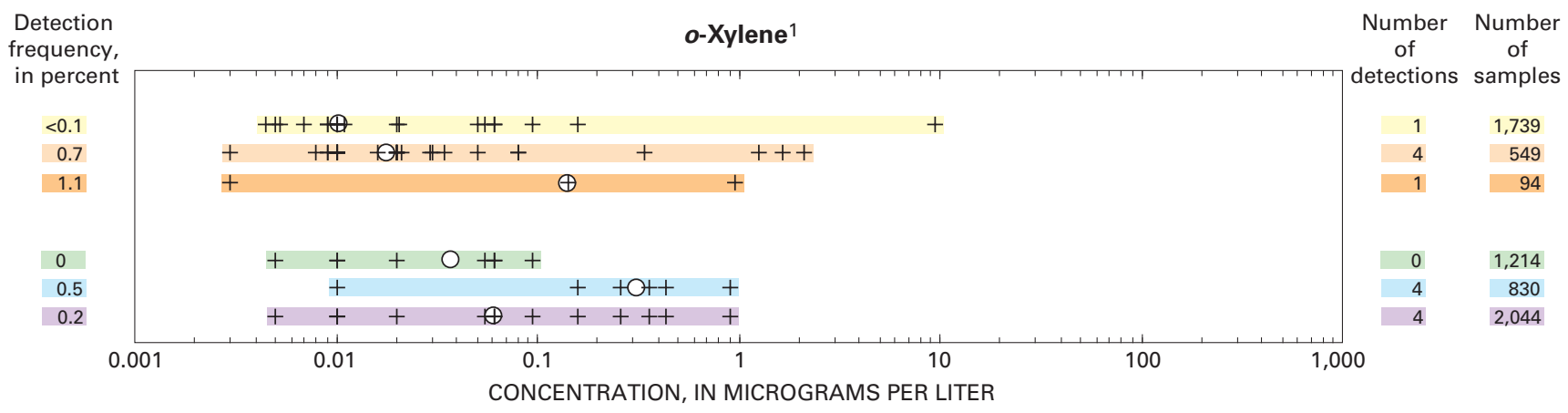

${ }^{1}$ The MCL is for total xylenes $(10,000 \mu \mathrm{g} / \mathrm{L})$.

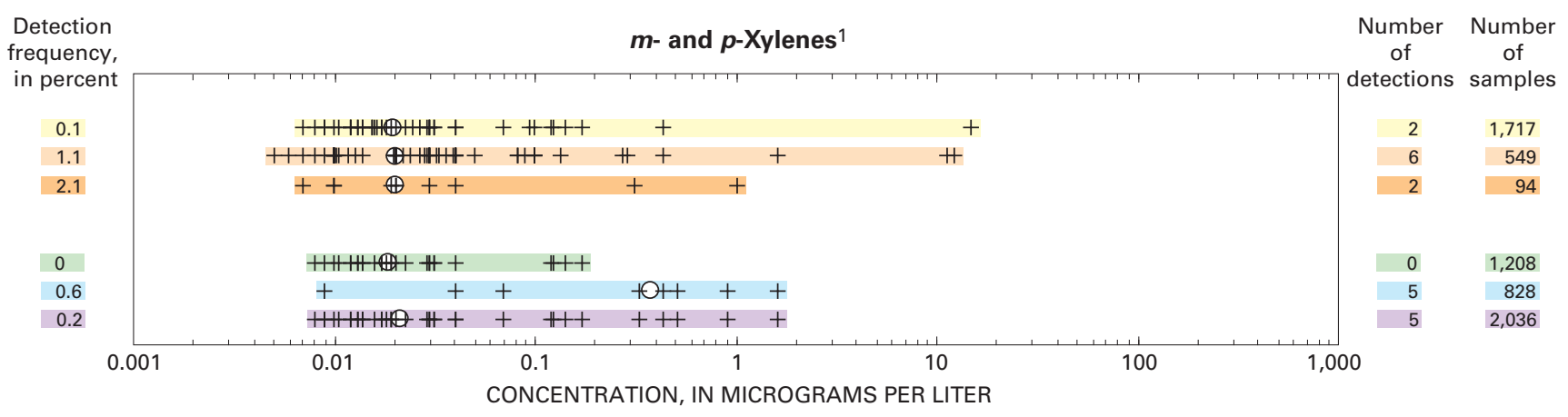

${ }^{1} \mathrm{The} \mathrm{MCL}$ is for total xylenes $(10,000 \mu \mathrm{g} / \mathrm{L})$. 
Appendix 7. Concentrations of selected volatile organic compounds (VOCs) in samples of untreated ground water.-Continued
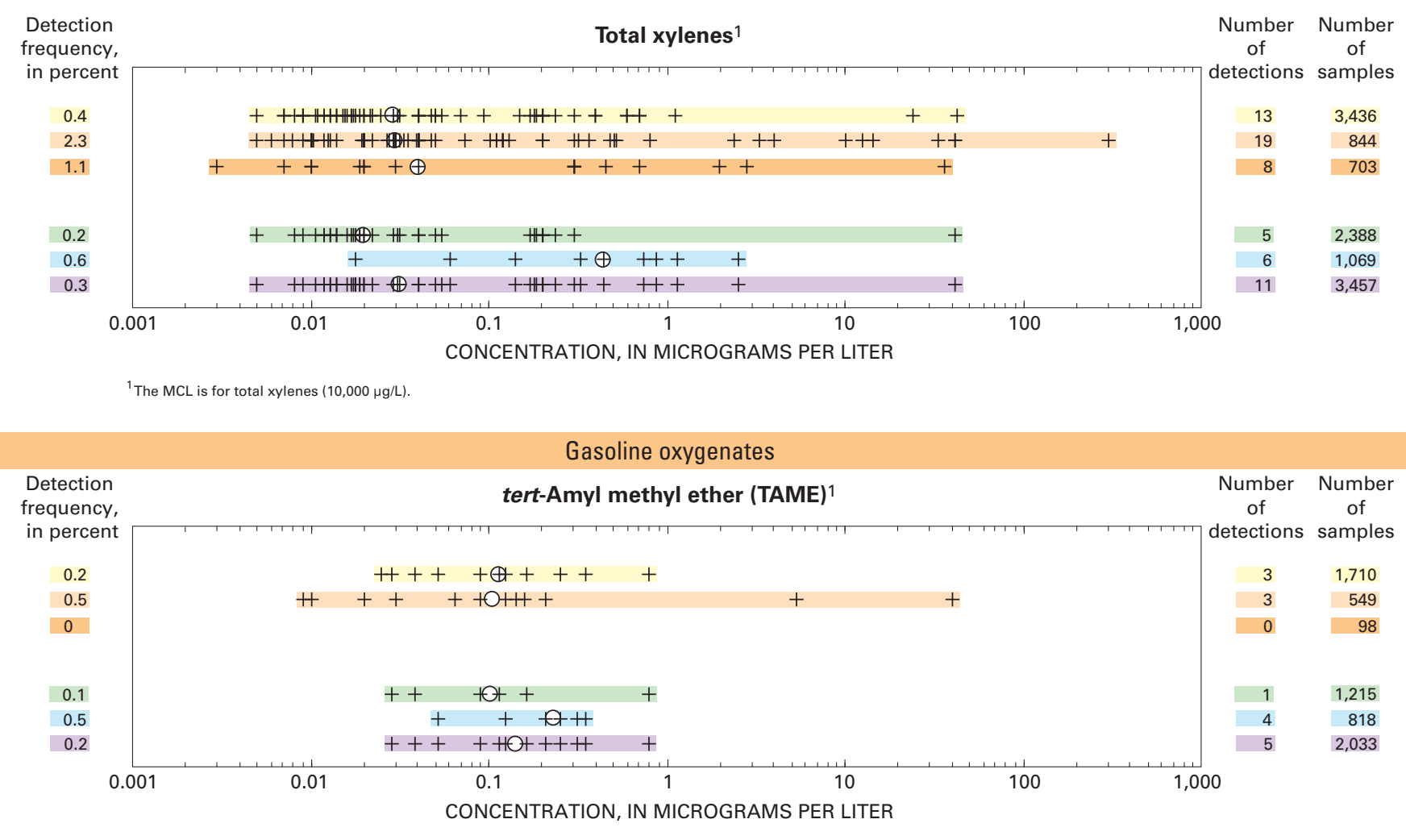

${ }^{1}$ Neither an MCL nor HBSL has been established for this compound.

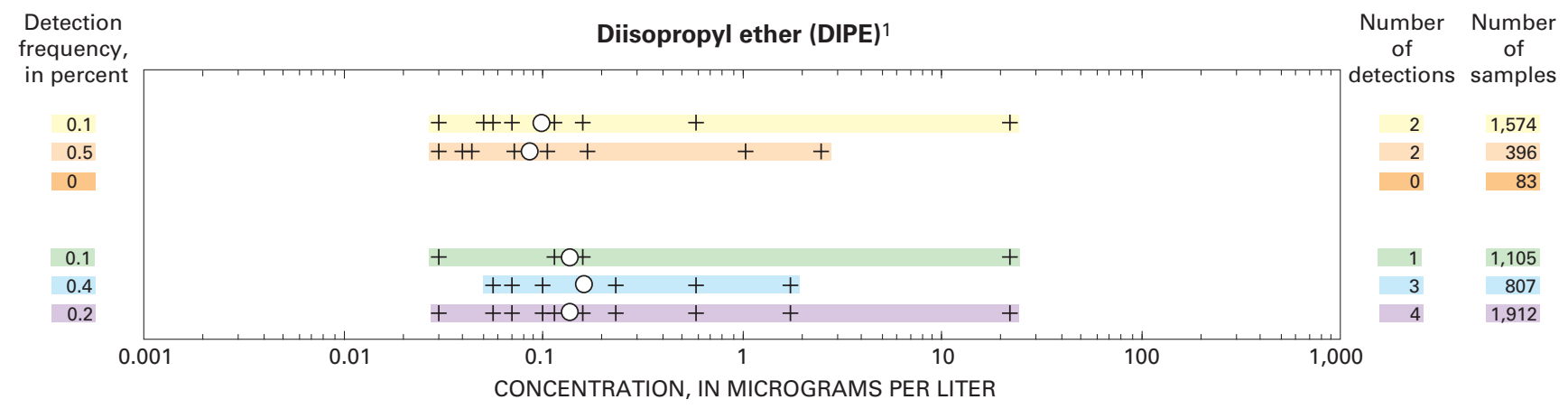

${ }^{1}$ Neither an MCL nor HBSL has been established for this compound.

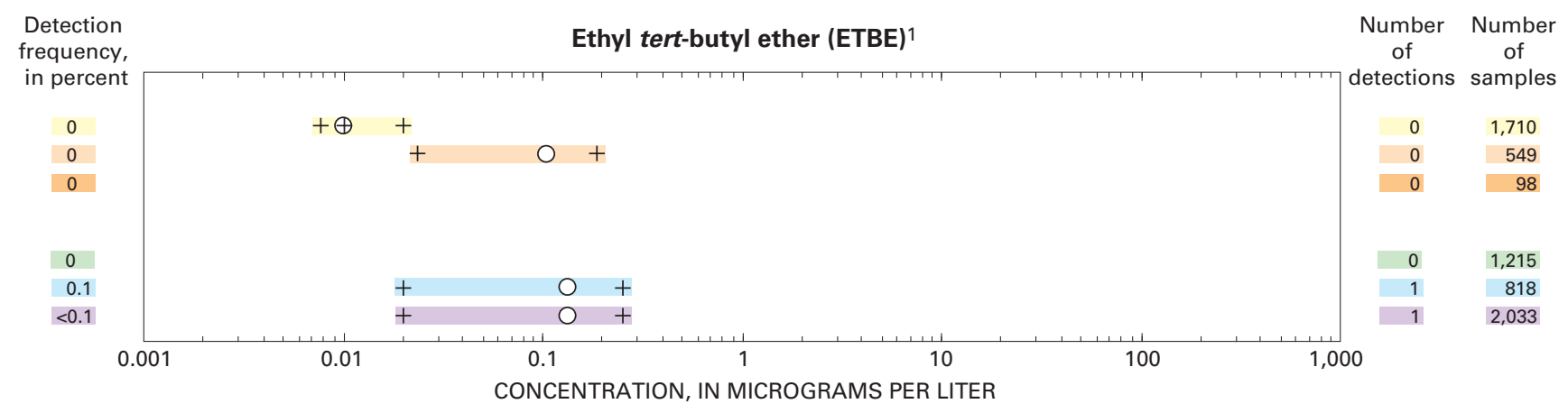

${ }^{1}$ Neither an MCL nor HBSL has been established for this compound. 
Appendix 7. Concentrations of selected volatile organic compounds (VOCs) in samples of untreated ground water-Continued

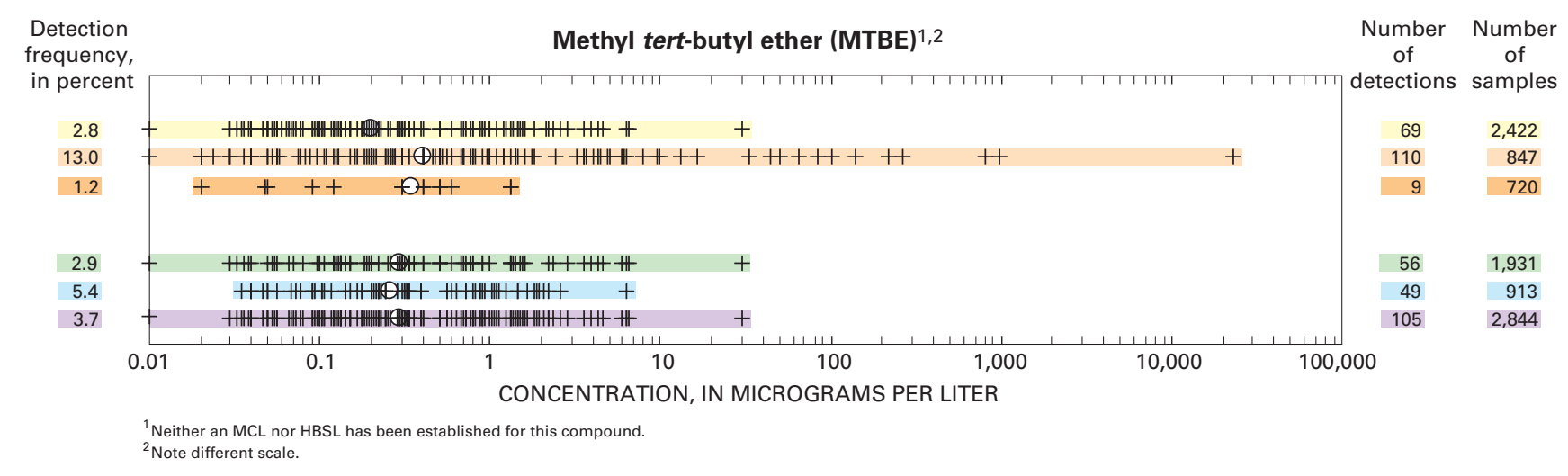

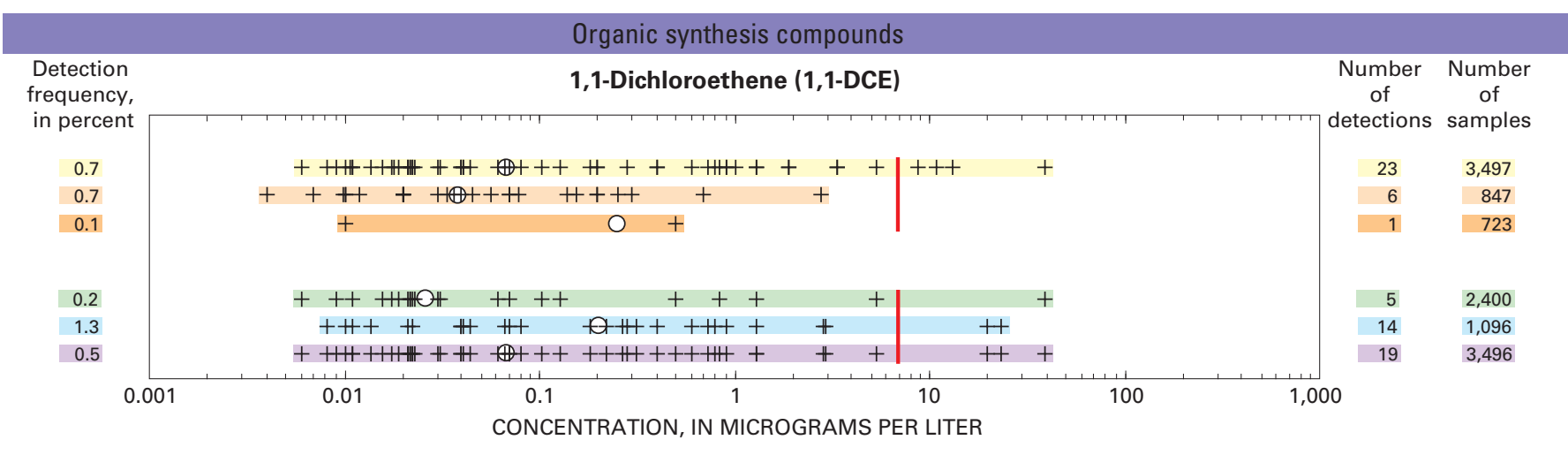

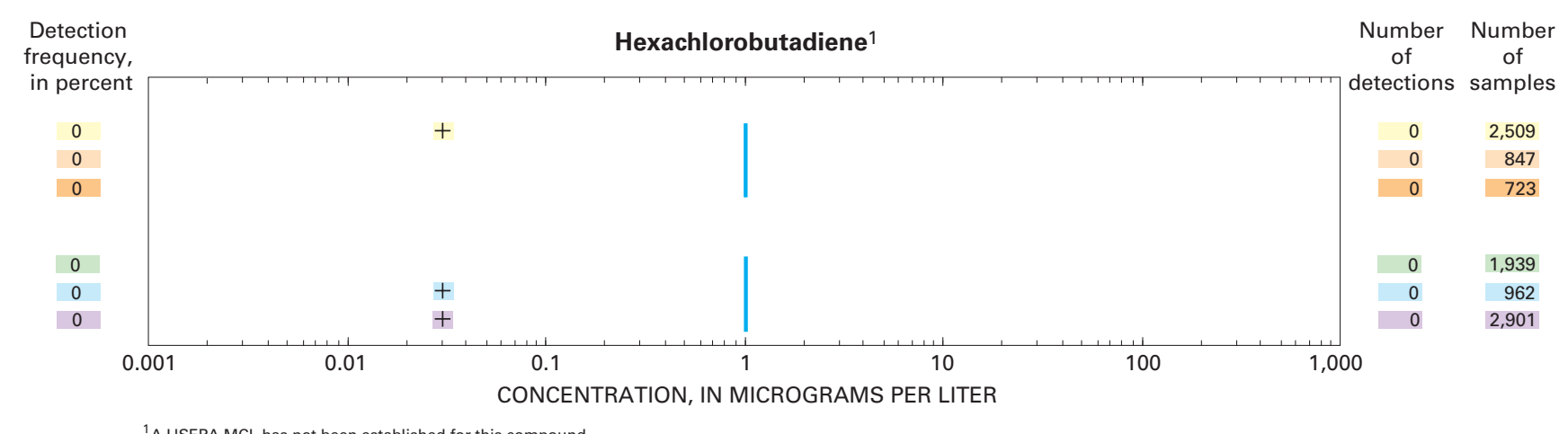

${ }^{1} \mathrm{~A}$ USEPA MCL has not been established for this compound.

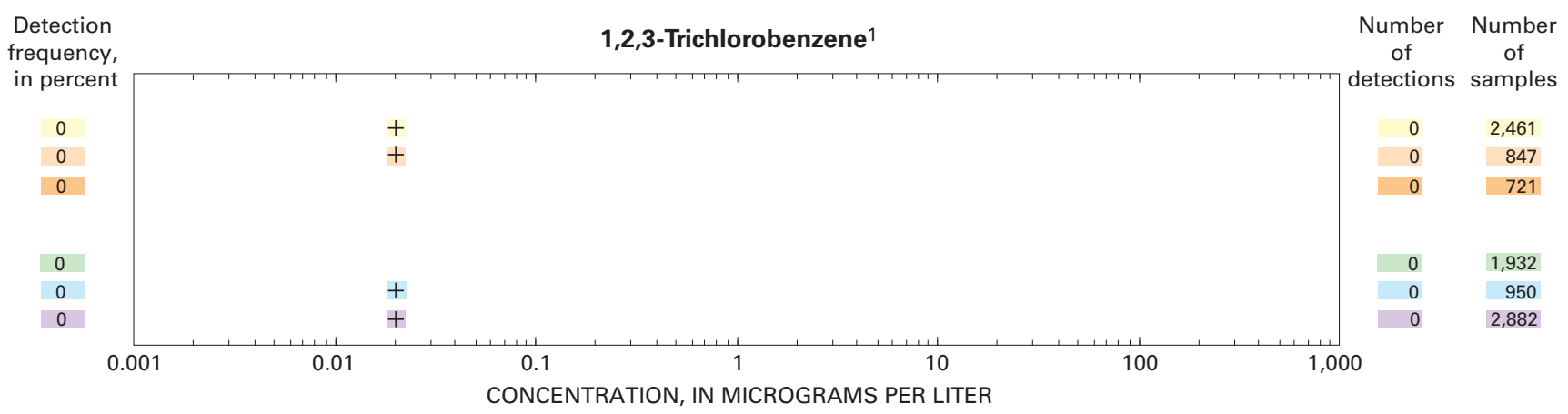

${ }^{1}$ Neither an MCL nor HBSL has been established for this compound. 
Appendix 7. Concentrations of selected volatile organic compounds (VOCs) in samples of untreated ground water.-Continued

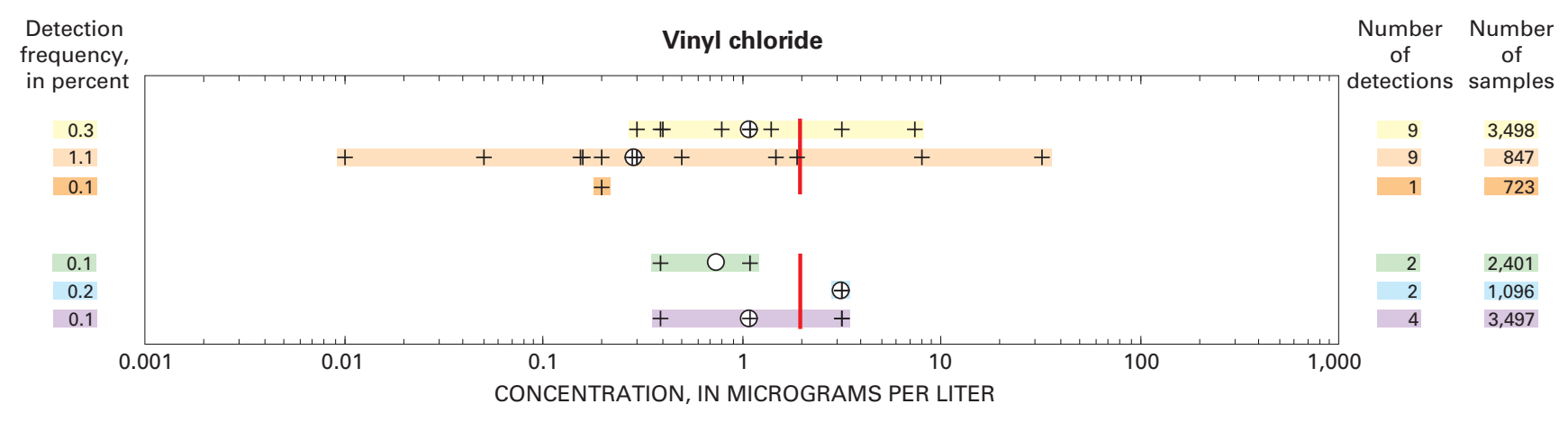

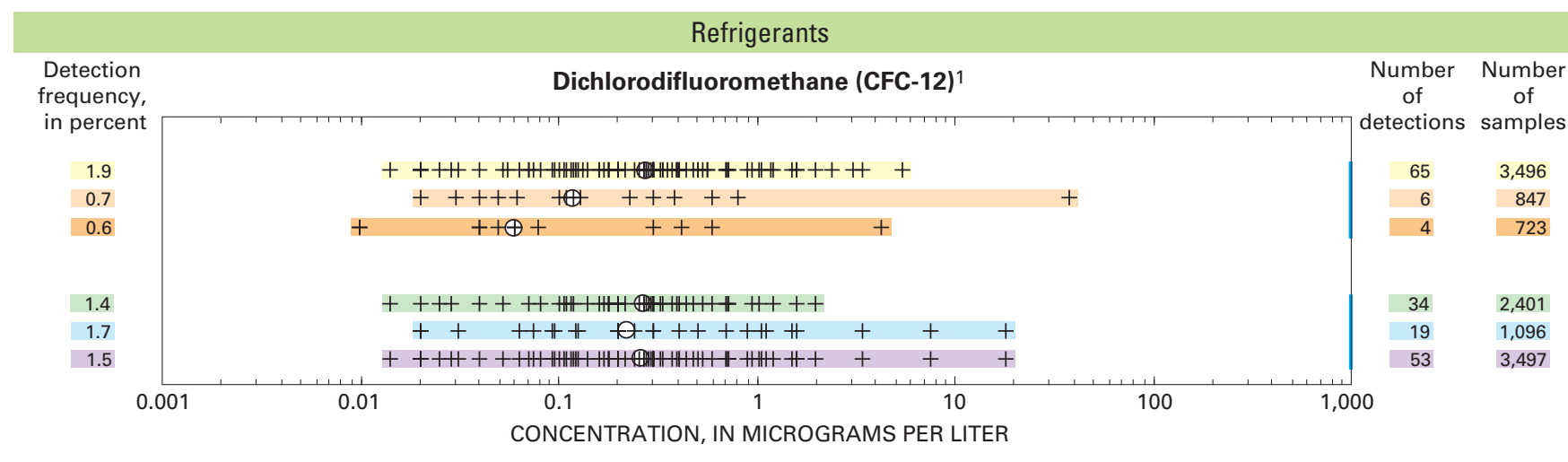

${ }^{1}$ A USEPA MCL has not been established for this compound.

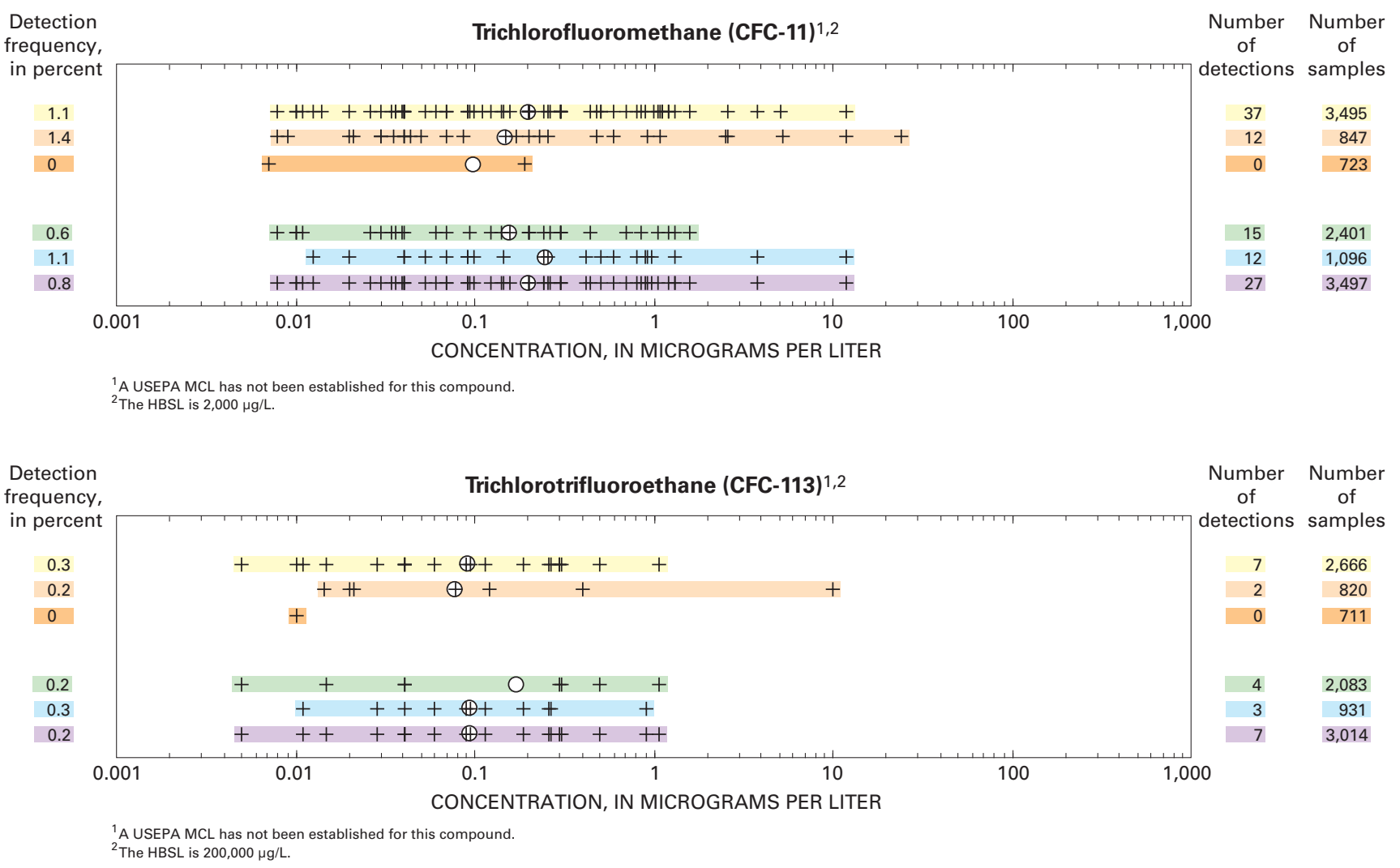


Appendix 7. Concentrations of selected volatile organic compounds (VOCs) in samples of untreated ground water-Continued
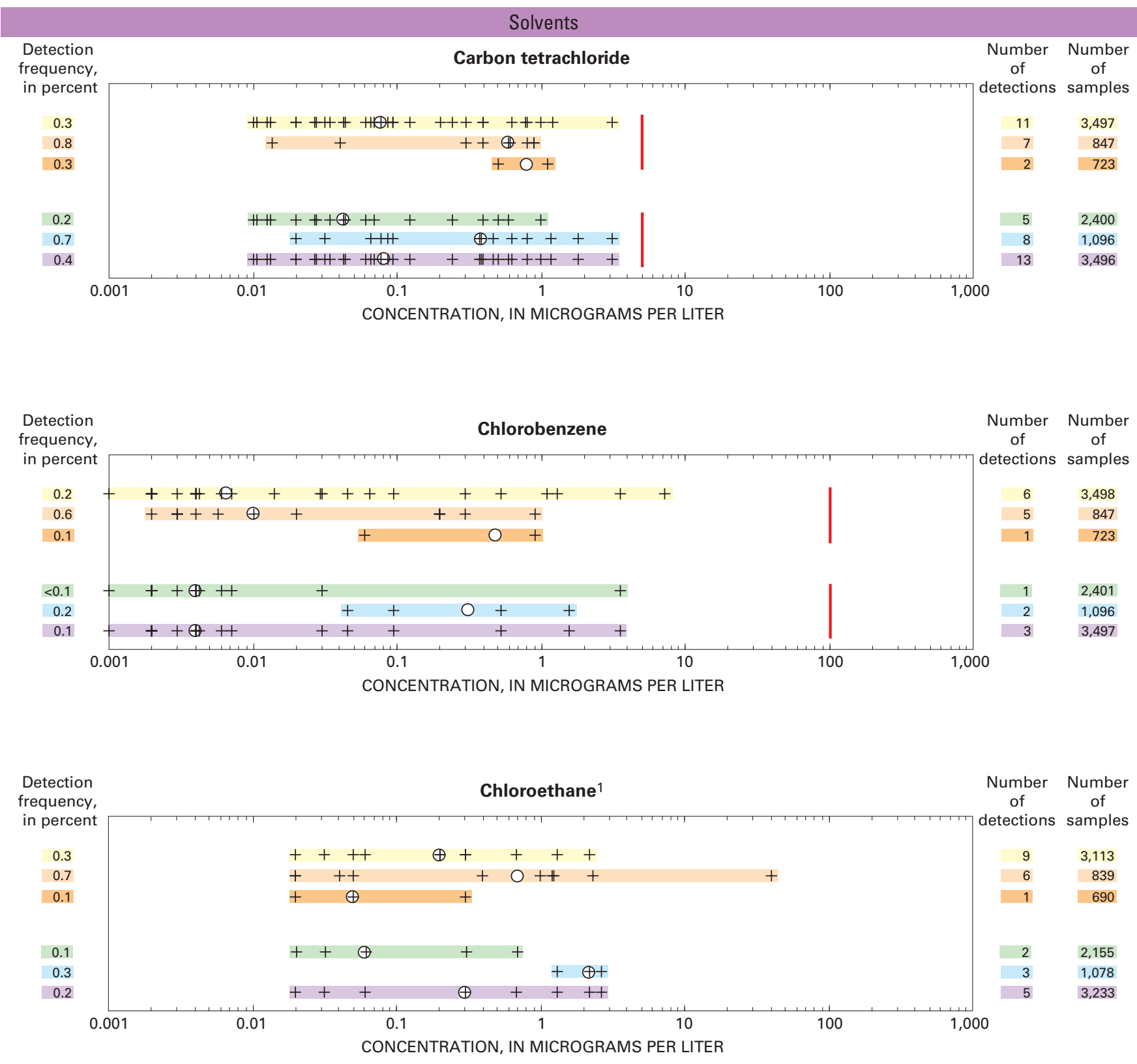

${ }^{1}$ Neither an MCL nor HBSL has been established for this compound.

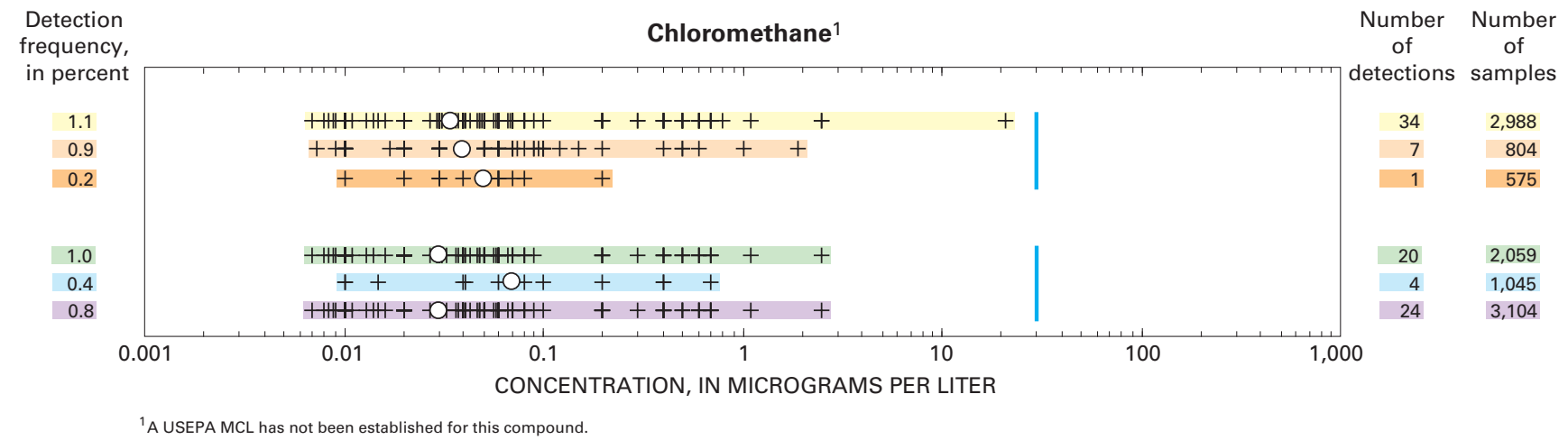


Appendix 7. Concentrations of selected volatile organic compounds (VOCs) in samples of untreated ground water.-Continued
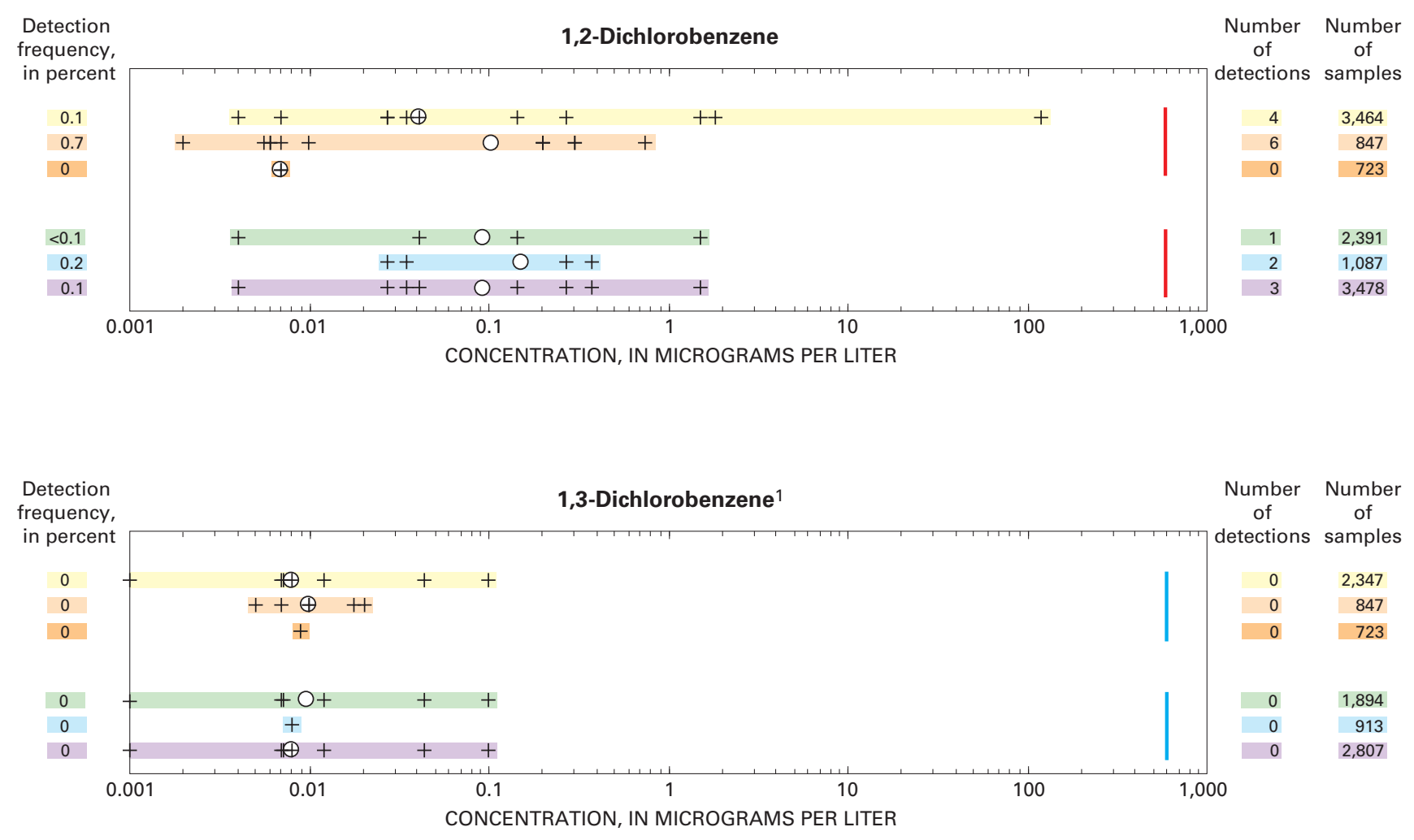

${ }^{1}$ A USEPA MCL has not been established for this compound.

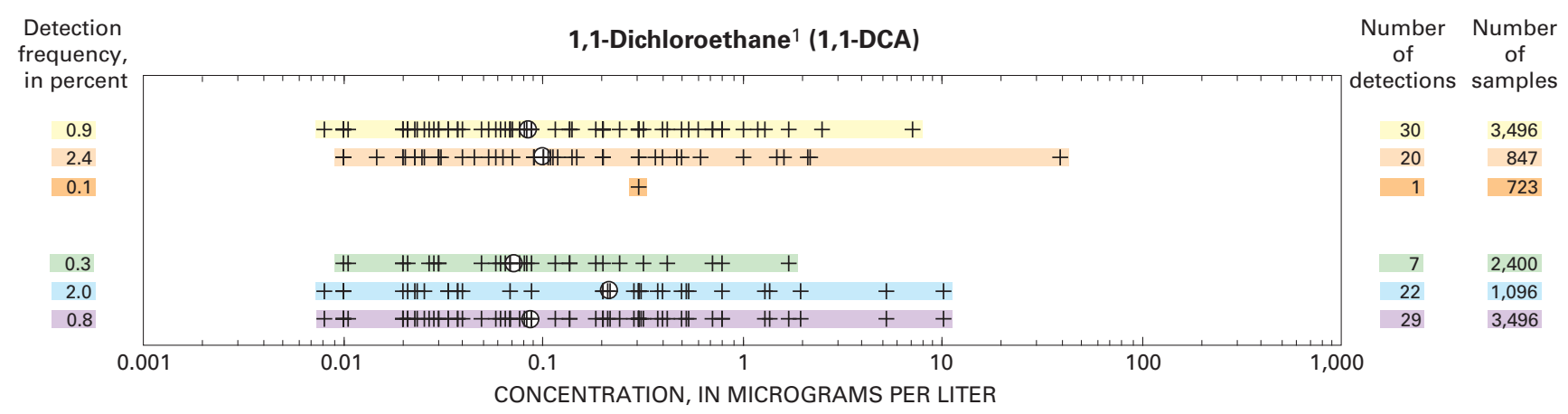

${ }^{1}$ Neither an MCL nor HBSL has not been established for this compound.

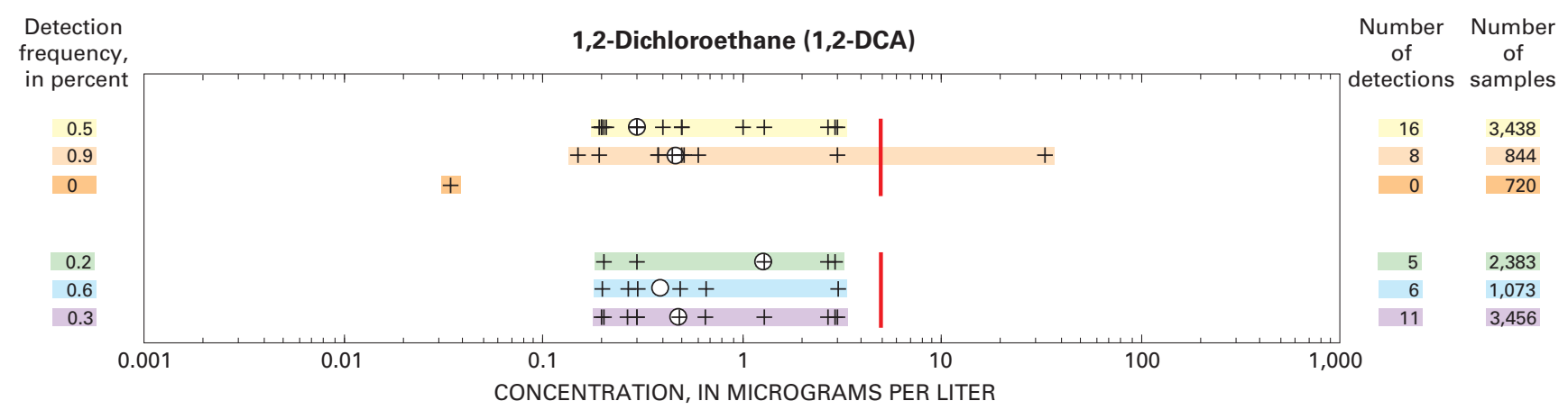


Appendix 7. Concentrations of selected volatile organic compounds (VOCs) in samples of untreated ground water.-Continued
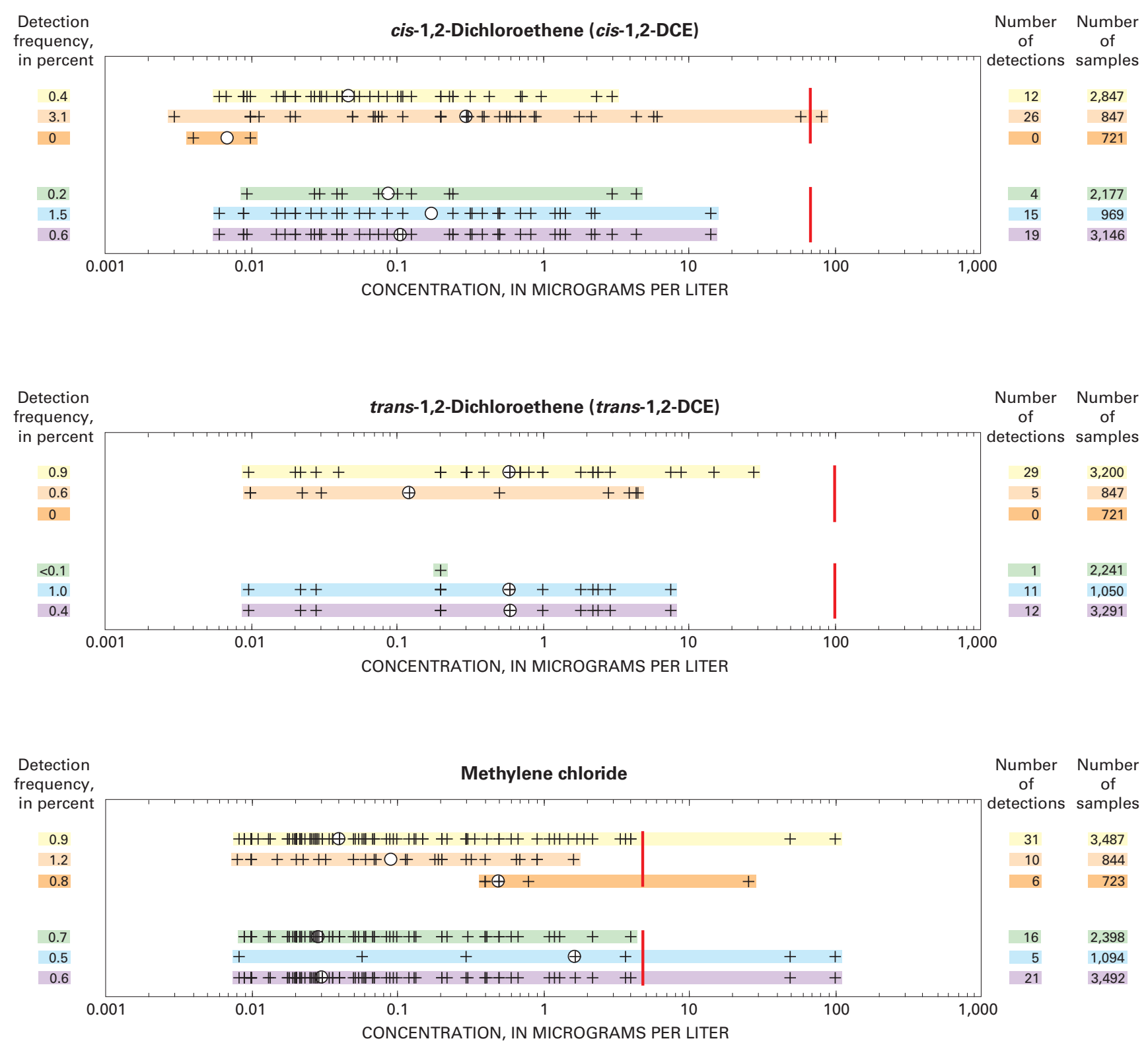

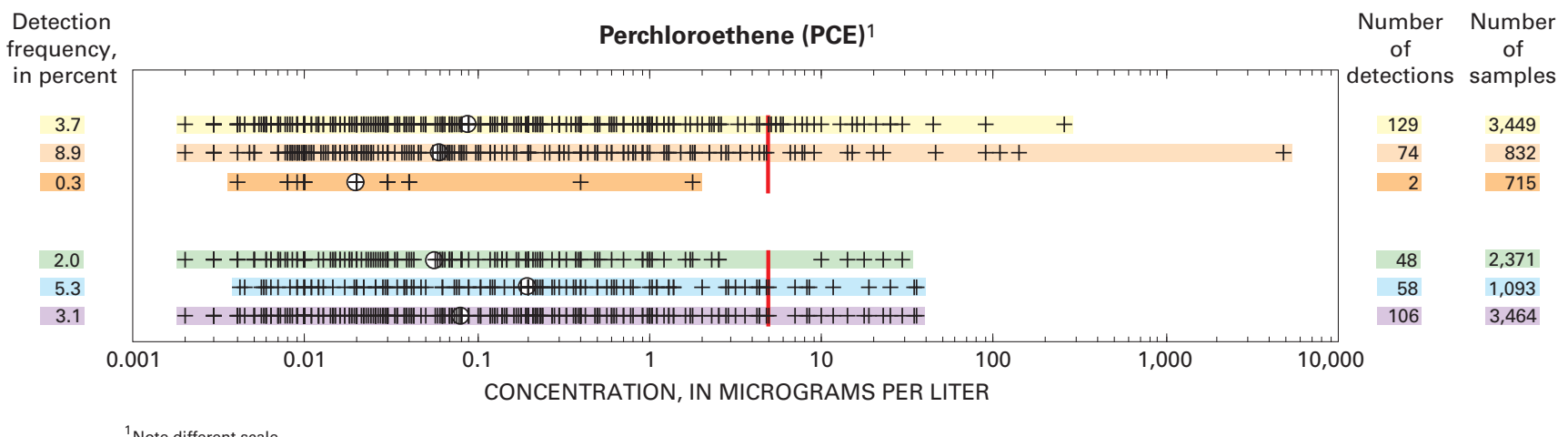


Appendix 7. Concentrations of selected volatile organic compounds (VOCs) in samples of untreated ground water.-Continued

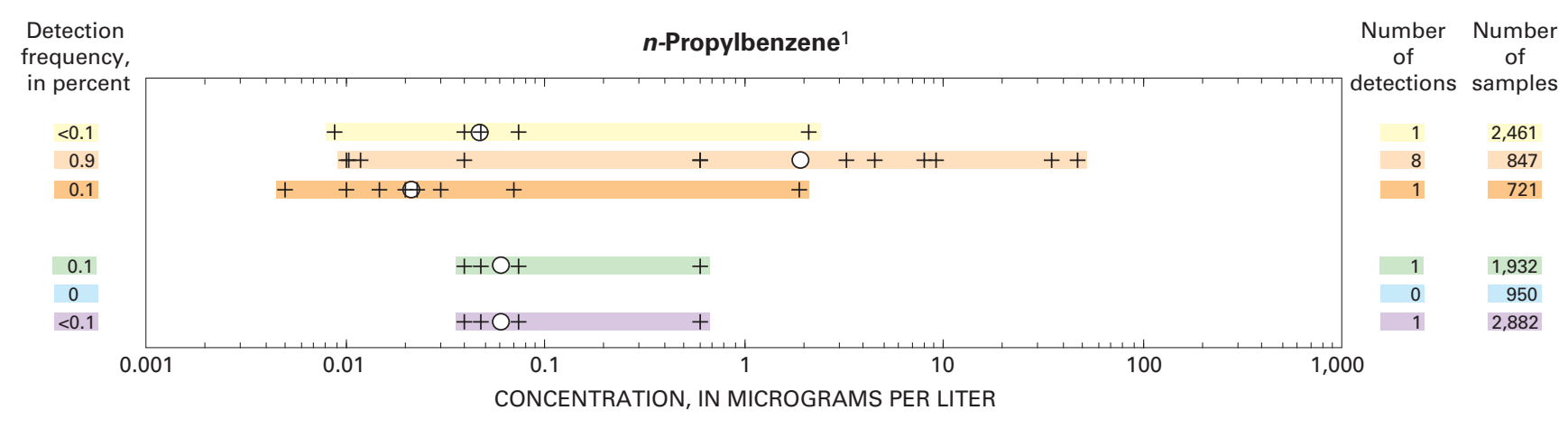

${ }^{1}$ Neither an MCL nor HBSL has been established for this compound.
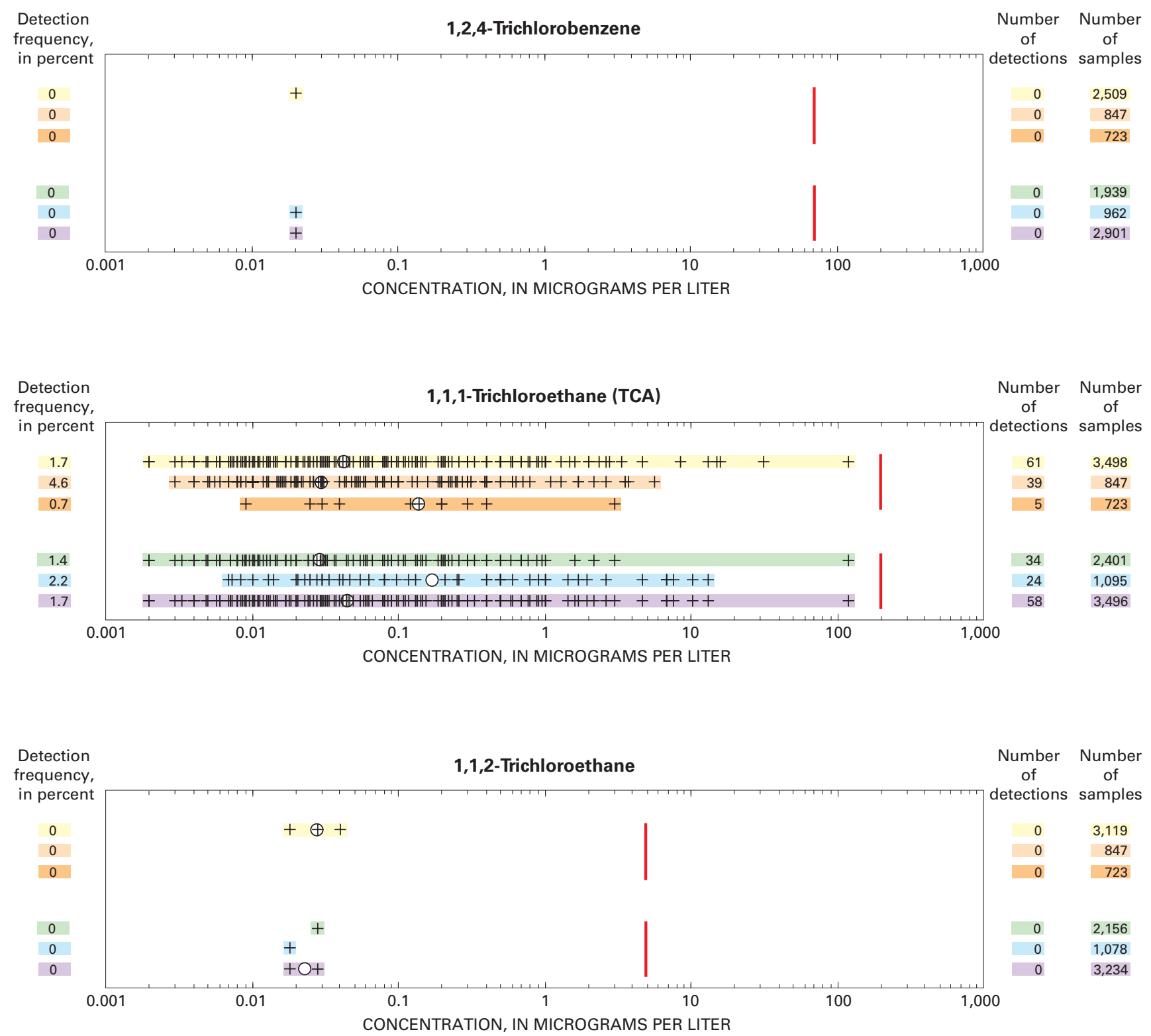
Appendix 7. Concentrations of selected volatile organic compounds (VOCs) in samples of untreated ground water.-Continued

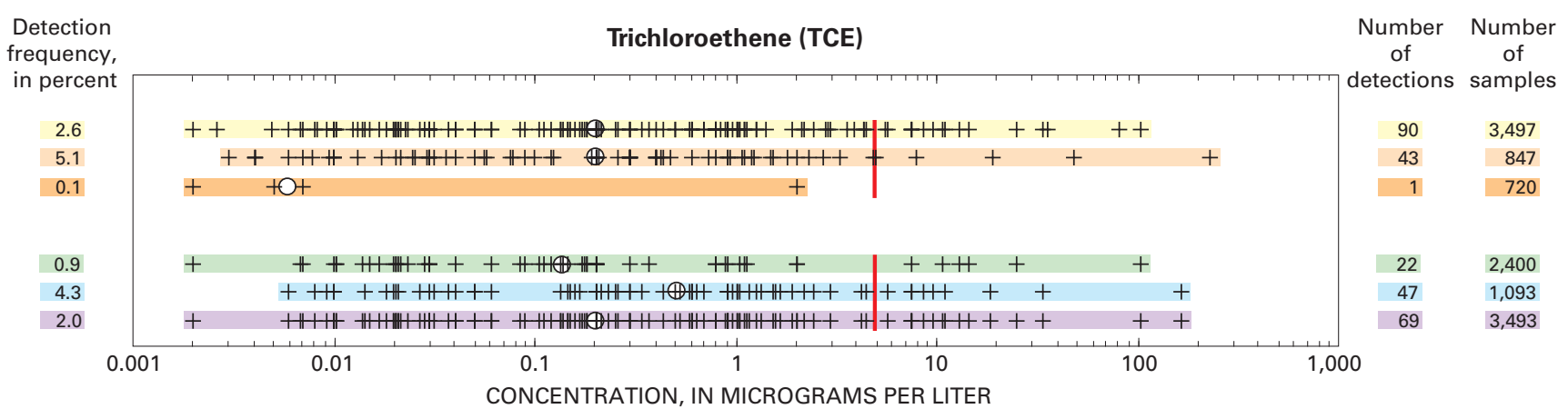

\section{Trihalomethanes}

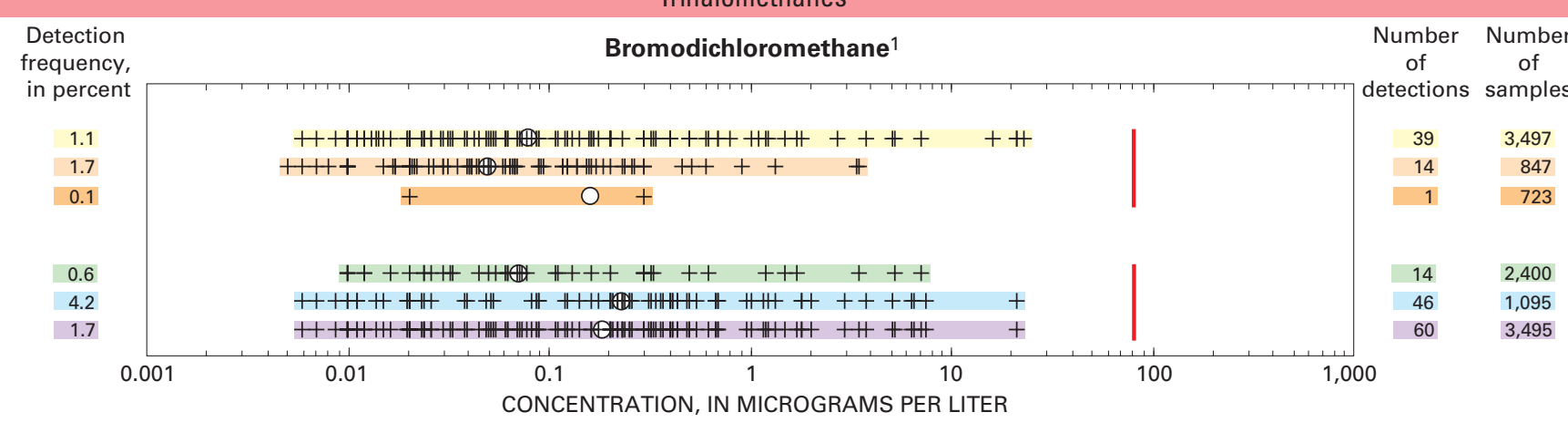

${ }^{1}$ The USEPA MCL of $80 \mu \mathrm{g} / \mathrm{L}$ is for the sum of the concentrations of four trihalomethanes including bromodichloromethane, bromoform, chloroform, and dibromochloromethane.

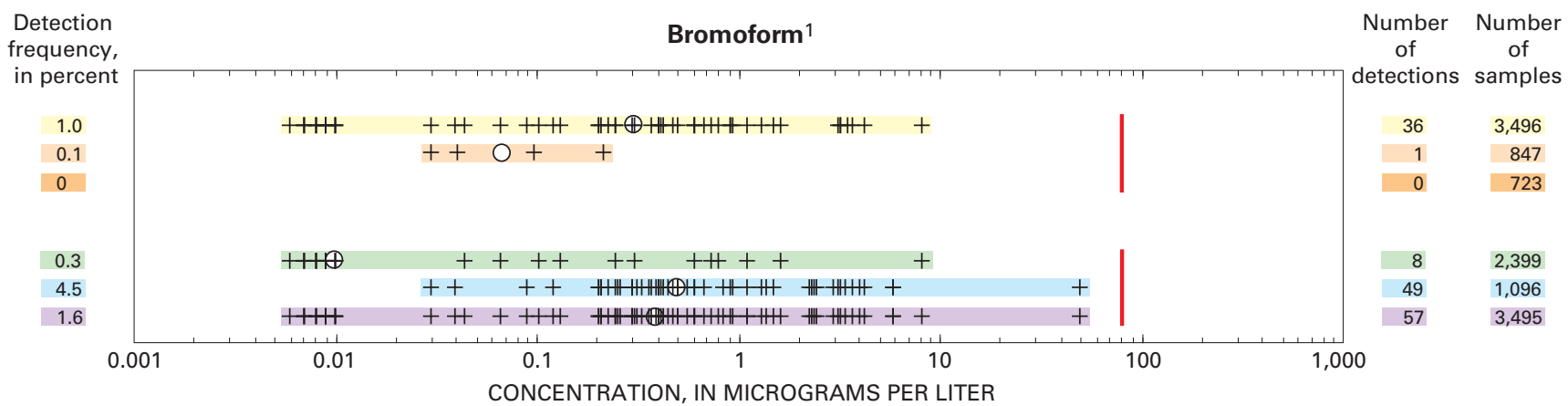

${ }^{1}$ The USEPA MCL of $80 \mu \mathrm{g} / \mathrm{L}$ is for the sum of the concentrations of four trihalomethanes including bromodichloromethane, bromoform, chloroform, and dibromochloromethane.

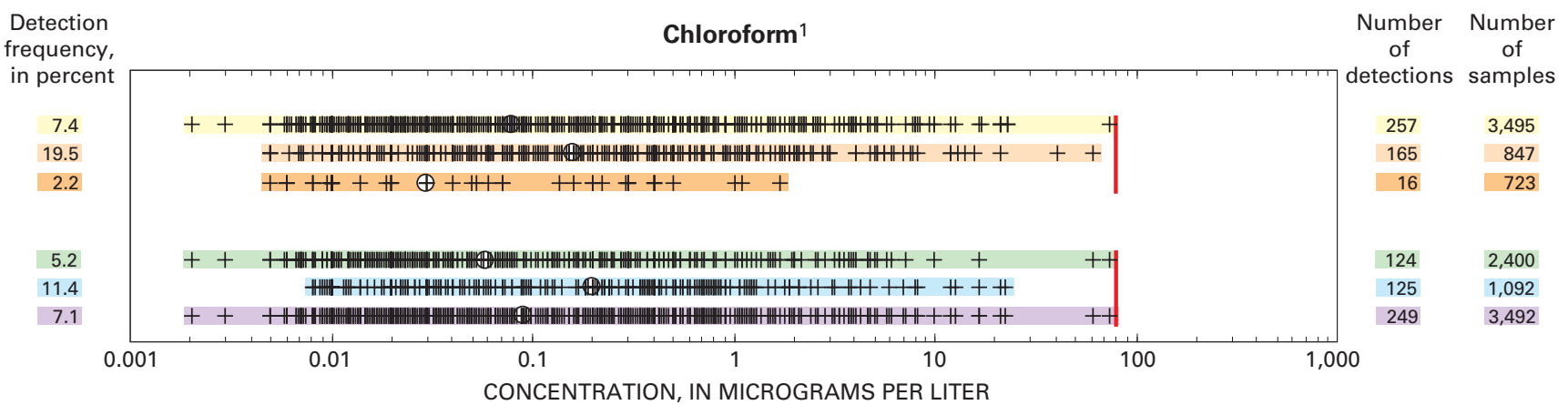

\footnotetext{
${ }^{1}$ The USEPA MCL of $80 \mu \mathrm{g} / \mathrm{L}$ is for the sum of the concentrations of four trihalomethanes including bromodichloromethane, bromoform, chloroform, and dibromochloromethane.
} 
Appendix 7. Concentrations of selected volatile organic compounds (VOCs) in samples of untreated ground water.-Continued
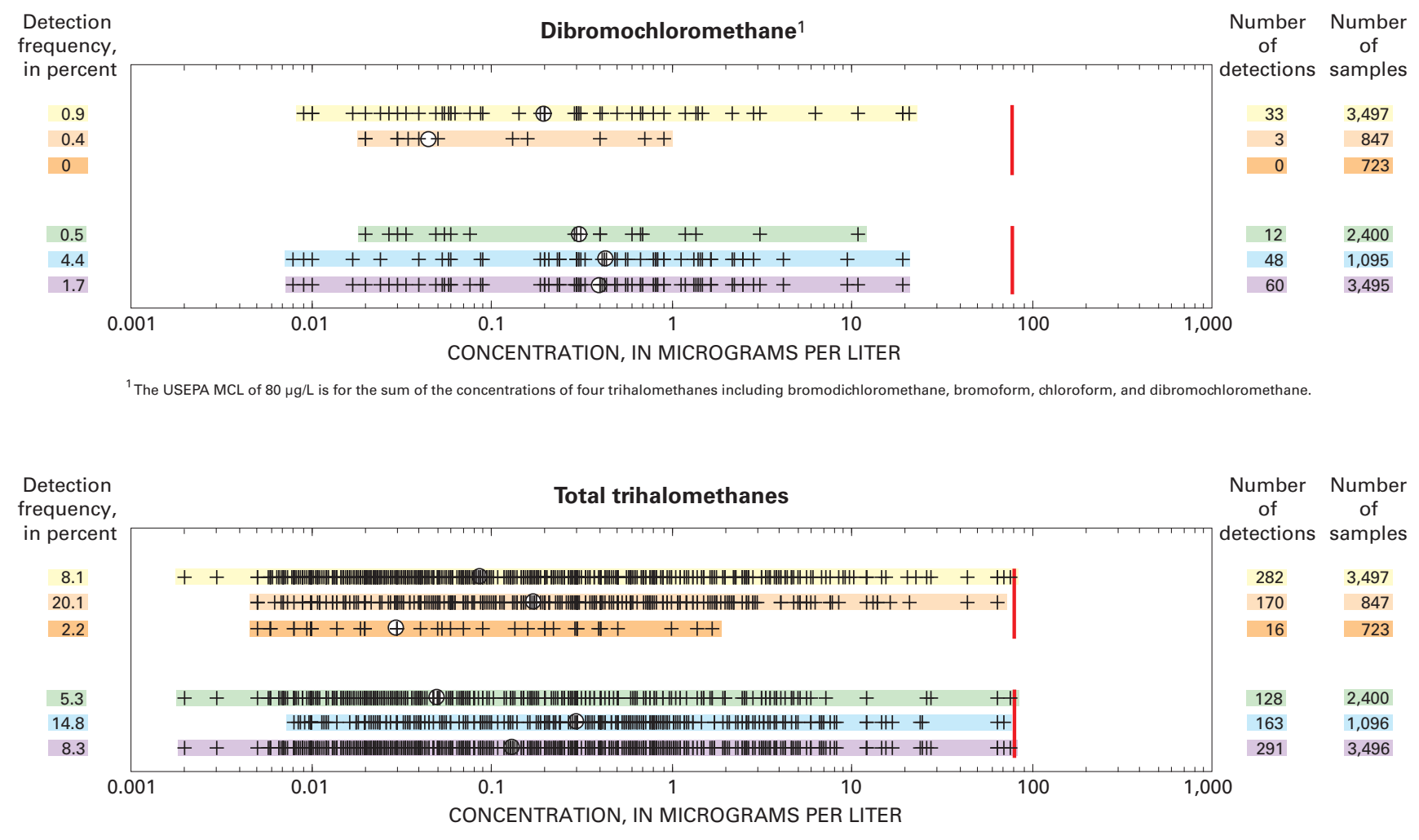

VOCs not detected: Acrolein, Acrylonitrile, cis-1,3-Dichloropropene, trans-1,3-Dichloropropene, Hexachloroethane, and Vinyl bromide 
Appendix 8. Detection frequencies and median concentrations for selected volatile organic compounds in samples from domestic wells.

[ $\mu \mathrm{g} / \mathrm{L}$, micrograms per liter; ND, compound not detected; <, less than; --, not applicable]

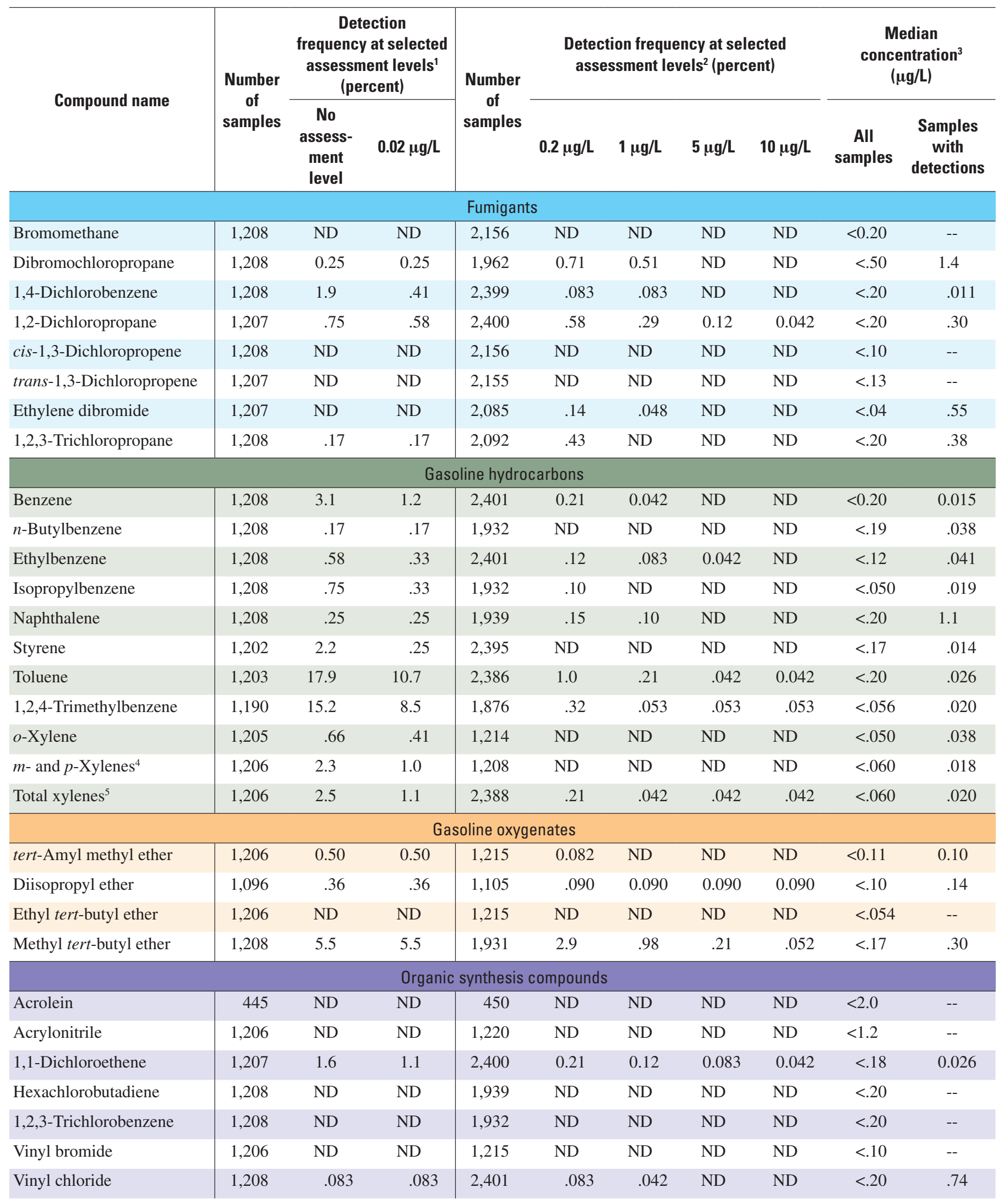


Appendix 8. Detection frequencies and median concentrations for selected volatile organic compounds in samples from domestic wells.-Continued

[ $\mu \mathrm{g} / \mathrm{L}$, micrograms per liter; ND, compound not detected; <, less than; --, not applicable]

\begin{tabular}{|c|c|c|c|c|c|c|c|c|c|c|}
\hline \multirow{2}{*}{ Compound name } & \multirow{2}{*}{$\begin{array}{l}\text { Number } \\
\text { of } \\
\text { samples }\end{array}$} & \multicolumn{2}{|c|}{$\begin{array}{c}\text { Detection } \\
\text { frequency at selected } \\
\text { assessment levels }{ }^{1} \\
\text { (percent) }\end{array}$} & \multirow{2}{*}{$\begin{array}{l}\text { Number } \\
\text { of } \\
\text { samples }\end{array}$} & \multicolumn{4}{|c|}{$\begin{array}{l}\text { Detection frequency at selected } \\
\text { assessment levels }{ }^{2} \text { (percent) }\end{array}$} & \multicolumn{2}{|c|}{$\begin{array}{c}\text { Median } \\
\text { concentration }^{3} \\
(\mu \mathrm{g} / \mathrm{L})\end{array}$} \\
\hline & & $\begin{array}{c}\text { No } \\
\text { assess- } \\
\text { ment } \\
\text { level }\end{array}$ & $0.02 \mu \mathrm{g} / \mathrm{L}$ & & $0.2 \mu \mathrm{g} / \mathrm{L}$ & $1 \mu \mathrm{g} / \mathrm{L}$ & $5 \mu \mathrm{g} / \mathrm{L}$ & $10 \mu \mathrm{g} / \mathrm{L}$ & $\begin{array}{c}\text { All } \\
\text { samples }\end{array}$ & $\begin{array}{c}\text { Samples } \\
\text { with } \\
\text { detections }\end{array}$ \\
\hline Dichlorodifluoromethane & 1,208 & 3.6 & 3.6 & 2,401 & 1.4 & 0.17 & ND & ND & $<0.20$ & 0.27 \\
\hline Trichlorofluoromethane & 1,208 & 1.9 & 1.6 & 2,401 & .62 & .17 & ND & ND & $<.20$ & .16 \\
\hline Trichlorotrifluoroethane & 1,207 & .50 & .33 & 2,083 & .19 & .048 & ND & ND & $<.060$ & .17 \\
\hline \multicolumn{11}{|c|}{ Solvents } \\
\hline Chloroethane & 1,207 & .33 & .33 & 2,155 & .093 & ND & ND & ND & $<.12$ & .060 \\
\hline Chloromethane & 1,207 & 9.7 & 7.3 & 2,059 & .97 & .097 & ND & ND & $<.20$ & .030 \\
\hline 1,2-Dichlorobenzene & 1,208 & .33 & .25 & 2,391 & .042 & .042 & ND & ND & $<.19$ & .092 \\
\hline 1,3-Dichlorobenzene & 1,208 & .50 & .17 & 1,894 & ND & ND & ND & ND & $<.054$ & .0096 \\
\hline 1,1-Dichloroethane & 1,207 & 2.2 & 2.0 & 2,400 & .29 & .042 & ND & ND & $<.20$ & .073 \\
\hline 1,2-Dichloroethane & 1,208 & .17 & .17 & 2,383 & .21 & .13 & ND & ND & $<.20$ & 1.3 \\
\hline cis-1,2-Dichloroethene & 1,207 & .91 & .83 & 2,177 & .18 & .092 & ND & ND & $<.050$ & .087 \\
\hline trans-1,2-Dichloroethene & 1,207 & ND & ND & 2,241 & .045 & ND & ND & ND & $<.050$ & .20 \\
\hline 1,1,2-Trichloroethane & 1,208 & .083 & .083 & 2,156 & ND & ND & ND & ND & $<.10$ & .028 \\
\hline Trichloroethene & 1,207 & 3.4 & 2.6 & 2,400 & .92 & .46 & .25 & .21 & $<.20$ & .14 \\
\hline \multicolumn{11}{|c|}{ Trihalomethanes } \\
\hline Bromodichloromethane & 1,207 & 2.8 & 2.3 & 2,400 & 0.58 & 0.25 & 0.083 & ND & $<0.19$ & 0.071 \\
\hline Bromoform & 1,206 & 1.8 & .66 & 2,399 & .33 & .13 & .042 & ND & $<.20$ & .010 \\
\hline Chloroform & 1,207 & 25.6 & 18.0 & 2,400 & 5.2 & 1.7 & .37 & 0.17 & $<.052$ & .059 \\
\hline Dibromochloromethane & 1,207 & 1.1 & 1.1 & 2,400 & .50 & .17 & .042 & .042 & $<.20$ & .30 \\
\hline Total trihalomethanes ${ }^{5}$ & 1,207 & 26.5 & 18.0 & 2,400 & 5.3 & 1.8 & .42 & .21 & $<.20$ & .062 \\
\hline
\end{tabular}

${ }^{1}$ These detection frequencies are for the subset of samples that were analyzed with the U.S. Geological Survey's low-level method 0-4127-96. At this assessment level, detection frequencies are estimates. ${ }^{(19)}$

${ }^{2}$ These detection frequencies are for all samples included in this assessment, regardless of the analytical method.

${ }^{3}$ The analytical methods used for this assessment have varied sensitivity among compounds, and comparison of the median concentrations between compounds is not appropriate. No assessment level was applied to determine the median.

${ }^{4}$ Considered as 2 of the 55 compounds included in this assessment.

${ }^{5}$ Not considered as 1 of the 55 compounds included in this assessment. 
Appendix 9. Summary of concentrations of selected volatile organic compounds in domestic well samples in comparison to U.S. Environmental Protection Agency (USEPA) Maximum Contaminant Levels (MCLs) for regulated compounds and to HealthBased Screening Levels (HBSLs) for unregulated compounds, and concentrations within one order of magnitude of MCLs and HBSLs.

[ $\mu \mathrm{g} / \mathrm{L}$, micrograms per liter; --, no MCL established or HBSL reported]

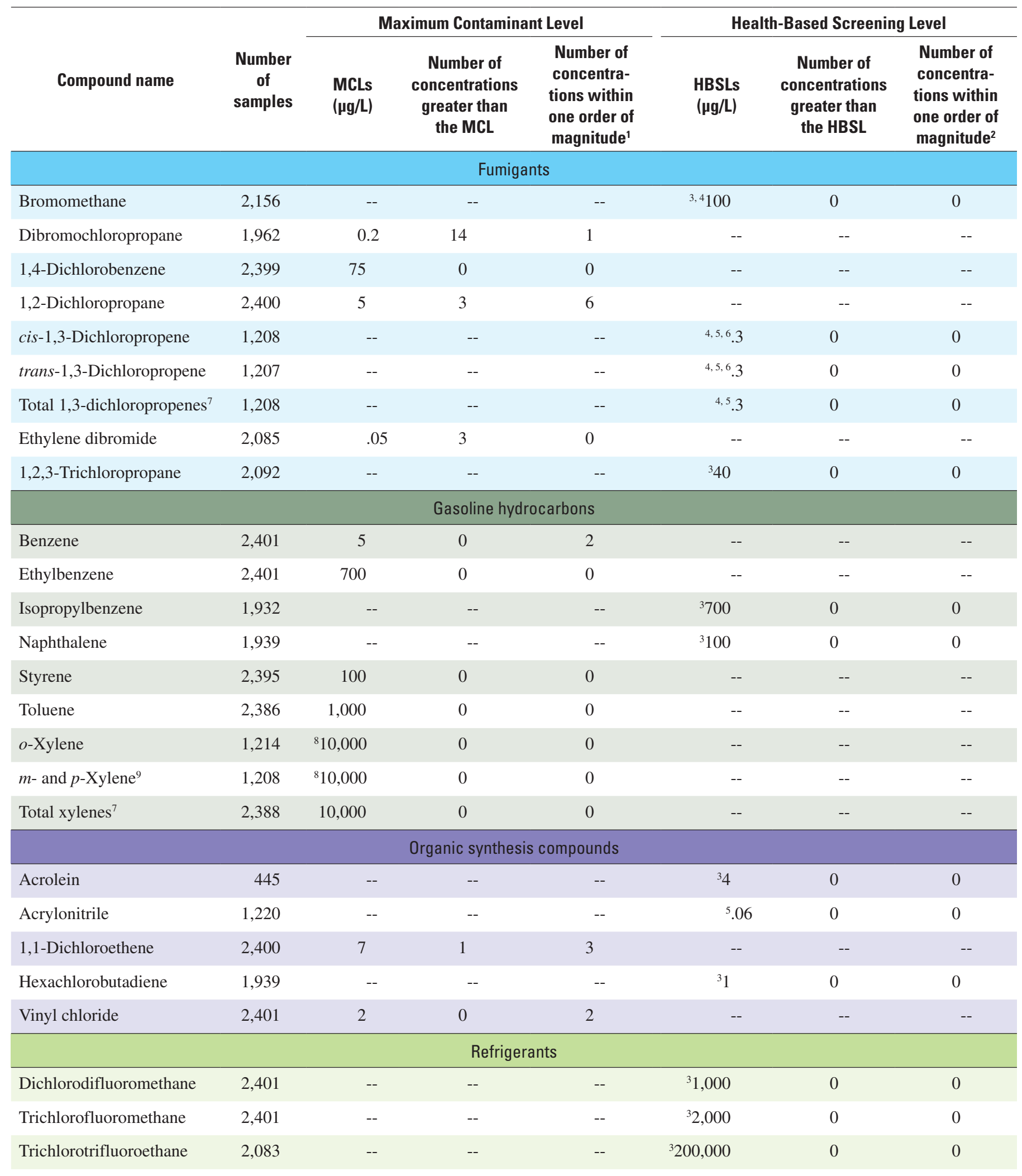


Appendix 9. Summary of concentrations of selected volatile organic compounds in domestic well samples in comparison to U.S. Environmental Protection Agency (USEPA) Maximum Contaminant Levels (MCLs) for regulated compounds and to HealthBased Screening Levels (HBSLs) for unregulated compounds, and concentrations within one order of magnitude of MCLs and HBSLs.-Continued

[ $\mu \mathrm{g} / \mathrm{L}$, micrograms per liter; --, no MCL established or HBSL reported]

\begin{tabular}{|c|c|c|c|c|c|c|c|}
\hline \multirow[b]{2}{*}{ Compound name } & \multirow[b]{2}{*}{$\begin{array}{c}\text { Number } \\
\text { of } \\
\text { samples }\end{array}$} & \multicolumn{3}{|c|}{ Maximum Contaminant Level } & \multicolumn{3}{|c|}{ Health-Based Screening Level } \\
\hline & & $\begin{array}{l}\text { MCLs } \\
(\mu \mathrm{g} / \mathrm{L})\end{array}$ & $\begin{array}{c}\text { Number of } \\
\text { concentrations } \\
\text { greater than } \\
\text { the MCL }\end{array}$ & $\begin{array}{l}\text { Number of } \\
\text { concentra- } \\
\text { tions within } \\
\text { one order of } \\
\text { magnitude }\end{array}$ & $\begin{array}{c}\text { HBSLs } \\
\text { ( } \mu \mathrm{g} / \mathrm{L})\end{array}$ & $\begin{array}{c}\text { Number of } \\
\text { concentrations } \\
\text { greater than } \\
\text { the HBSL }\end{array}$ & $\begin{array}{l}\text { Number of } \\
\text { concentra- } \\
\text { tions within } \\
\text { one order of } \\
\text { magnitude }^{2}\end{array}$ \\
\hline \multicolumn{8}{|c|}{ Solvents } \\
\hline Chlorobenzene & 2,401 & 100 & 0 & 0 & -- & -- & -- \\
\hline Chloromethane & 2,059 & -- & -- & -- & ${ }^{3} 30$ & 0 & 0 \\
\hline 1,2-Dichlorobenzene & 2,391 & 600 & 0 & 0 & -- & -- & -- \\
\hline trans-1,2-Dichloroethene & 2,241 & 100 & 0 & 0 & -- & -- & -- \\
\hline Hexachloroethane & 1,223 & -- & -- & -- & ${ }^{10} .7$ & 0 & 0 \\
\hline Methylene chloride & 2,398 & 5 & 0 & 9 & -- & -- & -- \\
\hline Perchloroethene & 2,371 & 5 & 5 & 17 & -- & -- & -- \\
\hline 1,2,4-Trichlorobenzene & 1,939 & 70 & 0 & 0 & -- & -- & -- \\
\hline 1,1,1-Trichloroethane & 2,401 & 200 & 0 & 1 & -- & -- & -- \\
\hline 1,1,2-Trichloroethane & 2,156 & 5 & 0 & 0 & -- & -- & -- \\
\hline Dibromochloromethane & 2,400 & ${ }^{11} 80$ & 0 & 1 & -- & -- & -- \\
\hline Total trihalomethanes ${ }^{7}$ & 2,400 & 80 & 0 & 5 & -- & -- & -- \\
\hline
\end{tabular}

${ }^{1}$ Includes the number of concentrations equal to and less than the MCL that are within one order of magnitude of the MCL.

${ }^{2}$ Includes the number of concentrations equal to and less than the HBSL that are within one order of magnitude of the HBSL.

${ }^{3}$ Value calculated using USEPA's formula for Lifetime Health Advisory.

${ }^{4}$ Value is provisional and is under discussion with USEPA.

${ }^{5}$ The HBSL is a range that is based on USEPA's risk-specific dose at $10^{-6}$ to $10^{-4}$ cancer risk level. The lowest value of this range was used in this assessment.

${ }^{6}$ The HBSL is for total 1,3-dichloropropene mixed isomers (cis- and trans-1,3-dichloropropene).

${ }^{7}$ Not considered as 1 of the 55 compounds included in this assessment.

${ }^{8}$ The MCL is for total xylenes ( $o-, m-$, and $p$-xylene).

${ }^{9}$ Considered as 2 of the 55 compounds included in this assessment.

${ }^{10}$ The HBSL was calculated using USEPA's Lifetime Health Advisory for Class C carcinogens.

${ }^{11}$ The MCL is for total trihalomethanes. 
Appendix 10. Detection frequencies and median concentrations for selected volatile organic compounds in samples from public wells.

[ $\mu \mathrm{g} / \mathrm{L}$, micrograms per liter; ND, compound not detected; <, less than; --, not applicable]

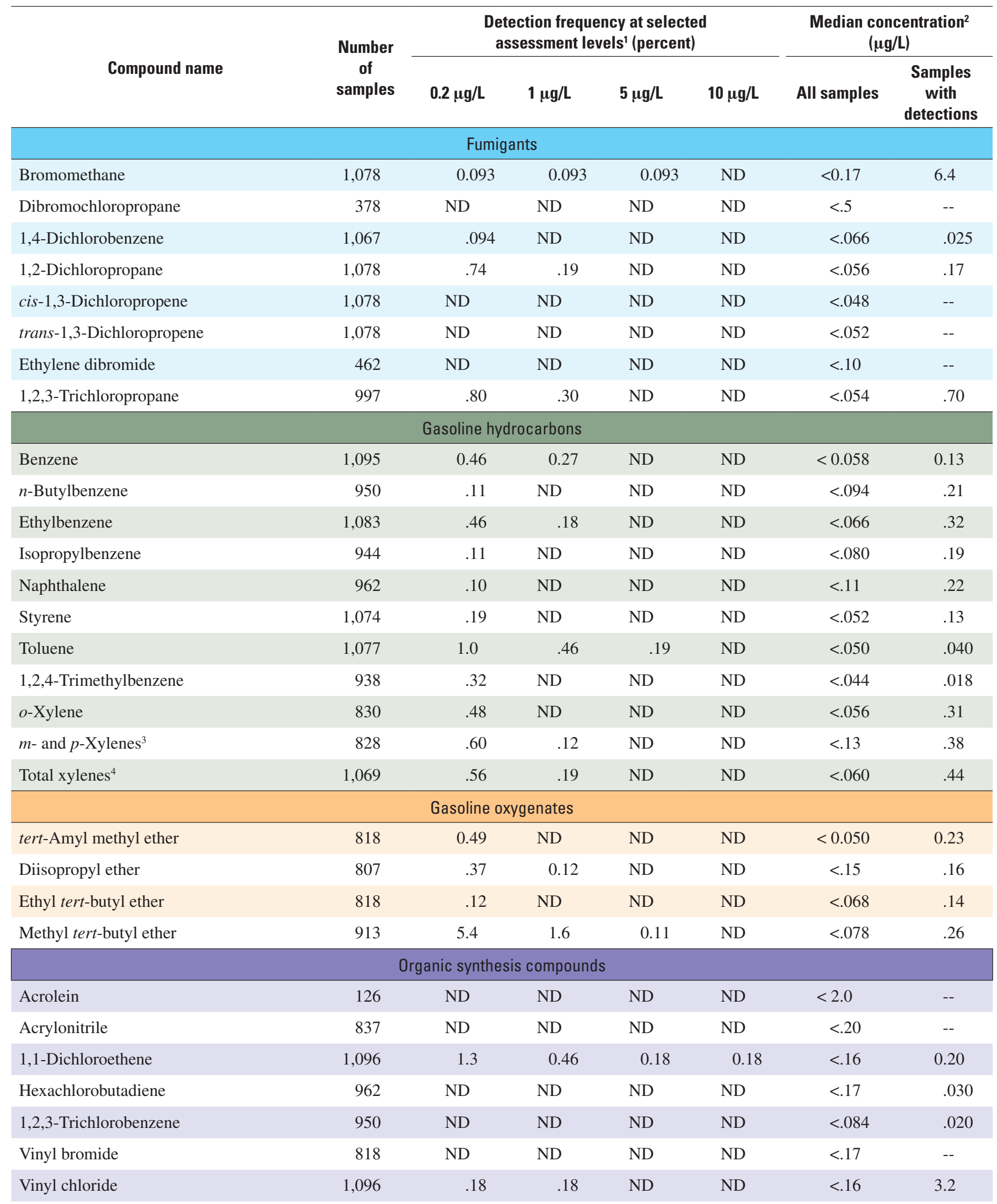


Appendix 10. Detection frequencies and median concentrations for selected volatile organic compounds in samples from public wells.-Continued

[ $\mu \mathrm{g} / \mathrm{L}$, micrograms per liter; ND, compound not detected; <, less than; --, not applicable]

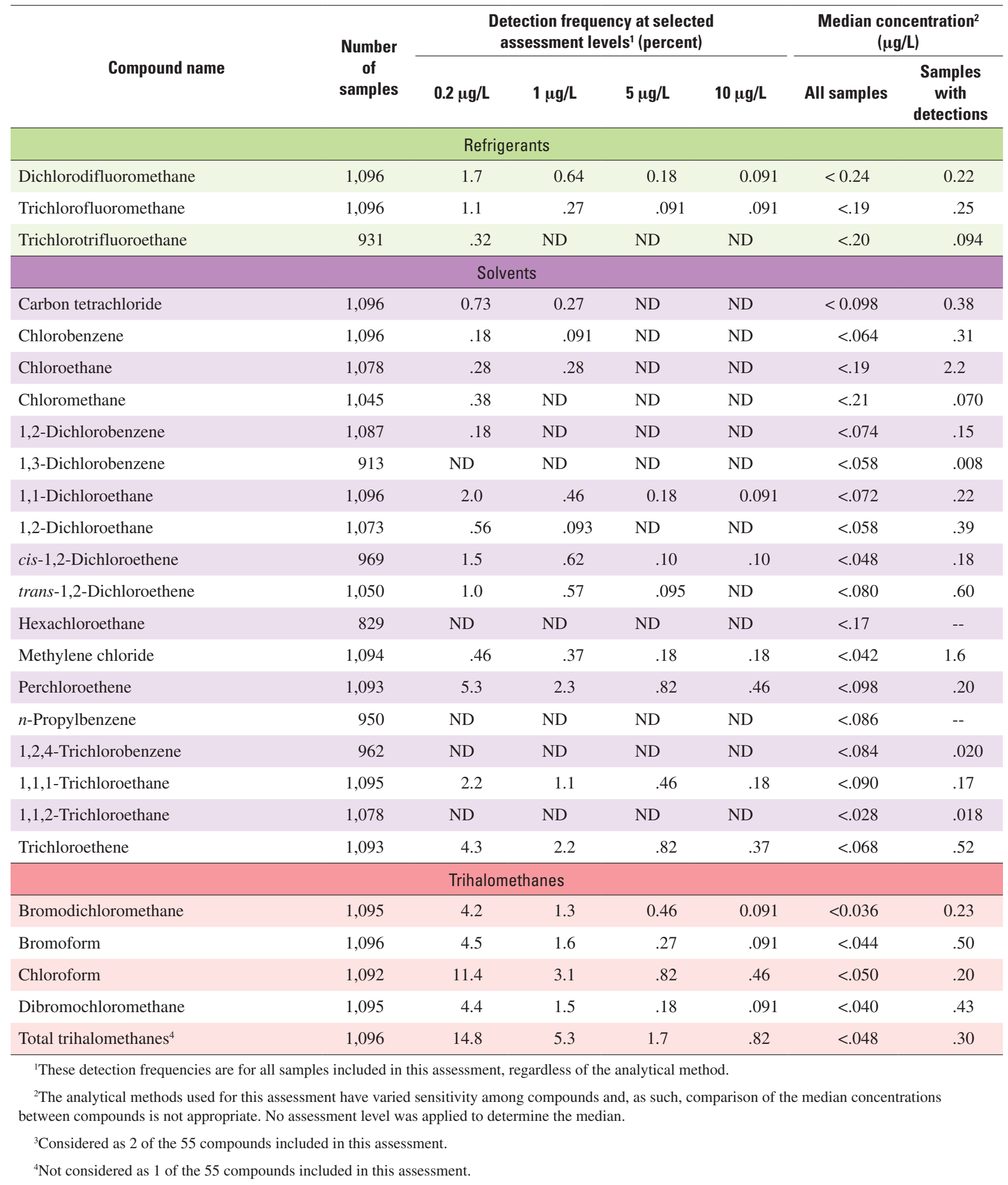


Appendix 11. Summary of concentrations of selected volatile organic compounds in public wells in comparison to U.S. Environmental Protection Agency (USEPA) Maximum Contaminant Levels (MCLs) for regulated compounds and to Health-Based Screening Levels (HBSLs) for unregulated compounds, and concentrations within one order of magnitude of MCLs and HBSLs.

[ $\mu \mathrm{g} / \mathrm{L}$, microgram per liter; --, no MCL established or HBSL reported]

\begin{tabular}{|c|c|c|c|c|c|c|c|}
\hline \multirow[b]{2}{*}{ Compound name } & \multirow[b]{2}{*}{$\begin{array}{l}\text { Number } \\
\text { of } \\
\text { samples }\end{array}$} & \multicolumn{3}{|c|}{ Maximum Contaminant Level } & \multicolumn{3}{|c|}{ Health-Based Screening Level } \\
\hline & & $\begin{array}{l}\text { MCLs } \\
\text { ( } \mu \mathrm{g} / \mathrm{L})\end{array}$ & $\begin{array}{l}\text { Number of } \\
\text { concentrations } \\
\text { greater than } \\
\text { the MCL }\end{array}$ & $\begin{array}{l}\text { Number of } \\
\text { concentra- } \\
\text { tions within } \\
\text { one order of } \\
\text { magnitude }\end{array}$ & $\begin{array}{l}\text { HBSLs } \\
(\mu \mathrm{g} / \mathrm{L})\end{array}$ & $\begin{array}{l}\text { Number } \\
\text { of concentra- } \\
\text { tions greater } \\
\text { than the HBSL }\end{array}$ & $\begin{array}{l}\text { Number of } \\
\text { concentra- } \\
\text { tions within } \\
\text { one order of } \\
\text { magnitude }\end{array}$ \\
\hline \multicolumn{8}{|c|}{ Fumigants } \\
\hline Bromomethane & 1,078 & -- & -- & -- & ${ }^{3,4} 100$ & 0 & 0 \\
\hline Dibromochloropropane & 378 & 0.2 & 0 & 0 & -- & -- & -- \\
\hline 1,4-Dichlorobenzene & 1,067 & 75 & 0 & 0 & -- & -- & -- \\
\hline 1,2-Dichloropropane & 1,078 & 5 & 0 & 2 & -- & -- & -- \\
\hline cis-1,3-Dichloropropene & 1,078 & -- & -- & -- & $4,5,6.3$ & 0 & 0 \\
\hline trans-1,3-Dichloropropene & 1,078 & -- & -- & -- & ${ }^{4,5,6} .3$ & 0 & 0 \\
\hline Total 1,3-dichloropropenes ${ }^{7}$ & 1,078 & -- & -- & -- & $4,5.3$ & 0 & 0 \\
\hline Ethylene dibromide & 462 & .05 & 0 & 0 & -- & -- & -- \\
\hline 1,2,3-Trichloropropane & 997 & -- & -- & -- & ${ }^{3} 40$ & 0 & 0 \\
\hline \multicolumn{8}{|c|}{ Gasoline hydrocarbons } \\
\hline Benzene & 1,095 & 5 & 0 & 5 & -- & -- & -- \\
\hline Ethylbenzene & 1,083 & 700 & 0 & 0 & -- & -- & -- \\
\hline Isopropylbenzene & 944 & -- & -- & -- & ${ }^{3} 700$ & 0 & 0 \\
\hline Naphthalene & 962 & -- & -- & -- & ${ }^{3} 100$ & 0 & 0 \\
\hline Styrene & 1,074 & 100 & 0 & 0 & -- & -- & -- \\
\hline Toluene & 1,077 & 1,000 & 0 & 0 & -- & -- & -- \\
\hline$o$-Xylene & 830 & ${ }^{8} 10,000$ & 0 & 0 & -- & -- & -- \\
\hline$m$ - and $p$-Xylene ${ }^{9}$ & 828 & ${ }^{8} 10,000$ & 0 & 0 & -- & -- & -- \\
\hline Total xylenes ${ }^{7}$ & 1,069 & 10,000 & 0 & 0 & -- & -- & -- \\
\hline \multicolumn{8}{|c|}{ Organic synthesis compounds } \\
\hline Acrolein & 126 & -- & -- & -- & ${ }^{3} 4$ & 0 & 0 \\
\hline Acrylonitrile & 837 & -- & -- & -- & ${ }^{5} .06$ & 0 & 0 \\
\hline 1,1-Dichloroethene & 1,096 & 7 & 2 & 6 & -- & -- & -- \\
\hline Hexachlorobutadiene & 962 & -- & -- & -- & ${ }^{3} 1$ & 0 & 0 \\
\hline Vinyl chloride & 1,096 & 2 & 2 & 0 & -- & -- & -- \\
\hline \multicolumn{8}{|c|}{ Refrigerants } \\
\hline Dichlorodifluoromethane & 1,096 & -- & -- & -- & ${ }^{3} 1,000$ & 0 & 0 \\
\hline Trichlorofluoromethane & 1,096 & -- & -- & -- & 32,000 & 0 & 0 \\
\hline Trichlorotrifluoroethane & 931 & -- & -- & -- & ${ }^{3} 200,000$ & 0 & 0 \\
\hline
\end{tabular}


Appendix 11. Summary of concentrations of selected volatile organic compounds in public wells in comparison to U.S. Environmental Protection Agency (USEPA) Maximum Contaminant Levels (MCLs) for regulated compounds and to Health-Based Screening Levels (HBSLs) for unregulated compounds, and concentrations within one order of magnitude of MCLs and HBSLs.-Continued

[ $\mu \mathrm{g} / \mathrm{L}$, microgram per liter; --, no MCL established or HBSL reported]

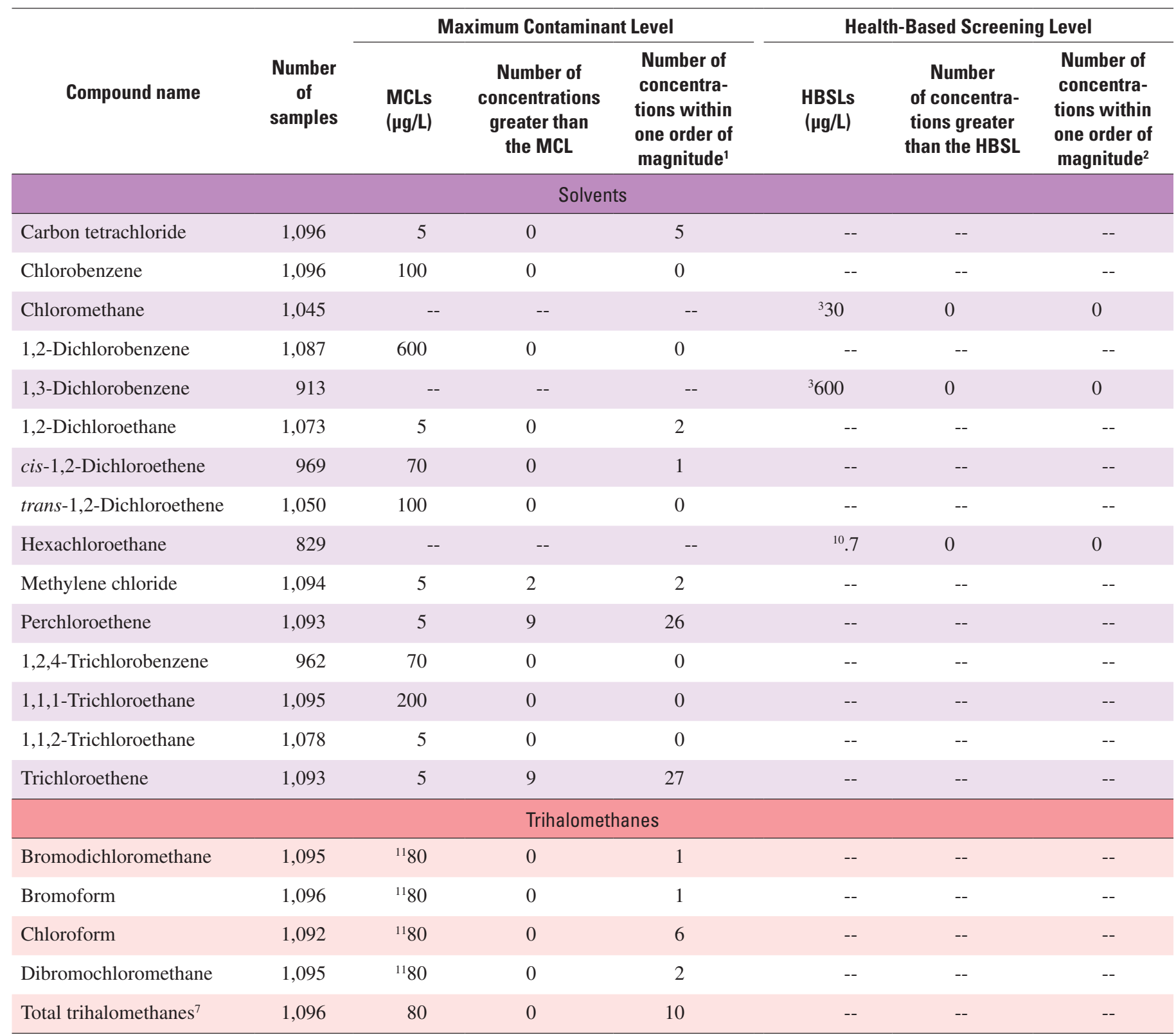

${ }^{1}$ Includes the number of concentrations equal to and less than the MCL that are within one order of magnitude of the MCL.

${ }^{2}$ Includes the number of concentrations equal to and less than the HBSL that are within one order of magnitude of the HBSL.

${ }^{3}$ Value calculated using USEPA's formula for Lifetime Health Advisory.

${ }^{4}$ Value is provisional and is under discussion with USEPA.

${ }^{5}$ The HBSL is a range that is based on USEPA's risk-specific dose at $10^{-6}$ to $10^{-4}$ cancer risk level. The lowest value of this range was used in this assessment.

${ }^{6}$ The HBSL is for total 1,3-dichloropropene mixed isomers (cis- and trans-1,3-dichloropropene).

${ }^{7}$ Not considered as 1 of the 55 compounds included in this assessment.

${ }^{8} \mathrm{The}$ MCL is for total xylenes ( $o-, m-$, and $p$-xylene).

${ }^{9}$ Considered as 2 of the 55 compounds included in this assessment.

${ }^{10}$ The HBSL was calculated using USEPA's Lifetime Health Advisory for Class C carcinogens.

${ }^{11}$ The MCL is for total trihalomethanes. 



\section{Acknowledgments}

\section{PROJECT MANAGER}

John S. Zogorski

\section{WRITERS}

\author{
Janet M. Carter \\ Tamara Ivahnenko \\ Wayne W. Lapham \\ Michael J. Moran \\ Barbara L. Rowe \\ Paul J. Squillace \\ Patricia L. Toccalino \\ John S. Zogorski
}

\section{GRAPHIC DESIGN}

Ella M. Decker

Connie J. Ross

Barbara L. Rowe

\section{REPORT PREPARATION}

Janet M. Carter, Reports Specialist

Sandra C. Cooper, Approving Official

Ella M. Decker, Publications Assistant

John Evans, Visual Information Specialist

Connie J. Ross, Illustrator

Chester Zenone, Pre-approval Reviewer

\section{RESEARCH ASSISTANCE}

David A. Bender

Rika Lashley

Hopa Yellow Horse

Jon Scott

Joshua F. Valder

\section{GEOGRAPHICAL INFORMATION SPECIALIST}

Curtis V. Price

\section{TECHNICAL PEER REVIEWERS}

\section{USEPA READERS}

\author{
Veronica Blette \\ Thomas R. Carpenter \\ Ann M. Codrington \\ Joyce M. Donohue \\ Irene S. Dooley \\ Elizabeth A. Doyle \\ Marilyn H. Ginsberg \\ Wynne F. Miller \\ Amy Mills \\ Edward V. Ohanian \\ Susan Richardson
}

\section{OTHER EXTERNAL READERS}

A. Scott Andres,

Delaware Geological Survey

Judy Campbell Bird,

Consultant

Denise D. Fort,

University of New Mexico

Adam Harris,

California State Water Resources Control

Board

Robert H. Johnson,

Center for Disease Control and

Prevention

Julia E. Norman,

Oregon Health \& Science University

Timothy Parker,

California Department of Water

Resources

\section{USGS READERS}

William M. Alley

Leslie A. DeSimone

Michael J. Focazio

Robert J. Gilliom

Pixie A. Hamilton

Donna N. Myers

Gary L. Rowe, Jr.

William G. Wilber

\section{SUPPORTING AGENCIES}

The cooperation of water utilities, State agencies, and American Water Works Association Research Foundation to develop VOC data sets is greatly appreciated.

\section{FOR ADDITIONAL INFORMATION} ON THE NAWQA PROGRAM:

\author{
Chief, NAWQA Program \\ U.S. Geological Survey \\ 413 National Center \\ Reston, VA 20192
}

Phone: (703) 648-5012

Fax: (703) 648-6693

Email: nawqa_whq@usgs.gov

World Wide Web: http://water.usgs.gov/ nawqa

\section{FOR ADDITIONAL INFORMATION ABOUT THIS NATIONAL ASSESSMENT:}

Project Chief, VOC National Synthesis

U.S. Geological Survey

1608 Mt. View Road

Rapid City, SD 57702

Phone: (605) 394-3214

Email: jszogors@usgs.gov

World Wide Web: http://water.usgs.gov/ nawqa/vocs/national_assessment

Neil M. Dubrovsky

Stephen J. Grady

James F. Pankow

Anthony J. Tesoriero 


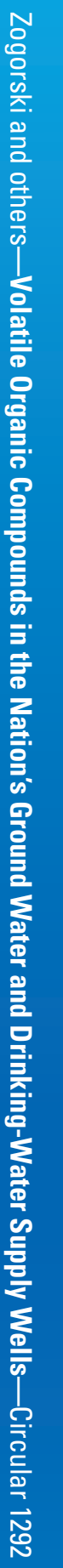

Printed on recycled paper 